Western University

Scholarship@Western

Digitized Theses

Digitized Special Collections

1991

\title{
Touch Monkeys: Nonsense Strategies For Reading Twentieth-century Poetry
}

Marion M. Parsons

Follow this and additional works at: https://ir.lib.uwo.ca/digitizedtheses

\section{Recommended Citation}

Parsons, Marion M., "Touch Monkeys: Nonsense Strategies For Reading Twentieth-century Poetry" (1991). Digitized Theses. 2116.

https://ir.lib.uwo.ca/digitizedtheses/2116

This Dissertation is brought to you for free and open access by the Digitized Special Collections at Scholarship@Western. It has been accepted for inclusion in Digitized Theses by an authorized administrator of Scholarship@Western. For more information, please contact tadam@uwo.ca,

wlswadmin@uwo.ca. 
The author of this thesis has granted The University of Western Ontario a non-exclusive license to reproduce and distribute copies of this thesis to users of Western Libraries. Copyright remains with the author.

Electronic theses and dissertations available in The University of Western Ontario's institutional repository (Scholarship@Western) are solely for the purpose of private study and research. They may not be copied or reproduced, except as permitted by copyright laws, without written authority of the copyright owner. Any commercial use or publication is strictly prohibited.

The original copyright license attesting to these terms and signed by the author of this thesis may be found in the original print version of the thesis, held by Western Libraries.

The thesis approval page signed by the examining committee may also be found in the original print version of the thesis held in Western Libraries.

Please contact Western Libraries for further information:

E-mail: libadmin@uwo.ca

Telephone: (519) 661-2111 Ext. 84796

Web site: http://www.lib.uwo.ca/ 
TOUCH MONKEYS:

NONSENSE STRATEGIES FOR REALING

TWENTIETH-CENTURY POETRY

by

Marion M. Parsons

Department of English

Submitted in partial fulfillment

of the requirements for the degree of Doctor of Philosophy

Faculty of Graduate studies The University of Western Ontario London, Ontario April, 1991

C) Marion M. Parsons 1991 
The author has granted an irrevocable monexclusive ficence allowing the National Library of Cenada to reproduce, loen, distribute or sell copies of his/her thesis by any means and in any form or format, making this thesis avallable to interested persons.

The author retains ownership of the copyright in his/her thesis. Neither the thesis nor substantial extracts from it may be printed or otherwise reproduced without his/her permission.
L'auteur a accordé une licence irrévocable et non exchusive permeltant à la Bibliotheque nationale du Cenada de reproduire, preter. distribuer ou vendre des coples de sa these de quelque maniere et sous quelque forme que ce soit pour meltre des exemplaires de cette thèse à la disposition des personnes intéressées.

L'auteur conserve la propriété du droit d'auteur qui protège sa thése. Nila thése ni des extraits substantiels de celle-ci ne doivent etre imprimés ou autrement reproduits sans son autorisation. 
Abstract

Literary nonsense is often relegated to the nursery. I suggest that much can be gained from coneidering the genre of nonsense (called "Nonsense" herein) and linguistic "nonsense" as challenges to sense which do not reault in a continual deferral of etable meaning. Such a view of Nonsense facilitates the reading of avant-garde and experimental poetry.

Chapter one provides a taxonomy of Nonsense criticism, and attempte to sort out the various, often conflicting, critical

"definitione" of literary nonsense. Chapter two adapts and extends Julia Kristeva's theory of poetic language to make possible a substantially different reading of nonsense language, and provides sample readings of both poetry and Nonsense.

My third chapter tackles the relationship, rarely considered in criticism, between Nonsense and the body; it responde to Gilles Deleuze's suggestion that Nonsense has no direct Iink to the body. I note the distinction between a nonsense of the senses (perception), as in the writinge of zukofkey and olson, and the metaphorical writing of the body of ecriture feminine, and consider how Nonsense relates to notions of a primal, phonic body imagined by writers like Ted Hughes. Chapter four examines the reliance of Nonsense upon sound. After a brief consideration of Derrida's grammatological re-writing of language, I discuse now, by playing with sound, Nonsense demonstrates the musicalization of language, and argue that Nonsense is characterized by 1ta imposition of another (in this case musical) way of making meaning within a verbal syetem. A range of poets and poetics are considered here, including sitwe11, zukofsky and sound Poetry.

My final chapter attempts to apply some of the principles of Nonsense to works and ldeas of the " $L=A=N=G=U=A=G=E^{\prime}$ poetry movement. Their approachee to materiality and reference are compared, and 
Nonsense's re-configuration of the bign into a palimpeeet is posited.

Six practical applications of the principles elaborated in each

chapter are given in "inter-chapters" which come between the theoratical

chapters. These demonstrate the usefulness of Nonsense's balancing of

reference and materiality, meaning and "meaninglessness," in reading many types of poetry. 


\section{Acknowledgements}

Before any other thanke are given, I want to acknowledge the many friende and family members who helped care for my daughter Rachel while I worked on my doctoral degree. Some were able to offer a few hours, othere whole days and weeks; but all provided Rachel with excellent care, and me with much needed pockete of time for thought. Two people, however, stand out from among the rest: Alanna Reabel, who has, for three shool years, been Rachel's other mother, and given her a second home and family; and my husband, who thought he'd given up single parenthood.

Most thought is developed over a large period of time, and is indebted to a large community of peers; this thesis is no exception. Many friends have directed me to books, poets and theorists over the years; anong them, I would especially like to thank Danny o'Quinn and Robin Edwarde-Davies, whose enthusiaeme for literature often eparked my own. Jamie Bush kindly let me quote from his insightful essay on Ted Hughes. An earlier version of "What then is a window" appeared in Brick 38; Inda spalding' editoral euggestions helped make the review and the resulting inter-chapter better pieces of work. Jan zwicky patiently tried to teach me about Wittgenetein, and gave generouely of her time to read and comment upon several sections of this work; whatever wrinkles remain in my treatment of philosophy are despite, not becauee of, her careful and lucid explanations. And Mike Groden's graduate course on Pinnegans wake initiated this whole process.

Several other frierde are important not only for their intellectual engagement, but also for their continued emotional (and mueical) eupport: Elisabeth Koeter, Dorothy Nieleen, sue Schenk and Jill sidda11. Each exemplifies the fact that education is most profitable when cooperative. 
Hy advisers have been a source of great encouragement and ineight. Martin Kreiswirth and Patrick Deane gave fresh ideas and some much needed perspective; they joined this project at its bleakest moment, and for that alone deserve many thanks. That they provided, as well, atute judgements and wonderful advice, all in the epirit of this etudy, makes them even more worthy of thanks. Don Mckay has for years been a model for me of intellectual and pedagogical excellence, and humanity. Hia participation in this thesis has been a continual pleasure. Always comprehensive, thoughtful and witty, his responses and commente have added to this thesis as no one else' could. I am indebted to them all. My examiners -- Frank Davey, Carol Farber, Elizabeth Harvey and Linda Hutcheon -- were both provocative and enthusiagtic. Their questions have set my mind to spinning, and will no doubt broacit! considerably the scope which this work takes in later forms.

Pinally my family, in Leamington and London, deserve many thanks for various encouragements. Their continuing jnterest in this project urged me on. To my husband and daughter, of course, go greatest thanks; to stan - for patience and suggestions and patience and support and patience again; to Rachel -- for letting me fall in love with language all over again, as I watched her do so for the first time. Thanks. 


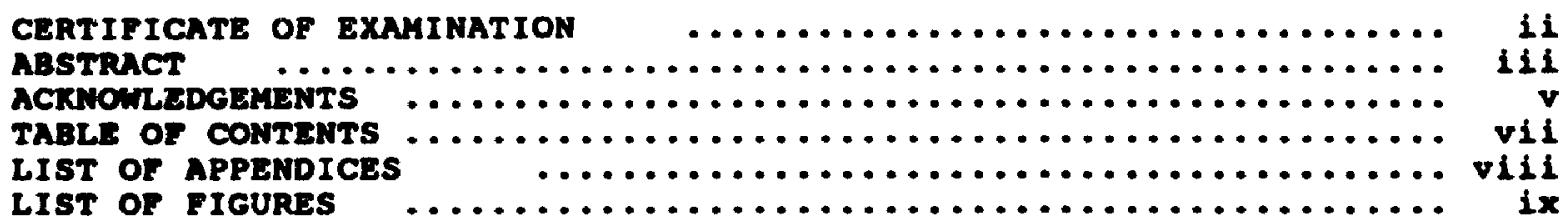

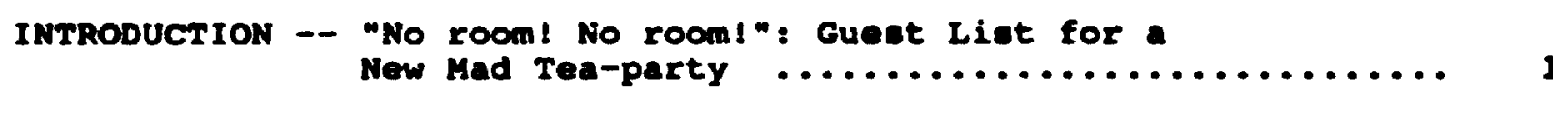

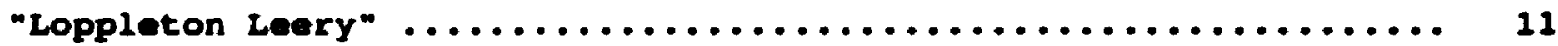

CHAPTER I -- Runcible Relationes A Taxonomy of Nonsense Criticiem and Theory $\ldots \ldots \ldots \ldots \ldots \ldots \ldots \ldots \ldots \ldots \ldots \ldots \ldots . \ldots \ldots$

"Nobody"

CHAPTER II -- "Touch Monkey": A Semanaltyic Approach to Noneenee ............................... 86

"Hunting-song of the Bandar-logician" $\ldots \ldots \ldots \ldots \ldots \ldots$

CHAPTER III -- "There was an Old Man with a nose" : Noneenee and Body Language ................... 129

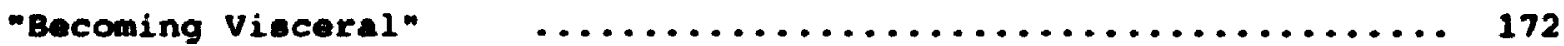

CHAPTER IV -- "as birds as well as words": Nonsense and

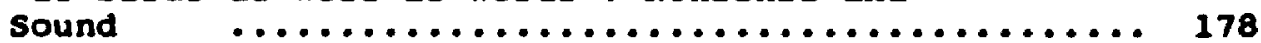

"o fongleurs, 0 belly laughs" ........................... 227

ChAPTER V - "A Silly Corpse" ?: The "L=A=N=G=U=A=G=E" Poete, stein and the Nonsense of Reference ............ 232

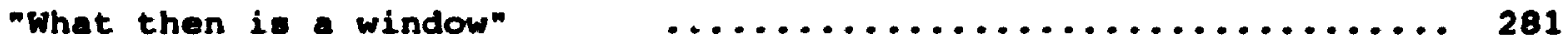

conclusion -- Killing the Rhino: The (a)Political Nature of Nongenge

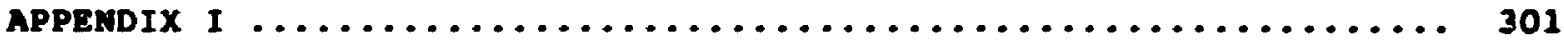

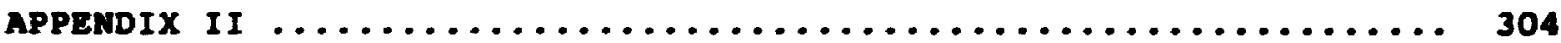

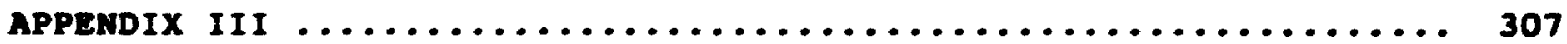

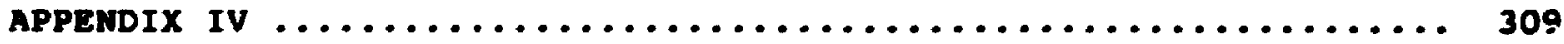

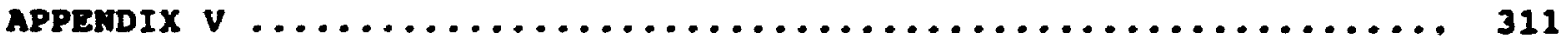

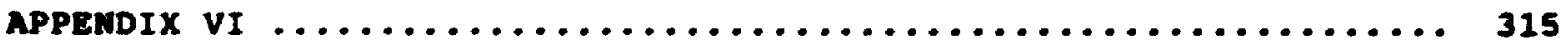

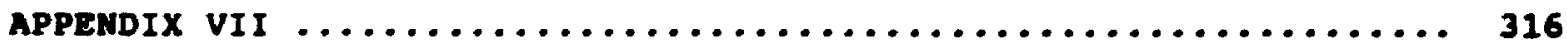

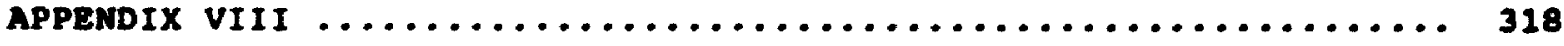

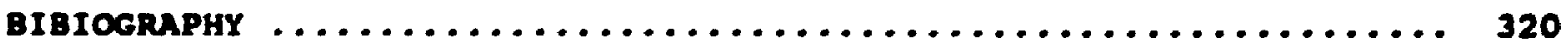

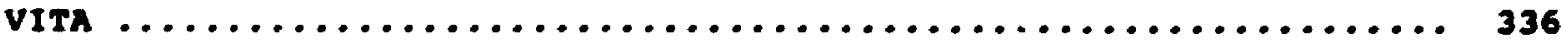




\section{LIST OF APPENDICES}

Appendix

Page

APPENDIX I "trom Throge, jle E Engestchins

A Relationship"

-- Colleen Thibaudeau . . . . . . . . . . 301

APPENDIX II "anyone lived in a pretty how town"

-- e.e. cumminge

"Verses from the Triai of the Knave of Hearta"

-- Lewis Carroll . . . . . . . . . . . . 304

APPENDIX III "Spelt from Sibyl's Leaves"

-- Gerard Manley Hopkine

"Sonnet VI" of "Altarwise by Owl-light"

-- Dylan Thomas . . . . . . . . . . . . . . 307

APPENDIX IV "Road-Song of the Bandar-log"

-- Rudyard Kipling . . . . . . . . . . . . 309

APPENDIX V "I's (Pronounced Eyes)"

-- Louis zukofaky . . . . . . . . . . . . . 311

APPENDIX VI "Our Whole Life" -. Adrienne Rich . . . . . . . 315

APPENDIX VII "Foxtrot" -- Edith sitwell . . . . . . . . . 31,

APPENDIX VIII "Pumpking" -- Tim Lilburn . . . . . . . . . . . . 318 
PIGURE 1 "Looking-Glaes Ineccte" . . . . . . . . . . . . . . . . 24

FICURE 2 from "Noneenee Botany" . . . . . . . . . . . . . . . . 24

Frgure 3 from "Noneenee Botany" . . . . . . . . . . . . . . . . 132

FIGURE 4 from "Noneence Botany" . . . . . . . . . . . . . . . . 132

FIGURE 5 "There was an Old Man with a nose" . . . . . . . . . . 132

PICUR: 6 "There was an Old Man who eald, "Hush" . . . . . . . 135

FIGURE 7 "There was an old Man in a tree" . . . . . . . . . . . 135

FIGURE 8 "There was an Old Man with an owl" . . . . . . . . . . 135

PIGURe 9 from "Empty words" . . . . . . . . . . . . . . . . . . 202

FIGURE 10 from the Metyrology Book v . . . . . . . . . . . . 204

FIGURE 11 msilver Blrch"; sound poetry score . . . . . . . . . . 224

PIGuR 12 Optophonetic sound poetry ecore . . . . . . . . . . . . 224

Frgure 13 from The Aleph Beth Book . . . . . . . . . . . . . . 256 
Introduction -- "Ho roon! wo room!" :

Guest Iist for a row Mad Tea-perty

"At any rate I'll never go there againl" said Alice, as she picked her way through the "ood. "It's the etupidest tea-party I over was at in all my life! "

(Lewis Cerroll, Alice' Adyentures in Nonderlend 83)

The stupidest tea-party Alice ever attended is one of the seminal instances of Nonsense in English literature, rife with the Bort of linguletic pratfalle that make the whole genre so marvellouely and multiply miscommunicative. Puns, riddles, literalistic wrenching of words and of logic, alliteration and various other types of sound play. non sequitur, parody -- each of these literary devices makes an appearance at Carroll's party. The actual gueste at the party are few, and are themselves literal jokes. The Mad Hatter and the March Hare are permonifications of colloquial expressions; the never fakeful Dormouse i. an exuggerated etymological exercise -- ite name comes from the Latin dormire, to sleep (Gardner 94). Alice crashes the party.

Who would be invited if one were planning another sort of Mad Teaparty, one for the inventors, not the inventions, of Nonsense? Carroll, of course. And Edward Lear. Some lists might expand to include A.A. Milne, Mervyn Peake and Christian Morgenstern; the Marx Brothers and Monty Python's Flying Circus; or John Lennon, whose books of Nonsense verse In Hie Own Write and A Spaniard in the Forke were published in the mid-sixtles. Not much potential for a long liat -- unlese one were to reconeider the genre from a theoretical perspective and to examine what it has to offer the reading of other types of literature, especially, as I am concerned with here, avant-garde and contemporary poetry.

I will examine both how adaptable aspecte of the thought of such literary theoriets as Krieteva, Derrida, Barthes and Bahktin are to the 
study of Nonsense and nonsensical language, and how poets like charles 0lson, Louis zukofsky, Edith Sitwell and Lyn Hejinian engage language in much the same way as writers of Nonsense do. The purpose of this thesis is not to hand out free passes to a hypothetical tea-party, or to make Nonsense writers out of writers who clearly are not working within the genre. However, if the result of this reconsideration is that possibilities broaden, that unexpected guests arrive at the party, then so much the better.

Throughout this study I will use upper and lower case "n"'s to differentiate between the literary genre (Nonsense) and the linguistic or philosophical disruption (nonsense). As chapter one indicates, the former grows out of the latter, and the two are intimately connected.

Linguistic nonsense, because of its symbiotic relationship with sense, has long been the concern of philosophy; in fact it lies at the heart of much philosophical questioning. Yet it is not in a philosophical way that I intend to consider nonsense. While I touch very briefly on the general philosophical tradition concerning nonsense in the first chapter of this study, and use the writings of French philosopher and nonsense theorist Gilles Deleuze throughout this thesis, I at no time attemrt to discuss the linguistic disruption or the genre as a philosophical construct.

There is, I believe, a fundamental difference in philosophical and literary approaches to the topic; for the former nonsense is, as I have suggested above, central and a potentially crippling error in thought, while for the latter it is marginal but, in my view, a playful indicator of language's ability to make meaning in many ways. Any aspects of a philosophical argument which I entertain will be recognized, implicitly or explicitly, as existing at a considerable and inevitable distance from literary perspectives on nonsense.

Though philosophical theories of nonsense have not been highly 
influential in this study, many other approaches have been. Chapter one is a taxonomy of various critical responses to nonsense and its companion literary genre, Nonsense. A basis for understanding of nonsense is established by looking at the following categories into which criticism invariably places it: madness, anarchy, meaninglessness, dreams, riddles, play, philosophy and linguistic operations. These categories provide a convenient, though by no means rigid, method of organizing and accounting for often conflicting critical responses to nonsense. This chapter essentially maps out the territory of nonsense, gives the reader a sense of the terrain upon which the later chapters are played out.

Julia Kristeva's semanalytical paradigm for poetic language, developed in Revolution in Poetic Lanquage, provides a starting point for the theory of nonsense proposed in chapter two. She holds that many linguistic disruptions (such as sound play, portmanteau words, the collapsing of word divisions, morphemic displacement, are examples of the "semiotic" exupting into "symbolic" language. Her use of the word "semiotic" is markedly different from the word's usual use as "the study of signs," and relates to the notion that the aspects of language which one "values" and dwells in before being able to make sentences and other grammatically- and syntactically-directed assertions are dramatically

different from those privileged after one begins to use symbolic language, which is purely communicative and single-minded. To her, the semiotic is a linguistic mode whi.ch grows out of a "primeval" and preOedipal relationship with language; it is a mode which engages the material aspects of language.

My suggestion is that nonsense is an expression of this semiotic materiality entering into discourse, entering simultaneously with the production of language itself. This simultaneity is indicative of the 
symbiotic relationehip between eemiotic and symbolic,' between noneenee and sense. Susan stewart, whose groundbreaking work -- Nongenge: Anpecte of Intertextuality in Folklore and Iiterature -- has been a continual source of inspiration as well as of valuable information, sees - imultaneity (as in, for example, the pun which means at least two thinge at once) as a central characteristic of Nonsense (146-70). A related characteriatic of Nonsense essential to the thought of this thesie is the balance between meaninglessness and meaning, which grows out of both symbiosis and simultaneity.

An elaboration upon and an application of the simultaneity and balance characteristic of Nonsense leads to my departure from Kristeva's model of poetic language. Her model, when epatialized, preente the semiotic and symbolic as eparated by a permeable barrier called the "thetic" which "divides" the two modes; thus she offers a three-termed gystem that is based upon, but does not entertain, simultaneity. She argues that the chora, a hypothetical repository of the semiotic's inexpressible drives and pulsions, is a construct dependent upon the eymbolic for its expression, but that it also "exists" before, and is neceseary for the formation of, the symbolic. The two modes exist simultaneous $2 y$ and both contribute to the creation of poetic language. The thetic is absolutely essential for all forms of enunciation. However, it is something to be breached by one mode entering the other, not a meeting place where the two modes merge.

My theory re-conceives the nature of the intermediary term, makes it not merely another term but a combination of the semiotic and symbolic; I posit a model in which nonsense is the third term. The aystem is composed of meaninglesenese (analogous to Krieteva'. eemlotic), meaningleesenes/meaning (or noneense), and meaning (analogoue to Kristeva's sybolic). It re-designatee the role played by the thetic

'Language often plays into a critic's hands: "symbiotic" can be read as a portmanteau-esque combination of "semiotic" and "symbolic." 
in poetic language, making what was the thetic a zone of co-habitation rather than repression. The ramifications of this re-designation are most fully acknowledged in chapter five, where the status of the Nonsensical sign is reconstrued.

Once this subtle but important deviation from Kristeva has been established, and this new theory's usefulness has been demonstrated in reading both poetry and claseical Nonsense by Gerard Manley Hopkins, Dylan Thomas, Edward Lear and Lewis Carroll, I move on to explore two linguistic connections implicit in the theory -- that which nonsense has with the body and with sound.

Chapter three examines how nonsense facilitates the body's dwelling in language, and discusses what nonsense as a reading strategy has to offer poetries and poetics which claim to root themselves in the body. A nonsensical body very much in the tradition of Rabelaisian carnival is proposed, a body of "shoots and branches," which protrudes beyond ite normal confines and breaks down accepted barriers between itself and the outside world (Bakhtin 316-17), a body and a self in flux. Central to the body' fluctuating relationship with the world are the senses; this chapter also explores the importance to nonsense of this other type of "sense" by considering, among other examples, Charles olson's concepts of "open form" and proprioceptive verse, and Louis zukofaky' heightened use of synaesthia.

The third chapter also entertains a comparison of the nonsensical body and the Deleuzian schizophrenic body, recognizing that part of the discrepancy between Deleuze's ideas about Nonsense and my own lies in the relationship each body has with language, a relationship which Deleuze characterizes as articulated in the depthe of the body and at 1t: "mensical/sensual" surface, respectively. I attempt to undermine the polarization of these locations, using my slightly altered version of Kristeva, and Barthes" notion of the "writable" text, which requires active participation on the part of the reader. My approach is 
admittedly un-Deleuzian.

Finally the chapter considers the nonsensical language/body relation at another depth, a primordial, as opposed to schizophrenic. depth. The discuseion includes such varying viowe of a primordial or originary body in language as Ted Hughes' "Orghast," a dramatic experiment directed by Peter Brooks; Tim Lilburn' contemporary reworking of Duns scotus' concept "haecceitas" or the intense and essential being of an object; and the relationship between writing and the minther' body put forward by some French literary theoriate. It considers as well ecriture feminine's mandate to disrupt language by writing the female body into it. Here I argue againet a purely essentialist reading of feminist writing and of the female body in language, suggesting instead that language is radically recontextualized, musicalized, by the infueion of desire and drives, either female or male.

One of the areas of language in which nonsense is most anarchic is that of sound. The fourth chapter gives attention to how sound works in nonsense, how it exist. as an alternative source of sense within nonsense language. After a brief discussion of Derrida, in anticipation of charges of phonocentrism, I argue that the playful use of sound in nonsense requires a modification of one principle of deconetruction; by phonically incorporating semiotic materiality, nonsense (and poetic language as Kristeva conceives it) is responding to, though not fully resolving, the lack which Derrida perceives within all language.

The semiotics of music, how sound and music mean, is then explored, using as a jumping-off point avant-garde composer John Cage'. guery "If words are sounds, are they musical or are they fust noise" (stlence 42). Cage's radical experiments with language, sound and form provide a convenient juncture at which several of the concerns of this chapter meet. Once musical meaning has been explored, I move on to the central thrust of this part of the thesis: how nonsense language can 
mean musically.

The musicalization of language involves not only Poundian meloposis and rhythin, though the latter is clearly one of the most important and frequent expressions of a musicalized language. It involves as well a confluence of eign systems, in which one way of meaning is "transliterated" into/onto another; one type of language, in thie case muelc, wrape itself around another, here verbal language, resulting in destabilized but multiple meaning. Such a trarsilteration whether "subtle," as in the poetry of Edith Sitwell or colleen Thibaudeau, or overt, as in the experiments of Cage and bp Nichol, is highly nonsensical.

Chapter four then goes on to consider poems which are progressively more musical. A quite lengthy reading of sitwell's "Foxtrot" is followed by a look at "Privet," a poem from Loule zukofaky's 80 flowers and at his highly controversial "translations," with his wife celia, of Catullus. This section concludes with a brief introduction to some of the issues raised by sound poetry, a pure example of sound as sense, which traces its roots back to the great Nonsense writers of the nineteenth century. Here I focus primarily on the theoretical writings of Steve Mccaffery, a Canadian sound and experimental poet who is loosely aseociated with the American $" L=A=N=G=U=A=G=E$ " poetry movement.

My concluding chapter is both theoretically and practicaliy an extended application of the principles developed in the earlier chapters. It concerns the " $L=A=N=G=U=A=G=E$ " movement, a group composed of some of the most experimental poets in North America today. The term " $L=A=N=G=U=A=G=E$ " poetry is an umbrella for the work of many and various writers; most of these poets share an interest in the nature of meaning and its relationship both to the political utatus quo and to language' materiality. Several of the iseues they address are also central to nonsense as it is styled in this study. Not surprisingly, a nonsense 
atrategy for reading this often difficult poetxy proves extremely helpful. I explore how several of these poets, including Charles Bernetein, Ron Silliman and Lyn Hejinian, underatand the role of the reader, reference, reforentiality, materiality and grammar, and what nonsense can offer to a reading of these matters. As a result of these discuseions, I argue for the reconstitution of the sign within a Noneeneical paradigm; the re-materialized sign becomes a palimpsest through which both eignified and ignifier, concrete and referential qualities, may be glimpeed. The chapter concludes with readings of Gertrude stein, one of the most important literary ancestors whom " $L=A=N=G=U=A=G=E$ " poet have, and of Ron Silliman, a major " $L=A=N=G=U=A=G=E$ " poet, theorist and anthologist.

The study, as I have presented it so far, then, is a theoretical exploration of the relationship nonsense has with various aspects of language and how that relationship might facilitate a reading of poetry. There are sample readings of selected poems in each chapter, but the general tendency of the thesis is not one of practical application. In an effort to address this imbalance between theory and practice, to disupt the generally communicative momentum established by the chapters -- this is after all a study of linguistically and structurally discuptive phenomena, so a little structural disruption is not out of place -- I have included six "inter-chapters." These offer practical applications of some of the principles discuseed in the chapter. surrounding them. They are also a dramatic example of my own belief that literary theory needs to have (at least) double vision; it must focus on its own "genre" of thought without losing sight of the texts to which it is intimately tied.

A nonsense style of reading may not lend itself to all types of poetry, but it does accommodate quite a wide range of writing. The poet. and poems in these inter-chapters have been selected to reflect the extent of that range, the flexibility of this approach. An analyais 
of Colleen Thibaudeau's "from Thxognoyle and Ingestchint A Relationehip" a poem composed in an entirely invented language, precedes the first chapter. A consideration of pronominal use in e.e. cummings' "anyone lived in a pretty how town" and Lewis Carroll's "Verses from the Trial of the Knave of Hearte" followe the first chapter; a reading of Rudyard Kipling"s "Road-Song of the Bandar-log," a poem connected both metaphorically and analogically to the concerns of the second chapter, comprises the third inter-shapter. The third and fourth chaptere are eeparated by an exploration of Adrienne Rich's poem "Our Whole Life," which attempts to demonstrate that even poems which are very politically purposeful may engage a nonsense strategy. Tim Lilburn's poem "Pumpkins," an eclectic and witty play with sound, is discussed in the fifth inter-chapter, and Lyn Hejinian's My Life, a poetic "autobiography" and a fine example of " $L=A=N=G=U=A=G=E$ " poetry, is considered in the inter-chapter that precedes my conclusion.

There was a table set out under a tree in front of the house, and the March Hare and the Hatter were having tea at it: a Dormouse was sitting between them, fast asleep. . . The tablu was a large one, but the three were all crowded together at one corner of it. "No rooml No room!' they cried out when they saw Alice coming. 'There' plenty of room! said Alice indignantly, and she sat down in a large arm-chalr at one end of the table (Lewis Carroll, Alice'e Adventures in Wonderlend 74-75).

Being of the critical "camp" which tends to have little sympathy for Alice, I rarely agree with her take on things in Wonderland. I must admit, however, that this once she may be right. When one re-construes noneenee, when one recognizes it as an extremely valuable tool for 
approaching experimental poetry and acknowledges its affinities with ard potentlal for modifcations to contemporary literary theories, one scon realizen there may indeed by "plenty of room" at the tea-party table. 
"Loppleton Leery "

The first three lines or "argument" in Colleen Thibaudeau'e "from Throgmogle E Egeotchin: A relationship" (The Martha Landecapes 53-54; see Appendix I for the text of the poem) contain its only English sentence, or its only gensible English sentence: Inwhich you meet Throgmogle and Engestchin and you may feel that the latter is not a fully developed character and you are probably right.

The reat of the poem is a phonic romp through the nonsensical potentialities of language. Thibaudeau doesn't write "standard" English In her poem; but she does make "words" that are phonetically possible in English by bringing together phonemes which utilize the wandard acund conjunctions of the language. As well, she plays with some standard ordering principles of Englieh -- grammar, punctuation, capitalization and typography. Those first three lines, along with the presence in the poem' latter portion of capitals and commas, elicit expectations (whlch will later be undone) of conventional and coherent meaning and so lure the reader unsuspectingly into a semantic morase.

T.S. Eliot claims in his essay "Dante" that "genuine poetry can communicate before it is understood" (238); such is certainly the case with Thibaudeau' poem. The "argument" and ordering conventions, which appear more conepicuously later because of her unremitting phonemic anarchy, help make "from Ihrognogle" a succeseful piece of Nonsense and of poetry, for they communicate a type of, or possibility for, meaning despite her linguistic inaccessibility. Somewhere under the apparent gibberish characters are buried, although one's a bit famished literarily. So a meaning-reaking mind sets to work. Throgmogle Fordful 
manty overgoo

bog manty gong goppling

rill cum nack throggins.

The poem'- more rounded character, if a reader can aseume the argument 1s suggesting that only one is not fully developed, ie immedlately introduced: Throgmogle Fordful (Fordful -- her/hie/ita last name?). Tentatively Throgmogle can be called "he" and Engestchin "ohe" -- the sounde of Throgmogle". name are harder, more etereotypically masculine than those of Engestchin. And the ending of "Engestchin" recalle the Germanic feminine and diminutive suffix "-in." The repetition of "manty," with ite implication of reiterated meaning. encourages a reader to use repetition as a key to break Thibaudeau'a "code." Other worde at first ecen to be Englieh -- "bog," "gong," "rili" -- but their context makes them noneenaical deapite suggestions, espacially from "bog" and "rill," of landecape or setting. "Overgoo" at the end of the second line combines two worde ("over" and the colloquialism "goo"); it pushes ite energy acrose the line break (the open "oo" sound sipe more vigorously out of the mouth than any other sound ending words in this otanza) and spill" into "bog" -- an appropriate oliding aince "goo" might be thought to have much to do with bogdom. But the connection is tenuous and offers no reliable meana for deciphering the otanza.

sound patterne give more plausible resulte. Though none of the lines rhyme overtly, there is a complex network of sound and rhyme, of aseonance and alliteration, among the eyllables: "throg," "mog," "bog"; "goo," "gong," "gop." The flial word of the stanza, "throggine," circles back to acho the first syllable of Throgmogle, and the predominance of "og/go" rhymes auggeste many of the other worde grow out of that "name". The stanza offer: a quite thorough "throggin" of ita firet word; each rhyme or parmutation is perhape an aspect of the rounding of Throgmogle. "Rill" is a partial rhyme with the end of 
"Fordful," so the character is given back to front and front to back. All Throgmogle': sonal cornere are covered.

stanza two raiees another problem in the search for the poem'a "meaning." Which words are Throgmogle's, and which are Engeatchin'e? (Or has Thibaudeau introduced an entirely new character -- Choomin, the "In" ending may suggest, as it seems to in Engestchin, a proper noun. The firat word of the stanza could then be read an an indication that it i. Choomin who is epeaking now.)

$$
\begin{aligned}
& \text { choomin: } \\
& \text { chillchinchar Engestchin } \\
& \text { chanty chopcharchill } \\
& \text { chorey chopcharchill chooley } \\
& \text { chingle choon chingley } \\
& \text { choodle. }
\end{aligned}
$$

The insistent repetition of "ch" makes the stanza choom along at a staccato pace which implies that the discussion is less than pleasant, and that the relationship mentioned in the poem's title is not a sooth one. As well the repetition of words ("chopcharchill") and eyllables ("chill," "chin," "char," "choo") develop a chattering cacophony, a nagging insistence, which cuts short and intrudes upon the eilence following the colon of the first line. "Chillchinchar" is placed as if it is part of Engestchin's name, though one might argue its role is adjectival, and "Fordful"'s adverbial. Thibaudeau'e use of capitale here is no firm clue since throughout the poem there seems no comprehoneibly consistent approach to their use, except for the continual capitalization of "Throgmogle," "Fordful," "Engestchin," and "Chillchinchar". Reading Chillchinchar as part of Engentchin's name allows the stanza's syllabic distortions of "Chillchinchar" and it: alliterative "ch" pattern to be viewed as some more raucous name-play in the epirit of the first stanea. Here, however, the containment or cyclical completion of the previous stanza is lacking, and "choodle," 
far from being a pull back Into Engestchin' name (or her adjective) seeme the stanza' atrongest movement away from it.

Because two variatione of typeface (italic and roman) are used, thie "excerpt" (the title indicates it is part of a whole, but this is the complete text of the poem as published) unfolde like a dialogue between the two characters, with one typeface attributed to each character; when Thibaudeau reads the poem publicly, she usee three "voices" -- one "narrative" voice and two character volces. If the poem'e ergument can be trueted (and why not try?) one of the characters 1. underdeveloped; I'm inclined to think it' Engestchin because the rhyming aseociated with her name doeen't round her out the way that associated with Throgmogle does. And if character is partially developed through "epeech," one clue for attributing volce would be the sheer number of lines given each etyle. Maybe this underdeveloped character has little to say for hereelf. Since the roman-face has had more to "say," and Ince the phonic play on Throgmogle's name is more sustained than that on Engestchin's, perhape Throgmogle should be associated with "roman," the more sustained typeface, and Engestchin with "italic."

But the next stanza puta a sight crimp into this: Throgmogle Fordful?

\section{Chillchinchar Engentchin?}

There are two poseible directione for identification to take here. Either one is tempted to use this stanza as a meane of equating the characters with the typeface they are named in, and thereby to confirm the suspicions above about which "part" each character has. or, maintaining the poem's sense of dialogue, one is tempted to read the otansa as vocative, a tentative naming or recognition -- as in, "Hey Throgmogle Fordful! Is that cenlly you?" -- or a query like "Are you fordful today, Throgmogle?". (That's assuming, of course, the poseiblility of Throgmogle and Engestchin questioning theaselves is 
ruled out: are you feeling Chillchinchar today, aelf?, an I really Throgmogle Fordful2) The poem' dialogic etructure eeme to suggeet that Throgmogle' "part" is "italic" and Engeetchin"s "roman."

Thie is aleo the poem'e mallest, most perfectly balanced and most hesitant etanza; it is tenuoue not only in ite alightneas and tone, but in its placement as wil. This etilinese in the eprightlinese of dielogue ecems nonethelese to participate in that dialogue. Fo:.lowing the implication of its questone, one realizes that Engestchin may have much more to ay for and about heraelf than Throgmogle.

Next is the poem's longest etanza; ite alternating etyles of typeface make the etanza antiphonal, convereational:

Fulford mog-gle throg

Throgaing

Besaboom

Bepeboom

Throcaing

Manty choon Manty

chorey manky

manky minsteven

Befaboon chorey

Choodle chin chin char

Gundalling tandy

upert bee neery

Upert a choodle,

Laddledy leery

Upert a choodle

Nin Min Min

Besabogn chorey.

Poudler

Binke

Upert a choodle 
Nin Nin Nin

Manky Minsteven

\author{
loppleton leery, \\ laveling. \\ limpeling. \\ leddledy lumpoling...
}

The inverting, aseerting of names and identity begins again; this time turning Fordful and Throgmogle inside out and upside down -- a frolicking which Throgmogle interrupte with a bullfroggish chorus ("Throgging/Begaboom/Besaboom/Throgging"). This repeats the final "throggins" of atanza one, and "besabogn" rhymes with the initial "choomin" of stanza two, thereby connecting this stanza with earlier ones. The stanza continues with thie phonic play, here glightly more lilting (because of alliterating "m"'s and "l"'s) than in earlier stanzas, with the strains of "besaboom" intermingling occasionally. Ironically. Throgmogle's last word in this stanza land for some time to come) is Blanko, word which, although not English, has some quite specific semantic connotations for English readers. And soon Engestchin will be reduced to speaking a blank of a different sort. Before thle "reduction" of Engestchin, however, there are her loppeling lines which trail off in a quite individual and non-nominal way. Perhaps significantly, many of these words are participial, active words that etrike out in a grammatically and phonically new direction. Only one of these words, "leery," and few of the sounde ("Op," "um") have been used so far. In a poem governed almost entirely by verbal and phonic repetition this is a noteworthy shift away from the norm and one which Engestchin eeems not to be able to maintain or resolve; the stanza ends in ellipeis, with an unexpected lack of energy -- unexpected especially because Engestchin has never yet seemed at a lose for worda. She regains her volce in the name play of the next etanaa: Fordful mogle 
chorey chumbles

dipdum danker.

Engestchin chuh

chuh

ch

h

What is interesting here is not so much the introduction of new words ("dipdum," "danker") despite her earlier slip into silence, but the reduction of her own name to sputtering sounds and then, again, to silence. "Chuh" is the sounding out of the phonic unit which appears most commonly when Engestchin's name is played with. This is collapsed into the phoneme itself ("ch"), and then collapsed to "h," an aspirant, a silent breathing, and then to the silence of blank space and the asterisk. Reducing her name to air, dismantling her "self," leaves Engestchin (the name itself sounds reminiscent of "anguishing") again silent.

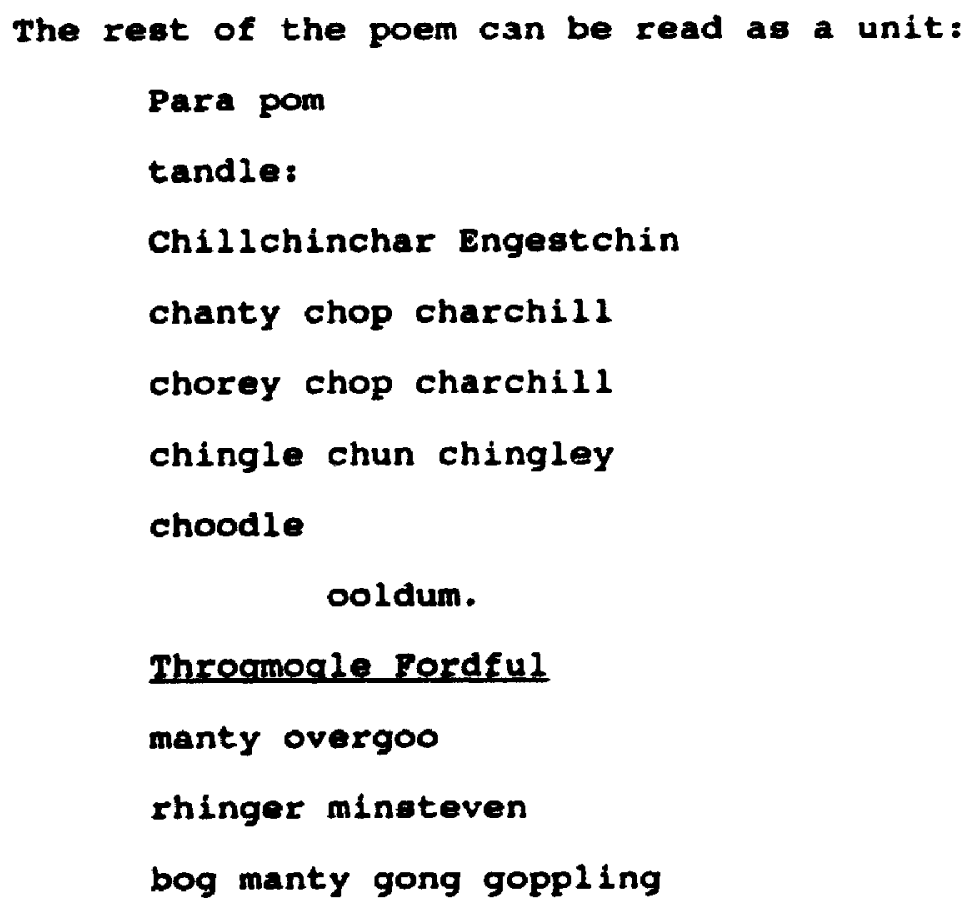


rill cum nack throggins.

Para pom tandle.

The phrasing of "para pom/tandle" -- first with a line break, then without one -- mirrors the reunification offered in this reprise (with variations) of the inital name and sound play on both Throgmogle Fordful and Chincharchill Engestchin. Such thorough-going play on the names has not yet occurred in the same stanza. But this union is qualified by the divilion of a word which was not originally divided -- "chop charchill" -- and which, perhaps not surprisingly, has thus far been associated with Engestchin's name. The second last stanza offers a resolution, an amalgamation which at once counters and contains the previous stanza' movement. A solution to Throgmogle and Engest.chin's mutual silence, succinctly put in the isolation of "Para pom tandle."

This is a brief, so partial, and necessarily uncertain reading of some of the elements in Thibaudeau's poem, but it glimpses, at least, the delicious give and take of her language. "From Throgmogle Engestchin: $A$ relationship" works as poem and as Nonsense because it "loppleton leery"-s along the border between meaning and meaninglessness. Each reading offers the possibility of a new sense, a new scenario. Is this a relationship in decay (marital? parentals) making a (last ditch) effort at reunion? Is Engestchin, despite "her" verbosity, feeling her identity squelched and distorted, her individuality sapped of energy? Are the two characters blithely going about their lives, effortlessly making room for each other? Is this just the empty chatter of a cocktail party? I have an urge to imagine Engestchin cleaning kitchen cupboards and talking to herself, while Throgmogle leans in the door from the living room with an occasional comment. Any and all of these suggestions fit the poem's teasing poseibilities.

While no one reading of the poem can definitively translate the 
Throgmoglian dialect (who would want to, since such translation would inevitably squelch Thibaudeau's lively and witty poem?), each can reveal meaningful structures underpinning the seemingly garbled words, and dramatize the poem's movements towards and away from sense. As in the analysie of more conventional poetry, one can find alternative oysteme operating to create alternative ways of meaning. What at first appears to be utter gibberish has the potential for different types of meaning (most notably sound as sense) quite different from what many $r$. rdere have been taught to expect. But meaning nonetheless. 
Chepter I - Runcible Relations:

A zexonony of Honsense Criticien and theory

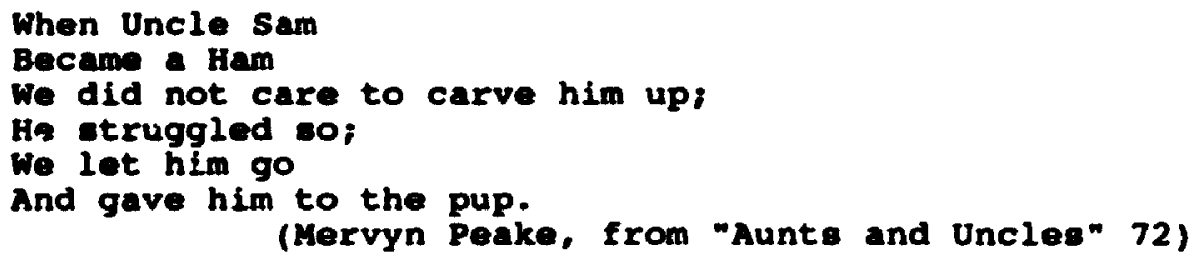

A casual read through The Martha Iandecapes doesn't prepare one for "from Ihrogrogle a Egestchin," even if Thibaudeau's use in other poems of occasional portmanteau-esque and abbreviated worde (for Instance "anyfool wo know it wd have to be/ a muchlesefarcone Head" ("st. Thomas: the great Heat wave of '36" 48)/ have regietered themelves as more than rare forays into linguietic invention. Despite the quirkinese of her atyle. Thibaudeau's other worde eeen to ground a reader in a fairly trustworthy framework of meaning. But this poen with ite radically undercut gestures towards meaning is, some might argue dismiesively, gibberish, sheer nonsense.

Wel1, 18 it? Implicit in my analyeis of Thibaudeau's poem, in the avertion that it works as both poem and Nonsense, is an understanding of Honeenes as a positive linguistic venture. But what aseumptions underlie that atatement? Is "nonesnee" more than a derogatory term for language that is "garbled"? This chapter provides a taxonony, and a survey of the widely varioue reapones to nonsense and its adjacent literary genre, Honeense. Ar such, it will attempt to carve out a enee for the two by plotting them roughly on a literary and 1 inguletle map. Deciding what constitutes either form of nonsense is not imple. 
Emile Cammaerts writes in The Poetry of Nongenge, the genre's firot extended treatment: "It is far easier to say what is not nonsense than to say what is" (8) and Myra Cohn Livingston insists that "nonsense, like poetry, eludes definition" (123). Even a cursory glance at critice and reference sources illustrates just how slippery the concept "nonsense" is.

The Oxford Engliah Dictionary defines nonsense as "That which is not sense; spoken or written worde which make no eense or convey absurd ideas." On the other hand, susan stewart argues throughout Nongenge: Aspects of Intertextuality in Folklore and Literature that Nonsense is symbiotic with common sense. And A.C. Baier in the Encyclopedia of Philosophy writes "Nonsense is parasitic upon sense and never departs so far from sense that it ceases to be part of some language, to the minimal extent of sharing its alphabet with that language" (521). According to Lionel Trilling, nonsense, "when it succeeds, . . makes more than sense" (quoted in Bloom 4). Dutch Nonsense specialist Wim Tigges adopts Frye's "basic types of melog and opsis, of babble and doodle ... respectively the charm and the riddle," and offers "(a)nother way of characterizing (it, as) . . charm and riddle at the same time" ("An Anatomy of Nongense" 41). And Richard Gott, in a review of a recent anthology, The Chatto Book of Nongenge poetry, attributes to nonsense a Britishness akin to "cricket and Marmite": "silly, usually unpleasant and meaningless, often racist and mysogynist [sic], nonsense poetry is to British imperialism what Donald Duck is to the American variety" (37).

These sample definitions lide between nonsense as a linguistic venture, and Nonsense as a genre. Such sliding lo endemic to the subject because the two feed each other, inform their respective definitions. Their relationship grows out of a shared approach to language, and to language' principles of order and meaning. Writing within the Nonsense genre is comprised of works, either fictive or 
poetical, which use nonsense language as a focal point and a fundamental etyliatic principle. Both forms manipulate language (although it may be argued that nonsenee doesn't always do so intentionelly); both, consequently, frustrate one' comfortably staid certainties about the way in which language tranemits or, as is more to the point, makes meaning. The growing interest in nonsense language is due, in part, to an Increased awareness of Its literary uses and of how those literary uees reflect a changing understanding of the role language playe in the formation of the individual and wociety.

While critice continue to disagree about what nonsense is, the definitions above demonetrate that most critice isolate the "sense" within the "non". With the exception of Gott's (which defines it as a manifestation of the Britioh Raj mentality) and Tigges' (which 18 one of the fow "characterizations" of Nonsense he offers which doesn't include sense), every quotation or reference above describes nonsense and Noncense in terms of their relationship with sense. And that seems "reasonable"; for, how can one claselfy something which, by its very nature, makes suspect the language with which and the systems of thought by which one attempte to claseify it? How deecribe the limits of a concept which questions the reliability of such limits? The answer: one doesn't. Rather the word or concept is described in terms of other words, despite the fact such description, instead of "explaining" or "clarifying" the word, pushes it deeper into language, further towards abatraction. Definition and claseification are actually attempte to broaden the Iinguistic bases of a concept, to tie it more firmly to a series of abstractions. A definition may be thought of as literal, but it is actually literary -- this is just what Alice's experiences with Looking-Glase Insects and Lear's Nonsense Botany demonstrate (see Figs. 
1 and 2).' When Lowis Carroll and Edward Lear take definitione and claseifications literally. Nonsense is the "predictable" result. Not long before her visit with the Looking-Glase Insects, Alice has an exchange with the Red Queen which makes euspect, as well, that compendium of definition, the dictionary. When Alice charges that the Queen'e boast "I could show you hills, in comparison with which you'd call that (hill) a valley" is nonsense, the Red Queen shakes her head: "You may call it 'nonsense' if you like... but $r$ 've heard nonsense, compared with which that would be as ensible as a dictionary!" (Through the Looking-Glage 162-63). Ironically, the queen' claim is true; her nonsensical statement is as sensible as the dictionary, because the dictionary (as much as it purports to contain the many "senses" of words) is highly nonsensical. stewart writes that because "they reduce the world to discourse ... there is nothing that is so nonsensical as the dictionary, the telephone book, or the encyclopedia" (190-91). With definitions, then, one 18 between a rock and a hardly existent place. Taken literally definitions can result in nonsensical incongruity; taken literarily definitions create a Nonsensical and hermetic world of worde. 2

In The Eield of Nonsenge, Elizabeth sewell points out that Humpty Dumpty, the only character in Carroll who pontificated on language and meaning, sits high atop a wall in a very precarious position (122). This position is shared by those who try to define anything succinctly, especially nonsense. That being the case, I won't manufacture my own

1 Carroll's Looking-Glass insects also demonstrate that, as Sherril Jaffe wittily points out in a lecture/discussion led by David Bromige ("Intention 8 Poetry" 41 ), there's a very little gap between etymolooy and entymolony.

\footnotetext{
2 It's important to note that neither Nonsense nor nonsense is solely lexical in nature. Syntax often stands as the representative of "sense," or maintains its own sort of sense. The reliance is central to the symbiotic nature of both types of nonsense. As will be argued in later chapters, Nonsense works most effectively when it is either, according to Chomsky's levels of grammaticality. "grammatical" or "semi-grammatical." That is, when it preserves an at least moderately accessible/translatable level of syntactic order.
} 


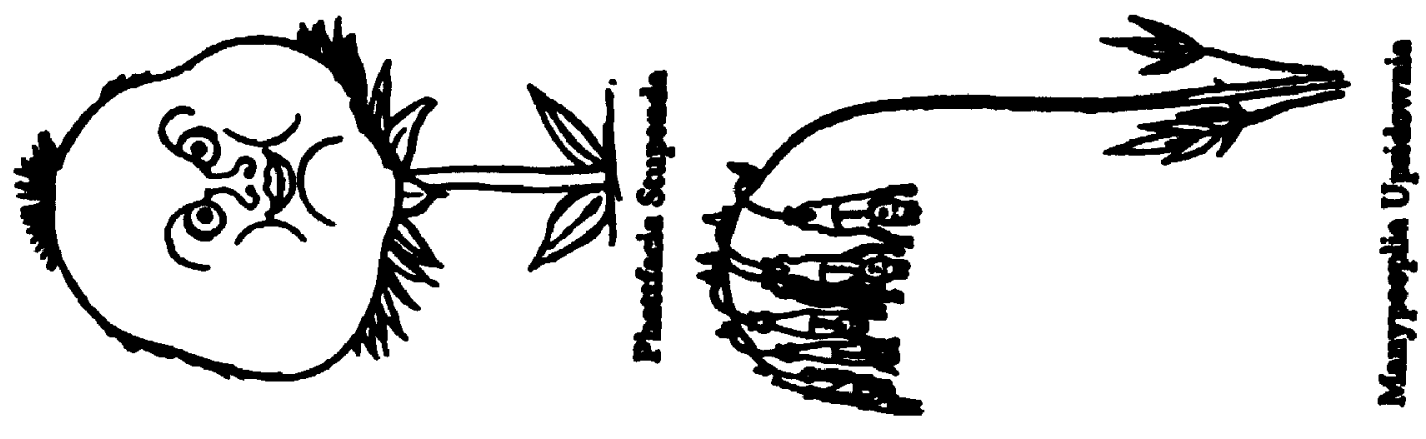

8

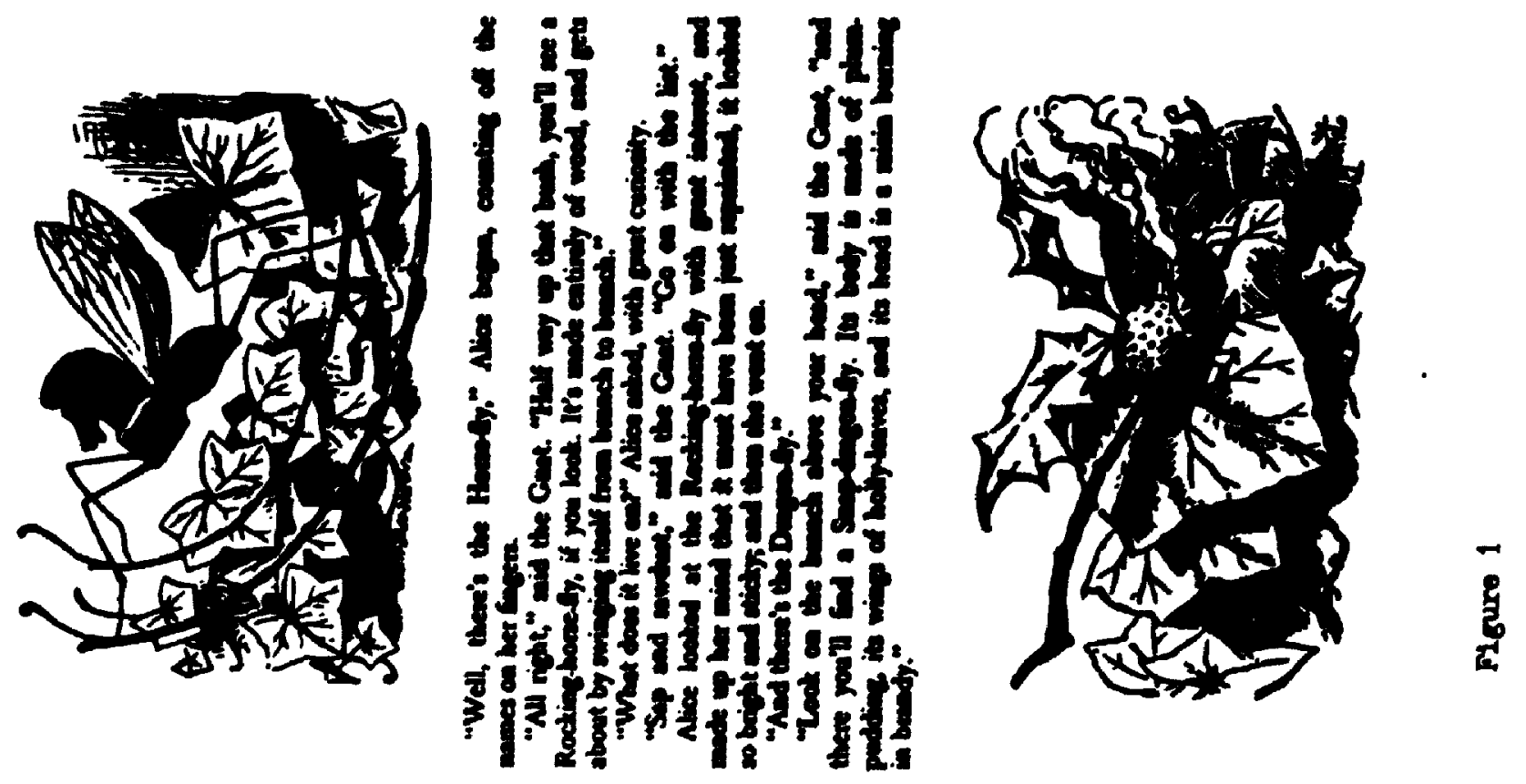


definition. Wittgenstein's characterization, in Philosophical Investigations, of meaning as use is handier in this situation than are atandard waye of defining. Rather than having an icolatable oubetentive definition, words -- for Wittgenstein -- evolve a meaning over an extended period of use; meaning becomes allied with context. I'll take my cue from wittgenstein and from Gilles Deleuse who suggests that "meaning is not an entity but a relation" (quoted in Baum 69) -- as the "definitions" above (for the most part unwittingly) show. What followe is an attempt to let an understanding of the terms "nonsense" and "Nonsense" evolve out of their relationships with other concepts, and is an exploration of how the terms relate to linguistic and (to a leseer extent) psychic distortions in these categories or contexts: madness, anarchy, meaninglessness, dreams, riddles, play, philosophy and linguistic operations. This exploration will facilitate an organizing of, and an accounting for, the often conflicting critical responses to both forme of nonsense. These groupings seem naturally relevant to Nonsense, but others could be suggested, for instance relations with the Absurd, the grotesque, the nursery rhyme; most of these categories stretch to include other tangentially-related topice as well.

The first section, on madness, looks briefly at the historical association between Nonsense and madness and the literary tradition of the fool, and lays the groundwork for a topic which will be taken up again in chapter three -- the opposition between the Nonsense of Carroll and schizophrenic "nonsense," as discussed in the works of Gilles Deleuze and Jean-Jacques Lecercle. My consideration of anarchy in the second section deals primarily with subversion, as it is found in Lear's rigidly controlled limericks and their thematic use of violence, and in the benevolent anarchy of Bakhtinian carnival. The discuseion of Bakhtin branches out into one of Julia Kristeva's adaptations of hil theory, and onds with a quick detour to discuss self-reflexivity, an aspect of Krietevan carnival which superficially secme disjunct from anarchy. The 
third section, which deals with meaninglessness, notes Nonsense': differences from Absurdiem and Dadaiem, both of which are frequentiy linked with weaninglesenese. It also discusees the disparity between critical contentione concerning nonsense' meaningleseneses viewe which can be eplit, roughly speaking, into two campe -- meaningleseness as achieved through minimal (or literal) meaning, or as achieved through a multiplicity of meaninge. As a part of the exploration of the latter contention, which I agree initiates Nonsense' gesture toward meaningleasnese, theoried of the portmanteau word will also be presented. Nonsense' relationship with surrealism is considered in the fourth section on dreams; this eection alwo includes a refutation of Elizabeth sowel1', claim that Nonsense and dream are antithetical, and a consideration of how Freudian dream-work inhabite nonsense language. The fifth eection looks at the importance of riddles to nonsense and, by extension, the nonsensicalness of religions. Carroll' use of games in the Alice books, the many co-relations between social theorist Johan Hulzinge': theory of play and Nonsense, and the character of Alice as a game-player are dealt with in the section on play. The philosophical espects of nonsence, as construed by Wittgenetein in Philorophical Inventiantione and more generally by A.C. Baier in The Incyelopedis of Philonophy, are discussed in the seventh section. so too is the relationship some critics see between Carroll'" mothod of "exposing" nonsense and wittgenstein's. The final section on linguistic operatione deale briefly with reference, materiality and the double-nees of language, and anticipates the second chapter' discuseion of desire in noneense language.

Thece groupinge and contexts are not meant to offer an exhaustive reading of the area, but rather to provide a convenient way to synthesise some of the varied tacks people take when writing about noneense and Nonsense. None of them entirely excludes the others. As M.R. Halght writes: "Nonsense shades gradually, in varlous directions, 
into pure fantasy, pure farce, the grotesque, the surrealiet, and so on" (255). This ohading is true of noneense relationally as well a generically. Mont critice blend at leaet two of the groupe coneidered below: the eelf-contradiction which can result is particularly apt. Eesential to an understanding of nonsense, and of the tenuous blending of these groupinga, if the recognition, promoted by riggea and many other critice, that Nonsense always maintains a delicete tension between (at least) two seemingly incompatible or antithetical concepte. The iscue is not one of polarity, but of duality, not of a separable either/or nature but of a multiply inclusive one.

What etrings these categories together is language. For nonsenne is at the heart of language; and Nonsense creates a world of worde (Sewell 17). As such both forms of nonsense have much to do with semiotice, the study of sign systems -- especially with inguistic semiotics, although Nonsense' close ties with illuetration indicate it i. also important to visual semiotics." By stretching conventional attitudes about language, by playing with words as if they were things, these two types of nonsense draw attentior, to, question, the way words mean, the way they relate to each other and to the things they refer to in any context.

While it would have been possible to avoid the continual Interweaving of associative phenomena (dreams, madness, games, carnivals, etc.) and the logical and linguistic properties of nonsense, such interweaving demonstrates that nonsense can be dealt with in the context of a lingually conetructed reality; because one relates to the world thrcugh language, and because nonsence is at all times inherent in language, it 1 a an inescapable "presence" within all anpecte of "reality" -- social, paychological, historical, literary, political.

${ }^{3}$ For an extended consideration of Nonsense's relationship with visual semiotics see Wendy Steiner's The Colors of Rhetoric. 
The very pliable groupinga used in this chapter indicate, as well, that my focue le not so much on Noneenee as a genre (though of couree that w111 com into play) as on the act of reading and what one can bring from a reading experience of Nonsenee to the reading of other. supposedly "senelcal," writings.

Orchestrating oplnione whose variations are sometimes great. gowetlmes a mere eplittlng of halra, cen make for a gangly and gracelese dance, a pas-de-deux in hip-wadere. But looking at noneense in these waye will facilitate a elightly different approach to the worke of Cerroll and Leer, whose writing will be frequently uaed as examples: wore lmportant, these waye of looking at the two types of nonsense will Lntroduce nowe of their wide range of aseociations, and a few of the other writere who, it is claimed, belong to the Nonsense family. According to eowe genealogied, Arietophane, Rabelaie, Shakeepeare, Jarry, Steln, Joyce, the Marx Brothere and Flannery o'Connor ere mambers according to othere this fanlly energed only with the riee of Victorlan England and is very much a nuclear one (Tigges, Anatomy 13839).

Looking Through Dark Glaces: Moncence and the Iancusas of yadnese

Framing this discussion of runcible relations with madness and Iinguiftic operations has a certain propriety because much of the language theory employed in the latter parta of this study uses madness as a mane of explicating some of the ways language functions. Foucault, in Hadnege and civilisation, writess "Ianguage is the firet ind lat atructure of madnes, its constituent forms on language are based all the cycles l; which madness articulates its nature" (100). He uses the term "language" both metaphorically and literally, suggeating on the one hand that madnese can be defined in the simple structure of a diecourse. . 
[which] is both the silent language by which the mind epeaks to iteelf in the truth proper to it, and the visible articulation in the movemente of the body $(100)$.

But on the other that madness is also "of both body and soul, of both language and image, of both grammax and phyaiology" (100-1).

Because one engagen reality through language, and because madness is, on at least one level, a socially unacceptable perception of reallty, madnese and languags are intimate. One of the forms their intimacy takes is the kind of linguletic disruption typical of a nonsenee which brings together the body and language; and nonsense is often styled as a discourse on the edge of madness.

Madness leape immediately to mind when considering Alice's Adventures in vonderland. This leaping may be the result of the presence of the Mad Hatter (deranged by the mercury he used in making hate), the March Hare (crazed with the spring and the need to mate) or the Cheshire-Cat who, in a notorious passage, tells Alice: "we're all mad here. I'm mad. You're mad" (72). Such a ready association with madnese is suggested perhape by the fact that all three crazed characters are turns of phrase turned to life, or perhaps (and most likely) by the dementia of the place itself. Peter Heath argues that Alice". is "a mind driven almost to the verge of unhingement by its encounter with the dark forces and mysterious taboos of language and thought" (52).4

The connection between Nonsense and madness, however, goes back

\footnotetext{
- Heath insists, however, that Carroll is not a Nonsense writer but, because of his rigid adherence to logical and linguistic rules, an absurdist (47). While Carroll's delight in following logic to its illogical ends may be a technique shared by Absurdist writers, I hesitate to label him such. The reality which he presents is not a senseless one, as is that which marks Absurdist literature; rather, as Tigges arques, it is a reality made up of senseless language (Literary Nonsense 128). The difference is subtle but important: one uses language to create a senseless reality, the other uses sensaless language to create a reality (Tigges 128 ). As well, his use of the narrator to remind the reader continually of the status of Alice's waking world works against any desire to read the human situation in tre Alice books as devoid of meaning and order. Alice's world does have order; Carroll uses Nonsense to show that, within that order, disorder is necessarily found.
} 
much further than to Alice's Adventures in Wonderland. In 1711 Addison, writing for The Spectator, deemed Nonsense the daughter of Falsehood and the mother of Frenzy (who eventually married one of the daughters of Folly) (Ross 336), thereby placing Nonsense precariously between madness and unreality. Addison's designation also relates Nonsense, if cnly by marriage, with the tradition of folly and fools. This is a relationship confessed (with clearly differing sentiments) by such critics as G.K. Chesterton, who calls Carroll's Nonsense "a sort of defiant folly" ("Lewie Carroll" 112), Alison Rae Rieke, who connects it to the traditions of the Shakespearean Fool (11), and Hugh Haughton, who claims it may be "the modern descendant of ... feasts of asses, and the culture of fools and folly" $(9) .{ }^{3}$

Nonsense' purported kinship with fools and folly is one reason why Shakespeare is often considered kin to Lear and Carroll. King Lear' madness and his Fool provide obvioue connections with the genre. Both characters balance sense with incomprehensibility, and would be solid illustrations of the common assertion that madness is associated with a hidden truth, that the cryptic messages of prophecy or the phenomenon of speaking in tongues contain truths which challenge the limitations of verbal expression. They would be illustrations, as well, of the similar tendency on the part of many readers and critics to fird

5 The tradition of the fool is not one that escaped Edward Lear's notice; in his introduction to The Complete Nonsense of Edward Lear Holbrook Jar. I quotes Lear's letter to his friend Fortescue asking him:

to 'write to Lord Palmerston to ask hir ask the Queen to ask the King of Greece to give' him a 'place' specially created, the title to be 'Lord High Bosh and Nonsense Producer ... with permission to wear a fool's cap (or mitre) .- three pounds of butter vearly and little pig, -. and a small donkey to ride on' (xvii).Lear connects himself more with the fool than with folly, as may be surmised from another letter, this one to his friend Drummond: "(it is not generally known,l that I refused the throne of Greece - King Lear the first -- on account of the conduct of Goneril \& Regan my daughters, wh. has disturbed me too much to allow of my attention to governing" (quoted in Noakes 159 ).

And as Edward Lear playfully prefers domestic lunacies (and three pounds of butter) over King Lear's passionate madness, so too do most critics fall back onto George Pitcher's qualification that "nonsense takes ' $n$ the form of something like madness" $(611$; my italics) and ultimately reject madness as a synonym for Nonsense. 
"senee in noneense" ar,d "method in madnese."

The garbled wanderings of King Lear' mind dramatize his initiation into "another" reality (his burgeoning awarenese is clearly digjunct from his earlier undergtanding of his place in the world), and his language is torn by the struggle between the "syntax" of his (and grammar's) previous rule and the semi-grammatical passion of verse. Tigges rightly classes such moments in Shakespeare as "partial nonsense" (An Anatomy of Iiterary Nongenge 217 ), for he points out that the work as a whole is motivated by a desire to do more than contest the hidden mechanizations of sense. Yet it is hard to find anyone who juggles sense and senselessness, order and chaos, clarity of perception and mental upheaval with shakespeare's grace and precision.

But while Nonsense (be it the partial nonsense of Shakespeare or the Classical Nonsense of Lear and Carroll) may be a balancing act, madness is frequently an act of excess. The two differ in the degree and intent of their linguistic disturbances. In his study of the relationship between language, nonsense and desire, philosophy through the Looking Glass, Jean-Jacques Lecercle argues that, far from being monozygotic twins or even blood-brotherg, Nongense and madnegs are at best cousins-once-removed. He uses "delire" as a point of connection, something he describes as

a form of discourse, which questions our most common conceptions about language (whether expressed by linguists or by philosophers), where the old philosophical question of the emergence of sense out of nongenge receives a new formulation, where the material side of language, its origin in the human body and desire, are no longer eclipsed by its abstract aspect (as an instrument of communication or expression) (6).

pelire is language "tainted by desire, by the actions and passions of 
our body, by its inatinctual drives" (7); it is the language of madnese itself. This definition connects with Foucault's reading of classical madness which

does not designate so much a epecific change in the mind or in the body, as the existencs, under the body' alterations, under the oddity of conduct and conversation, of a delfrious discourse - . which liberated passion from all ita limite (99-100).

Lecercle's characterization of delife does not agree with most readinge of Nonsense, however, which require a complementary tension, the delicate joining of seeming opposites. He allows that Nonsense is a very mild form of délice since it admits the incomprehensible into language and so treads on language's frontiers, but simultaneously dismisses it (especially in Carroll's works) as "a pedagogic trick ... to teach children their way into communicative languagen (79). The dismiseive attitude he adopts from Gilles Deleuze who, along with Felix Guattari in their jointly-authored anti-oedipue, dubs Carroll "the coward of belles-lectres" (135). More important, he also borrows from The logic of sense, an earlier work by Deleuze, the antithetical structuree of aurface language (equated with Carroll's work) and depth language (their example is Artaud) (Lecercle 41) which underscore his argument.

What Deleuze argues, in the logic of senge, is that there are three types of nonsense. One of the surface, which never fully engages the potential riaks of language and which is therefore inextricably allied to the production of "sense"; this, he claims, is the nonsense of Lowis carroll. The other two forms of nonsense are of the body, the schizophrenic body, and experience language as a physical assault, these are the nonsenses of the depths and have nothing to do with sense; such is the nonsense of a writer like Antonin Artaud. While the relationship which various types of noneense have with madness may be radically 
different, and their degree of involvement with the body may vary, I suggest in chapters two and three that no form of noneense is unrelated to the body. Understanding Deleuze's theory of sense and nonsense wi t be useful for these later discussions.

The distinction between these nonsenses, between surface and depth, is one Deleuze arrives at through contemplation of stoic causality and its implications for understanding how sense resides within a proposition. Stoic causality is re-construed in such a way that it seems to anticipate Husserl $(20-21)$. The connection between cause and effect, between depth and surface, is split apart; causes are on one side of an un-breachable barrier, effects on another, although some initial cause must first have generated an effect. After this initial split, effects generate other surface-efects, which are in no way related to causes, to depths. Deleuze insinuates that this "causality" is almost phenomenological (21). Sense for Deleuze, according to Ronald Bogue in Deleuze alig Guattari, "seems to be something that is produced through language, a mere linguistic result or after-effect, yet at the same time, something that is presupposed by every statement as its antecedent condition" (70). Deleuze notes the three bagic relationg within a proposition: denotation (the association of words with the particular things which they are said to represent), manifestation (which relates the proposition to itg speaker and so "manifests" the speaker's desires and beliefs), and signification (the word's relation to "univergal or general concepts" and "the syntactic connections to the implications of the concept" (14)). But, he determines, sense itself can reside in none of these relations since, as Bogue explains, each of these "[presupposes] one another" and all three assume an already existing framework of meaning (70). Consequently Deleuze proposes that sense be counted as a fourth relation within any given proposition. It is "the expresed of the proposition. . an incorporeal, complex, and 
irreducible entity, at the surface of thinge, a pure event which inheree or subsists in the proposition" and is "neutral" (Logic of sense 19).

What is commonly refered to as sense, is for beleuze, "common sense" or "good sense" (Bogue 74). He construes sense as not meaning, Der as, but an "expression" or flow growing out of, but separable from, the tripartite structure of any given proposition or word. The sense of the word "table" is not the four-legged object to which I point; nor is it that particular table which $I$, in writing the word, intend or believe I am referring to; again, it is not the general concept of "table" -- a flat-topped construction of variable size, propped up by legs. Deleuze insists that the linguistic functions, which are often considered to conetitute measing and are deemed interchangeable with the sense of a word, are not sense. Rather sense is the fluid border "between propositions and things" (22). "It seems," as Bogue explains, to inhere in language, but to appear in things. If one seeks it in words, it seems to be both a mere after-effect and something that is always already there. If one seeke it in things, it seems to be an event that is spatially and temporally 'there,' yet always somewhere else, always already over and about to be (73).

The senge of the word "table," then, is at once "a simulacrum, a paradoxical, contradictory entity that defies common sensen (73) and an attribute of the object itself $(72)$.

Deleuze explaing it this way: Sense is never only one of the two terms of the duality which contrasts things and propositions, substantives and verbs, denotations and expressions, it is also the frontier, the cutting edge, or the articulation of the difference between the two terms (28).

sense, being the boundary, the intermediary, between things and propositions, is relegated to the eurface, a realm of effect: and guasi- 
causes, a name Deleuze gives to effects which generate other effects. It "is never a principle or an origin" (72). True causes, or "bodies" and "states-of-affaire," belong to depthe from which sense and the surface are cut off, excluded, because, having left these depthe (24), their natures are irrevocably altered."

Sence is co-present with nonsense, or with "surface nonsenee" of the sort which Deleuze gays Carroll writes (68). Nonsense means itself and so has no sense of its own, no need of mediation between thing and proposition; but it does generate the possibility for sense: nonaense does not have any particular sense, but in opposed to the absence of sense rather than to the sense that it produces in excess -- without ever maintaining with its product the simple relation of exslueion to which some people wc.uld like to reduce them. Nonsense is that which has no sense, and that which, as suci. and as it enacts the donation of sense, is opposed to the absence of sense. This is what we must understand by "nonsen e" (71).

But Deleuze "understands" by "nonsense," as well, the existence of two other types of nonsense, which are not gurface-related but schizophrenic. These are the language of the fragmenting body, of Artaud's body without organs, and have nothing to do with the production of sense or the surface. They are akin to the type of language Artaud sought for his theatre of cruelty, a "new physical language based on signs" (Artaud quoted in Hayman 77), and to the type of language he strove for in his poetry. Precisely because of their relationship with depth, Deleuze privileges these types of nonsense over the surface nonsense which he attributes to carroll. Bogue laborates upon the schizophrenic's nonsensical experience

\footnotetext{
- Deleuze's very specific use of the word "sense" lends itself to confusion in certain respects. His definition will not be that used throughout this study, except when he is being discussed. At all other times the less precise definition, that interchangable with "meaning," will be intended.
} 


\author{
of language in this way: \\ Schizophrenice experience words as devouring, lacerating, or \\ jubilant physical entities within a teeming plenum of \\ matter. They have two fundamental intuitione of the body: \\ as a collection of diseociated body parte, diemembered, \\ interpenetrating and mutually devouring; and as a \\ miraculously golidified 'body without organs' . . . For \\ echizophrenics, worde elther enter the diemembered body ae \\ exploded words, wounding, rending phonetic elemente devold \\ of meaning, or issue forth from the body without organs as \\ glorious unarticulated sonic blocks (74-5). \\ Noneenee which is experienced as depth, as a lingual assault on the \\ echizophrenic body, is the nonsenes of the fractured word, of the body \\ ecream, of Lecercle' defire, not of the Jabberwock or the Queen of \\ Hearts. Or so Deleuze and Lecercle contend. This nonsense is the \\ result of a schizophrenic subjecting herself not merely to linguistic \\ dieruption but rather to a bombardment of words and sounds which \\ devatates the "self." While Carroll's language remains situated at the \\ "surface" which sense dominates, for the schizophrenic there is no \\ longer any surface; language must be experienced bodily.' \\ Following Deleuze differentiation between surface and depth \\ nonsense, Lecercle uggeste that Carroll and Artaud (and so Nonsense and \\ delfrel offer different responees to the question raised by Humpty \\ Dumpty -- "which is to be maeter?" (ILG 214 ) -- raised, that is, by the
}

\footnotetext{
'There is a great degree of difference between the writings of surface and body, but there is an unavoidable connection between them too. As chapter two will argue, there is no point at which language can be wholly divorced from the libidinal drives of the body that produces it. The type of psychic landscape which allows for such an inter-relationship is of no real interest to Deleuze because he is dealing with nonsense from a very different perspective than the one which I use, and especially because he attempts, with Guattari in Anti-Oedious to trounce psychiatry and its, as they claim, unwarranted emphasis on the Oedipus complex. It is at this point, where a continuum between surface and depth is denied, that I part company with Deleuze, though his ideas remain of interest and other aspects of his theory will be borrowed and set to work in my admittedly different context. This parting of ways will be more thoroughly broached in chapter three.
} 
Humpty Dumpty who, not long after asserting his ouperiority over language, is made subject to the language of the nursery rhyme which plots his fate. Lecercle concludes that the dream framoworix of Carroll's novel detracte from his commitment to risk the physical experience of language, to suffer the painful link between body and word (32) and so effectively keeps his Nonsense on the safe side of madness. Nonsense and delire do confront the question raised by Humpty Dumpty differently. Quite early in his study, Lecercle defines dellire as that state in which the question of mastery (if not completely reeolved) leans heavily in favour of language; in delire, language is master (9). This is an ironic contention, given that the body, in the delirious speech of which Lecercle and Deleuze write, is said to be the master over language; its flows and drives pulsate and break up the articulable sense traditionally associated with language.

What better way to illustrate this difference between Nonsense and dellfe than the one Lecercle chooses -- comparing Carroll'a "Jabberwocky" with Artaud' translation of it?

-Twas brillig, and the slithy toves Did gyre and gimble in the wabe:

All mimey were the borogoves, And the mome raths outgrabe (TLG 153).

Il etait Roparant, et les vliqueux tarands Allaient en gibroyant et en brimbulkdriquant Jusque la où la rourghe est a rouarghe a rangmbde et rangmbde a rouarghambde

Tous les falomitards ctaient les chats-huants Et les Ghore Uk'hatis dans le GRABUGEUMENT (quoted in Lecercle 34). A friend once used "Jabberwocky" as a parsing exercise; a glance at the first stanza show how succeseful that could be. One way carroll 
balances sense and senseleseness is by preserving ayntactical form despite the intrusion of neologisms and "non-content." Neither Carroll': early etymology fcreated for his brothers and aisters when a veraion of this first stanza was still just a send-up of Anglo-saxon veree) nor Humpty Dumpty' "masterful" Interpretation can push the verse into the realm of definitive and definable meaning. Yet the nonsenseworde don't push eyntax over the edge of meaninglesenese either; eyntactical meaning is not disrupted, so the poem makes one sort of meaning while undermining another.

Probably Artaud's version could be used as a similar parsing excerclee. He keepo "rational" connective and fairly conventional, if unpunctuated, sentence structure. That is as it should be, though; certainly in Nonsence, words themselves are violated much more frequently than syntax (Stewart 34). Thibaudeau in "from Throgmogle" maintains a much more coherent deictical and syntactical than lexical order, although her poetic lines do cause some mild syntactic discuptione. Can one even imagine an asyntactical language? Even seemingly asyntactical compositions, like concrete poetry, usually elicit from the reader a syntactical impulse, the ordering inherent in the act of reading. Nevertheless language in Artaud's tranelation seems to be breeding itself -- not only are the extra, longer lines indicative of this, but also the hyper-sense of his portmanteaux. These are, if anything, beyond Joyce' neologisms in Einnegans Wake -- so much packed into one word that the suitcase pope open en route and one barely knows how to repack, how to begin sifting for meaning. Artaud of fers excess where Carroll shows restraint. It is this guttural excess which Lecercle connect: with the schizophrenic body, it is, he suggests, indicative of "incentation and animal noise, the scream" (35).

Lecercle, too, 10 guilty of an Artaud-ian excess when he eaya: They [Artaud's portmanteaux] show that the phonetic laws of language go beyond the rules of phonotactics, that the 
sequences of sounds that emerge from the body and are a cause of pleasure or pain go beyond the conventione that epecify possible words. They also show that the attribution of one meaning to a word does not correspond to the instinctive working of language... . (L ] eft to itself language screams, in meaninglese utterances, or is riddlad with ambiguity, which gives it an appearance of meaninglessnese (35).

Lecercle seems to be ignoring the presence of discernible, or almost discernible, worde in Artaud's translation. What about "chat-huanta," for instance? It isn't entirely translatable but one can certainly make a beginning on it, as one can make a beginning on "borogoves"; the same is true of the stranger, more stuffed words like "rouarghambde." Even when one can't pin a word down to five or six meanings or cognates, there is always the affective meaning derived from sounds and shapes of the words themselves. Moreover, is it at all conceivable that language could be "left to itself"? Surely Artaud's translation isn't an example of automatic writing; and even that is controlled, conceivably, by something -- be it the unconscious, the spirit, god.

Artaud does "go beyond the conventions that specify possible words," although he is not always very far acrose the boundary. (And sometimes he doesn't crose it at all.) But crossing that boundary doesn't preclude meaning, as Lecercle suggests; if at times artaud's language screams, a language of the schizophrenic body, it may still evoke some meaning in the scream, and consequently never completely evade the poseibility of sensical interpretation. A mad, peychotic, exceseive language rules in Artaud's "translation" but it is not without 1ts affinities to carroll' quieter, more controlled yelpa, his more balanced Nonsense. Nor does its excess demand that Carroll' work, and 
Nonsense generally, be conetrued as milque-toast pieces of frivolity." Foucault offere lovely image for classical unreason, which, when elucidated, may provide a metaphor for nonsence's connection to and divergence from madness. Madnese it

reason dazzled.

Dazzlement is night in broad daylight, the darkness that rules at the very heart of what is excessive in light's radiance. Dazsied reason opens its eyes upon the sun and seea nothing, that is, does not ree" (yadnese and Civilization 108 ).

Foucault' Image appeals, in part, because it carries over the idea of madnese having accese to secret truth (the sun as light and knowledge), but also because it can be aptly turned to apply to Nonsenne and so respond to Lecercle and Deleuze. If claseical unreason it reason dazzled, then Nonsense is reason in dark glasses, looking into the eclipee of language and sometimes risking a alip of the glases, a flash of exposure. Reason in Nonsense risks what Joyce Thomas calls "a moment, a fl:ckering, tluttering instant of disorientation" (119). An optician would tell anyone that staring right into a solar eclipee in madness, she would insist that risking even one sip of the glasses is courting blindness.

Moncence maintaine the tension that madnese forsakes. When a writer of schizophrenic nonsense stares wide-eyed into the eclipse of language, one is well aware of what will happen; suffering is palpable in her words. But when a Nonsense writer peeks momentarily above the glasees, the reader doesn't know what the result will be. This is the risk in Noneense -- not of utter blindness (or total blindnese to

- It should not be forgotten that, relatively speaking, what Carroll does in the Alice books, given the climate of Victorian children's literature, is almost as radical as Artaud's dissolution of language nearly forty years later. Virtually from the time of its publication, Alice's Adventures in Wonderland was recognized as pivotal, an exceedingly radical addition to a canon comprised of the distressingly didactic books of Sara Trimmer and the like. 
socially accepted reason) -- but the riek of not knowing, and ultimately of never knowing, if the Nonsense le finely conetructed. Wendy steiner contende that in Alles's Adyentures in Wonderland "[al1] the nonsenee interruptions, all the spatial diecontinulties and logical leape of the book are aigne of this struggle between the knower and his undoing" (colore of Rhetoric 131). The struggle is nover wons the knower it nover wholly undone, but neither lo she ever entirely eucceseful. She remains euspended in the half-light of "negative capabllity," the discomfort and delight of uncertainty.

Loosing the straitiacket: Nonsense, Anarchy, and carnival

If noneense is not linguistic madness, is it perhaps subveraion? I. Nonsense verse, as Henkle would have it, "rigidly controlled anarchy, in a straitjacket of conventional verse forms and rhyme schemes" (116)? Henkle'- image appeare to entertain the paradoxical nature eseential to Nonsense, but it denies Nonsense any freedom of movement, any chance for risk. Once again Nonsense is deemed to be playing it safe.

Lear's limericke succeed precisely because of their balancing it a tight rhyme scheme, rigid metrics and incongruous words and behaviour. Interestingly, it is a verse form tailor-made by Lear. He adjusts the traditional five line, aabba limerick form to four lines with an aaba rhyme. The resulting $\underline{b}$ line contains an internal rhyme -- in order to find the traditional 1 imerick rhyme scheme, Lear's reader must turn inward to the line' centre. Much as he does in a smaller way by collapeing the third and fourth rhyme, Lear forces the energy of the whole in upon itself. This turning back occurs not because of the final rhyme echoing the first two lines, but because of Lear' refusal to allow a linear progreasion or climax (Ede 22). Rarely in Lear' most succeseful limerick: do hie final lines stand as more than mild alterations of his first. An adjective (generally misused or purely 
Invented) changee olightly the subject -- be it "That lively old Percon of Ischia," "That intrineic Old Man of Peru," or "That ombliferous perwon of crete." The result is a sugar-coated entropy typical of Nonsence ae both Ede and stewart understand it, with ite "imposeibility ... to go anywhere, to proceed in a etraight line towarde a purpose at hand'" (stewart 71).

To counter Hankle's atralt-jacket lmage, then, there is Ide': ineightful obeervation:

$$
\begin{aligned}
& \text { Even the limerick' formal valuation of sound over sense, } \\
& \text { its external emphasis on rhyme, rhythm and } \\
& \text { alliteration, while in one sense restrictive and } \\
& \text { perhape represeive, is at the same time a pr sal to make } \\
& \text { "regular" sense at all, and hence aleo an } \\
& \text { expression of the self, of the individual's right to } \\
& \text { manipulate his own environment for his own purposes (27). }
\end{aligned}
$$

The controlling form, which Henkle implies structures anarchy, is itself unetructuring. Lear rentructures 1 imerick form to facilitate the breaking down of sense, and the forcing of both the poem and the reading process back in upon themselves. By working againet diachronic unfolding in the poem, Lear creater the static world tipical of Monsense, a world which is constantly in procese but in which nothing happens.

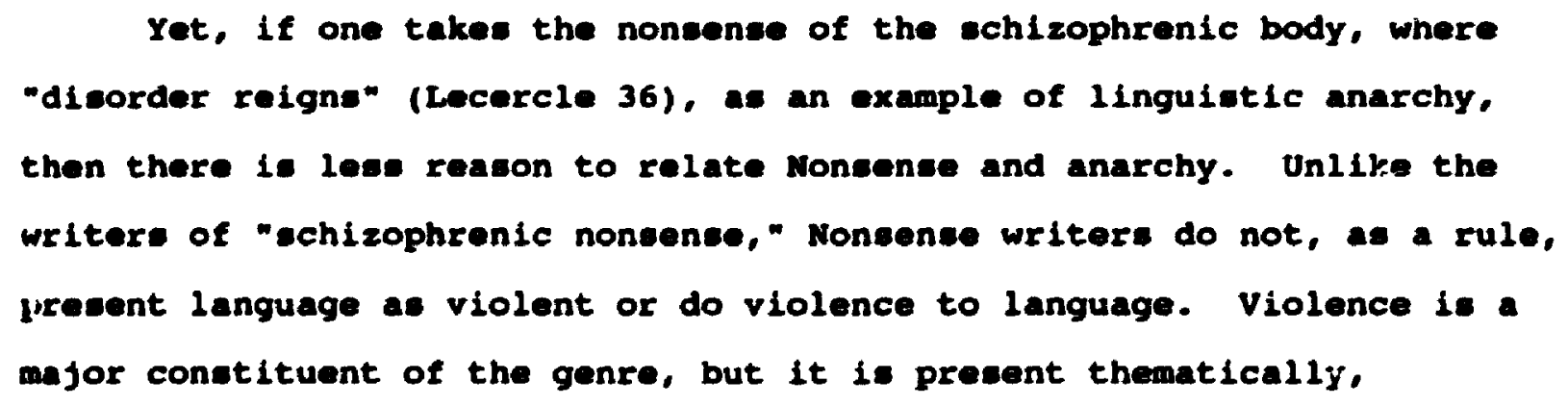




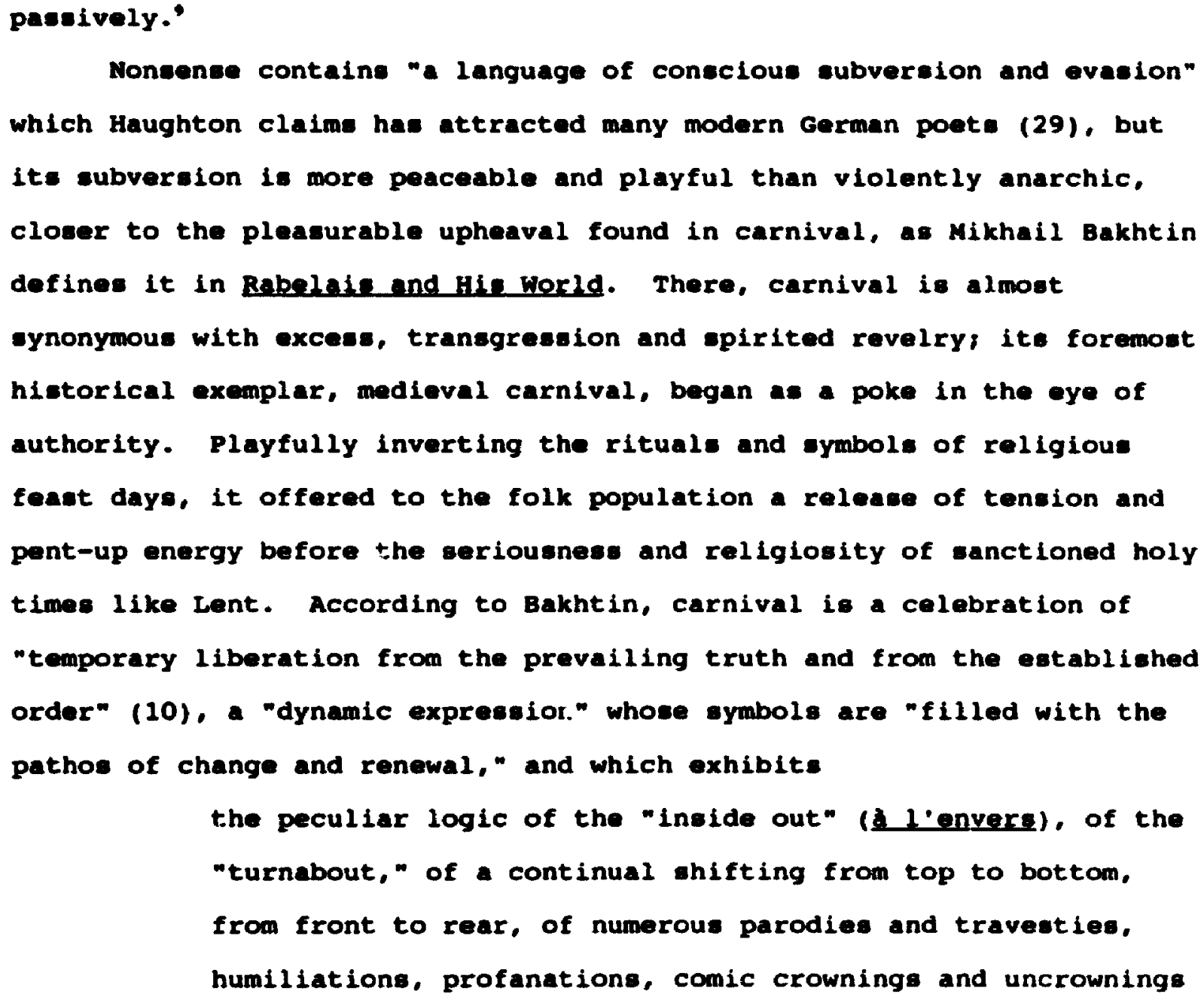

\footnotetext{
- Lear especialiy uses violence as part of his work. Take, for instance, There was an Old Person of Buda,

Whose conduct grew ruder and ruder;

Till at last, with a hammer, they sllencec his clamour,

By smashing that Person of Bida.
}

"They" are symbolic of society at large fintercstingly Lear's illustration shows a threatening individual much larger than the oppressed Man of Bud s), and persecutors of innocent and eccentric people. But "their" actions are qualified by the verse's entropy, its lack of linguistic progression. By encroaching upon the containment of Nonsense verse, by smashing through into the last line which is more often than not a mere repetition of (and so an affirmation of) character, violence is not without its threat. "They" attack physically, energetically. But the linguistic resilience of "their" victim undercuts the action; the old Person of Buda is still the last word. 
Nonsenve.

Ae well, Bakhtin notes one essential ingredient in carnival, the tone of its laughter, which turne upon precisely the sense of belance essential to successful Nonsense. Carnivalesque laughter is "complex." A "festive laughter," "it is universal in scope... directed at all and everyone, including the carnival's participants." And it is "ambivalent: it is gay, triumphant, and at the same time mocking, deriding. It aseerts and denies, it buries and revives" (11-12).

But carnival, despite its participants' tendency to engage in self-parody, lacks Nonsense's rigorous self-awareness. Nonsensical eelf-reflexivity, as will be argued, lends itself as much to infinitely regressive questioning and threats of stagnation as to dancing in the street. Nonsense is at heart a more serious offshoot of the folk tradition -- John Cleese to carnival's Benny Hill -- profaning similar sacred traditions but with more telling means.

Kristeva, following Bahktin, defines the carnivalesque text, and cativivalesque discourse, in terms which can be applied almost wholesale to the Alice books. "A carnival participant," she writes, "is both actor and spectator; he loses his sense of individuality, passes through a zero point of carnivalesque activity and splits into a subject of the spectacle and an object of the game" ("Word, Dialogue, and Novel" 78). For both Alice and the reader, 1058 of identity, becomes a crucial theme from the moment Alice decides she must have turned into Mabel (29). Both are objects, observers and unwitting players of Carroll's game; and since the game is one in which the limitations of our logic, ur language and our way of making sense of the world are being exposed, ultimately the limitations of the very foundations of our identities are expused, as Lisa Ede argues so well (93). The many different sizes Alice becomes, the roles she plays, the many cases of mistaken identity she experiunces (with such a long neck she muet be a serpent, insists the pigeon who shoos Alice away from her nest (61-62]) all fracture her 
assumed unity of being.

Kristeva continues: "The carnival first exteriorizes the structure of reflective literary productivity, then inevitably brings to light this structure's underlying unconscious: sexuality and death" (78). All three are foregrounded in Carroll' Alice books. Alice's Adventureg in Wonderland is infamously framed by its dreamy bookends. Such framing adds to metafictionality, to self-referentiality, according to stewart (21-27). This reflectiveness is emphasized in the book's prefatory poem "All in the gnlden afternoon" (which in maudlin verse describes the original telling of "Alice's Acventures Underground,") and in the book's final episode. In the latter Alice's elder sister has an equally maudlin "dream" of young Alice, Wonderland and Alice grown to womaniood. Carroll makes Wonderland t've core of a telling-seguence. He tella the story; Alice tells it to her sister; her sister imagines Alice telling it to her own children. Within the story itself, there are many stories told and re-told: for instance, the mouse's tale (40) and the story of the mock turtle (102-105), and Alice's twisted attempts to recite famous poems (such as "How doth the little crocodile" [29]; "You are old, Father William" (56-57]). All of these emphasize the act of telling, and the extent to which context affects the tale told or verse recited. Alice's recitations and the other characters' stories are framed by Wonderland, as Wonderland is framed by dream, as dream is framed by earlier and later tellings. Story is continually being recontextualized and so re-configuring itself within the paradigm of its telling.

Quasi-Freudian readings are too frequent for the unconscious sexuality of the work to need much explanation; whether or not one choses to see the rabbit-hole and tunnel as a vagina and birth canal, the pool of tears as amniotic fluid, and Alice's physical fluctuations as pubescent, the presence of sex in the book need not be dwelt upon long. But it is worth roting that none of these sexual elements is 
overt; in this instance, Carroll diverges from the carnivalesque model which Bakhtin and Krioteva present.

Nor is death a hidden component. The queen of Hearts is continually and loudly threatening death to anyone who disturbs her. And alice, when shrinking in the firat chapter of the book, contemplates being reduced to nothing (23). No one dies in the book, of course, because that would move the zone of action away from linguistic threat: and threats to language and into realm of physical and material danger, out of Nonsense, where seemingly senselese language creates a reality and into the senselese reality of Absurdiem (Tigges, Literary Nencenes 128). Sexuality and death express themselves in non-thematic ways too. These, as they relate to Kristeva's theory of poetic language, will be discussed in the next chapter.

When Kristeva moves on to "[figures] germane to carnivalesque language," such as "repetition, 'inconsequent' statements ... and nonexclusive opposition" (79), the reader of Alice is surely on home ground. The mad tea-party (74-84) is replete with inconsequence, repetitions abound throughout the text, and "nonexclusive opposition" is another way of naming that complementary tension which lies at the heart of Nonsense. Her insistence that "drama becomes located in language ... [which) parodies and relativizes itself, repudiating its role of representation" (79) is almost a synopsis of the tale's procedures.

Although self-referentiality seeme a departure from Rabelaisian carnival (more a product of the "interior infinite" Bakhtin locates in the melancholy leanings of Romanticiom [44] than the fruit of unadulterated carnival joy), this strand of Kristeva's description is so popularly and so aptly applied to Noneense it demands coneideration. Ede defines Nonsense as a "self-reflexive verbal construction" (12) throughout her diesertation on Carroll and Lear, and sonetroem, in his article on Lear and Gerard Manley Hopkins, names its strength a "tidy self-consistency" (198). Michael Holquist regards "The Hunting of the 
Snark" as a poem about itself (147). This is Nonsense as Deleuze, in part, construes it: something which means itself. Susan Stewart examines how nonsense' self-reflexivity ultimately undermines the common sense with which it is eymblotic. For her, Nonsense is "an untouched surface of meaning whose every gesture is reflexive" (4). Each gesture is a "split in consciousnese ... (which) breaks open the pervasiveness of common sense" and reveals that it 18 both ideologically and culturally bound (49). She suggests that Nonsense has connections with metafiction: With the construction of metafictions there is a reflexivity, an articulation of the conditions under which the fiction has come to be, and this movement is one that makes conscious aspects of the unconscious. Not only does the text itself appear as a surface replete with signification, but it also makes conscious aspects of context that would remain unarticulated in everyday life and the fictions of realism. The text thus comes to pack it: own context, to carry its own set of interpretive procedures "spelled out" on its surface. This is the movement of nonsense with its impossible context -- a context that is unrealizable, that "no one can stand" in everyday life precisely because it is overburdened with consciousness (87).

stewart argues that nonsense, by undoing what it relies upon, is always in danger of undoing itself. Since common sense is integral to nonsense and nonsense is always assaulting and exposing it, then nonsense simultaneously assaults and exposes itself. One is reminded of Hamlet. crippling self-reflexivity, and it comes as no surprise that stewart comments upon nonsense's entropy. Such hyper-consciousness makes each word the site of struggle and upheaval. Pure nonsense is, in stewart's words, "the most impossibly social gesture" (22). It is "good for 
nothling " (119).

\section{The cadence of Meaning: \\ Meaninglesenese Intruding on Meaning}

In plotting Nonsense on a linguistic map, Cammaerts wrote: "It lies in the somewhat inacceseible region where the human tongue loses all meaning" (51). His point is one with which almost all other critica of Nonsense agree to disagree. Even Susan Vigeurs, in her lively "dialogue" with Fose, Edward Lear's cat, will "allow" Fose -- Nonsenee's champion againet an alliance with poetry -- to go no further than to aseert that Nonsense has "the cadence of meaning without the content" (139). If "meaning is not an entity but a relation" -- the underlying premice and motivating structural principle of this chapter -- then cadence may have as much to do with meaning as content does; a seeming lack of lexical sense does not exclude all types of meaning. That is precicely what my preliminary reading of Thibaudeau's "from Throgmogle Engestchins A relationship" tries to demonstrate. Thibaudeau 's poem meets Tigges' criterion for Nonsense, that meaning be suggested and then taken away (Literacy Nonsenge 73) -- like most good Nonsense it always has particles of meaning resonating with the accompanying meaninglessness, it always undercuts itself.

Thi. resonant meaning, pitted against its co-present meaninglessness, saves Nonsense from the absurdity which Heath ascribes to the Alice books' stringent logic (see footnote 4). While Carroll's Noncence does follow a rigour of logic which may seem "abourd," it never creates Absurdism's meaningless or senseless reality. Nonsense presents both meaning and meaninglessness at once, the symbiosis of sense and eeneelessness. To insist that Carrosl doesn't write Nonsense because he writes logically is wrong-headed. His work illustrates potential for censelesenese within seemingly rigid constructions of meaning, without denying the presence of, or scorning the possibility of, sense. 
Therefore his Nonsense is also unlike Dadaism, which is by intent antimeaning. Rather, nonsense questions meaning by allowing meaninglessness to intrude upon it, and (as stewart's discussion of intertextuality indicates) questions meaninglessness by dieputing the meaning on which it dependa.

How meaninglessness is allowed to intrude into meaning is an iseue over which critics are split into two fairly clear camps: those who see Nonsense as reducing meaning to a minimum and those who see it as reproducing meaning ad infinitum. Lecercle, Holquist and Sewell are among the minimalist contingent. For them Nonsense's language is constrained and literalist; much Nonsense derives its initial effect from just such literal readings.

Taking literally statements like Lear's about the Jumblies ("They went to sea in a sieve, they did,"), or the following passage, is a great part of the fun of Nonsense:

At this time, an elderly Fly said it was the hour for the Eveningsong to be sung; and on a signal being given all the Blue-Bottle-Flies began to buzz at once in a sumptuous and sonorous manner, the melodious and mucilaginous sounds echoing all over the waters, resounding across the tumultuous tops of the transitory ritmice upon the intervening and verdant mountains, with a serene and sickly guavity only known to the truly virtuous. The Moon was shining slobaciously from the star-bespringled sky, while her light irrigated the smooth and shiny sides and wings and backs of the Blue-Bottle-plies with a peculiar and trivial aplendour, while all nature cheerfully responded to the cerulaean and conspicuous circumstances ("The story of the Pour Little Children who Went Round the World" 100). Attributing just one meaning to each word results in the continual qualification, contradiction and confusion so typical of Lear's work -- 
oxymorone abound, adjectives and adverbs constantly undercut each other or the words they modify: "trivial splendour," "sickly suavity," "uhining elobaciously." This is a mild version of stewart's selfnegating Monsense text $(72)$.

But an advocate of meaning as multiple in nonsense, like stewart or Rieke, might argue that the assonance and sibllance (this is possibly the most sibilant paseage Lear ever wrote) get up a buzz like that of the Fliee" Eveningsong, one almost "mucilaginous"; the sound itself is another form of senee. The lexical meaninge of the worde are almost drowned out by the possibilities of phonic meanings in Lear's language, from which they, the words, cannot be wholly separated. And what doee one do with a word like "slobaciously"? Even though it's composed of recognizable morphemes and has an identifiable syntactical role, this neologiem cannot be read juet literally; it has no readily definable lexical meaning, only echoes of other words (slob, slobber, gracious?, tenacious?). "slobaciously" becomes the final conduit for those other forme of sence (the rip in the screen where the fly gets in) and encourages one's mind to root around in its "self," to look for different ways in which these words can mean.

Lear was an inveterate user of neologisms, and Carroll, with the publication of Through the Looking Glags, revealed a similar passion (Partridge 179). Sewell says Carroll' neologisms "can scarcely be said to be words, since worde should have reference but these have none" (115); but clearly she is working with a limited definition of "word" -one which demands that a word be wholly a unit of definable lexical sense. What then of the words in Thibaudeau's poem, or in Einnegans Wake? Both worke employ lingual untte evocative of sense, but not entirely recognizable. Thibaudeau' poem is not meaninglese, though one would be hard pressed to tie its meaning down. And even the most nonsensical (and longest) word in all of Joyce's "epic" ( "bababadalgharagh- 
takamminarronnkonnbronntonnerronntuonnthunnt rovar rhounawnskawntoohoohoordenenthurnuk!" (3)] is replete with meanings, being a macaronicportmanteau-compendium of "thunder" and packed full of social, theological and parodic "genses" as well.

Joyce's neologiams, and portmanteau worde generally, provide a convenient point from which to look more closely at the arguments for and against multiplicity. Those who consider Joyce a nonsense writer, or a writer of partial nonsense at least, use him as a prime example of the multiplicity of noneensical meaning; Rieke inaiate, throughout her discussion of Joyce's work, on nonsense's "excess of meaning" (8). And Stewart, writing of Joyce's language in Ulysseg, comments: "Ironically, the 'over-loading' of language with significance approaches the limite of language. The point where the discourse bursts with significance is the point of pure ornament and opacity" (102). Consigning Joyce's language to the limits of language is consigning it to, among other things, the field of Nonsense, a field with which he was quite familiar -- if the notable presence of Lewis Carroll, the Alice books and the sylvie and Bruno books in Finnegans wake is any indication. Lecercle, however, classes Joyce among the writers who "[rely] heavily on (the) dark side of language" (65) or defire; and it is true Joyce writes not classical Nonsense per ge, but rather a flowing, flowering nonsense, fecund beyond pruned reason. Joyce's hyperportmanteaux ("crogmagnom," "reversogassed," "expectungpelick" (20)), in their excess, stretch the portmanteaux of Carroll's works, which Humpty Dumpty describes as "like two meanings packed into one word" (TLG 215). Carroll corroborates, albeit somewhat tentatively, Humpty Dumpty's explanation ("seems. . Iike the right explanation for all (of them)" ("Preface to The Hunting to the snark" 754)] and extends it by attributing the ability to speak in portmanteaux to those blessed with "the rarest of gifts, a perfectly balanced mind" (754). Perhaps this is the reason why Lecercle characterizes portmanteau worde as an attempt 
"to control language" (35).

There are a few problems with Humpty Dumpty's account of portmanteau worde. My initial instinct, despite Carroll's assent, is to dietrust his attempts at definition. This is an egg, after all, heading for a great fall at the handa of language. How much "control" does Humpty Dumpty have over the language he uses? How much underatanding of the way it worke? His explication of "Jabberwocky" does little to make senee of the poem, and his converation is opaque at best; if language is a tool for communicating, Humpty Dumpty is not a very akillful ueer of that tool.10 Perhape Humpty Dumpty is too entertaining and attractive a character, for he has alwaye been taken quite readily as the authority he claime to be. Why truct him any more than the proprietor of the Sheep Shop, Tweedledum and Tweedledee, or the Walrus and the Carpenter?

Because of Carroll's sanction. Interestingly enough, Carroll's firet etymology and explanation of the same stanza of "Jabberwocky" -then titled "Stanza of Anglo-Saxon Poetry" -- contained some definitions different from those of Humpty Dumpty. "Tove," for instance, was initially defined as "a species of Badger. They had smooth white hair, long hind legs, and short horns like atag. lived [sic] chiefly on cheese" (quoted in Huxley 63). Humpty Dumpty describes "tover" as "something like badgers -- they're something like lizards -- and they're something like corkecrews . . . also they make their nest: under sundiale -- also they live on cheese" (TLG 215). "Mimsy" is first fust "unhappy" (Huxley 63) and then both "flimsy and migerable" (ILG 216). If he seriously intended to corroborate Humpty Dumpty's explanation of

10 Michael Hancher notes that the drawback to Humpty Dumpty's discussion with Alice land one assumes with anybodyl is not his use of stipulative definition, but his use of it in Looking-Glass Land where all orders are inverted (50). Humpty Dumpty is subjected to a temporal system which greatly hampers his ability to communicate; seemingly unconcerned about language's intimate relationship with temporal and causal contingencies, he chooses to speak in a manner which directly conflicts with these qualities of language. 
portmanteaux, Carroll could not claim a "perfectly balanced mind" eince the meaninge of his portmanteau worde and other neologiams shifted. Moreover, one of the worde which Humpty Dumpty glosees as a portmanteau word is an actual, albeit obscure, Englieh word: "slithey" (which he -and Carroll before him -- calls a conflation of "lithe" and "elimy") is a sightly modified form of the verb "to slithe," an early medieval variant of "to slide." In at least this one instance, Humpty Dumpty eithar speaks with his tongue in cheek or egg on his face.

Looking back at Carroll's discussion of such words reveale that he is talking about the words that go into making a portmanteau, not about the potential resonances such combinations can spawn. That he discusses only the method cf arriving at portmanteaux does not mean he denies the new word any generative powers. Portmanteau words and neologiams in Carroll'g Monsense are not "overloaded" with meaning as Joyce' and Artaud's are, but neither are they as closed and confining as some critica make them out to be. Rather they indicate the ability of the word to mean beyond literalism.

Deleuze's explanation of portmanteau words offers another, and perhape more useful, way of understanding this linguistic phenomenon. The successful portmanteau is not merely the joining or contracting of two words with a resulting proliferation of meaning (45). And it is not just the connotation of "two heterogeneous series" (45), though this latter function of connotation is important. For, by fusing th, separate series, two different albeit related orders of meaning, the portmanteau anticipates one of the ways in which Nonsense itself is formed: the joining with each other or superimposing upon each other of two (or more) separate sign systems."

Moreover, a portmanteau word of the first order, according to Deleuze, has a content which "coincides with ite function" (45); for example

"This principle of Nonsense will be discussed more fully in chapters three and four. 


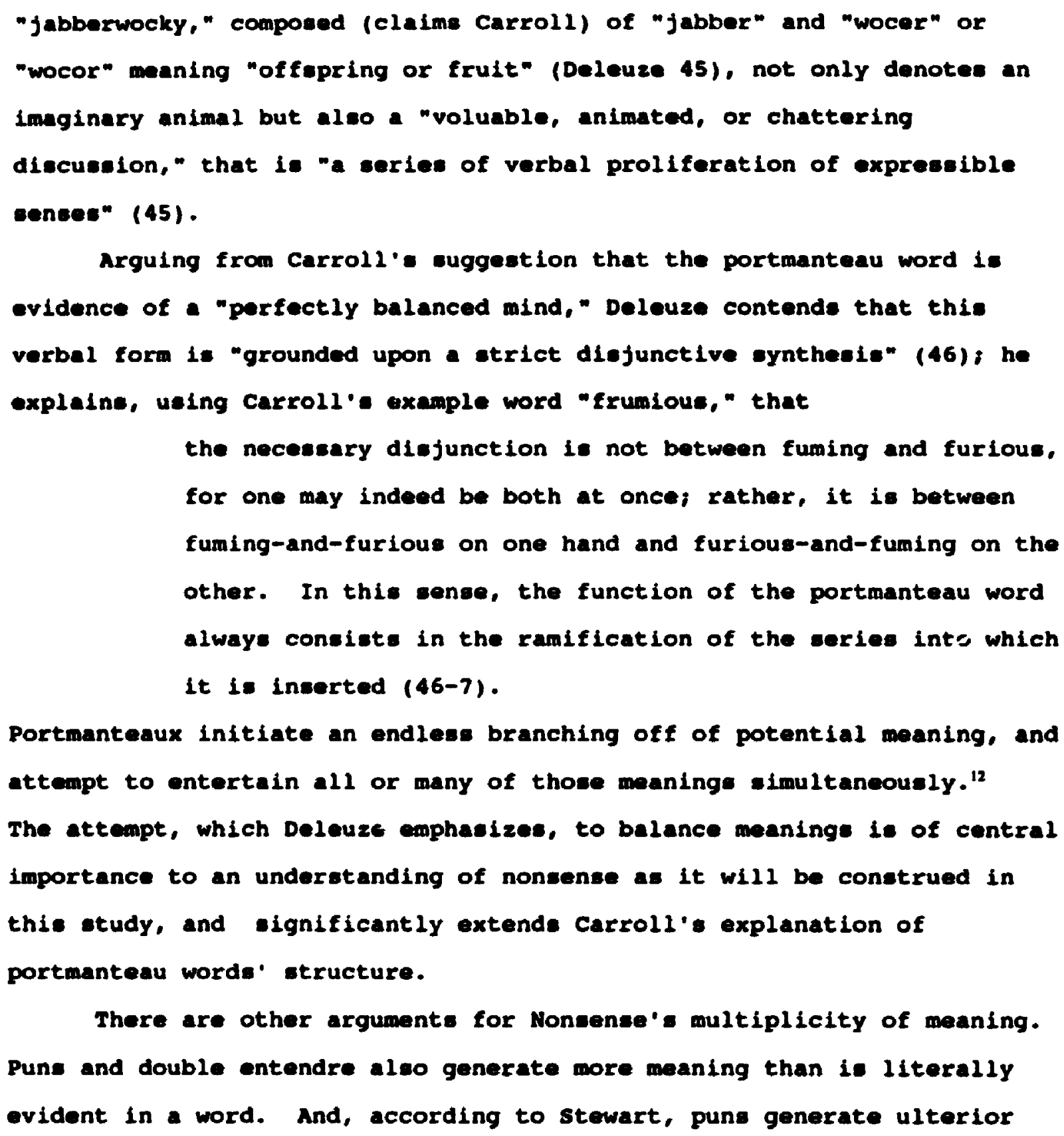

${ }^{12}$ Susan Stewart makes much of simultaneity in her study of Nonsense. She contends it is an effective and frequently used method in Nonsensical writing:

It is defined as the quality of existing. happening. occurring at the same time in more than one space; the quality of being coexistent in time while being contiguous in space. . . . Simultaneity is neither here nor there, but the reconciliation of a paradoxical contradiction between hereness and thereness. It is like the paradox of nothingness, for it cancels itself out -- to say that two events are simultaneous is to dissolve those events into each other in time while they cannot be dissolved in space, and therefore to deny the possiblity of simutaneity by saying "two events" (146). 
texte as well by splitting the movement of reading into several

directione -- one to follow each connotation of the pun eimultaneouely (162). Given stewart' assumptione about nonsense' self-reflexivity, even the most "literal" words should be seen as able to appeal to another side of language -- each word in noneense is a trying on and a sending up of at least two language systems and so inherently containe more than one meaning.

If anyone comes close to resolving the oplit between minimaliets and pluraliate in Nonsence criticiem it is stewart, when ahe argues that noneenes, fettered mainly by its own ongoing, selfperpotuating context, becomes perhape the most multiply-meaningful of fictione, while, at the ame time, it becomes the least meaningful of fictions in everyday 1 ife terms (36).

Nongenge and Dream: Things flow about so here 1"

That's Alice's plaintive cry in the sheep shop of Through the Looking-glase (202) and it's certainly an accurate assessment of a trying situation. With the mere crossing of a brook (represented in the text by a pattern of asterisks) the white queen has turned into a sheep who is knitting inceseantly. And though the sheep continually takes up and uses more knitting needles so that, se Alice notes to herself, "She get. more and more like a porcupine every minutel" (203), the shop itself is atranger atill:

The shop seemed to be full of all manner of curious things -- but the oddest part of it all was that, whenever the looked hard at any shelf, to make out exactly what it had on it, that particular shelf was always quite empty, though the others round it were crowded as full as they could hold (202). 
Things even float through the ceiling to get away from Alice's gaze. And then, of course, the shop turne into a boat, with Alice at the oars. This paseage is perhape the most dramatically dreamlike in the Alige booke. It may trace its roote back to the transformations of theatrical pantomine (Gray 153n), but it elides ealily into Carroll'a Monsense world, which is replete with transformatione and physical changes. Because such a paseage is organic with the rest of the work, a closer relationehip between dream and Noneense than the one sewell admite seeme probable. The paseage above le not sewell " "concrete, clear and wholly comproheneible" (23) Nonsense.

Much of sewell' : The field of Nonsene is devoted to breaking down the relationehip between dream and Nonsense which critice like Cammaert: (32) and Chesterton ("Defence of Nonsense" 447) had eatablished. She argues againat the synthesis typical, for her, of dream and poetry (23) and charecterises Nonsense as dealing with "[amallnese], ordinarinese, artificiality, dietinctnede of unite and a tendency to concentrate on the part rather than the whole" (101). Nonsense, a product of "the mind " force towards order" (44), is intimately related to reason and logic (5). Its world is "carefully limited," "controlled and directed by reason"; Nonsense itmelf is "a construction subject to its own lawe" (5).

One would be foolish indkad to argue against the presence of $\operatorname{logic}$ in Nonsence -- looking to Carroll gives ample evidence of ita importance. What undermines the strictness of sewell's argument, however, is (ironically enough) a tendency towards inconeistency. she claims that "although Monsense playe on the side of order, its aim and mothod is to defeat disorder with disorder's own weapons" (122), yet the principles of disorder creep into her own argument. Tigged (Literary Nonesne 13) notices her shift from the early statcment that: "Nonsense verwe is too precise to be akin to poetry. It seeme much nearer logic then drean" (Sewell 23) -- which the has already equated with poetry. 
Midway through her argument, Sewell say" that "Noneense adde to poetry' precision an element of incongruity" (102). Suddeniy poetry is on the -ide of logic, and Nonsence nearer to dream.

More disturbing, because more subtle, is sewell. fallure to recognize order, which chrracterizes her Nonsenee world, as a oynthesizing principle. She rejecte unity in favour of Nonsense's "universe in which everything goes elong serially, by one and one" (56), yet order, by its very nature, containe and holde together all parte into a whole, and connects them into a syatem which usually fails to acknowledge ite own existence. During her entire argument againat "an underlying and occult unity among phenomena, created by a multiplicity of irrational relatione and perceived by the dream faculty of the mind" (112), she seeme oblivious to the fact that such "occult" unitien do not merely connect but, like metaphor, implicitly highlight the disiunction between the combined elemente. Irrational oynthesis, espocially as Nonsense entertains it, never loses sight of the tenuousness of combination; rather than affirming unity it illustrates the delicate and hesitant relations between parts of any whole -- even between the parts of an ordered whole.

By determining Nonsense to be "a construction subject to its own lawe" (5), sewell implies that the ramifications of those lawe Ion't apply to her argument. Unlike stewart, who recognizes nonsense's symbiotic relation with common sense and its connnection to the very process of her study, sewell faile to recognize that nonser.we spille over into and comments upon her own systems of thought. Because of this failure, she feels confident in declaring order a sure winner in the nonsensical conteat between the irrational and logic; she implies that ultimately the tension between order and disorder, logic and dream, which motivates Noneense, is resolved.

By privileging order over dream, sewell disturbe the delicate balance eseential to Noneense. Tiggea explicitly locates that balance 
on the border "between the 'nightmare of logic' and the 'logic of dreams"- ("An Anatomy of Nonsenge" 26), and Dennis Lee considers Nonsense "work which unites precise logic and irrationality 80 as to make each seamless with the other" ("Roots and Play" 48). This balance is borne cut, as Lisa Ede coitends, in the very structure of Through the Looking-Glase, where the dominating precision of the chess game pattern is subtly undermined from within by the novel's dxam-like movement (76). This insistence on balance, on seamless unity is precisely what distinguishes Nonsense from other forms of writing, including surrealism.

Surrealism certainly admits a friendship (if not consanguinity) with Nonsense: Andre Breton and many others consider Carroll a precursor of the movement, and Nonsense techniques are ingredients essential to Surrealism (Stewart 76-i7, 153-54, 159-60). But Surrealist dreamwork exigts because, as Breton writes, "we are still living under the reign of $\log i c^{\prime \prime}(9)$. The surrealist intent is to liberate the imagination from logic's tyranny, to find in the dream a meang of solving -irrationally -- life's fundamental problems (sreton 12). Breton tipa whe balance in the direction opposite to sewel:, but tips it nonetheless.

Carroll's dream frames are one reason why Surrealigm and Nonsense are often made to seem more analogous than they really are. But Carroll's dreams are distinctly used for framing, for a self-reflexivity that sets them off from "reality" -- the structure outside the text, Alice's waking world -- whereas surrealism unites dreams with perceived reality in the search for a truth. The whole concept of the dream structure becomes most interesting in the cross-over between dream and language.

Freud proposes in The Interpretation of Jreams that dreams have a latent-content, a i.idden tneaning made Inaccessible by the Uisconsciouc's principles of distortion -- for instance, condensation, displacement and 
simultaneity. These processes can also be found in language; "A word," writes Freud

as the point of junction of a number of ideas, possesses, as it were, a predestined ambiguity, and the neuroses (Obsesaions, phobias) take advantage of the opportunities for condensation and disguise afforded by words quite as eagerly as do dreams (230).

Language can become the seat of dream-work, then, of condensation, displacement and simultaneity; and when it does, one form of sense is obscured by the manufacture of the Unconscious's latent sense. Freud locates much of a verbal expression of the Unconscious, very much like its expression in dream-work, in jokes (Jokes and Their Relation to the U:iconscious 61), but the same techniques are found in nonsense's dislocations, non-sequitur, puns and portmanteaux. One of the most important connections between dreams and nonsense is that the language of each employs similar devices for the production of latent meaning.

Becauge "Each" Beains with "E": Religion and Riddles in Nonsense

Distortions of language and hidden meanings are not just dreamlike, however. Rieke cites Plato in the Timaeus where a lack of reeron is associated with the prophecies of Sibyls, and the Judeochristian tradition in which ophicieg are $\therefore$ milarly nonsenuical (9). Both Huxley (10) and Hoffstadter (22E) compare Nonsense to tine hidden and seemingly sensele ss wiscoms of zen Buddhism. These comparisons hold, in part, because of Nonsense's use of "concealment" (Byrom 178) and because of the tendency in most religions to discuss the ineffable in ways that defy the limitations of sense. Visionary poets, like Blake and Christrpher Smart, both of whom Haughton classes with Nonsense poets (14-5), also are part of this tradition. 
the landecape artigt, as "myetical" ("How Pleasant to Know Mr. Lear" 123). and avows:

Nonsense and faith (strange as the conjunction may seem) are the two supreme symbolic assertions of the truth that to draw out the soul of things with a syl logiam is as Impoesible as to draw out Leviathan with a hook. The wellmeaning perwon who, by merely atudying the logical aide of thinge, has decided that "faith is nonsense," does not know how truly he epeaks; later it may come back to him in the

form that nonsense is faith ("A Defence of . nsense" 450 ).

But, while classical Nonsense is comparable to religious nonsense, it is not a part of this tradition. The point of religious nonsense is not to unite sense and nonsense but to reach a higher sense through nonsense; nonsense becomes a tool, a means to an end, as in Buddhist koans, and that end is considered far more important than the noneensical procese used in getting there. Moreover, Nonsense toys with senee in order to question sense and, implicitly, itself; religious nonsense may question systems of secular sense but it certainly does not doubt its own religious sense.

But two common elements of religior, the charm (a magical incantation whose worde are believed to hold special efficacy) and the riddle (a cryptic naming and teaching game that is meant to reveal some hidden knowledge (Welsh 26]), do have closer affinities with nonsense. Tigges' claim that nonsense is "charm and riddle at the same time" ("An Anatomy of Nonsense" 41) has already been noted. While his contention may be slightly extreme, both charm and riddle have their function in the creation of nonsenes.

Andrew Welsh, in Roote of Iyric, quotes Valery's discuesion of charme:

Magic formulas are often without meaning; but it was luver thought that their power depended on their 
intellectual content. ... These words work on us for at least on some of us) without telling us very much. They tell us, perhaps, that they have nothing to tell us; that, by the very means which usually tell us something, they are exercising a quite different function $(149-50)$.

What Valery describes is a musical meaning that 1 ies beyond the semantic, a practice that sounds very like Tigges' "communication without communicating" (Literary Nongense 248), or Eliot's genuinely good poem which "can communicate before it is understood" ("Dante" 238 ). It is a meaning which, like that in Thibaudeau's poem, defies lexical norms by establishing meaningful cadences, part of whose efficacy resides precisely in its opposition to traditional sense. The musicality of nonsense will be considered at length in chapter four. The emphasis often placed on the riddle's teaching function, however, doesn't argue strongly for a relationship with nonsense, unless one accepts Chukovsky's theory that Nonsense is a game intended to reinforce a child's knowledge of the world. Chukovsky is not entirely wrong; a healthy knowledge of how the world works does help highlight the nonsensicalness of Nonsense, though it isn't essential to enjoy nonsense's rhythms and sounds. But his version makes the genre too practical, too directed a pursuit. Nonsense ultimately exists for its own sake.

Alice's Adventures in Wonderland is infamous, however, for its "unsolvable" riddle: "Why is a raven like a writing-desk?" (75) Unsolvable? Not quite. Huxley quotes Carroll's Preface to the 1896 edition of Alice:

Enquiries have been so often addressed to me, as to whether any answer to the Hatter' Riddle can be imagined, that I may as well put on record here what seems to me to be a fairly appropriate answer, vix. 'Because it can produce a 
fow notes, though they are very flat; and it is never put with the wrong end in front!" This, however, is merely an afterthought: the Riddle, as originally invented, had no answer at all (21).

Certainly not the greatest of Carroll': thoughts, fore or aft. But Huxley also provides other attempte at a solution: "Because poe wrote on both"; "Because the notes for which they are noted are not noted to be musical notes"; "Because it slopes with a flap"; "Because 'Each' begins with an E" (22). Here is the quintessential Nonsense riddle -one which originally had no answer, no sense, proving to have more senses than it can hope to (or might want to) contain.

Welsh suggest that "a riddle is not simply the 'anmwer' but the procese, a way of seeing that creates a space for fuller knowing" (77). In a way, then, both of the Alice books and Nonsense generally are never-ending riddles; the reader is thrown the tricks and game of language and joins in a "riddling" process about as accommodating as the Hatter' riddle. Getting away from answers is the point of the Alice books (if 'hey can be said to have anything so definitive as a point), for answer dictate resolution, necessitate a $108 \mathrm{~s}$ of tension. If these riddles teach, they teach the reader to question. But if, as Frye contends in Anatomy of Criticism, riddles are part of the process of reducing language to a visible form $(280)$, Nonsense is part of an inverse process, reducing visible forms -- reality -- to language. It'a not sacrilegious to appropriate a primitive religious form for sich playfulness; in Homo Ludens: A Study of the Play Element in Culture, the widely respected cultural historian and play theorist Johan Huizinga relates play to holiness (19) and contends that the individibility of belief and disbelief is central to play (24). since Nonsence is in part play, the reorganizing of language as game (Sewell 25), the play of indivisibles, it is working with a shared inheritance more than with borrowed religious forms. 


\section{mAlice soon came to the conclugion that it was a very difficult aame indeed": The Element of Play in Nongense}

On an obvious level, Carroll's Nonsense is play. Both Alice books include games: a card game and croquet, and a game of chess. Games are incidental to Alfce'g Adventures in Wonderland; that is they provide actual events in the plot. But they are also structural to a degree, since many of the charactere are cards. The overxiding atructure of the "card" section is, oddly enough, a nursery rhyme -- or the imagined results of one. When Carroll wrote the second Alice book, he seems to have taken up where the first left off in more than one way: where the first has but one nursery rhyme, the second has many; and where games are present in the first, they predominate in the second. He even includes a play-by-play diagram of the chess game structure of Through the Looking-Glass (137), and has the Red queen explain the principles of the game to Alice $(164-67)$.

But nonsenge and Nonsense have stronger genetic ties with play than these samples of Carroll's borrowings from organized games. Huizinga's characteristics of play include: a voluntary participation (7), a separation from ordinary life (8), a limitedness in terms of time and space (9), the creation of order $(10)$ and a tension or uncertainty about play' ultimate outcome $(10)$. At one time or another each of these features has been attributed to Classical Nonsense. Tigges, for instance, suggests that Nonsense adheres voluntarily to "its self-appointed rules" (Literary Nongense 54 ) but adds that these rules are both present and absent, for constant and iron-clad rules would almost by definition demand meaning, a determinable terminus point, and would cramp Nonsense's self-negating style. Sewell' view of the closed field of Nonsense entertains Hulzinga'second characteristic but so too does stewart's contention that the self-refiexivity of nonsense is language at the furtheat remove from ordinary common sense. 
The third characteriatic, however, doesn't fit with stewart's understanding of nonsense since, despite ite distance from ordinary 11fe, the belleves that nonsense remains symblotic with common sense and so Inversely permeates all cense-related activities. Sewell, as has already been mentioned, calls Nonsense a product of "the mind' force towarde order" (44) and Lecercle insists it is a "meaning-preserving ectivity" (140) implicitly contingent upon order as an underlying principle. Noncence creates a now order by creating a now reality and may be allied with order as with common sense. But it is not synonymous with order as Huizinga suggests play is, and as sewell and Lecercle ultimately claim, because it must simultaneously entertain disorder. There is tension in play as in Nonsense, but in play that tension ultimately finde a resolution with one player winning, unless, as occasionally happens, the game ends in a draw.

Nonsense always ends in a draw unless its game is rejected, violated in some way -- as Alice violates it at the end of both of Carroll' books by diminishing its other players: "Who cares for you?' gaid Alice (she had grown to her full bize by this time). 'You're nothing but a pack of cards!" (AW 129). These are the words of a spoilsport, of someone unwilling to play the game, as she has been unwilling to play the games of the mad tea-party ("'It's the stupidest tea-party I ever was at in all my lifel" " [83]).

Too often Alice' unwillingness is attributed to carroll as well (as in Lecercle and Deleuze) and consequently too often his Nonsense is diminished, called tire game of a apoilsport. But as Ede cogently argues (for what follow I'm indebted to her), Allce is not Carroll'. mouthpiece, nor is she held up as an archetypal and most perfect participant. Alice's character is replete with quirky problem for those who are used to considering her the sweet Disneyesque dreamchild of animation. Both Carroll' and Tenniel's illustrations (the latter oubmitted to Carroll' very fastidioue eye before being accepted for 
publication) depict an often harsh and quite unattractive girl. Alice'e behaviour tends to be smug and unthinking; she is utterly unquestioning about the rightness of her own world and its conventions, not unlike the stereotypical North American or English tourist abroad. And she brings up subjects which cause no end of distress to the inhabitants of Wonderland; for instance, she insists on telling the mouse in "The Pool of Tears" about her cat, Dinah, and then about a little terrier she knows, both of whom are terrific mousers (33-34).

And what does one say of a girl who unconsciously turns almost every poem sine recites inco a textbook case of the violence of a capitalist society motivated by survival of the fittest? "How doth the little busy bee" suddenly becomes, in Alice's mouth, "How doth the little crocodile" -- a fittingly ironic evolution since she thinks her world beyond reproach or savagery. The change is most explicitiy not attributable to the mood of Wonderland, for its inhabitants, the Mock Turtle and the Gryphon, turn the violence and didacticism of Mary Howell'g "The Spider and the Fly" into the lovely, cooperatively lunatic "Lobster Quadrille." "For in spite, or perhaps because of its anarchism," writes Ede, "Wonderland is able to convert a poem of entrapment and violence (Victorian social Darwinism?) to a comic celebration of social harmony" (87).

Alice's is ultimately not an affirmable vision or version of the world, not an ideal way to piay any game, especially not one as extreme and bizarre as Wonderland's. Alice, as game-player, is not to be imitated. Nor does Carroll urge us to accept readily her version of "fair play." As Ede remarks, by rejecting the Queen of Hearts and her court as "nothing but a pack of cards," Alice

escapes the burden of knowledge. As she has all along, she uses a mad concept of language (mad because $11 \log i c a l$ and ultimately not founded on reason] to protect both her ego and her imagination from risking an encounter with the 
chaos that 1 ies outside her narrow world of social rules (111).

The play which Alice rejecte is really fust the play of an unsystematic and illogical language. "Alice's chief illusion concerning both language and life in general is that they are based on a coherent, coneistent, inherently meaningful syatem which, if followed, allowe one to control one' destiry" (Ede 89). Carroll, by having the Wonderland characters seem to represent logic, pute Alice in the position of having to make her own language logical and so see how untenable her position really ie (Ede 89 ). $\frac{\text { When Lanquage Goes on Holiday: }}{\text { Philogophy's Nonsense }}$

Wittgenstein, one of this century' most influential thinkers about nonsense, was not writing about Carroll' "fairy tales" when he noted in his Philogophical Invertigatione that "philosophical problems arlse when language goes on hollday" (I.38), though he could well have meen. This comment about the problematice of philosophical language aptly aummarizes the crux of Alice' problems, especially in Wonderland. Wittgenetein and Carroll, according to George Pitcher in his article "Wittgenstein, Nonsense, and Lewis Carroll," "had radically different attitudes towards nonsense: it tortured wittgenstein and delighted Carrol1" (611). Nevertheless there are important similarities between the intensely serious philosopher and the writer of Nonsense/logician, and a connection between literary nonsense and philosophy in general, which need to be examined.

This connection, however, is a loose one, and if not allowed to remain so can lead to misinterpretatione; literary nonsense engages in many of the linguistic activities which result in philosophical nonsense, but engages in them for different reasons and to different degrees. Works of Nonsense are not easily placed within the traditional 
divisions of noneense set out by philosophers because they never wholly embrace those categoriea. Carroll' work, for instance, followe logic to ite illogical ende, and employe what A.C. Baler calle "noneenee vocabulary"; it uees, too, obvious faleehoode and eemantic nonsenee -all traditional types of philosophical noneense. But it also engages language at a more material level with portmanteaux, puna, and pereonifications of words. In philosophical nonsense, dieruptione tend to effect a very apecific type of sense, that neceseary for the communication of a precise, definable lingulatic meaning. In literary nonsenee, while euch dieruptione of communicative enee axe abeolutely essential, disruptions may also promote the establishment of more material forms of sense, related to the senses for instance, which may partially but not entirely interfere with the communication of sense. Literary nonsense, then, is not so much the interruption of sense, as the multiplying of sensical possibilities, the emphasizing of other ways to manufacture meaning. This section will not auggest that the connection between philosophical and literary nonsense is anything more than tenuous. But it may be useful to gain a general understanding what philosophical nonsense is, if only to help determine, for the most part, what literary nonsense is not.

In section I.7 of Philosophical Investiqations, wittgenstein talks of "language-games"; it is a simile which euggests that learning the meaning and function of a word is like learning a move in a game. carroll may never have articulated this concept, but he did present language as a game of another sort." Many of Carroll's language puzzles have a didactic air to them, which may have contributed to Lecercle' claim (quoted above) that carroll's Nonsense is that of a pedant. Heath too argues that Alice's Adventures in Wonderland was

${ }^{13}$ An example is the game of "Doublets" which required its player to make one wo-d out of another (e.g. "head" to "tail") by changing one letter at a time. The catch: at no time cjuld the player insert a letter that would not result in an English word. "Heal" would be an acceptable first move; "tead" would not. 
meant to "[meke) little logiciane" of children (51), that it wae perceived by carroll ae a "work of instruction and profit for the infant reader" and as such falled miserably since children invariably mise lte point $(50)$. He deecribes the book as a

ettleier: a horrendous catalog of philosophical blundere, logical fallacies, conceptual confueione, and linguistic breakdowne, which not only entertain but pereistently tease the reader, compelling him to ask himeelf, "What has gone wrong here? Why won't this do?" and to find that it is not alwaye perfectly easy to supply the anewer (49).

Two thinge are striking about Heath's view of the tale: he is not entirely wrong about carroll, and he unconsciously implies one of the connectione between Carroll and Wittgenstein.

Heath is on the right track about Carroll's work, but he' wrong about the Alice books. The sylvie and Bruno books are the clear example of carroll trying to use fiction as a forum for preaching logic, among other thinge. The latter present their logical play ineide a framework of didacticiem so unmitigated as to be embarraseing to Carroll' devoted followers. Their twists of language and logic never challenge such fundamental issues as the tie between individual identity, society and language; never question the foundation of logic and of sense; never expose the capitalist climate of Victorian England (whose logic and values Heath claims Carroll is trying to instill in young peoples as cruel, exploitative, or even limited, as the Alfee books do. Rather the distortione (so effective, so delightful, in the early novele) become, in the sylvie and Bruno books, saccharine attempts to sweeten an overly long fable brimming with the sentiments of High Victorianiem and High Anglicaniem. Even their prefaces are pulpits for Carroll's concerns -the need to expurgate the Blble for children, to do up shakespeare properly for young girl. (Bowdler' veraion being far too indecent) ("Preface" to sylyie and Bruno 280, 282) and to put an end to the 
cruelties of "sport" (the hunting, baiting and fighting of animale) ("Preface" to sylyie and Brune concluded 516-7).

But for all that, the sylvie and Bruno books employ noncense in much the way Pltcher describes Wittgenetein's use of noneenes in Philorophical Inventigntions (the comparison ien't meant to reflect badly on wittgenstein):

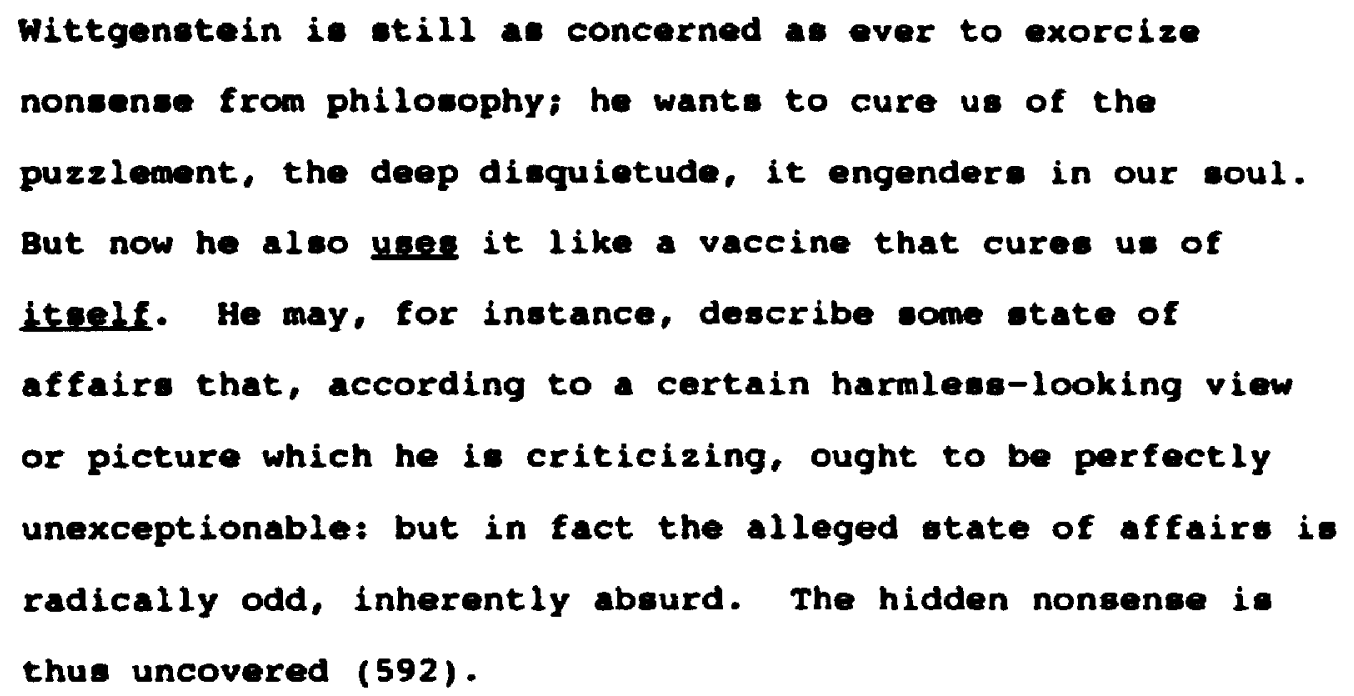

If carroll is trying to teach children how to avoid nonsenaical errors, his mothod, though fictive as opposed to meditative, is closely allied to wittgenstein's: to teach through example, to cure through innoculation. As Pitcher argues, "the very same confusione with which Wittgenstein charges philosophers were deliberately employed by Carroll for comic effects." And some of the same philosophical doctrines are ridiculed too (593).

For instance, Pitcher notes the similarities between Wittgenstein' insistence that knowing what a word means in one context doesn't eneure knowing what it means in another lone may know how to measure distance or length, but not how to measure time) (Pitcher 598) and the definitional sides in this excerpt from sylvie and Bruno Concluded:

"You seem to enjoy that cake?" the Professor remarked. "Doos that mean 'munch'?" Bruno whispered to sylvie. 
Sylvie nodded. "It means 'to munch' and 'to like to munch. '

Bruno smiled at the Professor. "I does enjoy it," he eaid.

The Other Profeseor caught the word. "And I hope you're enjoying youreslf, little Man?" he enquired.

Bruno': look of horror quite etartled him. "No, indend I aren't t" he said (730).

Both writerb, Pitcher points out as well, attack eseentialiem, the ldea that "a unique set of characterietics -- constituting an essence -- . . - 1. shared by all and only those individuals to which a certain general term (e.g. 'table', 'tree', 'rexpent') appliea" (601-2). Pitcher'e examples anticipate his Carrollian example -- Alice's run-in with the pigeon who insiete that Alice, with her long neck and her love of egga, muet be a expent (AW 61-62).

But how exactly does Wittgenetein define nonsense? for the Wittgenatein of the Iractatue, nonsense is an arrangement of worde (a proposition) which could not poseibly fit within an imagined reality. Hi. Ideal language or naming corresponde absolutely to Reality, is a diagram of ita functioning; nonsense is an incomprehensible clitch in the diagram -- not only is it not true, it is not even falre.

Later wittgenstein moved away from this systematizacion of language and toward a view of it as a deed, a gesture whish evolves through use and in a secific context. Philosophical nonsense, in this acenario, is language de-contextualized, language which has been mishandled, wrested from specific context, where it is serving, genturally, to communicate. This definition is closely related to Nonsence where language as a meaningful structure is de-stabilized, in part because of the misuse of words. An in Lear's limerick: There was an Old Man who supposed, That the street door was partially closed; 
But some very large rata, ate hie coate and his hate, While that futile old gentleman dozed (16).

By using the adjective "futile" in what seems to be a seneically inappropriatu manner (why "futile" instead of, say, "misinformed" or "deluded"?), Lear re-contextualizes it and so illustrates how much one's experience of meaning depends on the context, the use of a word. He also encourages the reader to look back and manufacture a new meaning appropriate to thie new use. Lear' misuse of the word "futile" drawe attention to the intertextual poseiblities of every word in the rhyme; each word has other meaninge and contexts which resonate behind current contextual usage. And each word has the potential to generate awkward sense if displaced. By forcing "futile" to stretch its range of meaninge in order to accommodate the verse" "sense," one admits into the "background" of the limerick, as well, the posaible range of meanings for its other words. Those meanings don't inundate and eradicate the sense of the poem; they are constrained, just barely, for the present moment of each word's lise.

Another example of meaning being affected by context is carroll's word "enark." One of its accepted definitions is now "an imaginary animal." However, far from having created a neologism to name the elusive object of the Baker's search, it is highly possible that carroll merely borrowed an English dialect term: "snark" -- an intransitive verb meaning "to snore, snort"; a transitive verb mesning "to find fault with, nag." If this is the case, then carroll, " jiving a rare but existing word." new nonsensical uee, gave it an entirely new context and initiated a transformation of meaning and function within sentence etructure. The trangformation or extension of meaning was completed when Carroll'. "definition" of "snark" became included in that social inctitution, the dictionary.

wittgenstein doesn't provide the sole philosophical accour. of nonsense, of course. A quick and general look at the six types of 
nonsense 1 isted by A.C. Baier in the Encrclopedia of Philosphy may help extend one's understanding of how philosophical nonsense works. Examples of most of these catsgories can be found in Nonsense, but neither the genre nor the inguistic disruption (as a literary occurrence) are limited to these types. Baier explains the types by placing them within a hierarchical pa. adign -- the first type distorts sease "the least" and is comprised of $t$. most recognizably English words and structurss. As one goes through the list, she claims, nonsensical disruption enters on a progressiveiy larger scale by assaulting progressively smaller units of sense; it moves from sentence in context (the equivalent of literary nongenge's text or faragraph) to sentence itself, to phrase, to word.

Baier begins with "obvious falsehood" (520), a statement which is clearly contradicted by the circumstances under which it is stated. If, for instance, at the Queen's Croquet match, Alice had told the CheshireCat: "Everyone's getting along oh-so-well, and hedgehogs are very appropriace and wonderfully accurate croquet balls," she would have been guilty of type 1 nonsense. Watching the game for a moment would reveal to anyone that the hedgehogs in Wonderland were hopelessly useless as croquet balls and that there was considerable tension and dis-ease amongst all of the players.

"Semantic nonsense" is the second type Baier lists; here "the rules or conventions violated are those tying [a] well-formed sentence to certain nonlinguistic contexts" (520). An example might be using "goodiye" as i gree:ing; Marx Brothers" movies are replete with such semantic nonsense.

Baier 1 ists "categcry mistakes" or "semi-sentences" next. In this third type of nonsense, a generally well-formed sentence includes a predicate which is not suitable for its subject. She admits that figurative language can break this rule without producing nonsense; "the kettle is boiling" is metonymic, not nonsensical, although it is 
physically inpossible for a kettle to boil (520). Baier acknowledges that this type of "mistake" is frequently found in Nonsense. Take, for instance, this extended category mistake in Lear's description of the Co-operative cauliflower in "The story of Four Little children who went Round the World":

they soon found that what they had taken for an immense wig was in reality the top of the cauliflower, and that he had no feet at all, being able to walk tolerably well with a fluctuating and graceful movement on a single cabbage stalk, an accomplishment which naturally saved him the expense of stockings and shoes $(102-3)$.

This example is more evidence of the fineness of Lear's lexical discriminations and of language's inherently nonsensical nature, the "mistake" being an extended pun on "stalk" -- as the stem of a plant or a manner of walking.

"Nonsense strings" are another form of nonserse which Baier notes. This type is made up of "strings of familiar words which lack, to areater or lesser extent, the syntactic structure of the paradigms of sense or any syntax translatable into the familiar" (521). Such strings are related to the nearly impossible asyntactical language posited earlier, and are examples of Chomsky's ungrammatical "sentence" which will be briefly discussed in chapter five. Baier'd sample -"Jumps digestible indicators the under" (521) -- is reminiscent of work by the more radical of the " $L=A=N=G=U=A=G=E$ " poets also discussed in the fifth chapter.

The next type of nonsense, "vocabulary nonsense," is a common, almost an essential, element of Nonsense. "Utterances which hare enough familiar elements to enable us to discern a familiar syntax, but whose vocabulary, or a crucial part of it, is unfamiliar, and untranslatable Into the familiar vocabulary" (521) make up vocabulary nonsense. Lear's toeless pobble and his luminous-nssed dong, Carroll's jabberwock and 
boojum, and Dennis Lee's silver honkabeest are included in this category, as are Joyce's Finnegans Hake, Thibaudeau's "from Throgwogle," and Artaud's "translat: on" of "Jabberwocky."

Baier's sixth and final type of nonsense is pure gibberish. "[Neither] familiar syntax nor familiar vocabulary, gtill lese familiar category divisions or semantic appropriateness" (521) can be found in such specimens of nonsense. Baier asserts that such nonsense continues to be a "part of some language, to the minimal extent of sharing its alphabet with that language (521)."

I quote this statement again (it was included in the initial gurvey of definitions) because of the importance of its claim that nonsense is never outside of language as it is broadly conceived. Because Wittgenstein's idea of meaning is inextricable from process, even the gibberish of type 6 nonsense may have a potential for lexical meaning. For instance, Carroll's new use of "snark" has found a place in the O.R.D. Since the meanings and 1 imits of language contract and expand over time, it is at least conceivable lalthough currently improbable) that at sometime "vokalupeist" might be a meaningful English word. And if it ig conceivable, one has to admit that gibberish can never be entirely excluded from the possibility of making sense. Note, however, that "vokalupeist" can not be made a meaningful word by my use of it; though it does have, as a result of my use, a second order meaning -- "vokalupeist" is an example of a word that cannot be made meaningful by my use of it. Language is saved from Humpty Dumpty-ism by the public element of Wittgenstein's definition; words don't mean according to individual use. In fact, Pitcher beileves Wittgensteinian philosophy, with its lasistence on the distinction between "definition" and "the mental activity of meaning" (PI I.665), can successfully silence Humpty Dumpty (603). Wittgenstein argues:

$$
\begin{aligned}
& \text { But -- can't I say "By 'abracadabra' I mean } \\
& \text { toothache?" Of course I can; but this is a definition; not }
\end{aligned}
$$


a description of what goes on in me li.e. the mental procese of meaning] when I utter the word (PI 1.665).

When Humpty Dumpty defines "toves," the word doesn't necessarily mean in that way for him; he has stipulated a definition which is probably utterly irrelevant to the question of what is meant.

\title{
"You've no idea how confusing it is ill things being alive": Linguistic Materiality, Reference and Innuendo
}

\begin{abstract}
For Wittgenstein, the nonsense of language on holiday is language de-contextualized; for carroll, it steps outside the system of what common sense deems acceptable, exposing common sense for what it is -- a constraint upon an inherently illogical and lively language. In Wonderland, and in Nonsense, language is alive. Ede offers a twist on Alice's complaint to the Cheshire-cat -- "you've no idea how confusing it is all the things being alive" (92); she notes that the words themselves are alive though Alice fails to see this, fails to realize how her limited view of language tries to "deaden," limit and classify all the wonder in Wonderland (111). Part of that wonder, as has already been pointed out, results from the fact that turns of phrase ("mad as a hatter," "mad as a march hare") become flesh and blood.
\end{abstract}

Nonsense is a world of words (Sewell 17), and exemplifies that language is "built up," according to Haughton "between babble and Babel" (5). Not only does it disorder reference, as sewell claims (38), but also : t questions the reliability, the possibility of a reference which is not arbitrary. As such Nonsense is also frequently construed as meta-linguistic (Sewell 18, 20), as using language to talk about itself (Sutherland 119). The most obvious and obfuscating example of this is Alice'g conversation with the white knight in Through the Looking-Glags:

"The name of the song is called "Haddocks' Eyes.". 
"Oh, that's the name of the song, is it?" Alice said, trying to feel interested.

"No, you don't understand," the knight said, looking a little vexed. "That's what the name is called. The name really is "The Aged Aged Man." "

"Then I ought to have said 'That's what the song is called"?" Alice corrected herself.

"No, you oughtn't: that's quite another thing! The song is carled 'Ways and Means': but that's only what it's called, you know!"

"Well, what is the song then?" said Alice, who was by this time completely bewildered.

"I was coming to that," the knight said. "The song really is 'A-sitting on A Gate': and the tune's my own invention." (244).

Alice's confusion, and the reader's, arises from a failure to distinguigh (as Carroll via the White knight does) "among things, the names of things, and the names of names of things" (Gardner 306). Nonsense requires that one does just that however; to survive in a nonsensical world one needs to recognize the separateness of thing and word, of referent, sign and signifier. Such acute awareness of language as language, and of its naming function often leads to the inability to communicate which is rampant in nonsense.

Foss the cat, Vigeurs' Nonsensical sparring partner, follows Humpty Dumpty's lead (perhaps this should warn of a potential problem), and says that words in Nonsense have "an independence that begins in their failure to communicate meaning and ends in [their] having no representative or symbolic function at all. Language becomes material" (Vigeurs 141-42). Linguistic materiality in Nonsense will be explored in detail in the remaining chapters of this study, but Foss's reasoning in his discuseion of materiality needs to be reconsidered here. Vigeurs 
counters Foss with a telling point, one that, although only slightly askew from Foss's contention, provides a better way of viewing Nonsense's materiality. "Words in nonsense," she argues, "have an independent life. They are not responsible for meaning" (142). Not responsible for meaning is not the same as not having meaning. Rather it suggests that nonsensical words do not themselves strongly suggest a context of meaning -- as "slobaciously" does not, as "borogoves" does not. And that the act of meaning as it is traditionally conceived is not their sole function.

But language which challenges the traditional conception of meaning often doesn't filter and make reality containable either. When nonsense occurs, language and reality fail to coincide (Steiner 107). This sounds a bit like the early wittgenstein unless it is extended -.. language and the illusion of an Absolute Reality fall to coincide. Far from being a screen protecting one from reality, larguage reveals itself as a factor in the creation of realities. Nonsense language often involves a type of "double-talk" (Sonstroem 198), akin to Kristeva's variations on carnivalegque or poetic language, language which is always read as at least double (66; 69). In a letter to 'the Lowrie children,' Carroll explains: As to the meaning of the snark? I'm very much afraid I didn't mean anything but nonsensel still, you know, words mean more than we mean to express when we use them: so a whole book ought to mean a great deal more than the writer meant (quoted in sutherland 97).

Unwittingly, Carroll replies to minimalists like sewell and Holquist (who claims Nonsense words have only one meaning (151)) by admitting the protean power of words. A literal reading of them invariably leads to miscommunica ion, something in which carroll himself w:s so interested he used it as a working principle for much of his Nonsense. Trgges argues to include the Marx Brothers in the Nonsense canon precisely 
because their movies centre on how tricky language is for communicating (Literary Nongenge 201).

Part of this doubleness, the excess of innuendo, and so potential failure to communicate (can this be read as a possibility of communicating too much?) involves the desire which is in and beneath language. Lecercle may attribute this desire to delire only, but, as Julia Krieteva argues, it functions at some level in all language. As Alwin Baum argues in "The Semiotice of Paradox," If Humpty Dumpty's language is impenetrable to Alice, it is nevertheless not "his own invention," as the White Knight would say, deepite the "extra wages" Humpty is willing to pay words to do his bidding. The language he describes is, on the contrary, ever present in waking life as the looking-glass reflection of social discourse -- ite alter-ego, the subconscious. It is precisely the anarchy of association which social language must attempt to repress, eince language is the primary vehicle through which pre-conscious desire may articulate itself $(78)$.

The difference is not the presence of desire, but the degree to which that desire is suppressed. In "social" or common sense language, desire, like the guinea-pigs which, at that Nonsensical parody of legal order, the Knave of Hearts" trial, are slipped head-first into a canvas bag and then sat upon (AW 120), is suppressed as firmly as possit'e. Delice lets desire run rampant -- no repression here. But nonsense both represses and indulges, structures and releases, desire. My discuseion of desire and language, of how desire can be seen as a link between Nonsense and poetic language, however, will be saved for chapter two. 


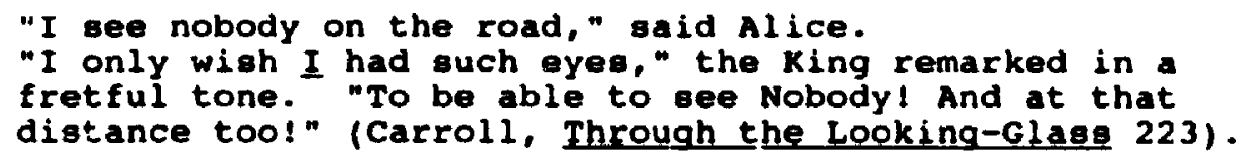

The White King's astonishment at Alice's ability to see Nobody, and from such a great distance, is another proof that the Nonsense universe is composed of words, and that its pratfalls are linguistic. The King thinks that Alice really can see Nobody, that "nobody" has an existence, a status similar to that of somebody, anybody, everybody else, in Locking-Glassiand. Carroll is exemplifying not only the miscommunication so common in his Nonsense, but also the personification or objectification which marks one aspect of nonsense language.

This playful 2 : of pronouns is not limited to Nonsense; in fact, e.e. cummings, one of the most "nonsensical" poets of the twentieth century, recasts pronouns as what might be called "pro(per)nouns." In "anyone lived in a pretty how town," cummings generates a multiple function for "anyone" and "noone"; they are simultaneously characters in a story and indefinite pronouns cramatizing their own grammatical function.'

This inter-chapter briefly compares the use of pronouns in the cummings' poem with their use in Carroll's "Verses from the Trial of the Knave of Hearts" (Alice's Adventures in Wonderland 126-7; see Appendix II for the texts of both poems). As such, the approach will be quite different from that of my other inter-chapters; rather than offering a close reading of these poems, I will use them to illustrate an important difference between Nonsense and poetry: Nonsense generally maintains its balance between meaning and meaninglessness; poetry entertains both of

'My discussion of cummings' use of pronouns in "anyone lived in a pretty how town" is rooted in James Paul Gee's excellent reading of the poem .. "anyone's any: A View of Language and Poetry Through an Analysis of "anyone lived in a pretty how town." 
these elements, but usually has at least one undefeatable movement towarde meaning.

Discuesing cumminge' poem solely in terms of its pronominal use may seem limiting, especially si, ce the poem contains many other, much more disruptive linguistic and grammatical innovations. Indeed, this discuseion aseumes -- perhaps unfairly -- th. : a reader recognizes within the poem, even if she doesn't have a technical underetanding of, such linguistic tricks as syntactical inversions; the changing cf a word's grammatical function from, for instance, verb to noun, conjunction to adjective; and semantic distortion. I concentrate on what eeeme to be one of cumminge' least radical linguistic moves in this poem because it provides one of the poem's atronge日t geatures towards meaning. Such meaningful gestures, as will be suggested in chapter two, help distinguish most poetry from Nonsense. While all of his disruptive turne of phrase help cummings to undermine and challenge normal sensical structures, his "pro(per)nouns" root the poem in a sensical tradition aightly removed from nonsense.

cummings' poem requires one to read "anyone" as a character's name or proper noun in order that it make grammatical sense. As James Paul Gee pointe out, "anyone lived in a pretty now town" "is a relatively normal sentence if we take 'anyone' as a proper name" (125). Since one does take "anyone" this way, and the poem clearly suggests that a reader should do so, what develops is a linguistic love story. The relationship between "anyone" and "noone" is sketched out in the veroe, although it is not clear from the poem if "anyone" ever notices "noone" or is aware of her love for him.

There is another aspect to the love etory "told" in the poem -- a negative aspect. The "someones" and "everyones" "in the pretty how 
town" are indicative of an apathy which underscores the "relationship" between "anyone" and "noone." These adulte "[care] for anyone not at all" and never notice that "noone" loves "anyone." some of the children in the poem, however, guese "that noone loved him [anyone] more by more." Reading this line with the indefinite pronoune functioning in their normal grammatical roles further emphaeizes the counter movement of cummings' poem; Gee suggests that, "Taking 'anyone' and 'noone' as pronouns, they [the children] have also gueseed that people are beginning to love one another less and lese" (133). "Noone"'s love for "anyone," then, is offset by the understanding that noone loves anyone anymore, a reality clearly demonstrated by the poem's "someones" and "everyones."

This narrative of love is also the personification (almost) of a grammatical rule. The close union between the characters "anyone" and "noone" is very much like the relationship between the pronouns "anyone" and "noone." "Any," Gee points out,

is what otto Jespersen has called a "pronoun of indifference.". . We can say, then, in a somewhat oversimplified way, that any basically occurs in two environments, negative environments and conditional environments - . - It is excluded from other environments, those basically involving simple positive (non-negative) assertions of fact (125-27).

so "noone," as "a negative element in language," createg the sort of environment in which "anyone," character and pronoun, can function happily and effectively (127). Despite his frequent abuses of grammar, and his reliance upon what Chomsky would call gemi-grammaticality, cummings animates a grammatical principle. He has stretched the categorical function of these pronouns, in part, so that he can vivify their traditional function; simultaneously he unmakes and makes grammatical meaning. 
The indefinitenese of cummings" pronouns allowe the poem to be read in at least two ways -- as a love story proper which is underscored by human apathy, and as the dramatization of a grammatical rule. While these pronouns can't be pinned down to a eingle referential capacity, the revult is that the poem hes eeveral poseible waye of euetaining meaning throughout ite entirety. When carroll plays with pronouns in "Veraee from the Trial of the Knave of Hearte" such is not the caee. The moet important technical difference between the two poems, at least in terme of this diecuesion, is that cumminge experimente with indefinite pronouns, Carroll with personal pronouns. Whenever cumminge uee personal pronouns in "anyone lived" there are clearly identifiable antecedente -- even if theee sce indefinite pronouns -- which fit into the censical patterne of the poem. Moreover, both the indefinite and the pereonal pronoune help to atabilize the sense of the poem; once the etretch to "pro(per)noun" is made, no matter how complex cummings" linguistic play may be, the sense of the poen. falle fairly easily into place. Carroll creates most of his lexical disruption with personal pronouns, which, if they have any antecedente at all, point back to other (unetable) personal pronouns. Consequently, an abeolute meaning, or the locating of meaning in some solid object, ia continually deferred.

The King of Hearts uses this poem as evidence to convict the Knave of Hearts, since he contends it's about the treachery surrounding the Knave' theft of tarts; as such, "Verese" would be a glose on another, much more sensical, poem. The poseible referents for most of Carroll' pronoune (and these are poesible as opposed to probable since there is nothing in the poem to support the connections made) lie outside the text of the poem iteelf. "He" may be thought to refer to the Knave, and "She" to the queen of Hearts, but even so the poem's sense ls not clarified by these antecedents since, despite the King's rather creative attempte at renciering such an interpretation feasible (Alice's 
Adventures in Wonderland 127-28), the rest of the poem doesn't conform to the theft/trial scenario.

The absence of antecedents for the personal pronouns isn't the sole disruption of sense in Carroll's poem, however. The sheer number of these pronouns -- forty-two in twenty-four lines -- help to muddle meaning. This excese is typical of Nonsense; Carroll' poem not only reveals how tenuously sense is tied to gramatical and linguistic rules, it also revels in this tenuousness. It is not enough to demonstrate this connection; Nonsense nearly always neede to inundate a reader with it. What might have been a minor disturbance to sense becomes a major upheaval precisely because of Carroll's excess.

The scarcity of nouns (only nine in the whole poem) also adds to its lack of concrete sense. Almost all of them refer to an abetract notion or category rather than to an actual, and well-defined, thing: "character," "word," "matter," "affair," "notion," "fit," "obstacle," "secret," "rest." Even these more concrete gramatical forms are vague and obscure in their reference. Nothing in this poem points to much of anything.

Given Carroll's quite serious disruption of referential sense, it's interesting that he has created no syntactical disruptiong at all. All of the lines in the poem are grammatically correct; the stanzas are too, though sometimes their grammatically sensical sentences don't fit together in a completely sensical way. For instance, in stanza one, the first two lines go well together, as do the last two $l$ ines, but the join between them, while grammatically possible, is less sensically comfortable than that between either of the two smaller groupings. As well, the stanzas have no clear relation to each other, apart from the fact they are in the same poem, that is.

What Carroll has done is disrupt language at a level analogous to that of co-reference, between lines or propositions, rather than, as 
cumminge does, within them." He gives a reader nuggets of senee but no auteined framework within which to place them. The poem's "logic" does hold, even if ite themes are undecipherable. Unlike the cummings poem, in which several poselble themes can be found, "Verses" has none. It creates sense on a mall, rather than a larger, scale. cummings does the opposite -- he makes a nonsenue of parte, but in the intereste of over-riding sense.

of course, many other aspecte of both poeme could be considered, and each of these comparisone would contribute to an un standing of how Monsense and poetry are, and are not, alike. But a look at pronominal disruption is useful in emphasizing one important way in which the two often differ. Whereas carroll preserves minute etructures of sense but gives no overriding one, cummings assaults minutiae in a eyntax much more complicated than Carroll'a, but never eradicates the poselblity of a seneical interpretation of hile poem. Both poems, to put the dietinction another way, establioh the balance between meaningleseness and meaning which chapter one suggests is central to Nonsence, but by eschewing a larger framework of sense for his poem, Carroll maintaine that balance. cummings does not.

These two poems, of course, illistrate the difference between Nonsense and poetry, a difference not always so readily discernible, not swaye discernitle in this way. Sometimes Nonsense verse exemplifies 1ese well the type of relationship with sense found in carroll' poem, a particularly fine example of the genre. And much poetry is not as nonsensical as cummings" "anyone lived," though that, as shall be seen, is nowhere near the disruptive extreme. Rather than providing any absolute measure of Nonsense and poetry, the distance between these poems suggeste possibilities for measure; their difference highlights

Chapter five, which deals with " $L=A=N=G=U=A=G=E$ " poetry, will consider co-reference again when discussing Ron Silliman's theory of "the new sentence." 
some of the characteristics their respective forms. The next chapter, and much of the rest of this study, is concerned with the Imilacities between Nonsense and poetry, or, rather, with the waye in which those similarities show the usefulness of a grasp of Nonsense strategies in the reading of poetry. 
Chapter II -- "Touch Nonkeys",

$x$ somenatic Approach to Nonsense

\begin{abstract}
Writing. like all the languages in the world, was invented, according to the ancient Egyptians, by the god Thoth, the Ibis. Scribes were represented as writing while squatting in front of an image of Thoth's sacred animal, the baboon.
\end{abstract}

(Julia Kristeva, Languege: The Unknown 63)

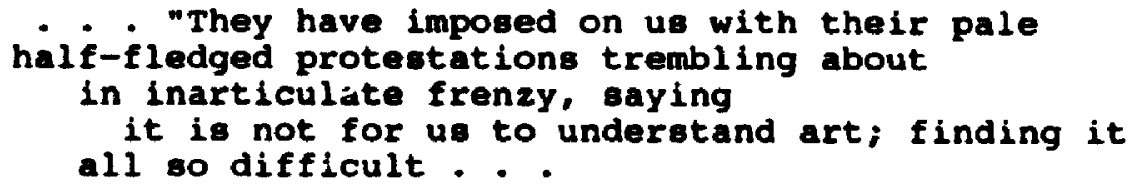

(Marianne Moore, from "The Monkeys")

The notion of desire provides a useful tool for considering linguistic disruptions found in both nonsensical and poetic languages. (I use the term poetic language as Kristeva does: not as a term exclusively applicable only to a generic use, but rather as a term which applies to language that is more consciously full of meaning than the communicative language, of every day use [Lechte 35].) Both types of linguistic play engaçe the same sorts of material practices -condensation, rhyme, rhythm, repetition and other melodic devices, which are often attributed to the eruption of desire within language. In fact, this shared materiality is one reason for arguing that Nonsense can offer a ueeful perspective for the reading of poetry.

Before the relationship with desise shared by nonsensical and poetical language can be explored, however, it is necegsary to look at the arguments for the presence of desire (roughly speaking a desire for the other founded on unsatisfied unconscious drives) in language. Such arguments stem generally from freudian psychoanalysis -- especially from the work of Prench Freudian peychoanalyet Jacques Lacan and hie view that the unconscious is structured $11 \mathrm{ke}$ language. The etatement of this 
Chepter II -- "Touch wonkey"

A soranalytic Approach to Nonsonee

\begin{abstract}
Writing, 1 ike all the languages in the world, was invented, according to the ancient Egyptians, by the god Thoth, the Ibis. Scribes were represented as writing while squatting in front of an image of Thoth's sacred animal, the baboon.

(Julia Kriateva, Langueqe: The Unknown 63)

- "They have imposed on us with their pale half-fledged protestations trembling about

in inarticulate frenzy, baying

it is not for us to understand art; finding it all so difficult...

(Marianne Moore, from "The Monkeys")
\end{abstract}

The notion of desire provides a useful tool for considering IInguistic disruptions found in both nonsensical and poetic languages. (I use the term poetic language as Kristeva does: not as a term exclusively applicable only to a generic use, but rather as a term which applies to language that is more consciously full of meaning than the communicative language: of every day use [Lechte 35].) Both types of linguistic play engaçe the same sorto of material practices -condensation, rhyme, rhythm, repetition and other melodic devices, which are often attributed to the eruption of dealre within language. In fact, this shared materiality is one reason for arguing that Nonsense can offer a useful perspective for the reading of poetry.

Before the relationship with desise shared by nonsensical and poetical language can be explored, however, it is necessary to look at the arguments for the presence of desire (roughly speaking a desire for the other founded on unsat lefied unconscious drives) in language. Such arguments etem generally from Freudian peychoanaly is - especially from the work of Erench Freudian psychoanalyet Jacques Lacan and his view that the unconscious is structured like language. The otatement of this 
Idea most useful for the purposes of this study comes from Julia Kribteva who, in Revolution in Poetic Lanquage, alters and combines, among other things, Lacanian peychoanalysis, Saussurean linguistics and Derridian grammatology to arrive at a provocative theory of poetic language and desire.

Somanalyeis in a Banana Peel: Julia Krieteva meets Rudyard Bipling

Krieteva' theory, though not rigidly applicable to nonsense, has much to offer it. An analogy drawn from Rudyard Kipling'a writing provides a convenient, if oblique, point of entry. This analogy might come as a surprise to Gott who sees Nonsense as very much of one blood with Xipling's rigid coloniallsm but absolutely separate, one assumes, from Kristeva's (and his own) Marxism (37), and from her conception of a socio-historically revolutionary language. This would come as a surprise, as well, to Kipling whose satiric "intent" and meaning will be wrenched open in the enterin.j. It might even come as a surprise to Kristeva, whose theory concerns avant-garde writing which attacks the very notions of atable sense of self and society implicit in Kipling's writing. The link I wish to forge between Kristeva and Kipling is not analytical or theoretical; neither is it allegorical. It 1s analogical, apparent only when Kipling is turned inside-out. Kipling's story involves a society, the rules and exceptions in its formulation, and it: efforts at communication; Kristeva' theory concerns the peychic and linguistic development of the individual.

In "Kaa'" Hunting," one of the stories in Kipling' The Jungle Book, Mowgli the Man-cub encounters the Bandar-log, the Monkey-rolk, who "play all day" (40). Mowgli's teacher, Baloo the bear, describes them in thls way:

They have no Law. They are outcasts. They have no spech of their own, but use the stolen words which they overhear 
when they ligten, and peep, and wait up above in the branches. Their way is not our way. They are without leaders. They have no remembrance. They boast and chatter and pretend that they are a great people about to do great affaire in the Jungle, but the falling of a nut turns their minds to laughter and all is forgotten (40).

These Monkey-Folk, "howl (ing] and shriek(ing] senseless songs" (41), lawless and playful and ultimately destructive, are analogous to Kristeva' idiosyncratic version of "the semiotic."

Kristeva's is a markedly different use of the word from its upual use (semiotics as a science of signs) as encountered in Chapter One. she writes in "The speaking subject":

By semiotic, I mean the primary organization (in Freudian terms) of drives by rhythms, intonations and primary priscesses (displacement, slippage, condensation). Genetically, the semiotic is found in the first echolalias of infants. Logically, it functions in all adult discourses as a supplementary register to that of sign and predicate synthesis (216).

The semiotic, then, is comprised of unconscious forces, drives, and "Instincts," which, moving through the subject's body, are arranged according to the various constraints imposed on this body . . . by family and social structures. In this wo the drives, which are 'energy' charges as well as 'paychical' marks, articulate what we call a chora: a nonexpressive totality formed by the drives and their stases in a motility that is as full of movement as it is regulated (Bevolution 25).

These drives, this semiotic energy, exist before and outside of "meaning" (Bevolution 36), before the subject (an entity which is alway in the process of becoming and whose development is connected to the 
regulation of a societal or "eymbolic" order (37]) is even posited by the recognition, like that in Lacan's "mirror stage," of its separatenese from other bodies. So the chors

is a sgnifying node where the linguistic sign does not yet speak of meparation of lack, doesn't demonstrate the absence of an object and so doesn't distinguish between the real and the symbolic (26).

Like Kipling' Bandar-log, then, the semiotic exiete outeide the Law of the "Jungle," of signification and the Other, of the symbolic which controls and orders the world in a supposedly unified and unbreakable way. It stands as a "O" to the symbolic's "1" -"linguistic, psychic, and social 'prohibition' . . (God, Law, Definition)" ("Word, Dialogue, and Novel" 70). It takes and twists the opeech of the Other; it is a "nonexpressive totality" (Revolution 40), exieting before language, and can only "speak" itself by breaking into and deranging the speech of the symbolic mode.

All this energy, all this drive, leads essentially to nothing. The semiotic is marked not only by its energy charges, but also by its etases -- a noneensical and non-contradictory opposition, not unlike the entropy in Lear's limericks. The shors, for Kriateva,

is no more than the place where the subject is both generated and negated, the place where his unity succumbs before the process of charge and stases that produce $\mathrm{hlm}$. We shall call this process of charges and stases a negativity $(28)$.

Kristeva argues that the semiotic chors is on a path to death and destruction because its negativity, it: opposition [generates] a dominant "destructive wave" that is drive' most characteristic trait: Freud notes that the most

\footnotetext{
'Kristeva takes the * im from Plato for whom it is a "receptacle ... nourishing and maternal, not yet unified in an ordered whole because deity is absent from it" (Revglution 26 ).
} 
inetinctual drive is the death drive. In this way, the term "drive" denotes waves of attack against stases, which are themselves constituted by the repetition of these charges (28).

The semiotic's inherent duality turns against itself. Kristeva holds language, and the "subject" or concept of the self, to be composed of eeveral heterogeneous regions, which are, according to Lechte, "disruptive of each other because there is no communicative link between them" (75). Kxisteva's subject, like language, is always "in process/on trial," always fluctuating, never stable and solidified, never consistent. The subject, and the language which articulates it, is constituted by desire, torn between the social and the stable realm of the symbolic (God/Law/Order) and the negativity of pre-Oedipal desires, the musicalized movement of origins. This unresolvable pull between the univocal symbolic and the multiple semiotic results in a negativity Kristeva likens to the death wish.

Nonsense holds in flux seemingly opposing states, too; in the firat chapter of this study its heterogeneity was emphasized. Yet even while it allows these states to exist within a larger continuum, Nonsense serves as the point at which they meet -- it both bridges and contains antithetical elements. Nonsense, as a meeting place, is quite different from what Kristeva names the thetic phase, the point at which semiotic and symbolic touch (if imagined spatially), the "threshold" (48) between the two.

The thetic is the break at which the other is symbolized, at which Maaning -- which resides in the identification of self and other, and which is in the oplit inherent in the signifier/signified relationship -- becomes possible. It produces a "transformation (from drive to signifier)" which is Indicated by syntactical divisions (55). "All enunclation, whether of a word or of a sentence," Krieteva argues, 1. thetic. It requires an identification; in other 
words, the subject must separate from and through his image, from and through his objects. This image and objects muet first be posited in a space that becomes symbolic because it connects the two separated positions, recording them or redietributing them in an open combinatorial system (43). In order to communlcate in a directed way, to indicate a epecific requeet or deaire, a child must recognize and acknowledge the difference between hercelf and the person with whom she wants to communicate, between herse if and the object about which the wants to communicate. For inetance, my daughter can't ask her father for her stuffed bear, Edna, if she doeen't rablize either her father or her bear exist apart from herself; or, at the very least, if she cannot conceive of them as very dietanced parte of herself. One's sense of wholenese muet be fragmented, or stretched to breaking, if articulation is to occur."2 The child's recognition that she is not connected inexiricably with the rest of the world, the awareness of her own separateness, conetitutes the thetic phase, and initiate language and, implicitly, 1ack. Signification marke the lose of semiotic wholeness, of a guaeiEdenic unity, and marks as well a movement into the need to symbolize, to represent the self in terms of linguistic structures -- as the "oignifier" rather than as what is being signified (48), rather than eimply being. This act of eymbolization attempts to supprese and regulate the semiotic which is a pre-condition of ita very existence. Kristeva remarks that "[because] the subject is alwayo both eemiotic and symbolir, no ignifying syetem he produces can be either 'exclusively' emiotic or 'exclusively' symbolic, and is instead necesearily marked by an indebtednese to both" (24). The chora may pre-

2 Alice's Adventures in Wenderland rife as it is with notions of an unstable self, provides another playful illustration of this idea. When Alice, after eating currant cake she finds in the rabbit hole, "Iopensl out like the largest telescope that ever was" (26), she begins talking to her far-away feet, and imagines sending them Christmas presents. She dismisses these thoughts, as she does so much else in Wonderland, as "nonsense" -. which is exactly what they are, though nonsense of quite a different sort than she supposes. 
exist the subject, and 80 pre-exist the eymbolic' attempted repreanion of the semiotic, but ironically it is acceseible only within a signifying process, articulable only in its fusion with the symbolic. One is made aware of the chora only as it is incorporated within wome system of meaning. Like the Bandar-109, the semiotic chora must steal an Other's words.

Such a system of meaning, Kristeva insists, is "ambiguous, " a defensive construction" because underlying it is the death drive inherent in the chora (49). Language, in this scheme, is an attempt to protect one's body from its own drives by linking it with the symbolic, by "making it. . . the place of the signifier" (49). But since the semiotic expresses itself through language, whether the symbolic would or not, then the language meant to set up a barrier between the body and its drives is partially in the service of the semiotic death drive which opens up that same language to a jouissance or ecstacy, and turns it "back toward the autoerotic body" (49). Language is an uneasy mix of semiotic and symbolic, a struggle to hold down and hold in the drives which ceaselessly threaten to erupt and undermine the stability of a symbolization unwittingly serving those very drives.

Lacan's principle of the "unary signifier" may add to an understanding of how the semiotic functions within language, although his system of thought does not include Kristeva's version of the semiotic. Lacan discusses the unary signifier when considering the alienation of the subject inherent in the process of signification. signification presents the subject with a double-bind, an either/or which ultimately translates into a neither/nor (The Four Fundamental concepte of Paycho-analysig 210-1), because it implies a choice between being and meaning. He argues:

If we choose being, the subject disappears, it eludes us, it fall. Into non-meaning. If we choose meaning, the meaning survives only deprived of that part of non-meaning that is, 
etrictly spoking, that which constitutes in the realization of the subject, the unconscious. In other words, it is of the nature of this meaning, as it emerges in the field of the other, to be in a large part of its field, eclipeed by the dieappearance of being, induced by the very function of the oignifier (211).

He diegrams the interaction in this way:

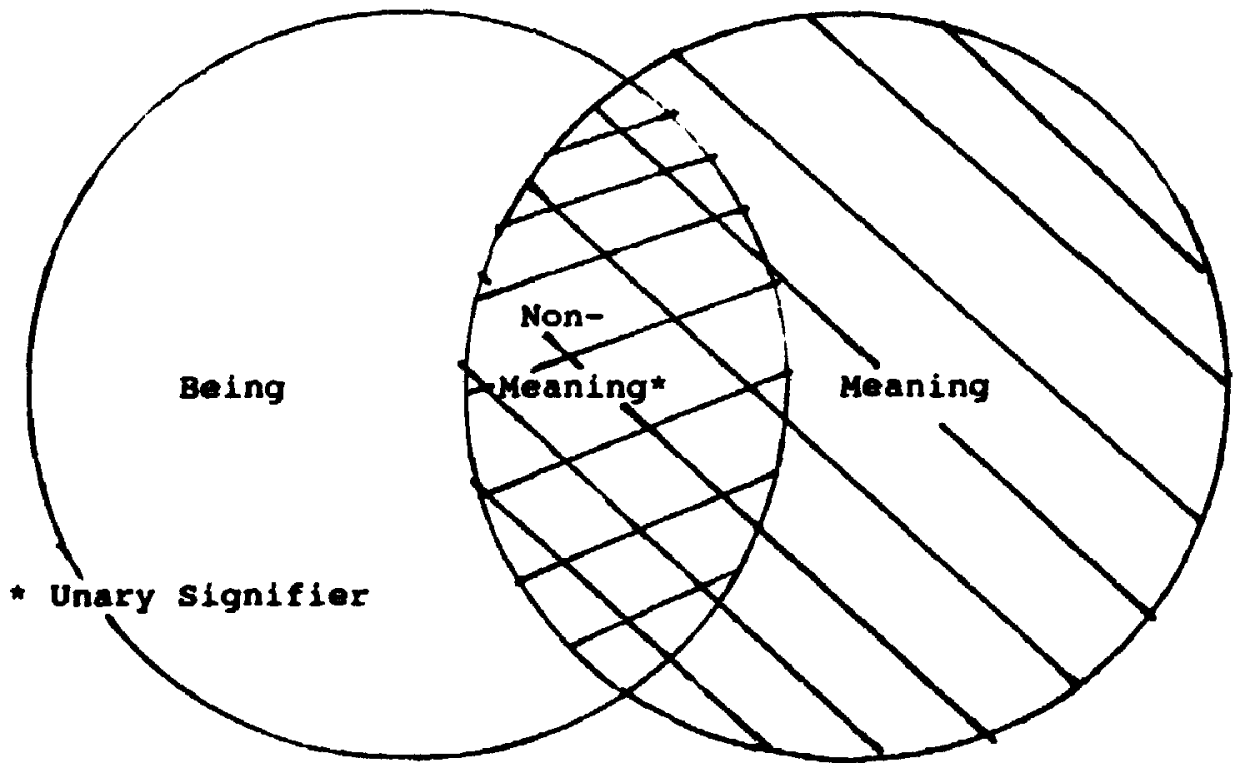

The principle is perhaps more concretely grasped in Lacan's use of the "fort"/"da" episode so important in Freudian theory. Freud links this childhood experience with the development of the preconscious, but Lacan ties it to the development of the unconscious (Silverman 169). Before the child uses "da," when he says only "fort," hil speech lacks paradigmatic and syntagmatic relationships; he is using a unary aignifier, "that thing which intervenes between the drives and meaning" (Silverman 170). Kaja silverman explains the unary eignifier as the point where Being and Meaning ohade into one another, an interface of non-meaning which is

both nonsensical and lrreducible -- nonsensical because there is no other ignifier into which it can be translated, or to which it can be reforrad, and irreducible bacause it 
does not represent, cannot be reduced to the drives $(170-1)$. Silverman continues:

Although the unary signifier remains external to meaning, it playe a vital supporting role. Because it is nonsensical, it sets in motion an absolutely fluid play of signification, one which has no fixed reference point. The unary signifier permite the establishment of aignifying eyetem within which there are no positive values, only differences (172).

It is therefore, Silverman contends, the extreme opposite of a transcendental signified (172).

The emergence of "da" (what Lacan calls the binary oignifier (218]), and the subsequent joining of the two words in a phonemic opposition ushers in a formal and a conceptual opposition, "a selfenclosed signifying system" (Silverman 170). But because these words relate syntagmatically, because "da" necegsarily points back to "fort" rather than to the drives, this coupling results in a complete break with the drives (171). This syntagmatic relationship, this newly established discourse, is not unlike Kristeva's symbolic, referring back to itself with a solidity which denies for, in Kristeva's version, attempts to deny) ite early origin in the drives.

There are several differences between Lacan's unary ignifier and Krieteva's semiotic: the relationship each has with pre-conscious drives (the unary oignifier is already a step away from those drives, the semiotic is those drives) is one example. Another is that Lacan's model has no room for anything analogous to the semiotic within language (Smith 121). It is, however, their similarities that most strike one: each is based on a wholeness in which signifier and signified, self and other are one; and each is outside meaning but essential to it: development.

The presence of the semiotic makes "communicative" language 
uneaey. But in poetic languege the semiotic eruptes it ruptures the thetic border which eeparates it from the eyt", lic (Revolution 62) and so "[prevente] . . . the thetic from hiding the semiotic process that produces it" (58). In much the same way that susan stewart eays Nonsense reflects back upon common sense, the ecmiotic calle attention to itself and symbolic language, pointing to its own quieter presence in more "rational" diecourse. Again Kipling supplies a convenient image which may serve to point up Kristeva's abstraction.

Mowgl1, a hostage of the Bandir-109, travele with them to the cold Laire, the ruine of an ancient human civilization. He sees them there, atterpting to uee the court and buildinge, but having no idea how these places were meant to be used:

They would eit in circles on the hall of the king': council chamber and scratch for fleas and pretend to be mons or they would run in and out of the rooflese houses and collect pieces of plaster and old bricke in a corner, and forget where they had hidden them, and fight and cry in ecuffiling crowde (53).

The monkeys' highjinks at the cold Laire offer a etrikingly vivid image of the working of poetic language. Here are the Bandar-10g playing at civilization, at humanness. They run about on the remains of some very fundamentel structures, the architecture of a whole society, and make a mockery of that society.

In much the same way, the semiotic element of poetic language runs unreatrained under the architecture of our civilizing language -lightly under syntax, but wore ignificantly, with a heavier tread, under semantica. It is unabashedly physical in the face of a rigid and threatened culture. The cemiotic picks up the commicative tools of language and uses them -- as the Monkey-Polk use the king's hall -- in the "wrong" way.

What the Bandar-log set up is a nonseneical society which, while 
admittedly lacking Nonsenee' eelf-referentiality, carnivalizee civilization and, in ite gevtures and articulatione, holde both the thing parodied and the ect of parody within a baelc nihiliam. And what poetic language ete up, eesentially, is a noneonsical utterance which entertains Noneense' - elf-referentiality, and undermines both denotation "(the positing of the bject)" and maning "(the positing of the enunciating subject)" (Reyolution 58 ) within the framowork of the very meaning it aseaulte.

The semiotic attacke the language through which it articulates itwelf, but, convereely, the semiotic is the origin from which that eymbolic language is born. The vulnerability of linguletic etructures which seem so strong, so unified and unbreakable, is a central tenet of Kristeva': theory. Engaged in a dialectical process, poetic language ancounters its origine and goes beyond thom. By paseing back through the "O" of semiotics, poetic language achieves what Kriateva calle a "02* interval -- continuum and multiplicity -- rather then ite earler, highly symbolic "0-1" dichotomy of unicity and Law (wee "word, Dialogue, and Novel" 70). Language no longer stope at eolidity and ainglemindednese; ite acchitecture has been broken down, ite meaning broken open to entertain an unending polyphony, a manynese.

This reaching beyond the eymbolic is the result of a breaching of the thetic border, a pouring of drives into language, and is an expreseion of desire, uneatiefied and uneatiefiable pre-oedipal drivea for the mother (the other) which are peychically and phyelcally interrelated. Such desire is negative for lt seeke to eatisy eemiotic neade by desiring that which exiets only outside of the semiotic mode. ${ }^{3}$ Kristeva Insiets desire is "the movement that leape over the boundaries

\footnotetext{
${ }^{3}$ It is important to be aware of a counter-definition of "desire" elaborated in Anti-0edious. In therr response to the Freudian over-emphasis of the Oedipal phase. Deleuze and Guattari typify desire as in no way lacking an Other:

Desire does not lack anythino; it does not lack its object. It is, rather, the swbiect that is missing in desire, or desire that lacks a fixed subject; there is no fixed subject unless there is repression. Desire and its object are one and the same thing (2e).
} 
of the pleasure principle and investe an already signifying reality -'deaire is the desire of the Other' -- which includes the subject as divided and always in wovement" (131). This desire is for the "wholenese" lost with the recognition of other bodies, for a return to a state which can be ecknowledged only after it has been left. The act of desiring requiree a subject sho experiences lack, who already exiete outeide of a solely semiotic state to which it longe to return (131). Here is a double-bind which makee the fulfillment of desire imposeible: the neede of a desiring subject can only be met scmiotically, but can only be articulated within, and directed towards, a symbolic structure. Deeire' negative nature, according to kristeva, makes it "esentially the denth winh" (131).

The poetically written text, Kristeva says, presente this dichotony between chore and "code" in its genotext and phenotext. The former includes the

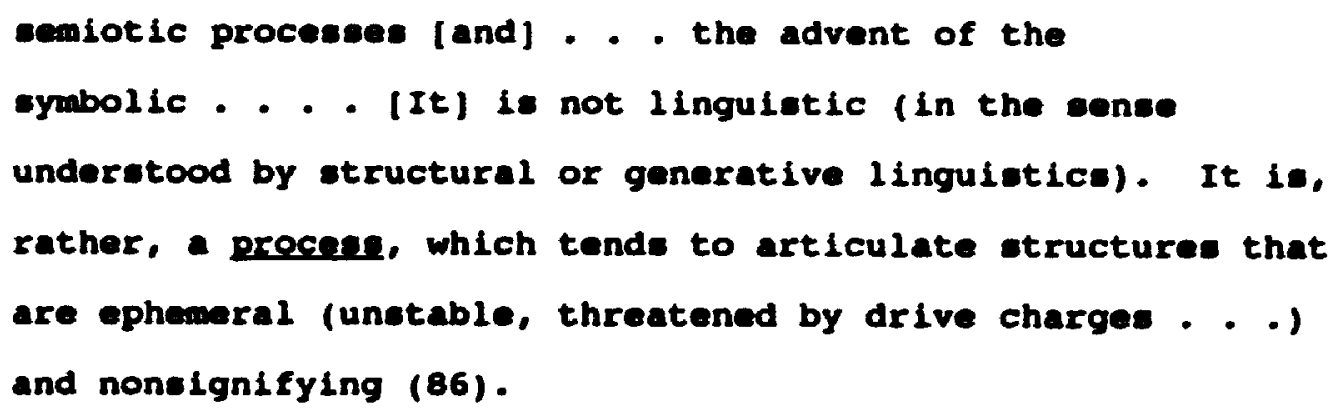

The phenotext, on the other hand, is not a procese but a "etructure"; it 1. "language that serves to communicate" (87). Every text containe both genotext and phenotext, but containe them in varying degrees.

One locates the genotext by

pointing out the transfers of drive energy that can be detected in phonematic devices (auch as the accumulation and repatition of phonemes or rhyme) and melodic devices (euch a intonation or rhythm), in the way semantic and categorical fields are set out in eyntactic and logical featuree $(86)$. 
For, Kristeva argues, the continued influx of cemiotic drives "produces a catastrophe in the space of symbollc reference" ("The Speaking subject" 218). It initiates the "[recreation] in ... epeech (of) this pre-sentence-making disposition to rhythm, intonation, nonsense; makes nonsense abound within sense" (About chinese women 29-30). This cataetrophe showe iteelf in the integration of "primary procesees" -moet noticeably perhape condensation -- within the order of syntax and word divieion, causing "the unity of morphemes" to break down. And she continues that "the most atriking example of this procese (which is only a implification of the complex semiotic/aymbolic relationahip) can be found in Lewis Carroll" ("The Speaking Subject" 218) -- or, more precisely, in the explanation of portmanteau words which he gives in the "Preface" to "The Hunting of the snark."

\section{A Slithy slobaclous semiotic:} Julia Kriftevs Mests Nonsense

The potential for a relationehlp between Kristeva's theory of poetic language and nonsense is made clear in her single, brief gesture toward carroll's work. Applying this theory to other examples, two of the pieces of Nonsense considered briefly in chapter one, will demonstrate its appropriateness for analyzing Nonsense.

The first, and most "logical," piece of Nonsense to return to is Carroll': "Jabberwocky," for in it carroll began using the portmanteau words (like "mimey") that Kristeva finds such apt examples of her deacription of poetic language's functioning. Looking at the first, and most difficult, stanza gives an indication of how the genotext and phenotext are interacting.

iwas brillig and the slithy toves

Did gyre and gimble in the wabe:

All mimey were the borogoves, And the mome rathe outgrabe. 
As was argued in chapter one, syntactical structure, the positioning eseential for communicating, is reasonably intact. So the phenotext, though not unscathed, is certainly discernible. Rrieteva would probably argue that the portmanteaux demonstrate how, in some places, the syntactical divisions of the lines have collapeed -- hence the condensation, for example, of "flimey" and "miserable" (if Humpty Dumpty's word is taken on this) into "mimsy." Perhape "brillig" is a word collapsing in on 1tself; Humpty Dumpty's glossing of it, read in a Kristevan framework, seems to imply as much. While one can still figure out which words function as nouns, which as verbs, there is a decided weakening of morphemic divisions.

of course another way the symbolic organizes language into a atable eyotem is by linking it (even if arbitrarily) tc a referent: "this" means "that." In this respect, the semiotic creates numerous catastrophea. Worde like "brillig," "toves," "wabe" and "borogoves" assault the denotative functioning of language; what, Alice and the reader ask, do such "words" refer to? However, because in Kristeva's system meaning is achieved through the process of establishing a "self" within a dichotomous flux, because that self is asserted only through discourse, the reader may be led to wonder not only about the sense of the word but also about the state of the subject. These words are not merely flippant coinages; they animate a tussle between the semiotic and symbolic -- a tussle which the semiotic is momentarily winning. They are language in its "0-2" dilwension, its carnivalized aspect, and show, denpite Humpty' attempts to ground them in definition, the potential for an unruly multiplicity. Meaning, and so the self, is split apart by this semiotic infusion. Language, likened to a body, wrenches itself apart.

Equally important is this stanza's illustration of how the semiotic and the symbolic can co-exist, as they must in poetic language. Because Carroll' - meaning doesn't fully dissolve, the ecstacy of 
jouissance doesn't completely destroy meaning. It never can. The symbolic mode is always needed to articulate that ecstatic drive. That is why the logical structure of "Jabberwocky" is so important. Like the reeds in A.R. Ammons" "Small Song" which "give/ way to the// wind and give/ the wind away" (The selected Poeme 1951-1977 69), the oymbolic gives form to the movement of desire. That is why, as was pointed out in the first chapter, even Artaud doesn't lose touch with form, though his translation of "Jabberwocky" is more desirous, less constrained, than Carroll' original.

One way of describing the genotext, according to Kristeva, is as "language's underlying foundation" (87). Part of that foundation is phonic -- so patterned sounds indicate a mixture of semiotic and symbolic. Lecercle insists that the phonetic laws of delire overcome phonotactics (35), and that Artaud is a dramatic example of this overcoming. An even more dramatic example of sound rising up againet meaning is found in the sound poetry which will be considered in chapter four. But all poetry uses sound patterns to work with or against (in Nonsense more usually against, the sense of its verse. And this stanza from "Jabberwocky" is no exception.

Its quite cacophonous balance of sounds 18 anticipated in the first word "Twas." There's a flexibility of tongue required to start a word with "tw," with its dramatic balancing of hard and soft sounds. That same dramatic balancing carries over into the $b, g$ and $t / m$, $\bullet$, and w opposition that marks this stanza. And neither hard nor soft can ultimately be declared winner -- an equality in struggle central to Nonsense. However, the sound patterns in this stanza produce an affective meaning -- as they did in Thibaudeau' "from Throgmogle Engestchin." "slithy" sounds slippery and slick, even if one doesn't know its archaic meaning; "brillig" harsh and curt. The sound pluralizes an already oplit meaning; not only is meaning wrenched apart by the introduction of undefinable words, but it ls also multiplied by 
the connotatione of sound patterning.

The genotext shows itself as well in such melodic devices as the regular and distracting rhythm of poetic language. In this stanza each of the first three lines is fairly regular lambic tetrameter. This bouncing rhythm leaves problematic words in its wake as the reader leape along over pockete of unmeaning. The fourth line however changes, seeme initially to fall short. Scanned $x x / / x /$, this line undercuts the dominance of the iambic tetrameter by substituting a trimeter which never settles into a dominant pattern. The stanza's central rhythmic organizing principle (and rhythm, though a semiotic device, is alwaye linked with the organization of the eymbolic when it is expressed linguistically) is upset, but not entirely deposed in this final line. Here the semiotic plays hell with the order of meter, first submitting to structure, then toppling it, and finally allowing it to re-emerge momentarily.4

When the passage from Edward Lear's "The story of the Four Little Children who Went Round the World" was discussed in chapter one, it: "mucilaginous"-ness, its buzzing intensity, was argued to be indicative of the push of a multiple and polyphonic language trying to break open unified signification. Krinteva offers a theoretical basis for just such a description; her diagnosis would be similar, her terminology different. The sound rush is not mucilaginous but semiotic; and the primacy of this pattern in which alliteration and assonance seem to dictate word cholce over and above meaning thows how, in Lear's crieply -tructured passage, the genotext asserts itself. The "tops" of his "transitory" "Titmice" are probably "tumultuous," not because Titmice's tope tond towarda tumult, but because alliteration demands it. In fact, how gan the top of a Titmouse be tumultuous? The influx of sound is

4 Phythm allows language to mean in different, non-communicative ways, to mean musically. The semiotic's relationship with music, its ability to make language mean multiply will be discussed in the succeeding chapters, especially in chapter four. 
such that either one's sense of the real, or one's understanding of the meaninge of words, must be altered. Again a death drive presents iteelf in the form of phonic play for, by undermining one's notion of atable symbolic meaning, these excesses of sound undermine the stability of identity.

of course there are far fewer examples here tian in Carroll: "Jabberwocky" of the collapee of morphemes and the challenging of ayntactic order. "slobaciously" is the only instance of a visible break in syntactical divisions. However, Lear's oxymoronic use of adjectives and adverbs puts a strain upon syntax as a relational construct. If the aymbolic maintains ite grasp on the world by relating one word to another based on a very fixed notion of what each word denotes and on what terms it can relate to the words around it, then Lear's semiotic impulse negates that ordering by insecting contradiction into the relational procese. How cen "splendour" be "trivial"?

What one takes away from this brief glimpse of Nonsense through Kristevan eyes is an awareness of how nonsensical language and poetic language function in very similar ways. One of the thinga the reader of Nonsense does is look for ways in which nonsense language works against meaning and attempte to unstructure sense within a sensical context or to infuse meaning with meaninglessness. And Kriateva's theory impliee that one of the ways to read twentieth-century literature -- especially avant-garde poetry -- is to look for ways in which it, too, Instructures and restructures meaning (see "Preface" to Desire in Lanquage $x$ ).

of course, any time poetry is analyzed one considers how formal systems of expression are shifted and distorted; one looks for ambiguities and multiple poselbilities in reference. Although deconstructive readings are urging criticiem away from singlemindednesse, traditional and practical criticism generally related percelved ambiguities back into a larger, thomatic framework. For instance, Hopkina uses alliteration to reify a theme, to consolidate the 
Inscape of a poem; he wrenches words to demonstrate the inadequacy of language to exprese the infinite, and on and on and on. Admittedly, Christ is the transcendental signified for Hopkins, but his linguistic play can signify other ways of meaning too. Kristevan and Nonsense theory both question the ability to mean univocally -- not just in the hope of serving a higher meaning, or in an effort to negate meaning entirely. These theorles explore how a poem can hold meaning and meaninglesenees in a eymbiotic relation, how it can work againnt its own inclination toward meaning. This inclination is important to acknowledge, however, because in all except the most extreme experimental poetry, it is embodied in an ultimately undefeatable geeture toward meaning.

The semiotic, in Kristevan semanalysis, is entertained in language not to reasert the validity of the eymbolic's stance, but rather to shake up notions of that stance, of self and society, to insinuate the tenuousnese of these "firm" ideas. Poetic language, as a burst of the seniotic within language, purposefully reveals the basis of the self in a semiotic process which the thetic attempts to hide. Wendy steiner argues that "poetry performs the feat of returning semiotic motivation to language, of resculng the word from its falled merging with the world" (93). And Nonsanee, enpecially in stewart' analyaie, increasingly dierupt. common sense, revealing the tenuoueness of common sense as a "foundation" for society, highlighting the ideology inherent in "truthe" which are commonly taken for granted.

Where Nonsense and semanalyeie differ, at least in my picturing of them, is in the pairing off of their inherent oppositions. Krieteva offer. a dual model, semiotic/eymbolic, which might be diagrammed like this: 


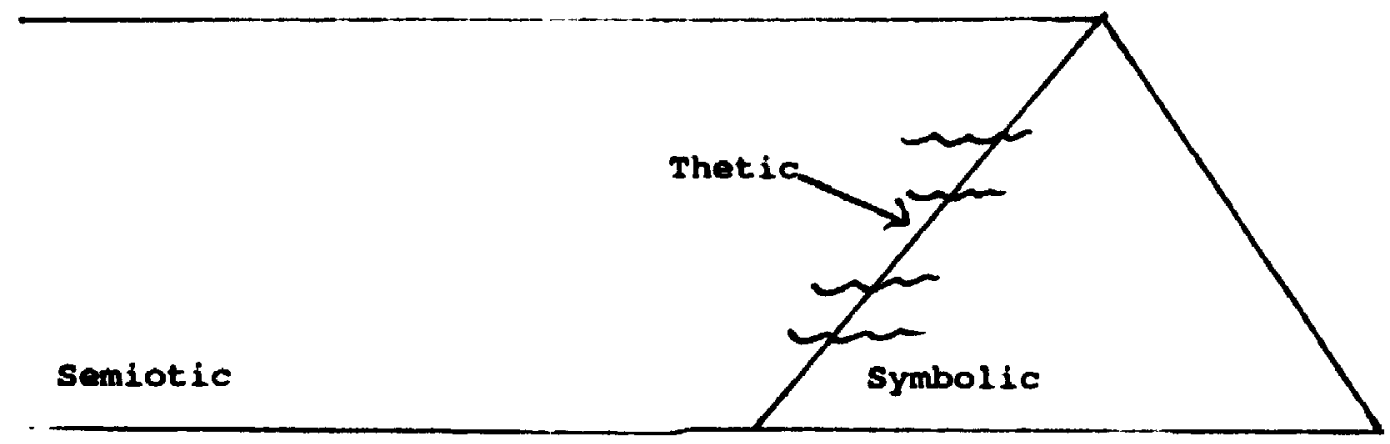

It could be argued that the thetic stands as a third term in Kristeva's systems if that is so the thetic (located about where I've put the slash, and taking a form similur to a slagh) is a silent term. It is a holding in, a separating of the semiotic and the symbolic. Lechte explains:

$$
\begin{aligned}
& \text { the thetic is also the precondition of the difference } \\
& \text { between signifier and signified, denotation and connotation, } \\
& \text { language and referent; in effect it is the basis of all } \\
& \text { theses and antitheses, of all oppositions (135). }
\end{aligned}
$$

It is a place of rupture, not merger, as is the site of the unary oignifier in Lacan's diagram (see p. 101). But the eemiotic is intensely elippery, and not easily held back. Nonsense language occure in a Krietevan framework when that third term, the thetic, is breached, when an abundance of the semiotic splils over into the realm of signification.

Nonsense, as I viow it, holds a different three-termed eystem: Meaningleseness

Meaninglessnese/Meaning (the domains of nonsense)

Meaning.

When epatialized, this syetem might look like this: 


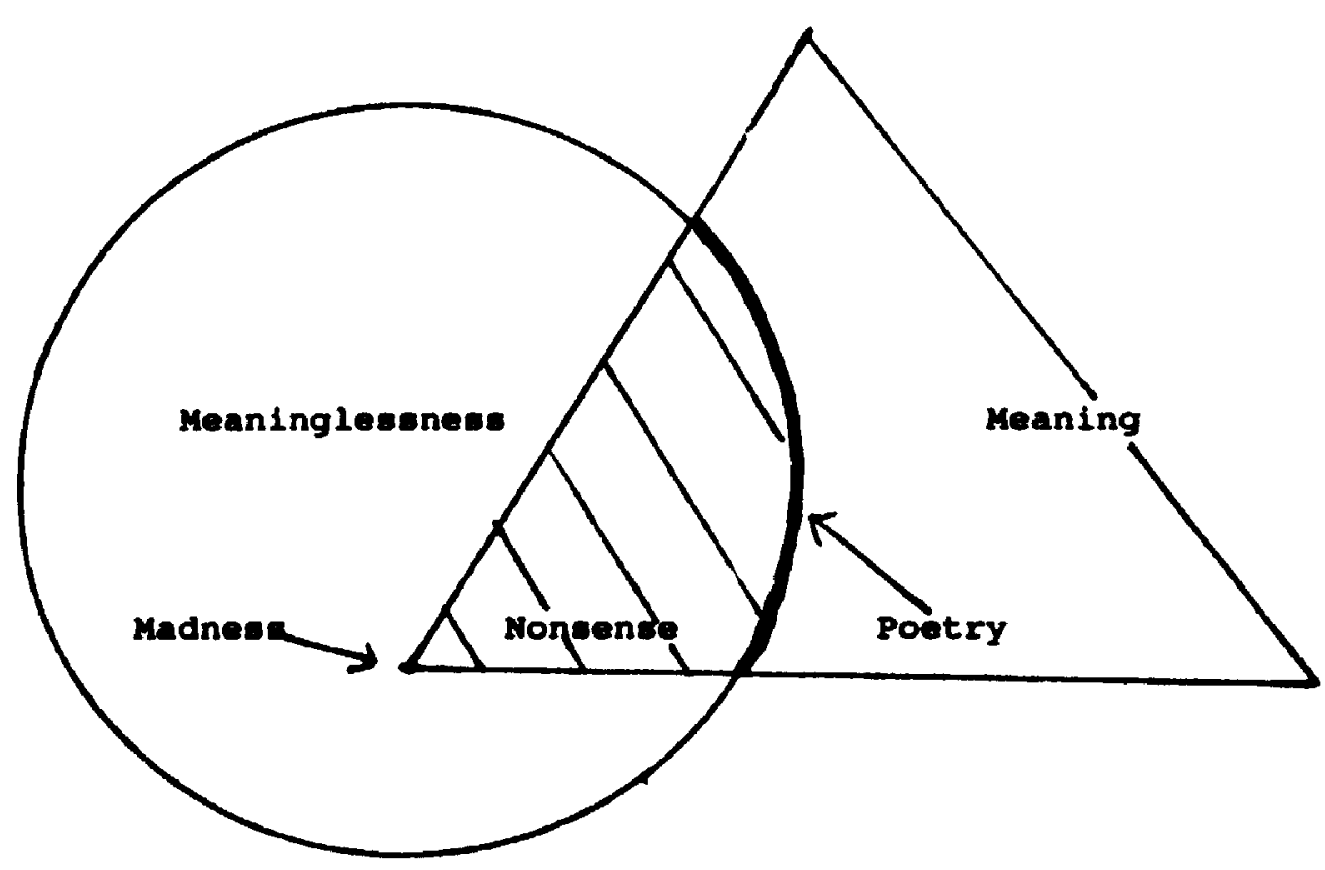

105

Meaning here is like the equilateral triangle of Krieteva's symbolic but, as In Lacan' picture of the unary eignifier, it blende with Meaninglesenese (what Lacan calls Being). This blending results in noncenee, not non-meaning, in a parody of the meaningful triangle whose one side bulges out in willful mockery. That bulge, at once the eide of the meaning's triangle and the arc of the meaningleseness' circle is the Iine poetry treads. That sharp focal point at which the last vestiges of sense appear in meaningleseness is the point of traditionallyconceived madness.

There are some dramatic differences between Krieteva's theory of poetic language and nonsense. Nevertheless, the imilarities between the two, and the potential usefulnese of her syotem in analyzing Nonsense and poetry, certainly justify using Kristeva's terminology and some of her ideas. Such borrowing, of course, is in the spirit of Nonsense, which steals in order to alter, which breaks apart what it borrowe.

Birth of the Bandar-logician: pongencicel Readinar of Poettry

The point of this thesis is not to equate Nonsense with poetry, 
which rests between Nonsense and Meaning. Rather its intent is to gelate Nonsense and poetry, to find ways in which a reading of Nonsense can cerve the reading of poetry, to make readere Bandar-loatciane who hunt out the "bandar-logos" in poetry, whe r6:eh out and (as David Byrne waye in the film, Stop Making Senge) "touch monkeys." Touch them, not become them. The intent is not, as in the epigraph from Marianne Moore, to "[tremble] about/ in inarticulate frenzy" but rather to recognize in another sort of (in)articulable frenzy, in the incuraion of the semiotic, a useful way into difficult poems. Neither is the intent to produce critical Nonsense, although there are examples of that form of criticism in existence. Frances Huxley' The Raven and The Writing Desk and Judith Crewes' "Plain Superficiality" are probably the best examples of this type of criticiem. Both approach Carroll's works "with a wry seriousness" (Huxley 8) and a wonderfully wingy logic (a la Carroll) that leaves the reader panting to keep up with their mental aerobics. Huxley and Crewes' works are spirited and exciting, but they aren't really in the realm of the Bandar-logician.

Numerous critics have noted a relationship of some sort between Nonsense and poetry since both play with language. A common cross-over point is the recognition of poetry as a game; Michel Beaujour (58) and Michael Riffaterre (14) are among those who comment upon this poetic quality. Susan Vigeurs argues that "all figurative language (itself an example of linguistic play (145) J begins in nonsense and depends for its euccese on retaining an element of that quality" (143); like figurative language, nonsense "must be fresh enough to catch the reader off guard" (144).

Poetry has something lse in common with Nonsense, another shared quality which makes the application of "nonsensical" reading techniques seem appropriate. While poetry almost always has an undefeatable gesture toward meaning (oven if that meaning must, as Derrida would 
Ineiet, be read as limited by the syetem of thought which produced it), that gesture is not, eepecially in twentieth-century poetry, limited to a thematic or sententious meaningfulness. In kodern Poetry and the Ides of Lenquage, G.L. Bruns quotes Valery: "if anyone wonders. . - what I 'wanted to say' in a certain poem, I reply that I did not want to gay but wanted to make, and that it was the intention of making which wanted what I said." Bruns concludes, then, that "[P]oetry in this sense literally ceases to be an act of meaning, insofar as the intentionality of the utterance is so thoroughly of a technical order" (87). Poetry can mean, or intend, without having a definitive statement. Michael Riffaterre argues in semiotice of pootry that "by saying something literature can say nothing" (17). Ind Canadian poet Don Mckay takes over Auden'" comment "poetry makes nothing happen" ("In Memory of W.B. Yeats" 82), and re-locates his stress, to insist "poetry makes nothing happen" ("Notes on Poetic Attention" 208). Rather than being powerless, having no "social" purpose, poetry is a means to energize, activate "nothing." Whether or not poetry engages social issues, whether or not it has a political point, it etill ca: embrace the negativity inherent in eignification, can in fact be more political, more active, by using semiotic devices to discupt the language which implicitly defines social structures. The nothing which poetry makes happen is the nothingness of the emiotic, a very potent nothingness.

Poetry may well share Nonsense's dynamic stasis, its determined waffing over meaning and sense, or at least a portion thereof. It is this point of kinehip, more than the ludic apirit of both poetry and nonsense, more than any other element that connects the two, which makes Monsense a ueful tool for looking at poetry. To make nothing happen, to make it happen even in a context which seome to be saying romething -- this is the quality of poetry which attracte the Bandar-logician. Looking at poems by Gerard Manley Hopkins and Dylan Thomas will dcanonetrate how the "nothing" of poetry is generated. 
David Sonstroem, in his article "Making Earnest of the Game," contends that looking at Hopkins in terms of nonsenes is a ueful approach. He suggest that "Hopkine' severity is tempered by occaelonal frolic - . and (that] a melancholy underlies Lear' auperficlal playfulnese" (192-3). Both writere have a childlike element in their work; but he adde. "the greatest similarity between the two is elmply in the texture and flow of their lines" (193). He goes on to liet the many otylistic (nonsensical) elements which shape the flow of Hopkins' lines, the flow of his desires, as Kristeva would say.

Hopkins, Sonstroem notices, uses portmanteau words, and runs other worde together -- for example "Amanestrength," "churlagrace" -- a technique which sonstroem considers a variant on portmanteaux. He also pulls words together by hyphenating them -- "dappled-with-dameon," "eeraph-arrival," "Never-eldering." In "Spring and Eall: to a young child," the first four lines are themselves a nonsense jungle. And what is noneensical about a word like "unleaving" (which seeme only a ehort faunt from the "legitimate" unleafing) is not juet its morphemic upheaval but also ite palimpeestic functioning. It conflates the forme of verb and noun, holds activity and stasis together in one nonsensical word. The roots of this neologlen are clear. "Unleaving" is itself, but it is also "leaf"/"leaves" and "to leave." Theologically thia functions as an incarnation of the active verbal, the divine union of spech and act 1 inked to creation in Genesie. It also creates anion of the temporal (static) and the eternal (active).

Hopkins uses sound, expecially alliteration, to connect dieparate words and ectablish a phonic subtext; this line from "The Hindhover" show how one alliterative pattern 11 ides Into another: "I caught thie morning morning' minion, King/dom of daylight' dauphin, dapple-dawndrawn Falcon, in his ridig". Internal rhyme -- "Fall, gall themeelvee, and gash gold-vermillion" ("The Hindhover"): "Stones rings like each tucked etring tel1s, each hung bell"g" ("he kingflehere catch fire") -- 
offere another, sometimes conflicting, pattern of sound to augment the aliteration. End-rhyme is often forced (Sonetroem 193): words are oplit "at the and of a line for an unueual rhyme" (194). Liete (ueually adjectival ones) are frequently ueed (194). for examples off her once okeinod otained velined variety upon, all on two epooles part, pen, pack" ("Spelt from Slbyl": Leavee").

After remarking upon the elmilarity of techniques ueed by Lear and Hopkine, Sonetroea entertaine their differences:

Whereas the conventional poet' practice ie firet to make sonee and yet have it come out rhyme, and the nonsenes poet's practice is firet to make rhyme and have it come out to the embarrasement of sense. Hopkins' practice is first to make rhyme and yet have it come out eenee (200).

The emphesis on rhywe can be traced to sonetroem'o insietence that "rhym if (Noneense' ) primary reacon" (198). And, while clearly his dietinction le not mine, it is of some ues here. In Krietevan terme the quotation above might read as follows conventional poetry aime at aeneo and cowinication (phenotext) but lete in moderate anounte of and play (desire/genotext); Noneense overwholmingly lete in desire until it inundates the phenotext, rovealing the thetic and ambarraesing the eymbolic, but never eradicating the phenotext, Hopkine etarte with desire (genotext) a a motivating principle but uses it to boleter the phenotext. Such a "tranelation" is not juet a handy way to work in wowe thick terminology -- for each word carries with it the connotations of peychology and desire in which Krieteva's purault io grounded, and so widene considerably the implications of sonetrom's distinctions. There i. no denying that Hopkins is a poet of ense, of theological ansef but like Buddhist koans, his poeme use nonsense to reach that sense.

Two elemente of Hopkine" poot1c -- "eprung rhythm" and "inecepe" -- add to thie nonaensicality. In his "Author" Preface,"Hopkine calle eprung rhythm the rhythm of common epeech, of written prove, of muelc 
and of nursery rhyme (49). In it, he says, the first syllable of every foot is always etreseed, and can be followed by elack eyllables (in number ranging from none to three). The length of feet is not fast, but varies from monosyllablic feet to those composed of four syllables. What is related to the establiehment of a genotext is not only the lilting rhythm this method of ecanning results in, but also ite tendency to "rove oyer" $(48)$, in this method of scanning the line breake are diecounted, feet can uninterruptediy epan the end and beginninge of linee. So the rhythm, the arrangement of the sound, worke againat the more formal line breaks. Paradoxically, the movement of common spech, or Hopkins' version thereof, is ueed to undermine its more etructured and conventional poetic equivalent.

Inscape, Hopkins" belief in the "Thisness" of a thing, in the presence of its being, seems at first an odd inclusion in the list of nonsense techniques and principles. But, while Hopking clearly is working with a different, a divine sense of being, quite alien to Xristeva's notion of the being-ness of semiotic presence or to Lacan'. concept of being, Inscape does motivate the linguietic distortione which Kristeva attributes to the cemiotic. Desire is not unlike a frustrated nead to "be" in language, to fulfill the demands of an overwrought "being" in terms of representation. Within a very different framework, Hopkine secme to have isolated a similar problem: the split between being and language. Where Hopkins differs most it his eventual attribution of inscape to language, to every word, so that -- even as it seeks to exprese the inscape of varioue things linguistically -language "becomen a counterpart of reality, not because it imitates some object, but because it acquires an inscape of its own, a self-sustaining individuality that dietinguishes it from all other realities" (Korg 15). By granting language an inscape, and so removing it from the realm of mere representation, of mere symbol, Hopkins theory of Inscape in effect resolves Kristeva's dichotomy theologicaliy. In Kribtevan terma, 


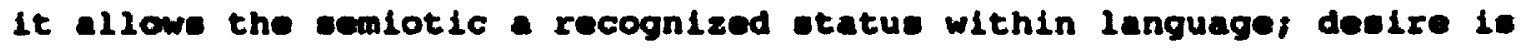
eatiefled, the thetic unneceesary because the eplit between eignifier and signified is reoolved, theoretically at least, by inscape. Rather than breaking the Krietevan diagram down further, as Noneenee theory does. Hopkine unifies the elements of the diagram and mixee together Maning and Beingr God, Law and bosire. Rather than reading divinity as the inetigator of division, he ees it as the cure for divielon. His axture doeen't dobae thoology and order, though it wrenches languages rather, in theory, it theologises language, accords it the greater euthority of concrete exietence.

A brief look at "Spelt from slbyl's Leaves" (eee Appendix III for the text of the poem) will 111 ustrate some of these principles more thoroughly. The poem followe the Italian sonnet form: the octave centres on the evening, as lt "etraine to be time' vast, womb-of-all, howe-of-a11, hearce-of-a11 night, " and as the speaker antlcipates ito descent apocalyptlcally as death and judgement for in the gulee of depair). The esetet warne that dualities alone exist, that one muet choose between "two flocks, two folds -- black, whites right, wrony"; lte world is perilous and bleak.

This is a difficult poom with many long, alliterative and aseonant words. These are often piled on top of each other, marnest, earthlese, oqual, attuneable, vaulty, voluminous, . . etupendous. " This firet IIne not only establishes three sesonantal and alliterative groupe (e. $v$, ) but also, with ite ellipeis, kepe one in awe, in anticipation, as the final a patern (a aecondary them in each of the firat) le confirmed. And the turn from a pattern of asconantal $0^{\prime} \mathrm{s}$ to aliterative $v^{\circ}$ is sot up to work ageinot lteelf initially. The breaking polnt is "Attuneable" - maning to be harmonlous, ogual, but phondc equivalency (alliteration/aceonance) is ohifted to anothor (albelt related) phoneme. Only after e111psis, after a further break, are the patterne made harmonious, otrung together by their al1iterated 
$\bullet \cdot \bullet$

Alliteration and sesonance are dominant motivating principles in every line of thie poem: "But these two; ware of a world where but these two tell"; "where, selfwrung, selfstrung, sheathe- and shelterlese, thoughte againet thoughte in groans grind." The genotext oi this poem 1. almost unavoidable. Sound overwhelme senes the thickly woven patterne eventually echieve the harmonizing effect of night, as all counde are muffled and fade into, merge with, one another. The individuality of the poem, of ite words, faces the eame threat of extinction which the spaker feare from overwhelming night. He moves to accomplish linguistically the very death which he dreads, the equalizing and evening out which causes his despair. Thus the poem is a capeule of dread and desire.

The frequent hyphenating of words is another example of aemiotic preseure, of the collapse which the tone of this poem so eloquently presces: "Fire-featuring," "tool-smooth," "womb-of-all, home-of-all, hearse-of-all."s This last example has also an incremental power which, becauce of the common denominator (of-all), implicitly joine womb/home/hearse and so runs the course of human life. Other words are run together, more solidly foined: "beakleaved," "selfwrung," "eelfetrung." And the dialect word "throughther" atands as a portmanteau, as two words welded almost indistinguishably. Other elements of the genotext lead one to perceive, beneath these tones of despair, a self-negating welcome. Words are repeated throughout the poem in various contexts -- "black" and "al1," for example. The conetant repetition, or rather near repetition, of worde and phrases in the same line is also another mark of the semiotic's involvement. One of the clearest examples is "her earliest atars, earlstars," where repetition breaks down syntactic diviaions, and the

${ }^{5}$ Regarding a linguistic device as common as hyphenation as an incursion of the semiotic indicates that even language which seems purely communicative may have elements of semiotic upheaval. 
component parts of the first blend in the second. One sees, in this near repetition, a phrase falling in upon itself, the way night works. Other partial repetitions give a sence of peering through a darkness in which worde maintain only the faintest outlines of their uniqueneses "selfwrung, selfetrung"; "Her fond yellow hornlight. . . her wild hollow hoarlight" (ironically it is the "hornlight"/"hoarlight" which is most deeply immersed in the darknese of echoic play); "But these two; ware of a world where but these two tell, each off the other." Besides Hopkins" overt geeture of interior doubleness ("off" as opposed to "of"), this latter example engages exact repetition and homonymic repetition: that is, rhyme -- which sonstroem, quoted above, calls Nonsense' reason for being, and which Barthes considers a "atructural scandal" (Elments of semiology 87).

Rhyming is another way Hopkins blends the poem into a homogeneous mass. The poem follows the rigorous rhyme scheme of its sonnet form (abbaabbacdcdcd) which, dempite its relationship with the semiotic, gives some order to the poem, but is counteracted by more determined half-rhymes and internal rhymes. This pull to internal sound play is reminiecent of cynahanedd, the Welsh metrical form which rigidly requires such rhyming and alliteration. Hopkins' reader is constantly shifted away from the poem's forward movement and back into the morass of the lines themselves. The prevalence of half-rhymes, 11ke "Earnest," "earthless," "earliest," "earletars" and "earth," depict a coming together across numerous lines, and not fust a turning back in towards the centre of individual lines. The tentative ordering of formal rhyme i. greatly shaken by Internal rhyme as, once again, words fold back into one another. Perhape it comes as no surprise that sonstroem likens Hopkins poetry to a word game similar to Carroll' Doublets, which works on the principle that one word contains many (al13) others (200). 
genotext, of the aemiotic's preseure. The rhyme echeme domande that the word break -- as/tray -- in order to rhyme with "etupendoue" and "ue." The etructure clearly favoure materiality over semantic value. But this disruption seems even more dramatic than that caused by the internal rhyming and alliteration because, while all other elemente of the amiotic intervention have tended to bleed things together, this one breake them apart. The breaking open of any word inside a poetlc which, because it sees a relation between the Divine Word and the poetically inscaped word, regards each word as a unique and vital thing in itself, is a serious matter. The wholeness of the word is eplit open. Krigteva might argue the self is shown to be fractured; her "diagnosis" would not be wholly misapplied.

In the midet of ite speaker's fear of death and torment, this poem animates just wuch a loss of individuality. Language is so distorted by this excess of inscape that, ironically, its own principle of uniquenese 18 undermined. All the phonic examples of life's manynese, its continual interconnectedness lead to uniformity -- except in the one Instance (dramatic in its very isolation) when one word is broken into parts. The reader is left, linguistically, with two poles: the choice between "two flocks, two folds," between the immersing or the fracturing of identity. Either all words become one word, in which case their uniquenese, their being-nese is lost, or each word becomes more than one word (and this is poseibly another way to read the rhyming and blending of worde), in which case, again, uniqueness is lost.

For the Bandar-logician, this poem courts union with that which it seeks to avoid. It is both a warning about the horrore of death, $n i g h t$ and fudgement, and a linguigtic invitation to enter into them. As the epeaker holds black and white to be the only alternatives, the only "choices," as he painte guch a chililng picture of this blacknese, his language blackene 1teelf. The beauty of this IIngulatic blackneas Eurther subverte the seeming direction of the poem. Hopkins uses many 
typically poetic conventions -- rhyme, rhythm, alliteration, repetition -- but uees them with an extravagence more akin to nonsense. What is most important to this reading is that he does so to the partial contradiction of his "sanse." The meaning of the poem is not destroyed, but it is pluralized and relativized as it entertains its own contradiction. Of couree, a great deal more can be ald about "spelt from sibyl' Laves." But the setic etrategien which a nonsensical reading discovers have, at least, been glimpsed.

Bringing a nonsensical point of view to Dylan Thomas' poems seems almost redundant, for he stands as a poetic home ludens. His work is full of jarring juxtapositions which make sense uncertain and difficult. Connections are far from obvious. Thomas claimed to use "old tricks, now tricks, puns, portmanteau-words, paradox, allusion, paronomasia, paragram, catachresis, slang, assonantal rhymes, vowel rhymes, [and] sprung rhythm" ("Notes" 189) in his writing -- almost all of which are to be found in Monsense's own bag of tricks.

The genotext of his poetry finds one of its strongest voicings in the musical elements and qualities which make up the latter part of this "list." His love of nursery rhymes, poems which he claims seduced him with their rendering of language into pure sound, is a focal point in his poetic:

The first poems I know were nursery rhymes, and befcre I could read them for myself I had come to love just the words of them, the words alone. What the words stood for, symbolised, or meant, was of very secondary importance. What mattered was the gound of them as I heard them for the first time on the lips of the remote and incomprehensible grown-ups who seemed, for some reason, to be living in my world. And these words were, to we, as the notes of bells, the wounds of musical inetrumente, the noises of wind, see, and rain, the rattle of milkcarts, the clopping sf hooves on 
cobbles, the fingering of branches on window pane, might be to someone, deaf from birth, who has miraculously found his hearing. I did not care what the words said, overmuch, nor what happened to Jack and Jill and the Mother Goose rest of them; I cared for the shapes of sound that their names, and the words describing their actions, made in my ears . . - Out of them came the gusts and grunts and hiccupe and heehaws of the common fun of the earth; and though what the words meant was, in its own way, often deliciously funny enough, so much funnier seemed to me, at that almost forgotten time, the shape and shade and size and noise of the words as they hummed, strumned, jugged and galloped along (185-86).

This love of "the shape and shade and size and noise of . . words" is carried over into his own densely musical lines.

Such phonic play is augmented by other, equally nonsensical tactics: his gentle bending of syntactic rules, his metaphorical and metonymic word replacements, his sensitive exploitation of line breaks, hie linking of constructive and destructive elements in ingle imagecomplexes, and his use of connotation to emphasize the reverberations occasioned by his juxtaposition of eeemingiy disparate matter.

Susan Vigeurs points to "Fern Hill" as an example of the apparent nonsense in Thomas" work:

rules of grammar are being ignored -- and those rules aren't arbitrary, but have to do with the way we order the world. Words have been folted out of their normal relationship with each other (143).

Vigeurs seems to be using "grammar" in an extremely prescriptive and narrow sense. Thomas may be quite associative in his linking of words but he has not disrupted, in any major way, the etructural integrity of his sentences; his sentences axe always, at the very least, semi- 
grammatical, more often fully so. However, she is right in commenting on the nonsensicalnese of his work -- a nonseneicalnese achieved lexically more often than ayntactically. Even the simple subetitution of "eun" for "day," quite a practical sort of metonymic twist, begins to take meaning in a non-communicative direction, to require a different sort of attentive engagement with the words and a questioning of their referential function.

All the oun long it was running, it wat lovely, the hay Fields high as the house, the tunes from the chimneys, It was air

And playing, lovely and watery

And fire green as grass.

Such motonymic substitution, like sound play, is central to Thomas' ludic writing.

Thomas describes his procese of writing in terms which could have been lifted right out of the discuseion of Nonsense in the firet chapter:

I let, perhaps, an image be "made" emotionally in me and then apply to it what intellectual and critical forces I poseses -- let it breed another, let that image contradict the firet, make, of the third image bred out of the other two together, a fourth contradictory image, and let them all, within my imposed formal limits, conflict. Each image holds within it the seed of its own destruction, and my dialectical method, as I understand it, is a constant bullding up and breaking down of the images that come out of the central seed, which is ltself dentructive and constructive at the same time (quoted in Treece, pylen Thomen $37 \mathrm{n})$.

Though one might question the presence of a rigid dialectic in hie work, 1t's Interesting that Thomas believes his images work this way. It may 
be more to the point to call his a poetic of noncontradictory opposition which revels in the fullness of meaning. Such an opposition, a "creative destruction, destructive creation," is what he required of fellow poet vernon Watkine (Watkins 38). To borrow Pound's phrase, Thomas' poetry, like Joyce's prose, is "charged with meaning," with the multiplicity of meaning such critics as Rieke and stewart relate to nonsense.

Thomas relies a great deal on connotation, on what Barthea call: "the development of a eystem of eecond-order meanings, which are so to speak parasitic on the language proper" (Elemente 30 ). In attempting to achieve thie language. Kaja silverman explaina the theory of connotation which Barthes develops in $\mathbf{s / z}$ this way:

A connotative signified or seme perpetuates the play of signification. It represents the antithesis of a transcendental signified... . The connotative aignifled Always refers beyond itself, appears... "pregnant" with additional disclosures. It constitutes a hermeneutic as well as a semic element since it prolongs the search for "truth"... Reading or viewing ... is thus a procese of "akidding" from one signified to another (256). Discussing Thomas reliance on connotation in his notes to "Altarwise by owl-light," which is arguably Thomas' most nonsensical piece of work, Daniel Jones suggests that the sequence is held together not by the common logic of reason but by "tha logic of a common relationship" (263). But such a suggestion seems limited, for the workings of connotation, of the plurality of Thomas references and interconnections argue for many relationships. These may be held communally, but they certainly (to read another sense of "common" into Jones' comment) are not ordinary. The continual sliding of images, of relations and so of sense, works dramatically againet the stability of communication which Krieteva makes requidite in the symbolic dimeneion 
and which would necesearily, one assumes, be found underlying "the logic of - common relationship." Jones' analysie, intentionally or not, impliee a tendency towarde univocality in Thomas work which is hard to hear over the din of hie echoing cat calls.

The nonseneical wealth of Thomae' work decerves sustained ettention, but a look at sonnet VI of the "Altarwise" sequence (see Appendix III for the text) will at least give an indication of the richnese of sound, image and connotation to be found in the poem as a whole, and in Thomas' corpue. The aixth is perhape the most indeterminate of all the sonnets in the "Altarwiee" sequence. While the worde engender numerous possibilities for meaning, and are densely allueive to (among other things) Chrietian and claseical mythology, they never settle down into any definite, definitive sense. Several of the images -- for instance Adam, the cock, the sirens, the carde -- connect with the reat of the sonnets in the eequence, others, like the eea, connect with different poems. Words are repeated within the stanza: "Love," "lop," "pluck," "eye," "tallow," "wax"; so their meaninge accumulate. These interrelationships don't help pin meaning down; inntead they offer more ways for various lines to mean, more context. for generating that meaning. What reverberations lie between "his" for the water's) tallow-eyes and the "tallow" the narrator blows from the "wax'- tower"? And what resonances lie between the "manwax" (the semen from sex with sea-women?) and "the wax'- tower" (candle? phallus?) and the "old cock"? Such "intratextual" webbing only accents language's manynese.

But to speak of language's manynese secms almost too underatated a way of deaignating what happens in this poen. Words not only relate to one another through deft twiets of image and ascociation, but alwo give the lllueion of containing or bearing other words as a result of those assoclations. The most dramatic example is probably "the etinging iren," which almost asks to be read as "the singing siren" also. As in 
Hopkine' poetry, language functione a a palimpeest; one roads through the printed word to the other poesible words, or combinatione of worde. which continually write other eenees into the poem. Thomas' language at once combines a raw phyeicality with his metaphorical and metonymic tendencies toward linguietic oubetitution; he uses language at a remove, subetituting one term for another $11 \mathrm{ke}$ an Inteneely eneuoue dictionary with metre ("what is the metre of the dictionary?" asks the firet line of sonnet IV). The comparison is not Intended to damn him as prosaic (who could?) ox dull (who would want to?): rather the comparison is meant to 1 ink him into that Nonsense world of linguietic equivalency and play, of language taken to literal and literaxy extreme - for he succesefully balances both in the multiplicity of his writing.

To augment this variousness of meaning. Thomas uses adjectives which eeem to have no immediately obvioue relation to the worde they modify. These rival Lear' "Diaphanous Doorecraper" ("The story of the Four Little Children" 106) for sheer nonsense and fun -- for instance, "oyeter vowels," those diphthongal vowels that close up on themselves. If proof of the nonsensical orientation of metaphor is needed, this image will surely serve. Yet the image can be read as a delineation of the selecting of meaningful phonemes out of the vast pool of prelinguigtic sound. These "oyster vowels" are "split through" by the "tallow-eyed" "He" of the previous line, as he "[burns] sea silence on a wick of words." The sibllance of "sea silence" is already awash, an amorphous noise to be cut through, sorted out, into meaningful sound, to be acriflced to the "wick" (of a candle, of livelinese) of words. The eplitting open of the oyster vowele is analogous to the fall into language, the coming into the phonemes of the symbolic and staid reason. such olicing open of nolse, to make it more easly categorized, more univocel, anticipates the lopping of the minetrel tongue later in this same sonnet. 
As well. Thomae dieplaces and juxtaposes words so that they modify in various directions. Because of its placement, "tallow-eyed" in the sonnet's second line could be referring not only to "he" but also to "water," though how water can be tallow-eyed is a puzzle. And to what doee the firet line of the etansa refer? Is "He" a "cartoon" -- a comic, or a oketch for a painting -- or is the cartoon the action which occupies the remaining lines of the connet? If this latter suggestion i. the case, what colouring does this give to the "charactars" -- to Adam and the meduse, to the "old cock" and the alrens, all figures of grave mythical import? Such relational dieparity breaks the hold of the aymbollc realm of representation, for it makes impossible a definitive reading of the poem. By granting worde like "Adam, time's joker" a measure of independence, Thomas insinuates the potentiality for all worde to elip away from representation.

There are semiotic pressures on morphology here too. The divilion between words is threatened, rather than using portmanteau words or running words together, Thomas joins words by hyphenating them, works againat the "[lopping of] the minetrel' " tongue" by forcing out words faoter, in closer auccession. "Tide-traced," "tallow-eyed," "pinhilled," "bagplpe-breasted": each of these relatively unconventional fuxtapositions moves towarde the weakening of what eyntax designates as - eingle word. That some of the pairs are alliterative only bringe the two words closer together.

slips in eyntax and morphology are not Thomas' sole means of pulling away from ingular representation. One need only mention the -lueivenese of hle allugions and his use of a grab-bag of myths, of poseible origins and explanations which all vie for a favourable prosentation. Thomas' mythic landscape is chaotic at best -- certainly an ironic comment on mythe intended to order perceptions of the world; many of these mythic symbole are also intended (in the beliefs out of which they grow) to direct perception away from the order of the world 
proposed by some of the very mythologies with which they are fuxtaposed in this sequence. Thus, Thomas again nods in the direction of manynese. Like his mythology. Thomas' soundscape is hardly clear-cut; the genotext is almost at the height of ite musical powers in this sonnet. The etanza's alliteration and sibilance are but one aspect of this: "aea -ilence on a wick of worde"; "stinging eiren'e eye"; "The bagpipebreasted ladies in the deadweed/ Blew out the blood gauze through the wound of manwax." The onomatopoeic sound of "Pluck" it followed by a euccession of equally brusque monosyllables: "cock, my see eye." Even the rhyme pattern of thie sonnet (abca' $a^{2} b^{\prime}$ bcadefel $f$ ) is hard to ctabilize. But many of these rhymes are achieved through a violent wrenching as sound refracts throughout the sonnet, as violent a wrenching, perhaps, as the opening of the first phonic oyater. Halfrhymes and near-rhymes predominate over true rhymes -- "manwax"/"index"; "till"/"tallow"; "pluck"/"cock", "lop"/"love." Like Hopkins, Thomas engages in heightened sound play. But the thruet of his genotext is far from homogeneous; rather it constantly pulls away from any attempt to knit together.

Another nonsensical feature of the poem is its self-consciousness. The denseness of the lines, the unnaturalness of image and juxtaposition constantiy remind the reader that this is a conetruction, an artifact, something outeide the natural flow of the world, of language and of sound. How could a line llke "By lava's light aplit through the oyster vowels" not set itself off? Moreover, if one accepte the interpretation given above, the line not only calls attention to itself because of ite arcane imagery, but also reflects upon the very basic lssue of the relationship between meaning and language. The awkwardnese of the images frames the work with an implicit self-referentiality, and highlights the poet' difficult and skewed relations with language. He is bohind all of these images, saying, "Here I am, back here, orchestrating all these oyster vowels, and it's not easy, given the 
rifte in the wholenese of sound."

It would be pointless to say that in the "Altarwise" sequence Thomae contradicte his eenees it would be pointlese as well to suggest that Thomas eotabliohes a solid and reliable, albelt hidden, framowork of sense. That is why Nonsense is such aseful tool in reading this poem and other Thomas poems. All these factors taken together don't make Thomas a poet who undercute the sense of his own poems, but rather one who engagee eenee viecerally, who gestures towarde meaning in an "un-meaningful" way. For all the abstraction which Jones notes in Thomase poetic (263), he writes muscle onto the sinew of sense.

An important aspect of the nonsensical nature of Thomas' work 11 es in the fact that it playe to the senses as opposed to "sense." This eceming contradiction of the senselessness of the physical senses, the noncence of the body, will be explored more fully in the next chapter. 
"Hunting-song of the Bandar-logician"

\begin{abstract}
Ae soon as linguietic desires are fanned, Critice the remiotic ante out of hand.
\end{abstract}

The Junale Book isn't unlike this thesis, at least structurall $;$. Between its prose chapters or storles are poems -- tight poems, quite formal in rhywe, rhythm and stanza, augwenting some aspect of the story they"re "attached" to. Poetic eruptione in the midet of a prose miecellany, their presence creates a tension, a linear dieruption in line with the temporal and geographic non-conformity of the volume. While Kipling is hardly an iconoclastic or experimental poet, when he surrounde one of his poems with lese materially-structured language he calla attention to the diecrepancy between etyles of language; the material or poetic elements of the posme' language are tougher to ignore because of their prose neighbours. "Road-Song of the Bander-log," the companion poem to "Kaa'g Hunting," demonstrates not only Kipling". atrong adherence to poetic form, and so the foregrounding of material - lement. of language, but also the dissolution of that form when those elemente get seriously "out of hand," and the semiotic establishes one order merely to supplant it by positing others.

sure eigns that the thetic has been breached are the presence in language of repetition and of a dominant rhyme scheme, the "Road-song," not surprisingly, has both. Its first two stanzas, of eight lines each, are strongly ordered by rhyme, are, in fact, clusters of rhyming couplets. And the final couplet of the first atanza -- Now you're 
angry, but -- never mind, / Brothere thy tail hanas down behind" -appeare with elight variatione in the final couplet of the second etanza. The change, minor as it is, establishes repetition as a force of Elux (aince it alwaye occasione change) in the poem, inetead of using it, as one might otherwise, as a stabilizing device the twiet in technique it important aince the Bandar-log we're told in "Kaa's Hunting," communicate almost wholly through the repetition of other animale' epeech, through inhabiting and diatorting other creatures' language. Repetition animates the parasitic nature of the Bnndnr-109' * epeech, animater as wall the subversiveness and anarchy inherent in it. The third stanza continues the pattern of clustering couplete, and the generative change encouraged by repetition. Rather than ending with - amall change to the closing couplet used in the earlier two stanzas, howver, it concludes with a triplet which altere that earlier couplet, and then extends it. Reworking the form, Kipling uses this final triplet not only to lend insietence to the most important rhyming sound in the whole pown, but also to herald an even greater break from the establishod forms the introduction of a new stanza form, a now rhythm and a now rhyme pattern.

The last atanza changen entirely; a quatrain with coneiderably longer lines, it has no couplets. Rather it follows an ABCB rhyme pattern. This loosening of the poem' previously rigid thywe scheme allowe other rhyming poseibilities to creep ing the phonic movement calle attention to 1teelf by miding (mlantwise) out of one pattern and into another. The stanza's firat line ends with a elant rhyme connecting it, tenuouely, to all the final lines of the previous ctanzas: "pines" -- "mind," "behind," "kind." and the third line of thie final etanza has no rhyming co-ordinate -- except internaliy. In fact, the only lines in the poem without true end rhymes are also the only lines with internal rhyme. 
Wuch of this poem concerno noive, "the noble nolse" which the Bandar-log make, stealing and jabbering the discourae of the world around them. It's eignificant, then, that the moet noticeable, most jarring, break in the poem's rhyme comes at the point when the Bandar109 jabber is named "nolse." The nolse of the poem, thematic and sonal, 1. doubly emphasized by this breaking open of the rhyming pattern. "Pines." though it has no true end rhyme, can still engage in some phonic patterning without relying upon the rhyme within its line. But if "make" is to rhyme, it can do so only by playing ite sound back over its own line, only by re-routing the forward flow of the poem's movement.

such turning back to the line renews attention to the changes in rhythmic structure within it, and the other lines of this stanza, as well. The lines of the firat three stancas ecch have four feet and balance lambs against trochees. For instance, the firet etanza is made up, with very little variation, of lines composed of two lambe and two trochees. A slight tension is created between these feet ince the verse never lets one rhythm predominate. The fourth stanza, comprised of four lines of lambic hexameter, throws itself almost wholly over to iambs. The stretching out of lines, and the privileging of one rhythmic foot, allowe sound, in a sense, to take over; the temporalizing of sound becomes at once more regular (so more noticeable) and more sustained. Like the word at the end of its third line, this stanza jars with the rest of the poem's movement, disrupts the patterns already established while instituting another type of regularity; a rigidity of rhyme and a doubleness of rhythen is replaced by a doubleness of rhyme and a rhythm of increased rigidity. Each "opposition" is orderly and alternative, but the final stanza provides greater room for sound to resonate and a less hesitant -- more oweeping -- rhythmic movement. Rhyma, rhythm and sound play are used to emphasize their own abilities to generate maaning, their versatility in exploring alternative ordera. 
Kipling may have etyled thia a poetic working through of the Bandar109' Inability to sustain any sort of order, to follow through on their Intentione (a theme of both the poem and the previous chapter), but this epiralling of cound is almultaneously indicative of the eemiotic' : explosive unrulinese. The formal structure which contains and promotes phonic play is potentially vulnerable to 1 t.

Another equally overt indication of the chora's assauit on comunicative meaning ie Kipling': typographical use of italice. Italice emphadize the one line truly shared by the firet thres sanzas -- "Brothere thy tall hanag down behind!" -- and the final disjunctive stanza. Each of these uses emphasizes one aspect of semiotic incursion already discussed here; the first repetitiun, almost a trademark of the aemiotic, and the other the dramatic change in sound value occasioned by an undermining of the rhythmic and rhyming patterne of the earlier etanzas.

The other use of italice in "Road-Song" is more intriguing; "-e --" which ends the fifth line of the poem is italicized. It gerves a double function, acting as a parenthetical, demonstrative adjective, a gesture that points at once outside of the poem to an imagined concrete object and inside the poem to the description in the next Iine, the very description wh.ch, by interrupting the flow of the language, it delays. "-- e0 --" giver the description through gestural language and prevents, momentarily, the relaying of such a description linguistically. The technique, itself a gesture, is both futile and full, potent. The word simultaneously resonates with the rhyming pattern it supports to the detriment of the aymboljc, and underlines the communicative and referential aspect of language. Similarly it offers both caesura and a partial stop for the end of a line which would, $c$. rwise, continue on into enjambement; the pause is inflicted, not natu. ... "-- 10 -.." in thie context is a highly Nonsensical word, an interface between semiotic and ymbolic, nerving the needs of both at the same $t$ ime. 
One aspect of the poem remains to be consldered; ita tendency to deflect epeech, to leave thinge unstated, to . . " never mind." The technique, repeated by kipling in the first three etanzas, does more than add to the characterization of the Bandar-log though by emphaeizing their shiftlessness and their lac: of etaying power it does do that. It raises the problem of nonsensical speaking, of things being said and unsaid simultaneously. Given the strength of the rhyme pattern, one is tempted either to view this "coyness" as being arbitrarily conceived in order to suit the phonic structure of the poem, or to substitute other rhyming and rhythmic possibilities, to seek out the words which may 1 ie behind the deflections. If the former ie true and Kipling chooese to aquash the communicative function of language merely to play to the more material qualities of language, then the poem is surely an example of the privileging of sound as another sort of sense.

Kipling's poem animates in several ways the rule of the semiotic; not only in its use of rhyme, rhythm and sound play, in its use of italice and deflected speech, but also in its establishing and destroying of orders, the poem's language demonstrates the bandarlogical eruptions which it attempts to describe. 
is one reault of the body dwelling in language, of the rhythmo and "orders" of the peychological body disturbing sense-making etructures. For many writers the body is a point from which to defy logical or patriarchal eenee, and so gesture towards noneense through a sensual intimacy and eroticiem. Part of this intimacy is directly located in the senses, in how they make "sense" of the world (the othere) around them, in how they make language. For language is, like perception, based on the severing and reconstructing of what is, on the reorganizing and crystallizing of the fluid dynamic between the body and its surroundings. Such language, sensual, physiological, is a common ground on which nonsense and poetic language meet.

This ground is also shared with other "languages," most noticeably the language of schizophrenia or madness. Some of what follows is a dialogue with Gilles Deleuze, one of France's foremost philosophers and thinkers about Nonsense and "schizoid" language. As chapter one indicated, Deleuze and I approach nonsense from vastly different perspectives, and with the intention of doing vastly different things with it. He contends that there is no common, co-habitable ground between bodily nonsense and Nonsense, that gorges too deep to crose separate the two. Such a view does not accept the potentially unifyino powers of the body; the nonsensical body and its primal energies, in my underetanding of them, provide a zone of flux, of communion and community -- the fluid intermingling of organic systems ("animate" and "inanimate"), of epecies, of individuals and of nonsenses.

"Shoots and Branches": Nongenge' a Grotesque Body

The Old Man's bird-housing beard; the famous curlicue nose; the pin-pointed, harp-plucking chin; that Young Lady' w-i-d-e- eyed stare: Lear's limericks and his illustrations for them are rife with phyoical deformity. Such bizarre representations of human physiology can't be 
put down just to dissatiefaction with his own ungainly appearance, though one might argue it is related to Lear's epilepey and to the diatortions of seizure. And it is not merely a case of "them againat mo," a way of singling out the eccentric, the marginal, for social abuse -- though clearly physical deformity often is the butt of such abuse. Looking to another of Lear' forays into phyelcal science, his Noneense Botaries (see, for example, Fig. 2 in chaptex one, or Figs. 3 and 4 in this chapter), proves helpful. The ridiculous deformations that result from his parodic Latiniems and literalisme aren't quite so far off the "real" world as might be assumed; "Tigerlillia Terribilis" (see Fig. 3) does look familiarly like a tiger-lily, albeit a terrible one with jte petals -- plush and purring carnivores. And "Bluebottlia Buzztilentia" (see Fig. 4) is just a few steps for the imagination beyond a bluebell. These are living flowers which exceed even the Inhabitants of Carroll's Looking-Glase garden, but their elements are part of Lear's world inu our own.

These excesses are the source of perhaps the least painful laughter lear offers. But they are also indicators of the world of shifting boundaries which characterizes many of his limericks. The worlds of animal and plant, insect and plant, object and plant, mingle. In chapter one these botanies helped lllustrate the nonsensical result of Ilteraliom, of taking things at their word, by pushing aside the curtain separating words and things. In this chapter a different curtain is pushed aside to reveal not the lively but limited prospect of literaliem but rather a different orientation to, and within, the world.

For that is really the "crime" of the old Man with the nose (Fig.5): not fust having a big nose, but hav'.ng nose so big it demands of ite viewers a elightly different underetancing of the world, and of the place the body makes for itself in the world. No matter what the old Man may say, his nose is extremely large. So large, in fact, that by ignoring it, one riske tripping over it. This is a fine example of the 

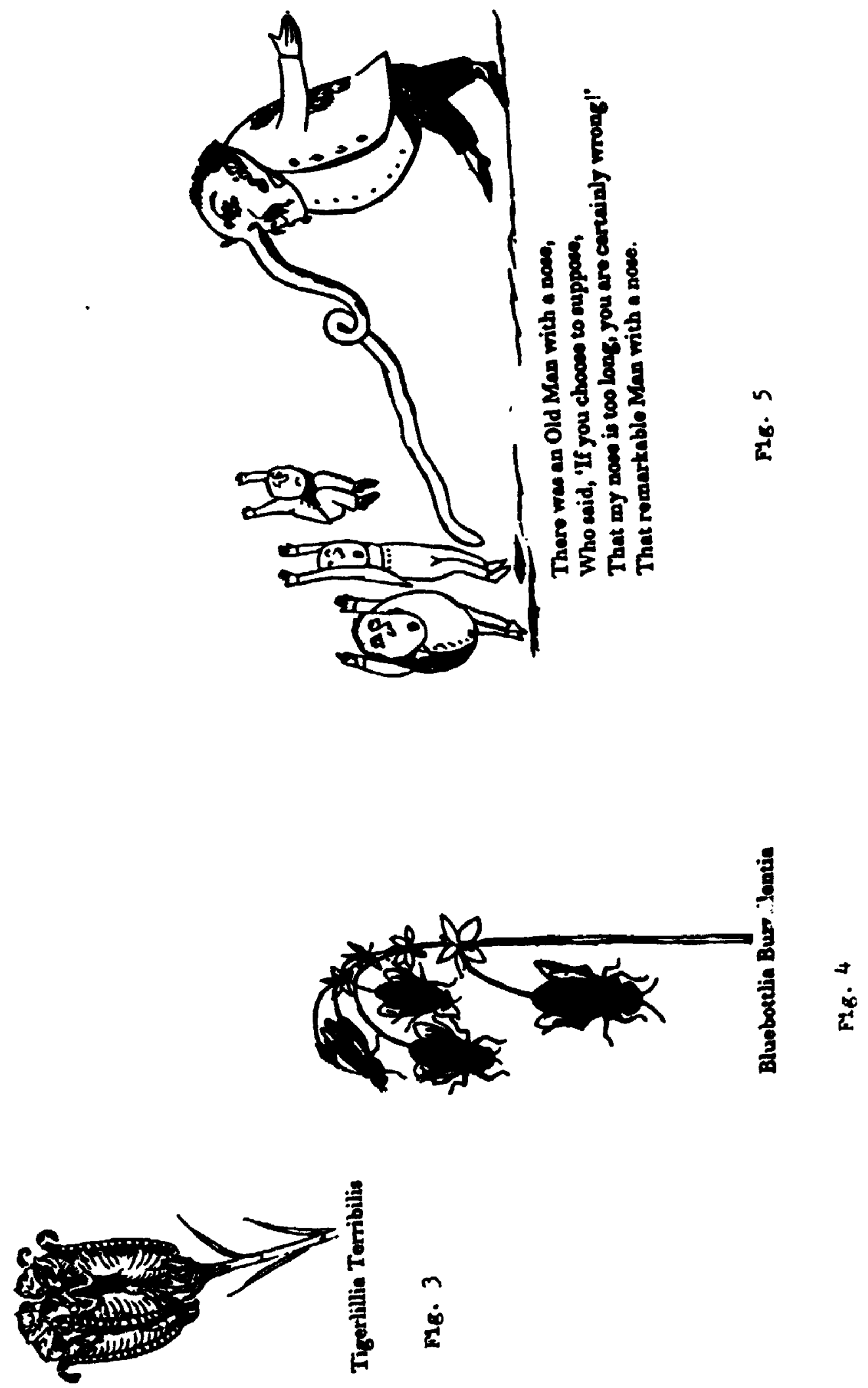
nonseneical body, which metaphorically challenges the spatial limitations of the body in the world, and literally questions the relationship between the physical "self" and the world, in much the wame way as the paychical body of nonsence challenges the location of the "eelf" in language. The noneeneical body etretches out into the world beyond and, by doing so, entere into a relationship with the world rominiecent of that found in the Rabelaisian carnival.

Katerina Clark and Michael Holquist credit Bakhtin with articulating a "eemantice of the body" (299) in Babelais and His World. It 1. playful and scatological semantics which relies heavily on the ambiguous nature of excrement and genitals, and seems quite unlike the writing found in Lear's work. But Bakhtin's semantics are not merely bawdy, and they can take a reader to Lear:

The grotesque. . . is looking for that which protrudes from the body, all that seeks to go out beyond the body's confines. Special attention is given to the shoots and branches, to all that prolongs the body and links it to bodies or the world outeide. . . The grotesque body... 1. a body in the act of becoming. . . . This is why the essential role belonge to those parte of the grotesque body In which it outgrowe ite own self, transgreseing its own body, in which it conceives a new, second body: the bowels and the phallue (316-17; emphasis is mine).

"That which protrudes." step back from the new body spawned by Rabelale' out-sized bowels and phallug' and one gets the old Man's overgrown nose, a phallus in its own metaphorical right. Even if one doesn't read Into thie appendage popular exusl innuendo, it is atill a dowerticated version of Bakhtin'. "unfinished and open body" (26). What

\footnotetext{
'Bakhtin, writing well before Lacan, clearly does not intend his use of "phallus" to have the meaning which the type of psychoanalytic readings frequently cited in this thesis would suggest. The term is retained, however, because of its important saturnalian connotations.
} 
Bakhtin says of the belfry with an impregnating shadow in Rabelais can be said as well of Lear's Old Man's nose, and of the nonsensical body generally: "The object tranegresses lts own confines, ceases to be itself. The limita between the body and the world are erased, leading to the fusion of the one with the other and with surrounding objects" (310). Such fualon is also seen in Lear's many illuetrations which show a person taking on the appearance of, merging with, the world around him or her (see Figs. 6, 7, 8).

As those limits are transgressed, so language is transgressed. The body which exceeds itself, visually, thematically, in Lear's limericks, is the ame body which exerts itself phonically, rhythmically, playfully in the linguistic subversion of his Nonsense. It' the genotext overstepping the bounds of the thetic, taking hold of the symolic' nose and tugging it out of shape.

The language of Alice' Adventureg in Wonderland seems less phonically, bodily playful, but it is, as Gilles Deleuze points out in The Loaic of sense, no less a language related to the body in a state of becoming:

When I say "Allce becomes larger," I mean that she becomes larger than she was. By the same token, however, she becomes smaller than the is now. Certainly, she is not bigger and smaller at the same time. She is larger now; she was smaller before. But it is at the same moment that one becomes larger than one was and amaller than one becomes. This is the simultaneity of a becoming whose characteristic is to elude the present. . . It pertaine to the essence of becoming to move and to pull in both directions at once: Alice does not grow without shrinking, and vice versa (1).

This "paradox of thie pure becoming" (2) carries over into the language of revereal, of pull in two directions, which marke all of alice's 
Fig. 6
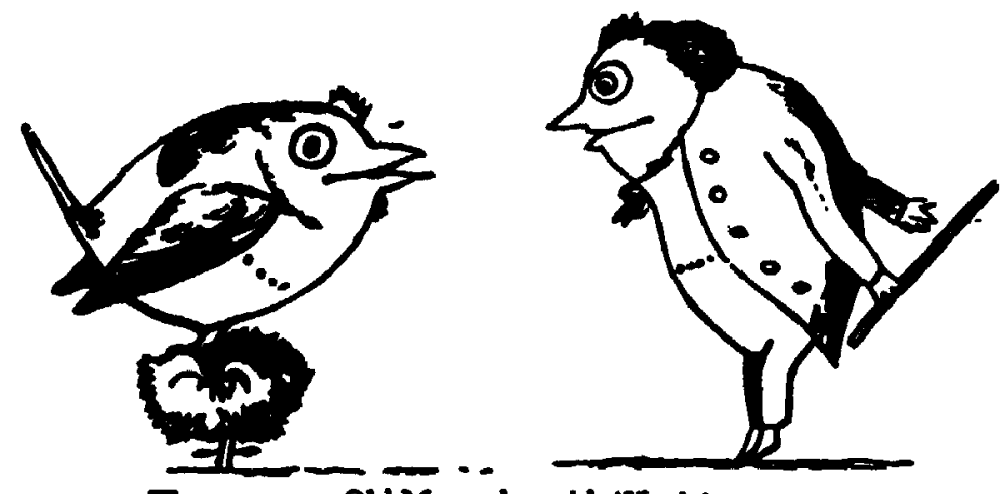

There we en Old Men who said, 'Hush!

I parcaive a young bird in this bush!'

Whos tboy raid-'Is it small? He replied-'Not at all!

It is four times as big as tho bush!"

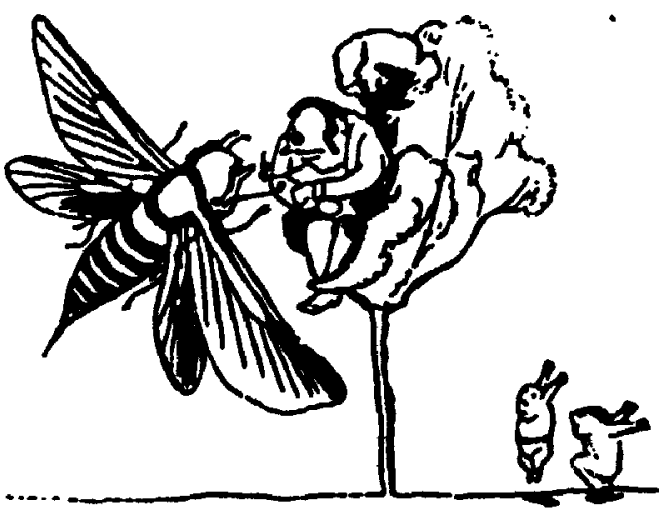

P16. $?$

There wes an Old Man in a tren,

Who wes borribly borod by a Bee;

When they cuid, 'Dowes it burn? be roplied, 'Yes, it dom!'

'It's a regular brute of a Beol'

12. 8

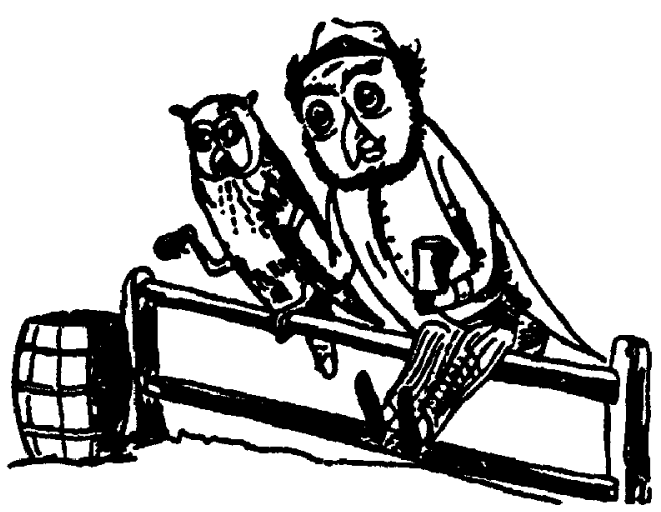

Thers was an Old Men with an owl, Who continued to bother and bowl;

He cute on a rail, and imbibed bitter ale,

Which refrubed that Old Mns and his owl. 
adventures (3): "Why, you might juet as well say that 'I see what I eat' 1. the same thing as 'I eat what I see' I" (AN 76): "jam tomorrow and fan yesterday -- but never jam to-daY" (TLG 197).

Even before she encountere the lingulstic upheaval which plagues her, Alice muet confront her uncontrollable body, this "becoming" body (becoming larger, becoming smaller), not language, is the initial Interface between herself and Wonderland. Physical fluctuations mediate between her own limited aseumptions and seemingly incomprehensible environment. Her elongated neck, her far-away feet: these require of Alice, as much as of the inhabitants of Wonderland, a shift in vilion to accomodate her "renowing" self. And it is this aspect of Alice's body that serves my purposes best now.

There is something comic and carnivalesque about Alice's contracting and expanding body, and it blends with Wonderland. It if most Bakhtinian in its role as conduit, as a point of intersection: The events of the grutesque sphere are alwaye developed on the boundary dividing one body from the other and, as it were, at their points of intersection. One body offers its death, the other its birth, but they are merged in a twobodied image (322).

Such intersection is genital and excremental, related to the lower stratum of the body whose gymboligm Bakhtun tries to exonerate from what he considers a simplistic and prudish rejection of good "clean" debasement. But the genital regions are not the only regions which interact with, and affect, the world.

The senses (perception) and skin (the surface which mediates between insides and outside) may also be construed as points of intereection. For it is through and at them that the body meets the world, transmits the world around it, or is altered by that world. How the nonsensical body and such points of intersection may be rendered in language will be considered next. 
Boplesing the sennes:

The Porriblitity of a Perceptually-based Lanousas

In one way or another poetry has alwaye played with the senees. Ite roote in wusic, which will figure in the next chapter, atteet to ito Intlmacy with hearing. And imagery has alwaye appealed to the eyee of both mind and body. When, however, poetlc langunge eeke to be what Daphne Merlatt calle a "direct tranemiesion" (Bowering 66), rather than - tranelation, of the sences' perception, it rieke noneenes. An odd twiat alnce, as Rieke notes,

Senes begine with phyolology, the body as it takes in data with the five anses. These sensations translate into mental phenowena, perceptione as underetanding. our epoken and written language then transmit the maning or gense that is supposediy in our hade (6).

Why then should an attempt at an "unmodiated" linguletic experience of the censes result in nonsense?

Because by breaching mediation, the eenses are breaching a vereion of the thetic, joining with the semiotic's revolt against the symbolic impoition of order. The purpose of the thetic, as the last chapter demonstrated, is to mediate between, to separate, the semiotle and the aymbolic. The thetlc may be seen to otand as a similar point of purported impase between the actual physical experience of the body and the world, on the one hand, and the linguietic embodiment of that experience, on the other. The key term in Rieke's explanation is "translate." The thetic is the point at which sensual perception le recognized as forelgn, as garbled, and where an atteapt to aplit the body from tte dynamic communion with the world is made, where verbel relations are translated lnto a language doened eensical by the eymbolic, tidied up before boing articulated. 
It is not merely, as Andre Breton belleved, that the censes could, if allowed, "lead" to "a wider horizon (than ill) available even to the conecioue mind" (sheringham 73), though clearly the way that Breton engaged the censee in his poetry produced sone very nonseneical work. For, while surrealists try to "dopayeer la sensation," to "delocallea" the sences, as sheringham translates it $(74)$, in order to leap right over rationality and into the unconscious, noneensical writere approach language by retrieving the eensed from rationality (rather than removing rationality from the senees). That is: it is rationality which, by winnowing out the perceptions of the senses, by translating their effects into organizable phenomena, actually dislocates, delocalises them. Theoretically at least, surrealiam, like rationality, takes the senses to a further remove from their source in the world, although these removes are quite remote from each other.

The problem is not so much how to dieplace the senses as how to replace them, how to keep them at the edge, "the cutting edge" of humanity and the world (0lson, "Human Universe" 62), while in language. And how to do this in a way which produces an actual perceptually-based language, rather than a mimetic version of such a language. Not all of the writers considered in this chapter succeed in their attempts to create this language, as not all are successful in their efforts to write the body. In fact, I regard the phrase "the body in language" ar figurative spech; a truly phyeical language is gestural, not verbal. The body in language is, for me, most closely realized in the semiotic in Rrieteva's model of poetic language discussed earlier. This is a paychical, not a phyaical, body.

A perceptually-based language, however, does not attempt to write the body, but rather to allow the least possible amount of interference (Ideally no interference, though such is literally impossible) in the transmiseion of the senses to words. This would require an attunednaes not to the body and ite rhythma, though paychically they may influence 
the shape of the language, but rather to the actual experience of perception. Often the point at which the theory and practice of writing from the censee differ is this point of attention; when there is another "agenda," one to privilege the body for inotance, the etatue of perception lo leseened and perceptual language may be lost to the sonesious mimesis of an unconscious experience.

\section{Lintening to the lifteninge of the body: The nonsense of percention}

A poet greatly concerned with creating a language of umimpeded sencea, and one who had a meavure of succese in doing so, was charles

olson. In "Human Universe" he inaiste, What makes most acts -- of living and of writing -unsatiefactory, is that the person and/or the writer ap .efy themeelves that they can only make a form (what they eay or do, or a etory, a poem, whatever) by selecting from the full content some tace of 1t, or plane, some part. And at fust this point, by just this act, they fall back on the dodges of discourse, and immediately, they lose me, I am no longer engaged, this is not what I know is the going-on (and of which going-on $I$, as well as they, want some lllumination, and so, some pleasure). It comes out a demonstration, a eoparating out, an act of claselfication, and so, a otopping, and all that I know is, it is not there, it has turned false (55).

Olson's answer to the problem of writing a perceptually - and physicallybaned language is the poem of body and breath.

With the other Black Mountain poets, he sought an "Open" form or "projective verse" that constituted an opening up of the poet to the eurrounding world, a lese active engagement of the selective procese which weeds through, or shapes, the world and exalts the human over the 
non-human. The distinction, as olson makes it, is mbetween language ae the act of the inetant and language as the act of thought about the instant" (54). His prose manifeato "Projective Veree" hollere that "alwaye one parception munt must must MOVE, INSTANTER, ON ANOTHERI" (17); he "(puts) it baldly" down to the physiology of the poet -"the HEAD, by way of the EAR, to the SYLLABLE the HENRT, by way of the BREATH, to the LINE" (19).

The best, most kinetic or energetic poetry, he suggesta, comes out of a listening to the workings, the listeninge, of the body, out of a transilteration of those listeninge.

Louis Zukofeky's solution is different from olson's; his language, which Rieke calls a "dance of the senses" (149), results from synaesthesia, the joining of senses to produce a tangible language. synaesthesia could result from crossing any two senses, though (as zukofoky goes on to say),

Let's say you start with a body, the way a kid does when it's born, and it cries almost immediately. It takes a long time for its eyes to focus, a month I suppose. But anyway, the eye concerne the poet; the ear concerne the poet because he hears noises, and like the kid he's affected. And you can do all sorts of things with the noises. You can imitate natural things, and so forth. I like to keep the noises as close to the body as possible, so that (I don't know how you'd express it mathematically) the eye is a function of the ear and the ear of the eye; maybe with that you might feel a sense of smell, of taste even. So much of the word 1. a phyolological thing. . . that its articulation, ae againgt that of other words, will make an "object" ("[sincerity and Objectification]" 267).

Like the language sought through 0lson's poetics, this is a language which resista translation, but does so in a very specific 
manner. Rather than opening up lines of communication and feeling between peychical, mental and physical realms as olson seeks to do ("the HEND, by way of the EAR"), Zukofsky conflates sentical experience, "describes" one sense in terms of another. He does not remove the experience of sight, for instance, to the realm of simile, instead he displaces it to the realm of wound. What "translation" does occur, does so within a wider range of senses and physical response. ${ }^{2}$ Peter Quartermain saye zukofaky' "Text is a movement of languages, of a number of frames of reference, held in the language of the poem amultaneously, at once. And it is a felt world" (223). Feeling, the felt, the perceived, the sensed, underlie sense and may be, in zukofaky' view, "the most important part of the whole definition of the word genge" (Rieke 141).

But the "felt world" of his poems is not a linearly sensical one. "I's (Pronounced Eres)" (Bee Appendix $V$ for the text of the poem), is one of zukofaky's more accessible poems and an example of the seen world transmitted by the ear, the joyful music of the eye, where synaesthesia waylaye concrete sense. In the poem's title, zukofsky has already anticipated the movement of its language; revolving around the "In of the poet, the title initiates the auditory pun which energizes the entire poew. For "I" can be read/heard as "eye"; sight is the most precious sense for the poet, to Zukofsky's mind ("lsincerity and Objectification]" 267). From the very outset of the poem, the auditory "pronounced" has pernitted a metamorphosis between "I'sand "eyes," has established the poen 38 a place where sight has a direct link to the ear.

As the poem begins, zukofsky names, re-names, his form; haiku, the

'Zukofsky's technique is strongly related to a principle of nonsense which will be discussed later in this chapter, and in chapter four; that is, nonsense superimposes one sign system upon another, one way of meaning, or in this case, perceiving, upon another, and so creates a palimpsest. Alternative sign systems are conflated in order to generate several types of meaning and to expose, simultaneously, the artificial structures of such meaning. 
delicate poem of the eye, born of the visual intensity of an image glistening in the moment of perception, is lent to the ear: "HI, Kuh." If zukofsky': poem stretches the 1 imits of its form guite radically, so too does his "auditory translation," his homonymic play, undo the literary and critical respect usually given the haiku and animate the subversive potential of his poetic; "Hi, Kuh" is also, as Rieke notes, a greeting to a cow -- "'Kuh' is German for cow" (126).

The route between eye and ear is kept open throughout the poem as each sight is shaped by sound, as the entire landecape of the poem is musicalized. zukofsky uses metalepsis to draw an auditory picture of the sea, its foam shifting phonically as well as visually as it "claws" and "cloys" its way up the sand. The "ah" of the first vowel closes over as the water becomer, "close," closer to the seer. Close sounds for the seeing ear; each push of water just frsctionally, phonemically. nearer the hearing eye. And the flashing ingtar:t of "AzURE," the colour of "A SEA" ("A B C"), falls into a linguistic lapping, a sounding of ebb and flow -- "as ever/ adz aver" -- as 'er, always, the water and the senses do: the rushing and receding of perception, the tidal pull of a becoming body. Because of the sensual engagement of hid language, the music of this and other zukofsky poems puts pressure on sense, orchestrates it. Sense becomes a roving and twisting dancer, no longer stable and stolid.

Zukofsky seems to privilege the senses of sigit and hearing. But others also work themselves into language. Luce Irigaray argues for a "womanspeech" which is tactile; her erotics of a woman's language consentrates on touch: "For in what she says, too, at least whon she dares, woman is constantly touching herself" (This Sex which Is Not one 29). Such touching circles back not only to Bakhtin's carnival of 
genitale, in an admittedly more onlightened way, ${ }^{3}$ but also to Alice's

shifting body. For touch almost inevitably involves the akin, what Olcon calla "the meeting edge of man and external reality . . where all that matter does happen" ("Human Univeree" 60), and the place where, Deleuze argues, Carroll worke out all hie noneenee, in a language of the surface, through the logle of senee (93).

Skin. Deep;

The longense of the surface, and Beneath

olson and Deleuze use the term "skin" and underetand the relationehip between akin and language in different ways, but both equate it with a conscious-bound eurfece. For oleon, akin is a physical thing, the tiseue which mediatee between the world and the body; for Deleuze it 18 a peychical construct as well as a physical reality. Yet for both, mere okin is not a satisfactory place for energized language to dwe11. It is, they would contend, too rooted in sense, in surface organization, to be a forum for anything but a very negligible form of nonsense or aubveraion.

In "Proprioception," an "essay" which modifies his earlier views, Olson locates two surfacess the physiological surface, "(senese -- the 'Bkin': of 'Human Univeree') the body itself -- proper -- one's own 'corpus"', and the peychological surface, "the surface: consciousness as

\footnotetext{
${ }^{3}$ It's important to note the limitations of Bakhtin's carnival of genitalia. He makes a concerted effort to justify what has Jong been considered Rabelais' hostility toward women by tying her debasement to the cycle of birth, by making her a symbolically regenerative and walking womb (240). Yet he fails, as Wayne Booth points out in "Freedom of Interpretation," to prove that women are in any way liberated by this spirit of carnival, by the laughter directed at, and through, them. Irigaray also, it might be argued, offers a carnival of gentalia and, like so many other theorists (Kristeva included -- see Revolution 223-5), seeks through laughter an initial form of liberation (This Sex 163). Her carnivalesque appeal for a re-vivification of woman's "lower stratum," of her countless erogenous zones also suffers from a biologically- and essentialist-based appeal, and so participates, in a lesser way, in Bakhtin's own errors. But at least Irigaray's argument does, ironically enough, provide a scathing critique of the patriarchal thought which initially established the limiting dichotomies it at once adheres to and tries to dismantle.
} 
ego and thus no flow because the 'senses' of same are all that sd contact area is valuable for, to report in to central" (1). Since olwon urgently demande that poetry get "rid of the lyrical interference of the ego" ("Projective Verse" 24), it comes as no surprise that he writes so condescendingly of the paychological surface, of the consclous ego. But this newer, fragmented, chart-like eseay, scems to turn ae well from the akin he has earlier cited as an essential location for the poetic act.

"Proprioception" is "the cavity of the body," home to the viscera, location of "the old 'psychology' of feeling, the heart; of deaire, the liver; of eympathy, the "bowels'; of courage -- kidney etc -- gall" (1). And it is to this place, this viscera, that olson wants experience brought:

The advantage is to 'place' the thing, instead of it wallowing around sort of outside, in the universe, like, when the experience of it is interoceptive: it is inside us/ at the same time does not feel literally identical with our own physical or mortal self (1). Proprioception is the knowledge of the body's depth; "the 'body' itdelf as, by movement of its own tissues, giving the data of, depth" (2). And if this depth of the body, this inner movement, is the place of poetry, of poetic energy, it seems that skin no longer is where what matters happene.

What, I think, olson desires in "Proprioception" is not the flaying of the skin, but a swallowing of it, a meeting of inner and outer. Skin is still where what matters happens, where the world and the individual meet; but the body's cavity is where the "skin" needs to be "processed." The skin, as a surface, must not be a barrier between the world and the body, but rather a conduit for their interchange. It must be folded into the gut of the poet, into an absolutely phyeical vision, in a motion the reverse of that advocated in his earlier poetic manifesto. Now it is the ear, by way of the head, to the ayllable; the 
breath, by way of the heart, to the line. Here is another incarnation of Bakhtin's qrotesque body in which the "outward and inward features are often merged into one" (318). More important, here olson gives his poetic alightly different angle, a more kristevan and a more radically noneeneical one.

For what Olson describes is -- oddly enough for a man who rejecte the Freudian notion of the unconscious -- a heightened intensity in the breaching of the thetic he has already implicitly called for in "Projective Verse." In this case the phyalology of the body, the organe aymbolic of deaires and emotions, rather than pulsions and drives in which prychoanalysis seats them, embody an unconscious which he defines as "the body itself," "the universe flowing-in, inside" (2). Rather than the semiotic leaping into the symbolic, however, the eymbolic is pulled ineide, into the semiotic womb. Language inhabits the body, the body language. Of course, in Kristeva's diagramming of the process of poetic language, an accomplished return to the womb is imposeible: the cemiotic has no stable shape in which to house consciousnese because the chers is an indeterminate, even hypothetical construct; and the unconscious requires the conscious to articulate it, so a smothering of the conscious in the unconscious would result in an almost inarticulable mace of language quite unlike anything olson ever produced. Nevertheless, olson moves closer to articulating the inextricable link between language, nonsense and the body.

Deleuze' opposition between body and skin, or surface, is not so easily reconciled; since it challenges the sort of relation I argue for between the body and nonsense language, and the potential endorsement of such relationship found in Olson's writing, this opposition is worth considering in some detail.

The inarticulable, indistinguishable mase of language which would result from atrict experience of 0lson's new poetic is reminiecent of what Deleuze refers to as "schizoid," the language of the broken body, 
of the diseolved surface, language which he describes in this way: when the surface is rent by explosions and by snage, bodies fall back again into their depth; everything falla back again into the anonymous puleation wherein words are no longer anything but affections of the body -- everything fall: back into the primary order which grumbles beneath the secondary organization of senee (125).

As the first chapter of this study demonstrated, Deleuze opposes the type of nonsense which is characteristic of this schizold language with surface nonsense. The latter is the type of nonsense he claims Lewis Carroll writes, and it is intimately related to, "co-present" with, sense (68). This co-presence is not unlike the symbiotic union integral to nonsense. Indeed, Deleuze argues that this type of noneence is essential for the production of sense.

Sense, as he sees it, is part of the "skin" of things, "not lecalized at the surface, but . . rather bound to it formation and reformation" (104). Sense is the result of a process of infinite regress because of "my impotence to state the sense of what I say, to say at the same time something and its meaning" (29). In other worda, one can't say "I'd like to fry that cat" and simultaneously explain just what "to fry" is, and what a "cat" is, and which cat "that" cat is, and how a cat could be fried. So the sense of that sentence exists at a remove, in the sentence or phrase which explains it. His is a type of relational sense which grows, perhaps obliquely, out of saussurean linguistics, in which sense (the sense of each word) is paradigmatically and syntagmatically relational.

But nonsense, the nonsense word and what Deleuze names the "esoteric" word ("it," "that" etc.), "says its own sense", "[it] is a word that denotes exactly what it expresses and expresses what it denotes" (67). Deleuze's brand of nonsense adds a dash of entropy to the regress of sense because it doesn't accomodate explanation; how, 
Deleuze wondere, does one explain what a "snark" is (67). For, to adapt Gertrude stein, a onark is a enark is a snark. In the word lies the thing. It only clear meaning ie linguigtic, its definition is contingent upon 1te paradigmatic relations, unlese carroll' " "anawer" to the whole mysterlous funting is used as a way to get out of this mess: "For the snark was a Boojum, you see." But, an Deleuze implies (66), "Boojum" is as problematic a word as "Snark". For a boojum is a boojum is a boojum, you see.

And it is just this momentary pause in regress, this point of temporary stasie where the word is the thing, which "donates" to sense some eignification (69), which grounds sense. Deleuze argues that, within any given series of signification, a term "has sense only by virtue of its: sition relative to every other term" (70). Such a position involves both its placement and function in a sentence, and ita ayatemic relationships with these other terms. However, this relative position itself depends on the absolute position of each term relative to the instancexx (that is, the self-defining word]. The latter is determined as nonsense and circulates endlessly throughout the series. sense is actually produced by this circulation as sense which affect: both the oignifier and the aignified. In short, sense is always an effect $(70)$.

Deleuze hastens to add that this effect "is.. - an effect in the sense of an 'optical effect' or a 'sound effect,' or, even better, a surface effect, a position effect, and a language effect" (70), which is part and partel of its cause. Nonsense at one and the same time breake and etrengthens the chain of sense; its challenge to sensical deferral merely provides the pivot upon which that deferral may more succesefuliy, meaningfully, turn. Lecercle, following Deleuze, explaine it this way:

Nonsence is a meaning-preserving activity: its implicit goal 
is to save meaning by maintaining the correspondence between -ignifier and aignified which communication requires. Nonsense may fiddle with the upholetery buttone, but only to check that they are sewn on firmly and in their proper places $(140)$.

Lecercle's reading of Deleuze condemne Nonsense; not only does he diemies many important facets of Nonsense, but he also diemieses eeveral Nonsense works from the canon. Many of Lear' Iimericks, for instance, are lmplicitly banished -- not urprisingly, perhaps, eince Lecercle mentione Lear only once, and briefly at that, in his book. Also one can detect a tendency to ignore the many other ways in which nonsense exert: Itself linguistically, its points of communion with poetic language.

Deleuze is right in his assertion of the co-presence of sense and nonsense, and in his attribution to nossense of an active role in the manufacture and deferral of sense and meaning. But the "effect" which he claims for nonsense, that of offering a moment stability to sense, isn't any more important than other "effects" of nonsense, such as its exposure of how meaning works. He spaks often of the paradox of sense and nonsense, and it is indeed paradoxical that the nonsense word which grounds sense also reveals, as stewart argues so deftly, the whole process of sense-making. However, by revealing it, the nonsense word opens this procese up to a critical probing which Deleuze does not acknowledge.

Nonsense helpe expose the very procese which it supports; and that fact surely suggeste that nonsense (and Nonsense, as chapter two argued) 1. much more than a meaning-preserving activity. Monsense simultaneously "stabilizes" (in Deleuze's rendering of it) and questions meaning, perhaps stabilizes meaning precisely to question it. This is not exactly a "preservation." Nonsense actively cute open, cut. through, the illusion of a stable and Meaningful Language, which it creates. 
Deleuze borrowe an image of cutting from Emile Bróhier'. explanation of how the stoics used the act of cutting as one paradigm to demonetrate two very different levele of being, and employs it to an end quite different from my uce of the image above. He quotes Brehier in The logic of senes, and equates this stoic paradigm with his own levele or types of nonsense:

when the ecalpel cuts through the fleah, the first body [the knife) produces upon the second [the flesh] not a new property but a now attribute, that of being cut. The Attribute does not designate any real guality .... it is, to the contraxy, alwaye expreseed by the verb, which meane that it is not a being, but a way of being (quoted in Deleuze 5 ). A way of being, then, is part of the "plane of facts, which frolic on the surface of being, and constitute an endless multiplicity of incorporeal beinge"; it is not part of "profound being, "of "force" (quoted in Deleuze 5 ). It is not corporeal.

As chapter one indicated, Deleuze argues that a new form of causality has been posited by the stoics, one that separates cause from -ffect, groups causes together and effects together, and even allows a certain unity among causes, a unity among effects. It is a dualiam which ultimately "refers ... back to language, either to the existence of a declension of causes or, as we shall see, to the existence of a coniugation of effects" (6).

Incorporeal as this surface language may be, it is nonethelese fragile. A large enough crevice will force the collapse of the surface, allow "a terrible primordial order" (82) to rush over and "coneume" the "eecondary organization" of sense $(82)$. The questions which I see Monsence (and nonsense) as asking, then, ares how deep a cut? how large - crevice can the eurface sustain before it dissolves? is there a path between incorporeal and corporeal, a link between attribute and quallty? is there a point at which the eleavage batween cause and effect is 
soldered? Because the surface is fragile, and ite senee is conetructed upon a hesitant amalgam, a delicate partnership of opposition which works only in, according to Deleuze, nonsense's not working. Is the breaking down of that sense, the frustated exaggeration of its hesitancy a way of altering the opposition between surface and depth?

These questione, of course, are ones which Deleuze absolutely would not ank, and rhetorically imply conclusions which are not viable within his underatanding of Nonsenee. But I wonder to what degree, to what level of inteneity, nonsence may stop the flow of sense, may "mean" iteelf, and etill preserve maning. For providing its own sense ien't merely the provision of its own syntactical and signifying relationship; there are other waye that nonsense can mean, that it can be a selfdefining object. Nonsense can mean visually (as do Lear' limericka, whose sense is significantly altered by the accompanying illustrations) and musically (as the next chapter will demonstrate).

Nonsense functions, I am suggesting, as the articulation or traneliteration of a different eign gyetem within a verbal one. Such a suggestion extends Deleuze's ideas about portmanteau words, discussed in chapter one, to a larger ecale. Nonsense, like the nonsensical portmanteau word which acts as an intersection point for two linguistic series, is created by the merger of two, three, four, possibly more, separate sign systems. Not the merger of codes or languages -- of literary and legal language, of French and English, of male and female, or any other sub-category of a verbal system -- but the blending of different waye of meaning: musically, linguietically, visually, phyoically, the one transliterated into another.

The metaphor of transiteration is not an entirely stable one, and a little misleading, for it suggests that these other ways of meaning are languages and that they somehow displace or take the place of the firat. While such syatems may be analogous to language, they are not Exuly languages: the unconscious may be etructured like a language, but 
It is not definable as one. Neither are muele, the viaual arte, or the body -- despite their unefulnese as forms of communication and one' readineee to tranelate them Into, and explain them through, language. It is thie fact which makes nonsence so radical, and so subvereive; it containe within one eyatem elemente of another (an Othar).

Each syotem or way of maning is euspended in a state of partial alienation: mueic that has adopted the terms of a verbal alphabet but not given itself over to the meaninge of wholly composed worde; worde that have moved towarde articulating the body without relinquishing their own meane of articulation. The result is the excess of eense(e), the etretching of meaning, epoken of in shepter one. Nonsense does far more than stabilize conse, it pluralizes sense, leaving no one sence, or way of ectablishing senee, stable. It finds aystems of meaning layered upon other, alternative systems of meaning, surfaces beneath surfaces, and wo finds surfaces to be, at times, depths, interiors. The implicit hierarchy in Deleuze' theory is queetioned when various aystems of meaning merge, when the verbel surface of sense diesolves into another seneical "surface," and one mode of being breaches the "boundary" soparating it from another mode of being.

Such a view ultimately questions Deleuze's claim about the separateness of the "body of language," its forme and functions, and the "language of the body," that schizold articulation which finds its highest and lowest point in Artaud. And, as was noted in chapter one, such a view attempte to reconcile theme oppositions, seeks a resolution which Deleuze himserf would find lacking, based as it is in an offehoot of Iroudian theory. While his firm differentiation between the types of noneanse is not mine -- I argue for a connection which is not tenable within his paradigm -- Deleuze's elaboration of these poles of body and surface help temporarily to localize som of the many, secaingly dieparate, movements of nonsense.

Even though the tactice and techniques of schizophrenic language 
are shared by Nonsenee, Deleuze severe it from Nonsense, which he insiets is a product of the surface. Rather than clessicel Nonsense, he finde in schiroid language two other types of nonsense, eeparate fxom that which is co-present with sense. These types, which "have nothing to do with" surface nonsense (91), are passive and active: the nonsense of the word devoid of sense, which is decomposed into phonetic elemente, and the nonsense of tonic elements, which form a word incapable of being decomposed and no less devold of senee. Here everything happons, acte and is acted upon, beneath senee and far from the surface. Sub-sense, a-sesee, Untereinn -this must be distinguished from the nonsense of the surface (90).

The means for determining the poles of nonsense is the presence or absence of sense; surface nonsense is absolutely not devoid of eense (71). schizophrenic nonsense is. And it is devoid as well of grammar, of syntax, and, at its most extreme, of articulation. But being ungrammatical, asyntactical and inarticulable doesn't free a language from the burden of sense. There is always the possibility of affective meaning which was noted in chapter one. Schizophrenic nonsense may, as Deleuze implies, entertain the possiblity of a "word" which Nonsense never would, may offer syntactical units composed of seemingly imposeible arrangements of letters; but it cannot escape a limited form of sense as long as it is relayed in a senseproducing medium. Types of nonsense which share the same alphabet, the same fundamental eign system, are not so utterly eeparate." They exist at different points on the same trajectory. Implicit in the notion that a shared alphabet indicates a potential for a shared method of sense-

- One needs to consider, too, the linguistic versus the alphabetic ground, a traneliteration of the words of one language into the alphabet of another can result in seeming nonsense though the words, when pronounced, would have eense for anyone versed in the language which had been traneilterated. 
making, is a poselblity which should, at the very leat, be raised. The path between corporeal and incorporeal, between the present and the abeent, may be located in the path of writing.

An interview which Roland Barthes gave in 1974 extende the notion of writing oe a cutting through, spart, the surface of senee. Writing, for Barthes, is more than the scratching of eymbols onto a plece of paper -- that could be either writing or "tranecription." Writing (Serlture) is procens-oriented, the infinite play of the world (the world as function) (before (t) is traversed, intersected, stopped, plasticized by som - Ingular syetem (Idoology, Genus, Criticiem) which reduces the plurality of entrances, the opening of networks, the infinity of languages $(s / 25)$.

I would suggeet that in seriture lies a potential link between both of Deleure's poles of nonsense. For Barthes argues, in the interview mentioned above, that

[in] writing, what is too present in speech (in a hyoterical fashion) and too absent from tranecription (in a castratory fashion), namely the body, returne, but along a path which is indirect, measured, musical, and, in a word, right, returning through pleasure, and not through the Imaginary (the image) ("From Speech to Writing" 7).

The body musicalizes language, alters and shapes it according to ite own puleions and drives -- so Krinteva contende in the case of poetic language, and Barthes in that of the "writablems text.

Krieteva'. conception of a relationship betwe. language, the body and history, a relationship which "[allows] the speaking animal to sense the rhythm of the body at well as the upheavals of hietory" ("The Ethice

\footnotetext{
'I use here Rosalind Coward and John Ellis' translation of Barthes' term (Lanouaqe and Materialism 451, rather than Miller's "writerly," which seems less of an encouragement to the reader to join in the process.
} 
of Linguistics" 34), suggests an alternative to Deleuze's unbridgable separation between levels of nonsense. The ready application of her theories to Nonsense, and her willingnese to locate in Carroll. portmanteau words a capeulized veraion of poetic language, indicates that the levele of noneense which Deleuse describet could be seen as part of a eliding scale.

Such a scale is easily accommodated on the diagram of nonsense in chapter two. The most extreme formo of active and paseive noncenee, of corporeal nonsense, would dwell in or beeide the point of madnese which lies deep in the seniotic, yet is still attached to nonsense. And the wost surface and sensical nonsense which Deleuze locates would tread the 1:ie where nonsense becomes poetry. But the thetic separating the ecmiotic -- which may well be analogous to the "terrible primordial order" (Deleuze 82 ) of Deleuze' schizoid body -- from the "symbolic" is alwaye permeable.

"IN OMBOLOY BULLORGA" : Hongenge, other godieg, and Going Degper still

Bodies meet with their environments and the objects surrounding them in many ways; senses and skin may organize the world around them, or may be organized by elements of that world. In Lear, the latter is often the case. It is not at all uncommon to find, in the illustrations of his limeriake, that the people who are the subjecte of the poems are also subject to some starting physical change directly related to the other things which populate their poems and their "lives." Iake for instance "the 0ld Man who said, Hush" (Fig. 6), the "Old Man in a tree, Who was horribly bored by a Bee" (Plg. 7), or the "old Man with an owl" (Fig. 8), on page 143. Each of these charactere takes on the characteristice of the animal or insect he 1 s depicted with. Such confusion or submeraion of identities confirms the shifting of boundaries in Lear' world. The old Man and his owl are perhape the 
best examples found in Lear; even the verse, with its pronouns which Ilide between the two poseible antecedents (man or owl), never clearly establisher a divieion between the two. A simple trick of punctuation and grammar on Lear'a part has man and owl bothering, howling, itting and drinking in a linguistic merger.

Poetry often works, usually in a verioue vein, toward a similar spirit of nonsensical sympathy between humanity and the environment. In an attempt to de-humanize the universe, to under-privilege the status accorded to people and to their sense, just such mergers occur. The ruasoning for this may lie in the correlation stephen-paul Martin makes, in Open Form and Feminine Imagination, between the "open sorm" of verse and the "Open systems" of life. "Note, for instance," he writes, the similarity between the notion of open form... and the notion of open gystems presented by the Nobel Prize winning chemist Ilya Prigogine. Instead of dividing the universe into living and non-living matter, Priogogine claims that everything is "alive" but that some things sustain themselves through dynamic interplay with the environment (open Bysteme) and others are more or lesa independent of ongoing interplay w.th it (closed systems; (53).

It is in responding to this animated world, be it clcsed or open, that poetry again articulates nonsensically. Responding to? Responding with. For, as zukofaky says, poetry of "direct contact" is a "thinking with the things as they exist," beginning "in a physiological response" (quoted in Dembo, "Louis zukofsky: Objectivist Poetics and the Quest for Form" 285). And it requires tapplng into a primal energy, one which is the experience of the semiotic in an other form of life. It requires the implementation of the pre-linguistic.

In a paper on Ted Hughes's language, Jamie Bush discusses Hughes's attempt to put the natural into words: 


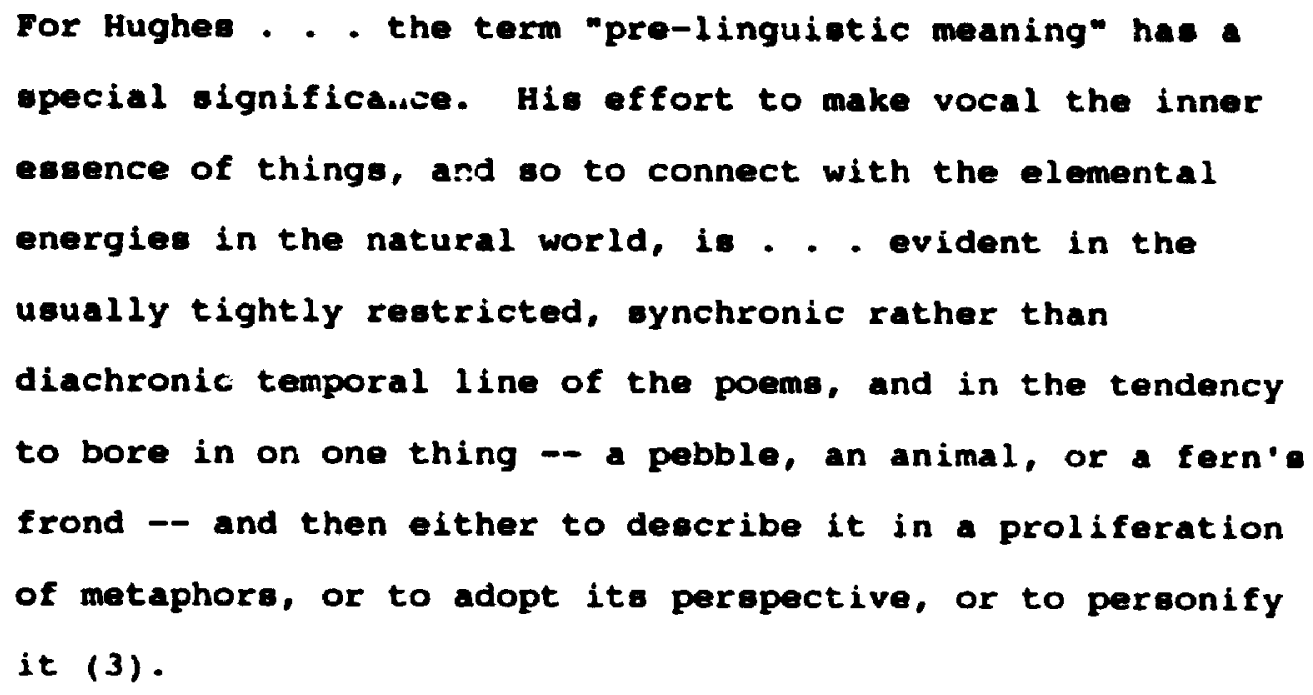

But as Bush notes, aid as Hughes's invention of an entirely new language for "Orghast" (Peter Brook's experimental dramatic "work-in-progress") attests, conventional language, one that is all, or almost all, phenotextual, doesn't serve the needs of someone who is "so concerned with expressing what 1 ies between and beneath and inside the interstices arbitrarily fixed in the conceptual continuum" (3).

What Bush has described as Hughes's method, this boring in, is a secular version of what Tim Lilburn calls "Haecceitas. . the insight of Chrigtified sensibility, a knowing-in-:ove; . . the source of what is strong and strange in verse" ("Thoughts" 35), an outgrowth of Duns scotus" haecceitag, "the ultimate reo ity of the being'" (35), and a close friend of Hopkins' inscape. It is the "thisnesg" of a pebble, an animal, a fern's frond, of a stone, a pumpkin, a tree, "as it exists in relation with its loving observer, tne tree-known-in-love" (35). As the reading of Hopkins in shapeer two i:lugtrated, such "thisness," caught up in language, stretches it considerably.

Haecce. .. $\underline{A}$, in fact, stretches language lmost to the point of nonsense. Thinking of such a poetics of presence, of thisness, in terms of Deleuzian nonsense is intriguing, for his surface nonsense posits the relationship between signified and signifier -- invests the word itself with its own sente. Following part of Lilburn's definition can lead to 
a more plausible union between nonsense and inscape than might initially seem likely. Inscape, haecceitag: it requires a presence, usually in both objects and language, found in syatems of thought which recognize the existence of an Absolute, a "transcendental signifier" at which the sence stope for good: the hub of the wheel which stabilizes.

And inscape requires an Idealiet turn of mind in ite positing of the exietence of an "essence" -- the essential tree, the essential stone, axticulation through the eseential word. Such Idealiem, generally considered to be quite far removed from the materialiat forum of nonsense, does not necessarily assume an essential link between word and thing, but it does seek to infuse the word momentarily with the essence of a thing, even if such infusion requires the wrenching of the word.

If surface nonsense provides stability, in an admittedly parsdic version of a transcendental signified, if it offers the temporary atus in which the word and the sign "mean" together, then it of fers as well the means to exprese a faith in presence which language, as the materialist system it is currently cast to be, does not allow. This is one of the most paradoxical and slippery functions of noneense yet; it undermines univocal sense, but it simultaneously incarnates linguistically just what and how that sense would be, if it could be. By being its own sense, nonsense is essentially the naming of its own eseence as well. This may be another reason why nonsense so often is made to serve religious ends.

It seems only natural for Martin to insist that the process of locating those elemental energies which Hughes prizes, the writing out of the fullness of being of the "object," lies in employing "unconditioned physisal senses," the listening to the listenings of the bxdy so important to 01 won and zukofaky. Unfettered perception facilitates an organic materialiem that allowe in-dwelling and is best articulated in the very rhythms within which it falls. Such perception, 
he suggeste, allowe one to become "an ignorant man again," ae Wallace stevene requires in "Notes Toward a Supreme Fiction." For, "no longer seeing only what we have been taught to see. - (we) find ourselves in a vivid non-rational world where the interplay of elemental energiee reaseumes the prime significance it had in ancient matriarchal societies" (Martin 142).

Because Hughes finds conventional, "civilized" language lacking when he seeks to infuse it with the life of thisness, he seeks his "Ignorance" in a "primitive language," one related, for him, to the originary condition

in which man was an integral part of the natural world and, accordingly, did not subscribe to a metaphysics of deferred presence, but was in contact with the elemental power circult of the universe. . . And the primitive language corresponded to this existential fullness, for men communicated intuitively, through a language of sound, a non-conceptual language of essential presence (Bush 9).

In this language of sound, the volcing of phonic articulation, Hughes locates human primal energies, their kinship, blood-relation, with the world around them.

Hughes's convictions about language find their greatest realization in the "Orghast" experiment. In creating orghast, he purposely attempted to leave behind the arbitrariness of language (Smith 42), "to offer the actors sounds from a physiolugical basis, which would, in the most literal sense, embody the mythic narrative he was couposing" (43). Sometimes he used onomatopeia; other times he would "concentrate on what was to be expressed, and intuitively seek the sound for it" (44). Here' a sample of Orghast with the translation Hughes provided for the actors:

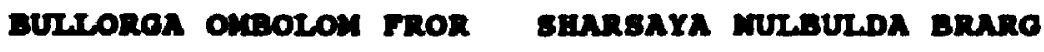

darkness opens its womb I hear chaos roar 
III ansoron guriogen

in the womb of darknese

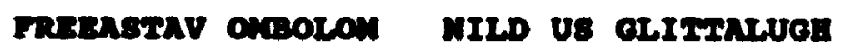

freeze her womb rivete like etars (50).

Because of ite heavy reliance upon sound and the physiological

production of language, Orghast was meant to speak "directly through the body," to be a language in which "all conceptual thought was a metaphor of what the body, first, had perceived" (51). Hughes's statement seems naive; the consistent use of "ombolom" for the word "womb," for instance, implies a good deal of conscious determination. And, while one can certainly understand the need for a translation like the one above, expecially during the workshopping of "orghast, " ite exietence does seem to curb, in part, the spirit of Hughes's probings. A sensical language seeme unavoidable as a foundation.

Orghast was, however, at the very least, an attempt to device "a language that reveal(ed) the body as a map of human experience" (78). So it' not surprising that, while creating it, Hughes thought about the relationship which the body has with language generally. "The deeper into language one goes," he explained to Smith, the chronicler of Brook' theatrical experiment,

the less visual/conceptual its imagery, and the more audial/v+cceral/muscular its system of tensions. This accords with the biological fact that the vigual nerves connect with the modern human brain, while the audial nerves connect with the cerebellum, the primal animal brain and nervous system, direct. In other words, the deeper into language one goes, the more dominated it becomes by purely musical modes, and the more dramatic it becomas -- the more unified with total states of being and with the expreseiveness of phyeical action (45).

While Hughes's intensely physical and pre-1ingual language is 
unrealizable, the implications of his ideas are exciting: buried beneath the sense and abetraction of language are waye of articulation which oppose or undermine linear, linguistic sense. The body, music, sound -these elements are borrowed from other ways of meaning, earlier waye of being, to build up the verbal eystem. These are the same element: which, when resurrected in excess, can break open the system whose foundation they contributed to.

It' a very little leap from this Hughes to the Bandar-log running riot in the Cold Lairs or the chora huffing and puffing at a atrawhouse-thetic. For Hughes's claims of the originary status of sound, the sound which he appeals to for a pre-logical and nonsensical language, is an Idealistic echo of the importance sound plays in Krigteva's genotext, in articulating a subtextual, contradictory "sense."

\section{"The ape is too distant to be sedulous": Feminism and Nonsense}

One needs only look to the writing coming out of the Feminist movement to question those critics who suggest that "women don't favour nonsense" (Haughton 31). Such a statement suggests not only an overly narrow definition of Nonsense, or nonsensical writing, but also a failure to recognize shared methods of disturbing sense. Much feminist writing dwells on and in women's bodies. Sexually and erotically energized, ecriture féminine, feminist writing at its most nonsensical makes demands:

Woman must write her body, must make up the unimpeded tongue that bursts partitions, classes, and rhetorics, orders and codes, must inundate, run through, go beyond the discourse with its last reserves (Cixous "Sorties" 94-5).

The basic premise of this writing and this movement is the oppression of women in all socio-historical matters, but especially in the matter of discourse, since the world is determined by language. 
Daphne Marlatt considers the language around her and wonders what part women' phyeical experiences actually have in it:

so many terms for dominance in Englieh are tied up with male experiencing, masculine hierarchies and differences (exclusion), patriarchal holdinge with their legalities. where are the poems that celebrate the soft letting-go the flow of menstrual blood as it leaven her body? ("musing with mothertongue" 47 )

Because men hold most of the poultions of power in society, many feministe argue men also have the power to create a way of opeaking which reflects only their world view, their selves.

This is a concern which echoes that of Virginia woolf' character Mary Beton/Seton/Carmichael, who, in A Room of One'g own, puts forth the need for a woman' sentence:

It is useless (for women] to go to the great men writers for help, however much one may go to them for pleasure. Lamb, Browne, Thackeray, Newman, Sterne, Dickene, De Quincey -- whoever it may be -never helped a woman yet, though she may have learnt a few tricks of them and adapted them to her use. The weight, the pace, the etride of a man's mind are too unlike her own for her to lift anything substantial from him successfully. The ape is too distant to be sedulcus (73).

Woolf insists that even those women, Emily Bronts and Jane Austen, who have found their own, non-masculine sentences, seem to exclude an essential part of femininity -- the friendship between women. The sexuality of women' bodies, which Marlatt seeks to incorporate in the sentence, is never broached. This absence is the concern of contemporary feminists influenced by the French Feminiet movement.

It is true that language doeen't accommodate any aspect of the 
body with ease. The God/Law/Definition, which kristeva associates with the eymbolic, is often construed ac the seat of an "androcentric" power (one I'm not overly inclined to distribute according to gender, though throughout history men have certainly been seduced by it) which actively curbe the semiotic. It is endemic in language, however, that the "social" should attempt to prevent the "individual," the sexual, from disturbing language. A sexual and sensual decorum demands that certain phyeical experiences be excluded from language, and limite one's abilities to express other seemingly inoffensive (usually non-human) experiences.

The evocation of sexuality or desire, be it male or female, ariees only in a disrupted language. For instance, Marlatt abandons punctuation, lets association, rhyme and rhythm guide her through thil prose love poem:

eating

a kiwi at four a.m. among the sheets green slice of cool going down easy on the tongue extended with desire for you and you in me it isn't us we suck those other lips tongue flesh wet wall that gives and gives whole fountains inner mountains moving out resistances you said ladders at the canyon leap desire is its way through walls swerve finger instinct in you insist further persist in me too wave on wave to that deep pool we find ourselves/it dawning on us we have reached the same place "timeless" you recognize as "yes" giving yourself up not in we come suddenly round the bend to it descending with the yellow canyon flow the mouth everything drope away from time it:

\footnotetext{
- It's important to keep in mind, while exploring briefly Feminusm's contributions to an understanding of how the body relates to nonsense, that there are at least two liberations in progress - the liberation of women (and men) from patriarchal oppression, and that of the body (male as well as female) from a linguistic repression based on limited notions of what sense is, how it functions, and what is appropriate for language to express.
} 
sheets two spoons two caved-in shells of kiwi fruit (Touch to My Tonoue 24).

The worde karlatt uses are not "different," or difficult; nor lo her ayntax disturbed Irremediably, by exploiting the rush of words, the associative blend of ideas -- articulated by pulling punctuation, the stope, out of language -- she attempts to bring her poem, sensually, to an edge of sense. The poem at once imitates the flow of desire and captures the dissolution inherent in such desire. The symbolic tendency toward compartmentalization, division and linear etructure is, in part, defeated by Marlatt' eclipsing of sentence divisions. Her use of the etream of consciousness techniqus imitates the unconscious' associative ordering principles, which stand in opposition to those of the eymbollc.'

There is a reason, then, to see in feminist writing a connection with nonsense; in feminiat theory, too, connections can be found. "Women have served all these centuries," writes Woolf, "as lookingglasses possessing the magic and delicious power of reflecting the figure of man at twice ite natural eize" (35). In spaculum of the other Woman, Irigaray extend this metaphor claiming that women must either reflect a narrow, grown-up, masculine world view, and so corroborate it (which creates, philosophically, artistically, psychologically, Pygmalione who can do just that) or be ailent; preferably both. She concludes that woman becomes "another specularization. Whose twisted character is her inability to say what she represents" (134).

The twisted character of reflected woman reveale her inability to speak herself. To speak she must twist in another direction, a direction which bringe her into contact with the bandar-logical poet, whose twiste have revealed the mirror itself to be twisted, and so who

A Imilar attempt to depict the flow of sexuality and desire by using a etream of coneciousness technique can be found in Joyce': Wlyene, when the rampant phyolcality of Molly Bloom is evoked in her infamous monologue. 
has shown up and parodied the dominating sense system. No matter how close they stand to each other, though, Irigaray' womanmpeech and nonsense are looking different ways: feminiem claime to infuse language with the body in order to reclaim both, and thereby to acquire woman'. self-determination; nonsense infuses language with the body for lese pointedly political and practical reasons. Not self-determining but self-referential, nonsense language ingesta the drives of the body for the exposure of sense -- a potentially political act with no programmatic intention or direction.

Women must twist language because they are excluded from it by the nature of worde themselves, argues Irigaray. She quotes Jacques Lacan to show that this is not just a perception held by women, but that the perepectives about this exclusion may be quite different:

There is no woman who is not excluded by the nature of things, which is the nature of words, and it must be said that, if there is something they complain a lot about at the moment, that is what it is -- except that they don't know what they are saying, that's the whole difference between them and me (quoted in Irigaray, This Sex 87).

Lacan's arrogant attempt at what one hopes is humour gives more than a different take, albeit a confirming one, on woman's exclusion from language. He is, after all, the one who holds that language and the human unconscious are organized along the same lines, and his theories make up the major point of access for those who link sexuality and writing. This remark, taken in the general context of his theory, can be made to argue for the need to articulate women's sexuality, to let women know what they are talking about, and how they are saying it. The articulation of women's sexuality is precisely what Irigaray, Cixous and the other proponents of eriture feminine are after. They envision a discourse which relates, in several ways, to a highlysexualized female body. One way is the entertainment of the other. 
cixoue talke of writing as the experience of an other, of a multiple "oneing" withln the lndividual:

Writing is the passagoway, the entrance, the exit, the dwelling place of the other in we -- the other that I an and an not, that I don't know how to be, but that I feel paseing, that makes we live -- that teare we apart, disturbs me, changes me, who? -- a feminine one, a masculine one, some? -- several, some unknown, which is indeed what gives me the desire to know and from which all life soars (85-6). She attributes the ability to write in this way to a bisexuality, which is not a matter of sexual orientation, but rather of

the location within oneself of the presence of both cexes, evident and insietent in different ways according to the individual, the nonexclusion of difference or of a sex, and etarting with this "permisesion" one gives oneself, the multiplication of the effecte of desire's inscription on every part of the body and the other body (85).

She finde the most natural model of this entertainment of the other in maternity, the housing and nurturing of a child within the womb $(90)$. Kristeva, in an interview quoted in Leon Roudiez' introduction to Denire in tanquage, makes a connection along the same lines, with an admittedly different emphasis. "The arrival of a child is," she says, *. . the firet and the often only opportunity a woman has to experience the Other in ite radical eparation from herself, that is, as an object of love" $(10)$.

There are etarting lmplications here. If language is born of the continuel, and constantly uneuccessful, search for union with the other, and if that sense of lack (articulated by the symbolic but expressive of the semiotic) can be even momentarily assuaged by the experience of pregnancy and childbirth, then it would seem that woman for at leate the pregnant woman) is closer somehow to the semiotic than man are, that the 
desire to return to the womb can be realized by carrying a child in the womb, that the womb has a direct link with the chore. And that pregnancy and childbirth can temporarily erene the thetic rather than merely facilitate the breaching of it.

These are implicationa, not assertions, and they do lean towarde a blologiem which can be unhealthy in either pro- or anti-fominiet writinge. Freud' "dark continent" of femininity could certainly be seen from some of these vantage points. In light of Kristeva'. theoreticel writinge. I'm hesitant to adopt these implicatione without amendment. Pregnancy may well be one way of experiencing the other, of momentarily filling the lack which motivates language. But different modes of erasure are conceivable: the madness dealt with in Krieteva'. dissertation is another. Kristeva certainly doesn't exclude men, who are excluded from the actual physiological experience of pregnancy, from the production of semiotically-sated literature; her doctoral thesis, part of which has been published as Revolution in Poetic language, deala exclusively with male writers. She's not as prone to the traps of escentialiam and biologism which much of the French feminist movement falle into."

Irigaray offers another reason for linking proliferation, division and disorder with femininity. Women' sexusl "organe" and erogenoue zones are prolific and scattered:

woman has gex organg more or lesg everywhere. She finds pleasure almost anywhere. Even if we refrain from invoking the hystericization of her entire body, the geography of her pleasure is far more diversified, more multiple in ito

\footnotetext{
- Cixous doesn't limit this woman's writing to women either. Her example of a man capable of this sexual stretch is Jean Genet (84). It's not so much Genet's sexual orientation which makes this stretch possible, as his ability to infuse his texts with the presence of an Other, and another "order." Cixous cites the tendency of Genet's texts to "divide," "dismember," and "regroup" as indicative of a "proliferating, maternal femininity" (84). This tendency to derange is indicative of femininity because women are outside the structure of order as defined by the current discourse of sense; they are by nature "derangers" (85).
} 
differences, more complex, more ubtle, than is commonly imagined (This Sex 28).

In Irigaray' configuration of thinge the body' sexual geography is the key to eyntax. Male exuality ie limited to the penis, she saye with dieturbing inseneitivity, hence the univocal, "one-way thinking" (Broseard 111) attributed to oyetems, oven language oyeteme, arranged eround male cexuality." Becauce women have a multidirectional sexuality. Irigaray contende they require a multifoliate language: a fluid, "(wholly) fluent" (Thit sex 216) ayntax, released from the "ohadow shaped something like the letter 'I'" (Woolf 95). Such a mntax is, I belleve, unachievable becauce the body which dwelle in language -the acmiotic -- requiren the aymbolic for articulation. Even Irigaray admite this syntax is hard to define, but, she epeculates, there would no longer be elther subject or object, "oneness" would no longer be privileged, there would no longer be proper meaninge, proper names, "proper" attributes.... instead, that "gyntax" would involve nearness, proxim'ty (134).

Thie idealized form of women's writing must be disruptive, circular, blurring; their writing must be in the "white ink" of their breast milk (Cixous 94). steeped in the blood and rhythms of their phyeical, periodic experience and so outside of culture (clement 8 ). It must "steal into language to make it tly. . , pleasuring in .. . routing the sense police" (Cixous 96). Irigaray's discuseion of sexuality and syntax, of language as multifoliate once it entertains the rhythms of the body, is a startlingly exact description of what a purely semiotic larsuage, were one possible, would be.

\footnotetext{
- Such diffuse and scattered eroticism is exactly what F. preaches in Cohen's Beautiful Losers, though a reader isn't expected to follow his teachings verbatim. Still, a pan-orgasmic body is envisioned .. Down with genital imperialisml All flesh can comel Don't you see what we have lost? Why have we abdicated so much pleasure to that which lives in our underwear? Orgasms in the shoulderl Knees going off like firecrackersl" (34).
} 
A seeming insensitivity to the problem of articulating any sexuality is an example of the biologism which Toril Mol finds so problematical in Irigaray and Clxoue. Noi claims that both subecribe to a biological or "metaphysical" viewpoint (102-49, especially 123, 139) which ironically is promoted by patriarchal thought. Subecribing to the Idea that woman embodies 'he fllp-side of all those dualities which preface Cixous' " eseay "Sorties" -- day/night; sun/moon; culture/nature; head/heart (Cixous 63) -- even if it is to find in the subversive combrace of them a sort of liberation, is etill to be defined by sexuality organized around a male principle. Not only are thry working with an idealized (born of Idealiem?) vision of woman, a primal EarthNother-Goddess not so far from Hughes' primitive originary beinge, but Irigaray, at least, evokes a "naive" version of male sexuality. She is falling prey to the lure of the phallus as omipotent sexual organ -- or at least to the myth that men need and want no other sexual identity than that found in the penis. As Ann Rosalind Jones contends, sexuality is by and large a cultural, not a biological, reality (367). If one chooses to define feminism and femininity through biological definitions, the source of the definitions that are oppressing women, $h$ : can feminism create any forward-moving change (369)? The writing envisioned by Cixous and Irigaray could be construed as a nonsensical writing if it acknowledged as well the need for the symbolic, for the sexual energy and multiplicity which they advocate requires an intensely semiotic volce. It is by definitiun subversive, and is in many ways a "feminine" writing (if such oppositions are necessary) since it does move closer to imitating the rhythm. women's bodies, and the rhythms of $z$ iy body in the world, through its engagement with the drives of the body. But the term "feminine writing" in their context remains uncorfortably close to a sort of literary blologium. Despite this weakness, Cixous and Irigaray go a long way toward creating and promoting a writing which works against the rigidities of the 
Bymbolic.

Drawing a distinction between feuiniot texta and fominist writing, Nicole Broseard (herself dt times seemingly guilty of biological oversinplification) argues that the body is not a specifically feminist domain:

Though we may speak of feminiets texts, it seems to me that we cannot speak of feminist writing. Insofar as I conceive of writing as a way of using the body, that is, how the body physically asserts itself to gain its formal status in linguistic terrain, I can speak only ..1 feninine and/or leabian writing. Certainly, the body $n, s$ ideas and feminist thoughts but the bndy it:elf is not feminist. . . Feminism can make a place for a 'body politic' but it cannot offer us a writing of the body or of the skin. However, feminist consciousness nourishes and transforms the body's cognitive and perceptual modes (91).

Brossard.' definition of writing, the body exerting itself linguiatically, is = Barthesian one. The influence is clear; she alludes to him in "The Aerial Letter" (68). But her notion of writing as it applies to women steps past his idea of "language lined with flesh" (The Pleasure of the Iext $66 !$, an idea which many feminists pick up and elaborate upon. Brossard's feminine writing results when the body meets the world from a feminist point of view, when selection of gensory perception is governed by an informed feminist consciousness. Feminine writing must go beyond the mere recording of the body and its unconscious thythms; it must use that semiotic energy within a clearlyfor" d, politicized sensory framework.

There's another direction to turn in the search for the relationghip between nongr sge, the body and feminist writing: back to the womb. The return to the womb is a return lo the pre-linguistic, whose importance $t \supset$ writers like Hughes and theorlats like Kriateva has 
already been seen. It is certainly central to Marlatt who claims, in an interview with George Bowering, "Everything is prelinguistic, as soon as you get into linguism, language, humming it, uttering it, you get back into the problem of translating" (58). What Marlatt suggests is that writing is an attempt at the impossible, a return to the inarticulate body; "the inarticulate is ground" (59), she continues. And the most inarticulate time of life is the time in the womb: birth is the movement towards and into organized language.

Gail scott suggests that the rhythms of the mother' body, heard in the womb, give to all infants an oral language. But the break in relations between $50 ; s$ and their mothers which occurs at the oedipal stage (the time of language acquisition) results in the narrowing of their speech; they become fluent in "the 'fathertongue' of education, the media, the law" (67). Girls, because of their double relationship with the mother (their confused and never completed separation during the oedipal phase), develop a double relationship with the oral speech of the mothertongue, a voice still vaguely heard despite attempts to speak in the official language of society.

The suggestion has some wonderful ramifications. First is the idea that one's "first language," the pre-linguistic semiotic, is originally the "language" of another body and not one'g own. Consequently both languages, that of the genotext and the phenotext, are languages of others. In trying to articulate this primary (primal) language, by disrupting the flow of symbolic language with the "articulation" of the body (those drives and pulsions which mark the genotext) one speaks the mother's body, the rhythms learned whilst in the Other who is now lacking. "The writer," says Barthes, is someone who plays with his mother's body... in order to glorify it, to embelligh it, or in oruer to dismember it, to take it to the limit of what can be known about the body: I would go so far as to take bliss in a 


\section{disfiguration of the language (Pleasure of the Text 37 ).} The pulaing rhymes and rhythms of genotextual nonsense are very much a movement towards the womb, a calling out in the aquaeous language learned by the fetus.

Another ramification of Scott's ideas about an oral womb-language is the importance lent to sound. An oral and rhythmic language neceesarily privileges sound anc sound patterns. Chantal chawaf writes in "Linguistic Flesh": "If a music of femininity is arising out of its own oppression, it materializes through the rediscovered body" (178). It's easy, and jugtifiable, to turn this phrase around and say that if a language of the "rediscovered body" is arising, it is materializing out of a music of femininity, out of that "animal music" which so appeals to Hughes, or the visual music which marks zukofsky's work. Or at least out of the musical relations of sound explored in the next chapter. 
"Becoming Visceral"

"Our whole life a translation/ the permissible fibo" begins Adrienne Rich's "Our Whole Life" (See Appendix VI), a poem of vivid social and political commitment, one in which words mean intensely according to their "accepted" definitions, despite Rich's cry against the limitations of language, the curbing of political minorities speech by official (oppressive) language. In this poem two apparent paradoxes resonate with each other. It may seem a paradox that Rich writes euch a powerful poem in a language which (so the poem itself suggests) oppresses her -- language may not be true to her experience, but it allows her to voice her objections. It may seem, as well, paradoxical to find a poem so bent on communicating a specific meaning entertain the subversive impulses of the semiotic. But that's what one finds upon reading this poem closely. Beyond, beneath, the rhetoric of Rich's poem are movements straining against the poem's perceived order. These semiotic incursions may well be examples of a voice jarring with the language it uses; whatever reasoning one applies to them, there is no denying the tensions which they animate throughout the poem.

"Our Whole Life" transforms its speaker into word; she becomes word, by association, because of the inadequacies of language to express her experience. Her life "is" a translation. I put that "ig" in quotation marks because in a very real sense the speaker "is not." There is a noticeable absence of the verb "to be" in this poem; the only appearance it makes is negated -- "there are no words for this." If Marilyn Farwell. is right, and Rich's tendency is to emphasize experience, to see a poem "as a verb instead of a noun" (196), then this lack is a substantial one. It is still a substantial lack if one reads Rich's poetry not as verb-oriented (or polarized diachronic) but as adjectival poetry. A poetry which frees attributes from a substantivizing or table centre, and whose movement away from a noun/verb opposition is emphasized by the shifting images created by her 
use of adjectives.

The poem concerns a life of absent or negated existence, of mi ing words and "dead letters." It is essentially a series of di. tions or fragments, a form which challenges at lecst one possible interpretation of the title: "Our Whole Life" -- "whole" as "unified," as "complete." But in many sections of the poem, and often between the sections (or stanzas) themselves, there are no firmly articulated connections; words are suppressed. The poem establishes a hesitant balance between speech and silence, between saying something and saying nothing for perhaps more to the point here -- not being able to say something), which is highly reminiscent of Nonsense. Words and meanings which are never raised in $t$, poem are entertained in it nonetheless, because of the power of Rich's use of silence, metaphor and fragment; these devices become palimpsests covering possible other ways of gaying and meaning. Allowing associative meaning where more direct "truths" cannot be stated.

Lines and sectione resonate with meaning, build toward the final three sections which stand as one disjointed unit. Indeed, the sectioning of the poem itself is unstable; associations that lurk in the -ilence between the sections suggest various ways of realigning the 1ines. And since the poem has no complete sentences, the logic of grammar and punctuation don't contest these realignments. Capital letters are structural rather than syntactical, and so lump the lines of the poem into groups of four, then three, then two, and finally six. They are indicators of a possible order other than that presented by the section hreaks themselves, an order spanning the silence of the breaks. The most obvious order which the poem seems to establish, the order of the section breaks (two stanzas composed of two lines and then one composed of one line) is quickly, nonsensically, undercut. By foining what shoild be the next ingle line stanza and so should, structurally speaking, stand alone, to the following stanza of two lines, Rich is 
destabilizing the poen's expected stanzaic structure. The number of lines in the poem is sufficient to continue the atanza composition, mentioned sbove, three times; the poem quickly undermines that order, however, with stanzas composed of three, two and finally one line. So the 1 ine count of stanzas reads: $2,2,1,2,2,3,2,1$; the last three stanzas set up a pattern of diminishment which will be discussed later. This slide away from the earliest stanza patterning is facilitated by the poem' only eimile, its only outright statement of "this is like that." Throughout the poem, Rich speaks covertly, relying upon metaphor to say, without saying, her meaning. While her use of a simile here is still a deflection of direct speech, a reliance on a figure of epeech to relay a point which cannot be stated outright, this simile is the most overt of all her images, the closest she comes to a declarative statement in "Our Whole Life." It is a breakthrough of speech in the poem and affects its structure. Always the poem has been spoken at a remove, with the words which forge connection between ideas and images remaining unspoken. This one "like," connected to its horrifying image, requires that the poem be restructured. The poem's tendency to be associative, to restructure itself in order to speak its message more openly, urges a non-centrist and asyntactical reading, one which is simultaneously diachronic and synchronic, which moves toward the grasping of "whole life" at once.

"Our whole life a translation/ the permisaible fibs" -- there is a leap in logic here as two seemingly disparate things, "translation" and "fibs," are associated, casting doubt upon the validity, the veracity of translation, positing the unreliability, instability, of language. This suggestion of failure is heightened when the "fibs" are followed by "and now a knot of lies," a correlation which at least tentatively implies a causal connection and which, despite the shift in intensity, provides a bridge between the first two sections, and almost threatens to pull the second line away from the first, tying it up to the third ine. 
The first line, as well, links up with the third last, by virtue of arallel etructure: "Our whole life a translation"; "his whole body a cloud of pain" -- the structure supports the analogies of our Iife/his body, translation/pain, joining the opeaker and the unnamed Algerian as they experience inarticulable oppreseion. While the second and second last lines do not continue the paralleling, the association of fibs with a lack of words furthers the idea of language lying, or feigning a reality which it is not capable of presenting.

The knotting of the lies in the third line is not only an entangling in, and so a trapping, but also a phonic negation: knot, not. such sound and word play is central to both feminist and nonsensical writing because it reveale the "lie" which the symbolic maken of language in trying to exclude the body, the semiotic, from articulation. Sound can allude to other, homonymic meanings, or to musical meaning. In Rich's poem, the 1 ies are a translation into a language in which adequate words are not allowed to exist; such lies, by their very exietence, negate experience and "silence" the speaker.

The fourth line, "eating at itself to get undone" carries over the idea of entrapment, indeed sound almost reminiscent of an animal gnawing at itself to get free of a trap, and speaks of a inovement not unlike that of the semiotic as it works against the symbolic's restraint, distorting and disfiguring the very language which it must rely upon to express it. While this fourth line has some alliance with the third line, with which it's paired, there is a strong pull at the line to join the fifth line, which stands alone, turning in upon itself in the act of devouring -- "Words bitten thru words." This shortened, commerclal-ese, form of "thru" looks partially eaten already, and exhibits the sort of semiotic collapse which results from a heightening of the sound value of a word, and the undermining of standard notions of words art word uses. The difficulty of envisioning this line's reference (juet how do words bite through words?) also challenges the 
way language works.

There is no metaphorical carry over, no drawing together of the fifth and sixth lines. Rather than expanding further the images of devouring, Rich turns to quite another image, equally aggressive: "meanings burnt-off like paint/ under the blowtorch." Using an image of paint stripping, in the process of wh' in a paint surface blisters with heat and then is removed, Rich seems to question the relationship between meaning and a word, a word, the more physical, concrete thing which is merely covered over, adorned by a removable meaning. Momentarily, this section floats by itself, dislocated, surrounded on both sides by quite unrelated sections. But the idea of "burning" connects with the twelfth line, where that participle describing the Algerian floats by itself, isolated from the poem and from the "village" by the only punctuation mark in the poem. Meanings, like the Algerian, are burnt; the Algerian, burning, becomes a word himself, the only word for himself; his pain, meanings c' troyed, devoured, the only means of truly speaking within the "oppressor's language."

The fifth stanza, too, stands alone -- "All those dead letters/ rendered into the oppressor's language." The "dead letters" can be both lifeless bits of alphabet, or undelivered mail, messages written but never received. Whether the letters were dead when written, or are dead because unread, whether the silence is caused by complete lack of articulation or the suppression of what meager attempts at articulation occur, is unclear. A subtle themat: = link turns upon the verb "rendured," for it can mean "gurrendered," "depicted, "given over," and, quite significantly, "translated" or "reduced by heat." The reading of the verb supports either reading of the silence, supporta either form of imposition. As well, the resonance of translation means that a link between the firgt line and the ninth does, in fact, exist, but mcre or less obscured by language.

The poem seems to reach a natural division between the fifth and 
eixth eectione; the sectione, after the fifth, are much more clearly connected than the earlier ones, and, through Rich's use of eimile, the poem is located in a more concrete political reality than it previously wae. These sectione progrese in a pattern of diminishment -- three linee, two lines, one line -- underscoring the breaking down of language to ite gut meaning, the rendering of language to a more visceral apeech. Thie diminiehment is also etyled in the firet half of the poem through Rich' une of capitale.

Thue the poem can be read nonseneically, despite the relative ecarcity of more "traditional" Nonsense strategies -- phonemic collapes, rhythm and rhyme. Its sensical movements and arrangements work against each other; lines move away from their partners, seem crawn through metaphor to other lines, sections seem only loosely united within and, sometimes, without themselves; capitala and themes urge a unity which the gaps and epaces between 1 ines and between metaphors "silence" at one level. Spaces between sections, however, are highly active, saying as much as the words of the poem do. "Our whole life," formally, turns in upon ltself, like the words that bite themselves. As the lines elide, as the form fluctuates against itself, the nature of the poem becomes the critical epeaking which cannot be articulated in the words of the cymbolic, the "oppressor' language." In a sense, the poem too is on fire, burning like the Algerian, becoming visceral. 
Chapter IV - "as birds as well as words",

Nonsense and sound

\begin{abstract}
That makes a sound that gently sings that gently sound but sounds as sounds It sounds as sounds of course as words but it sounds as sounds. It sounds as sounds that is to say as birds as well ae words.

(Gertrude stein. "What is Engligh Literature" 30)

The fish is indeed the most oral of animals; it poses the problem of muteness, of consumability, and of the consonant in the wet/palatalized element -- in ehort, the problem of language.
\end{abstract}

(Deleuze 135)

The Duchess was wrong, or partly wrong. "Take care of the gense, and the sounds will take care of themselves," she advises Alice (AW 97); but in Carroll's wonderland, and in Nonsense generally, sounds not only take care of themselves, they "take care" of sense too. Even her moral 1s proof. While she moralizes, taking care with the sense, a sight phonemic shift grants a traditional axiom ("Take care of the pence and the founds will take care of themselves") a liberation of sound; the very liberation, independence, which her moral implies.

of course, such phonic liberation reverberates in the heart of nonsense. The language of nonsense sounds, as stein puts it, "as birds as well as words" ("What is English Literature" 30). Every theory of Nonsense includes a consideration of how manipulations of sound, 1 ike the frequently cited pun, can fracture the sense of ordinary language. Locating nonsensical sound in the peychical body, however, relating it to a "feminine," animal music, as chapter three has done, is not common. Deleuze, for instance, categorically denies the location of claseical Nonsense in the body. His insigtence on calling most forme of nonsense (and Nonsense) incorporeal has already been noted. "What renders language possible," he writes -- and it should be remembered 
that, for Deleuze. Nonsense is integral to the production of linguigtic sense --

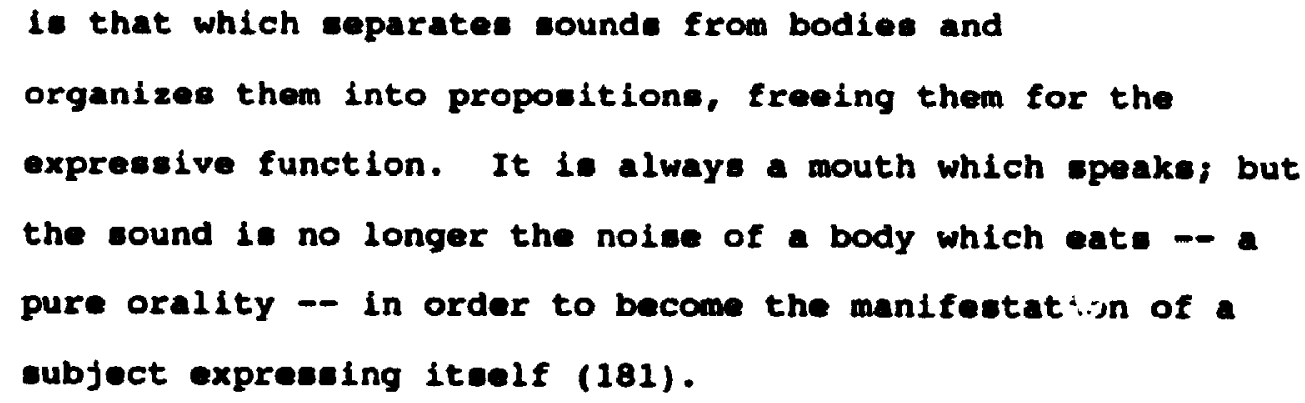


$(173-4)$

To eumarize: at the limit of dense bodies, an event is incorporeal (a metaphyeical surface); on the eurface of worde and thinge, an incorporeal event is the meaning of a proposition (ite logical dimension); in the thread of discourse, an incorporeal meaning-event is fastened to the verb (the infinitive point of the present) (175).

Deleuze' event, as it relates to language, is sense, that same sense which is so intimately dependent upon what he describes as surface noneense. The event mediates between the cause and effect of his radically reconstrued causality in much the same way that nonsense joine sense and senseleseness, by validating the former through the latter. The event "de-substantializes" or de-materializes the physical core of cause and effect, extracts their component being as articilable but ultimately kinetic, incorporeal; the event is the abstract and constantly repetitive occasion which links the bodies of cause and effect.

But nonsense, as was argued in chapters two and three, is another sort of mediator. Poised between language and the body, it is one of the many frontiers of language where distinctions begin to break down, just the sort of distinctions which are rendered feasible by Deleures's theory of the event. If the event occasions language by making sound incorporeal, then nonsense as I understand it reverses the event. For nonsense is an attempt to re-substantialize, re-materialize, language, and to do so in its own kinetic fashion. Nonsense explores the kinesis, the instability of the body by re-materializing language, infusing it with the roaming, and never stable, chora.'

'As I pointed out in chapter three, I depart from Deleuze's understanding of Nonsense when I imbue it with a level of materiality which he claims is found only in schizoid language. Nonsense, as Deleuze conceives it, is wholly incorporeal, is in fact a meaning-event. I argue that while nonsense and Nonsense may serve the function which Deleuze attributes to them (stabiiizing the contunual deferral of sense), they simultaneously reveal the process of sense-making and super-impose upon verbal language other (often more material) systems of meaning. I propose a multiple and material 
The music of the rediscovered feminized body proposed by Chantal Chawaf at the end of chapter three le linked to Kristeva's notion of poetic language. That rediscovered body is inevitably, for Krieteva, the mother'e. She argues that one vital component of "rejection," the procese which "interjects" semlotic devices into language, is ornliration: a reunion with the mother's body, which is no longer viewed as an engendering, hollow, and vaginated, expelling and rejecting body, but rather as a vocalic one -throat, voice, and braasta: music, rhythm, prosody, paragrame, and the matrix of the prophetic parabola (Revolution 153).

Nonsense simultaneously establighes and undermines sense, and it does so with the help of a "vocalic," polyphonic (but genderlese) body. How such a muscalized body enters noneenee and poetry is the subject of this chapter.

Cures of the Nummy' Tomb: Nongense, Poetry and the Porsibilities of sound

When asked if there would be a dictionary of Orghast, Ted Hughes replied "Where is the dictionary of music?" "There is one -- in your body" (Smith 209). Hughes's rhetorical question and his surprise response recall one of his statements quoted earlier: The desper intn language one goes, the leas visual/conceptual its imagery, and the more audial/visceral/muscular its system of tensions. . the more dominated it becomes by purely musical modes (Smith 45).

Hughes ties the body and language together at a primal level, it is, as 
has already been suggested, a similarly primeval position that cixous points to when she locates In women's bodies "the firet, namelese love [which] is einging" (93).

Even if one removes this originary notion, this primeval myth, from the body and music, an undeniable connection with language remains. The body produces the sound which informs language, or at least epoken language, so it must interact with language. In "Lyric's Larynx," steve Mccaffery writes: "It is sound more so than meaning binds/ the body to language" (North of Intention 178). A writing like Nonsense which is intimate with sound is bound to the body.

An obvious counter-argument: poetry and nonsense are usually written forms, meant to be read silently. Avant-garde composer $R$. Murray Schafer takes just such a stance when comparing music and language. Despite the numerous similarities between the two, he concludes that:

In language words are symbols standing metonymically for something else. The sound of a word is a means to another end, an acoustic accident that can be dispensed with entirely if the word is written, for then the writing conveys the word's essence, and its sound is totally absent or unimportant. Printed language is silent information (202).

Print is a "sarcophague" (171) for sound, he contends.

There is a limited logic here. Superficially at least one has to admit that the printed word is silent, voiceless, But to what extent does the printed word constitute language or, going to the opposite extreme, to what extent is it a notational form, a scoring for language? What one must ask oneself is not does language, unlike music, exist to communicate (that will be dwelt upon later) but rather what is the relationship of the printed word to language. For surely the written alphabet, the vieual medium of language, is not language per se, nut the 
entirety of language. To suggest. that the printed word is the ultimate or only incarnation of language is to sell short our communicative system. If writing is considered in part a notation for language's intimacy with sound, or considered only one facet of language (whether or not, as is usually the case, that language is directed at a meaningful end), then one can begin to open up language to its phonic possibilites. Print may be silent, but the reader of print is not -even as I write and re-read these lines my mind's ear hears each word, syllable, letter. The same is true of all silent readinga.

such questions abuut sound and writing cannot be asked, and such tentative conclusions can't be reached, without confronting Derrida's grammatological deconstruction of the privileging of speech. He argues in his early works, Speech and Phenomena, of Grammatology and Writing and Difference, that the opposing of speech and writing, and the subsequent privileging of speech over writing are the result of western civilizatiun's historical worship of the logos, a transcendental absolute which is an unprovable figment of its own philosophy. Such a hierarchy presupposes a presence, a fullness of being, associated with speech which is not, or cannot be, found in writing. Such an opposition implicitly defines writing as "a parasitic and imperfect representation" of speech (Culler 100).

Derrida, however, claims that writing, or what is meant by his redefinition of writing, precedes speech. Christopher Norris explains it this way:

Writing, for Derrida, is the 'free play' or element of undecidability within every system of communication. . . Writing is the endless displacement of meaning which both governs language and places it for ever beyond the reach of a stable, self-authenticating knowledge (28-9).

It is the "arche-trace" which is present in, and so comes before, all origine. speech is not indicative of a fullness, of a link to the 
primal origin; all origine are already dieplaced from the arche-trace, defined by their difference (or differance) from that trace. Here is Derride on thie trace:

The (pure) trace is differance. It does not depend on any sensible plentitude, audible or visible, phonic or graphic. It is, on the contrary, the condition of such plenitude. Although it does not exist, although it is never a being= present outside of all plenitude, its possibility is by right: anterior to all that one calls sign (signified/signifier, content/expression, atc.), concept or operation, motor or sensory. This differance is therefore not more sensible than intelligible and it permits the articulation of signs among themselves within the same abstrsct order -- a phonic or graphic text for example -- or between two orders of expression. It permits the articulation of speech and writing -- in the colloquial sense -- as it founds the metaphysical opposition between the sensible and the intelligible, then between signifier and signified, expression and content, etc. If language were not already, in that sense, a writing, no derived "notation" would be possible (of Grammatology 62-3).

All language is "written," then, even that which is spoken, for all language bespeaks a state of lack.

As soon as nonsense admits a participation simultaneously within language and within pre- or non-lingual modes, admits its incorporation of a Derridean arche-trace, it reconstrues one of the premises of deconetruction. By willfully incorporating Kristeva' semiotic within 1ta articulation in a very definite and disruptive way, by identifying that "free play" with the musicalized "materrial" body, nonsense is regponding to lack and differance. The breaching of the thetic doean't eradicate lack or desire; chapter two indicated that, because the 
semiotic mist be represented within the symbolic, the deeiroue lack which motivates the semiotic's assault on repression is never eatisfied. The interdependence of these two modalities precludes either of them over being eingularly satiefied. However, poetic language and, to a greater extent, nonsense go a considerable distance towards responding to this lack and towards blurring the boundaries which separate lingual and pre-lingual modes. They entertain and exploit this lack selfconsciously.

Rendering an account of "human delusion," voicing, that is, his version of the Rousbeauistic premises central to phonocentric civilization, Derrida writes:

Man calle himself man only by drawing limite excluding his other from the play of supplementarity: the purity of nature, of animality, primitivism, childhood, madness, divinity. The approach to these limits is at once feared as a threat of death, and desired as access to a life without differance. The history of man calling himself man is the articulation of all of these limits among thamselves (ㅇf Grammatology 244-45).

What Derrida, in order to expose humaniom's binary basis, sets up as the factors oppositional to Rousseauean lingual humanity are some of the many ela c sts related to nonsense. Nonsense is not childhood, madness, divinity, nature, animality or primitivism, yet, as the taxonomy in chapter one argued, it participates in almost all of them, through its engagement with play, the irrational and materiality. It epane or blure the eorts of opposition which deconstruction seeks to undermine.

Such blurring of boundaries is integral to nonsense's difference from deconetruction. The deconstructive principle is, according to Vincent Leitch, one which emphasizes the gap between traditional oppositions in order to encourage a questioning of the premises upon which these binaries are constructed. He suggests: 


$$
\begin{aligned}
& \text { This strategic inversion and stubborn expose lof binary } \\
& \text { oppositions] produce an unexpected gap, forcing the } \\
& \text { emergence of a new concept, which nameless mark neither } \\
& \text { neutralizes nor reforme the old opposition. Rather it } \\
& \text { functions as a disorganizing structural force that invisibly } \\
& \text { inhabits and transgresses the opposition somehwat (sic) like } \\
& \text { the Unconscious of Freud (180). }
\end{aligned}
$$

Nonsense inverts and highlights such oppositions as well, but does so not to open up a gap between them but to close one down. Rather than replacing meaning with the meaningleseness of a constantly receding meaning, nonsense requires the two, meaning and meaninglessness, to coexist.

And if nonsense is that place where meaning shades into meaningleseness, where sense shades into senselessness, it is no less the place where other oppositions blend while still maintaining their oppositional force. Each pole is demonstrably a function, an integral and parasitic resident of its opposite. Nonsense implies, to apply Charles Bernstein's words on a different (albeit marginally related) topic, a "deeper reality of the interpenetrability and interdependence of all oppositions as appositions" ("I Think I Understand Alan Davies" 287). Meaning is as parasitically related to meaninglessness as meaninglessness is to meaning. And speech is as parasitic to writing (in the common sense of the word, not Derrida's) as writing is to speech.' Yet integral as these oppositions may be to each other, they retain their own integrity. Unlike the traditional dialectic procese in which thecis and antithesis merge to make a higher, more valuable synthesis, nonsensical blending, as is the case with negative dialectics, never devalues its "thesis" or "antithesis," never privileges its "eynthesis" over its component parts.

\footnotetext{
"One reason why the term "bandar-logic" fits this theory of nonsense so nicely is that it
} phonically reflects the way nonsense banders/banters with logocentricism. 
Many of the writers I have been and will be discusaing might be termed phonocentric, whether or not one conceives of it as a pejorative term. That does not mean, however, that nonsense is phonocentric. A phonocentric writer would find a grounding in sound, which nonsense does not have. I'm inclined to borrow Foucault' description of Deleuze' theory as "phonodecentring"3 ("Theatrum Philosophicum" 180) to describe nonsense. Nonsense is an intimate and tenuous meeting of sound and print; as such, it is at once both, and neither, phonocentric and graphocentric; the same movement that centralizes sound, de-centralizes it. Lear's limericks delicately poise the visual and the lingual with and against each other; the illustrations, as was shown in chapter one, illustrate, extend or undermine the verses. The same is true of the inter-relationship between sound and print in nonsense. Because nonsense is at heart a balancing act, neither sound nor print can ever tip the scales.

To return to Schafer' metaphor: if print is a "sarcophagus" for sound, then nonsense is a Saturday-afternoon-at-the-movies-grade-Bquasi-Freudian-flick -- "Curse of the Mummy's Tomb." Sound may be buried but it's not dead yet; it's undead, or won't stay dead. Those elements of sound stalk through printed language raising the reader's epirits, spirits of a wholly other sort. Schafer might even give qualified assent to this suggestion; in The Thinking Eas, he quotes a small boy he once taught who defined poetry as "when words sing" (235), a definition which hardly suggests the printed language of poetry has both feet in the grave.

Nonsense relies on the hesitant fusion of speech and writing, of sound and print. But sounding out words in the mind, weighing their

\footnotetext{
3 Foucault attributes this neologism to Deleuze's work because it is very much concerned with orality ("the mouth where the profundity of an oral body separates itself from incorporeal meaning" ["Theatrum Philosophicum" 179l), but Deleuze's continual exploration of the margins of accepted philosophical schools of thought breaks away from the defining and confining traditions of logocentrism.
} 
sound against their printed veraion, also facilitates poetry. zukofeky' definition of writing is more than the "thinking with things as they exist" related in chapter three to a perceptually-based language; it is also, as he continues his statement, "directing them along a line of melody" (Prepositions 12). The organic life of the object in best reflected in the organic, melodic life of the word, in what Martin call. the "re-affirmation of its phyeigal properties, it: visual shape and aural resonance" (38). One way zukofeky worke towards such a re-affirmation is to write "okinny poems" (Hatlen 346); often lines are composed of only two or three words (see for instance "A-19"). The words seem more like separate entities than part of a syntactical whole, though syntax itself is preserved. Because the flow of the line doesn't pull her through the poem briskly, the reader is encouraged to dwell on each word as word, to turn lt over visually and aurally. Such turning, such renewed listening and looking, gives the phonic interrelationshipe of words the opportunity to challenge and supplement lexical and grammatical sense. "As such," Hatlen continues, the words "are perhapa beat enviafoned as pulses of energy, . . . as material artifacts, and as notes in an unending melody" (346). Schafer contends that "Music is sound as sound" (202). This being the case, zukofeky' poetice come startlirgly, but not surpriaingly, close to music. He succinctly presents them in " $\mathrm{A}-12 \mathrm{~m}$ :

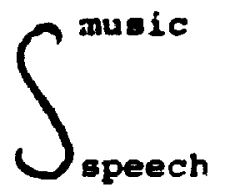

An integral

Lower limit speech

Upper limit music (NAN 138). He sees his poetry as an Integer composed of both speech and music, as a 
mediator between them. Writing and print, one noter, isn't mentioned; zukofeky etande firmly on the side of sound. An even clearer articulation of his phonocentrism is found in "A statement for Poetry," in which he posits the possibility of imagining a spech wholly separated from writing, one that is purely "a movement of aounds." This is the "musical horizon of poetry" (Prepositione 20), a horizon which will be explored, after the relationship between music and language has been considered.

Rubbing Aadinst the Grain: Lanquage and the Semiotice of Music

This discussion risks imprecision. When, if ever, does the use of the term "musical" cease to be metaphorical? Kristeva pointo out that "the beet metaphor" for the rhythmic assertion of the chora is "a piece of music or a work of architecture" (Revolution 126), but her paradigm allows for a non-metaphorical use of the term as well. Before looking more closely at how nonsense and poetry can mean musically, it will be helpful to determine what is meant by "music" and how it differs from language.

In sjlence, John Cage asks "If words are sounds, are they musical or are they just noise?" (42). The question is part of "Composition as Procese," a lecture comprised entirely of questions. It is also part of his larger attempt to question the limite of music and language, to promote a phonic continuum in which sound is never silent, and music incorporates all sorts of sounds -- even unplanned noises. His ldeas are important to this discussion because they provide an alternative to Deleuze' theory that language is made possible through its distinctness from sounde.

For Deleuze, worde are not sounds, or at least are sounde severely qualified by their diseociation from the body. Cage acknowledges such dietinctions by highlighting their arbitrariness. "Yes," he might say. 
"but what's the nature of those distinctione, and why are they made?" He purpoesy incorporates bodily noiver into some of his lecturea, pencile in when to cough or blow his nose (aee "45" for a speaker" in Silencel, wo that the idea of euch distinctnees can be questioned. Theee bodily noises become part of the "meaning-event" (Foucault "Theatrum" 174$)^{4}$ which it his presentation, the procese of inquisition which evoke sense. By virtue of their inclusion within the lecture's etructure, they resonate with meaninge. But they resonate with impreciee meaninge which cannot be individually defined apart from the sounde' broadly gestural flaunting of the conventions of language and lectures. No one cough meane separately from the other coughe, sneezes or snorts; yet each meane beyond the realm of basic bodily signification. Cage's sounde challenge Deleuze' theory by presenting incorporeal meaning corporeally, and thereby questioning the rigidity of his divisions between sound and language. Cage's experiment also confronts the distinction between sound and muslcs if, as has bean suggested, music is an arrangement of eounde meant to be lietened to (eee Schafer 18), then Cage' words as well as his snores, grunte, hisees and gargles are also music. For they have been arranged to be heard. Cage' probing of the border between language and sound, and between music and sound, may put a crimp in Deleuze's argument, but it doesn't supply a ready answer to his own question -- "If worde are sounde, are they musical or are they just noise?" This question raises

\footnotetext{
- My borrowing of this term from Foucault displaces its sense slightly. Foucault uses it to explain Deleuze's "event" theory this way: "This meaning-event is always both the displacement of the present [tense of the verb to which it is fastened and which posits the event] and the eternal repetition of the infinitive" of the same verb which "introduces meaning into language and allows it to circulate as the neutral element to which we refer in discourse" (174). I interd its use here to incorporate not only the attribution of some son of meaning to these noises by their inclusion in the structure of Cage's lectures, but also as a term for the form of the lecture itself. Cage never assents one crystalized meaning; many of his explorations are aleatory processes which evolve or seek out meaning in their delivery rather than proscribe it. In a way, his method of writing and delivering his lectures roflects the marner in which language grows out of a "meaning-event" -. "lintroducingl meaning into (his lecture) and lallowingl it to circulate as the neutral element to which we refer in discourse."
} 
another problem which Eduard Hanslick had already anticipated -- a

"fundamental difference" exists between language and mueic:

while sound in speech is but a sign, that is, a meane for

the purpose of expreveing eomething which is quite dietinct

from its medium, sound in music is the end, that is, the

ultimate and absolute object in view (The Beautiful in Muric

67).

Language, unlike music, has a field of reference outeide of sound (Springer 506), so it is, on at least one level, "sound as sense"

(Schafer 202).

"Pig," for instance, is more than a group of sounds strung

together. It denotes that porcine animal which all too often ende up on the breakfast table, or which, in Alice's Adventures in wonderland ia just "a phonemic breath away" from a fig (Miller 70). That seems to be the case, at least, when Alice tells the cheshire cat about her experience with the Duchess and her baby, who has turned into a pig. The cat interrupts Alice to ask: "Did you say 'pig' or 'fig'?" (74). Edmund Miller commenting on this passage in "The Sylvie and Bruno Books as Victorian Novel," contends that the "sound image floats free to attach itself to any other sound with which it has the alightest aseociation" (70). His point is that, in this Nonsensical world, the baby is only a hair's-breadth away from being a 'fig,' or a 'wig,' or a 'twig,' or any other 'ig'-word one can think of. The content, "what" the baby becomes, matters far less than the actual sounds of ito namo." But there is no avoiding the fact that whether or not sounds govern the sense, as the Cheshire cat's question implies, the sound also relates to a sense. The baby did become a pig, the physical referent of the sound-

s To a lesser extent this is also true of the songs which Alice sings and the poems which she recites while in Wonderland. The "revised" texts of these typically Victorian poems are too pointedly satirical to merit being called pure sound play, but they demonstrate that music has a mind of its own. Or, in more freudian terms, they demonstrate that music is one outlet for repressed emotion; the songs which Alice sings show the dark side of Victorian morality and capitalism. 
word. Noneenee node towarde the referential function of language; it may show such references to be arbitrary, but it exploits reference and controls it through sound.

Music points to nothing outeide of itself, however. And because this is the case, music is itself concrete; it "etande for the concrete experience of the unique, sensed reality of sound in procese" (Orlov 133). Like a Deleusian noncense word, which means itself, music has no "recognizable identity" (135) beyond itself. Since each note refere to nothing it is undefinables no other waningful note lende it substance. The same is true of mulical compositions as a wholes each plece of music, Winn ouggeets, "must establish within itgelf the conditione for understanding 1t'“ (293). Even variations on an pre-established musical theme can do no more than perpetuate a regreseive referral back to music, and so to itmelf. If a sark is a snark is a snark, then a note i. a note is a note.

Walter Ong commente upon the phonocentric paradox: sound'evanescence contributes to ite concretenese, to its presence in the present because it must "emanate from a source here and now discernibly active" (112). This is precisely the tradition which Derrida responds to, but in the field of music this tradition is lese susceptible to his skepticiem. Even its notational system doesn't ground music since the notes point only to their phonic counterparte and to nothing elee. Whatever music may evoke (and the responsen it elicits, like those elleited by humour, drama, and colour, are culturally determined lorlov 136) ) is entirely separate from what it "means."

If music conveys any meaning at all, that meaning is its form. As John Blacking claims, "In music, code and meseage are inceparable: the code is the meesage" (185). Contemporary literature' tendency to unite form and content $f$ inda a perfected counterpart here, and so does nonsense'. Inclination to man itself. Blacking goes on to argue that any attempt to make mugic symbolize something outside of itself 
nullifies it; when "music is treated as an arbitrary aymbol in eseentially social, political, economic, or religious interaction, . . it ceases to have moning as muic" (185). This does not mean muele is censelese -- it is too rooted in the phyelcal sensee for that to be the cases both Hanslick (49) and zukofoky (Botton 423) urge this understanding of music. But it does mean that music is more useful than verbal language "for revealing the purely structural requiremente for a aymbol evatem" (Blacking 186). There's no maningful baggage to trip up a person wending her way through musical structure, no abetractions tempting her to detour from the immediacy of the sound.

Kristeva take* Blacking' contention one tep further by calling music the furthest limit of a sign syetem. Actually it is not, she argues, a system of eigns at all because it has no signified; the eignifier, eignified and referent of mueic have all melted into one (Lnnounge 309). Perhape this blending of disparates is one reason why nonsenee is equated with music by some critica; Cammaerte consider claseical Nonsense to be "by ite very nature, pure music" (52). Both reach acrose the gap of eignifier, signified and referent. But mueic, according to $\mathrm{Kristeva,} \mathrm{fuses} \mathrm{the} \mathrm{three;} \mathrm{nonsense} \mathrm{joins} \mathrm{them} \mathrm{while}$ retaining their individuality.

Music, like language, is a differential system. But it has, for Kristeva, no semantic meaning $(310)$ and so can be regarded as exclusively semiotic (in her re-definition of the term) (Revolutio. 24 ). Language is musicalized when it is drawn out of its symbolic function (aign - syntax) and is opened out within a semiotic articulation; with a material support such as the volce (Revolution 63).

Her argument seeme pulled toward paradox since music is so rigidly structured; even jazz with its improvisational form is dependent upon a series of accepted structures and quite dependable rhythme. But as will be seen later, rhytho, despite its highly structured nature, is integral 
to the ecmiotic; etructure pere is not found solely in the realm of the eymbolic and of syntax.

Henry Orlov aee language and muele as "autonomous and mutually complementary domains, each having "ite own sets of patterns and values, field of competence, and view of reality" (132). Though euch a view is not wrong-headed, it prevalence has led inadvertently to an almost habltual palring off of music againat language in criticien. They are made to fell into binexy oppositiones expreseive/communicative; nothing/eowething/ motion/intellect; concrete/abetract -- auch dualities can be found in a range of critics. These oppositione are often ueeful because they provide a elear, eimple and dramatic view of one particular perepective, but they almost all reduce or mierepresent elther language or muelc. For instance in reaponse to claime that muelc ie expreseive and motive (a myth that Hinn claims rose with German Romant icien 259-70), Pierre Boulez offere stravineky'o inelatence that mule doesn't express anything, it morely orders (4). And language, because it involver a enelcal referent, extracts a maning from eound, but that does not 1 iminate lte sound component." Language can't be qualifled as merely abetract, only a more abetract than musics Gerald Brune, In Hodern Pootry and the Ides of Ianowace, contende that "[1]anguage, being sound, appears a a malleable subotance capable of being enaped into an infinity of forms" (18). Cage writes: "Hothing more than nothing can be ald" (silence 111) -- a otatement that might, given that the context is a lecture on nothing, be taken as a pun, when talking about nothing nothing can be raid. Such re-emphesizing to reminiscent of the many claime, introduced

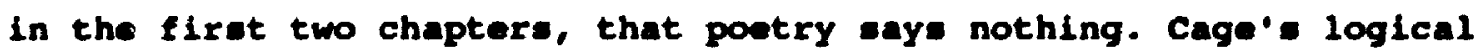
paradox (ho' clearly eying gomething, even if it's nothing) can be

- One of the ironies of phonocentriam is its tendency to imest sound with a present but separate meaning rather than let sound, in itself, be a meaning. Nonsense strives towards such a resonate meaning:; sound as sound. 
taken as a qualified "nothing," however. It is obliquely related to hia appeal for an ideal language rooted in a musicalized landscape. An ultimately ineffective, empty something is, in Cage's book, a nothing: since words, when they communicate, have no effect, it dawns on us that we need a soclety in which communication is not practiced, in which worde become noneense as they do between lovera, in which words become what they originally were: trees and stars and the rest of primeval environment (Empty Horde 184).

Which bringe one back to an insietent relationship between words, thinge and beings similar to that found explicitly in Hughes and implicitly in Lilburn.

The idea of words being germinated in the surrounding world is appealing on many levela; it's an idea that Nonsense embraces and reject: Imultaneously. But it is also an Idea which moves full circle to a theoretical position that has already been left behind. Such circling is an acceptable Nonsense strategy, a sort of active stasis, but it does not work in a theoretical argument. And neither, ultimately, does Cage's contention about a metaphorical, almost myetical, tie between language and music. It is necessary to break language down into it: component parts, to encounter it from an lgnorant position, in order to confront it similarities with music. This may be arguing the obvious, but it is essential for the understanding of how language can work musically.

Facing language out of ignorance or unfamiliarity is, in effect, facing it musically. Deleuze writes:

If the child comes to a preexieting language which she cannot yet understand, perhap conversely, she graspe that which we no longer know how to grasp in our own language, namely, the phonemic relation,, the differential relations of phonemes $(230)$. 
Language is at its most musical for is apprecia ed with a most musical frame of mind) whan it is not comprehensible, when its phenotextual aepects are short-circuited. That's why people may appreciate the eheer "muelc" of poetry read in a forelgn language. And why the "pig/fig" example, discussed above, so strongly demonstrates the musical rebelliousnese of Nonsense; it isolates the phonemic instant in language, makes that instant of ignorance and new recognition count as much as meaning does.

Deleuze'a euggestion about an ignorant grasping of phonemes unwittingly supports Springer's contention that the phonemes, the smallest units of language, offer "the most significant parallels" between linguietic and musical theory. Phonemic ayetems relate, springer suggests, to scales (509). A partial proof for this auggeation can be found in ancient Egyptian vowel music. Egyptian priegte, while singing hymns, would utter vowels in succession; "the sound of these lettera," according to Demetrius in on style, "[was] so euphonious that men listen[ed] to it in preference to flute ard lyre" (quoted in winn 2). The sounde were appreciated sensuously (3) and behaved very much like the "neume," of "ich Derrida writes in of Grammatolooy - it is "pure vocalization, form of an inarticulate song without speech, whose name means breath," "a song and an inarticulate language, [a] epeech without spacing" (249). Here, at the level of the phoneme, or of breath, music and languaye coincide.

In The Music of Poetry, T.S. Eliot describes the music of a word as a product resulting from the intersection of both the relationshipe the word has with the other words in ite immediate context and the range of its lexical meanings (intended or not) (19). While some of a word'a contextual relationshipe may well be phonic, ellot's verelon of muele 1s, for the most part, cerebral and metaphorical, as enencally compromieed as language iteelf; that compromialng of eund is the whole problem of music in language. Following springer, I would argue that a 
word can come closest to a "literal" music via the phonemen which combine to create it. This notion of "literal"/letter-al music is something to take up later in this chapter, when coneidering the translations of Catullus done by Celia and Louis zukof Bky. Since music is material, one way language can move toward musicality is by downplaying its phenotextual or abetract aspects in order to emphasize its phonic and phonemic interrelations. "The anteriorities/ of language" are carried by sound, writes Mccaffery in "Lyric' Larynx" (179). But his is not another Cagean plea for a return to primeval language. One doesn't need to return nostalgically to the anteriorites he speaks of because they exist in and with language: "the body at all times houses the / linguistic and pre-linguistic" (178). One wonders, then, if the anteriorities of language are carried by music as well. The suggestion may be that music and language are different growthe from a similar source. Such an extrapolation is hardly Derridean, but it is Kristevan. McCaffery is well-versed in Kriateva's theory of poetic language and it is evident in his work. If those anteriorities constitute the semiotic, or part of it, then it seeme likily that they are also found in music and so form one poseible interface between it and language. Nonsense explores and exploits this interface when playing with language s most minimal and musical - lements, phonemes. 7

Barthes turng to Kristeva to offer another interface, or to put that interface into different words. In an essay entitled "The Grain of the volce" (not to be confused with the book of interviews by the same name), he names the interface "the grain, the grain of the voice when the latter is in a dual posture, a dual production -- of language and of musle" (181). Of course, he is concerned for the most part with the einging of lyxical music, but his argument can be applied to a poetry

7 Admittedly, deconstruction attempts to break the phoneme down even further to the trace and the arche-trace (Leitch 28). 
intended to be read, to the "written" poem and poetic language.

Barthes speaks of the "geno-song,"

that apex (or that depth) of production where the melody really works at the language -- not at what it says, but the voluptuousnese of its sounds-signifiers, of its letter: -- where melody explores how the language worke and Identifies with that work (182).

This is a language of the "mother tongue," the body' a articulated materiality (182). It is the language in which scriture is written, that form of writing posed in the last chapter as a conduit between the body and nonsense. This "voluptuousness" of which Barthes writes, this cound-body of letters, is embodied in the grain of the voice. But that grain worke against another grain -- the grain of a phenotextual

language, the grain of music and literary criticism which want to keep language and music distinct. This chapter's final section, a delving into sound poetry, will sample what is perhaps the most deeply grained realization of this melodic exploration and identification of language. But how the grain inhabite the written word ("the body. . . In the hand as it writes" $(188))$, how it pushes language towards melody is the issue considered next.

\section{"Akin tabber": Noneence, Poetry and the Bhythme of sound}

\footnotetext{
"Above everything else," writes Wallace stevens in "The Noble Rider and the sound of words," "poetry is words; and.. . words, above everything else, are, in poetry, sounds" (32). Nonsense, poetry and poetic language have everything to do with sound. Ede finde some parts of Lear, eepecially "The story of the Four Little Children who went Round the World," to be language functioning as pure sound (58), while Cammaerts, as was noted above, equates Nonsense and music (52). Certainly the pronouncedly rhythmic disposition of Nonsense verse to
} 
which Cammaerte appeals lends a measure of credibility to his claim. Dennis Lee's "Quintin and Griffin," for instance, whether one claselfies it as poetry or nonsense, patterne sounde with tongue-twieting reveliy: Quintin's olttin' hittin' Griffin. Griffin's hittin' Quintin too.

If Quintin's quittin' hittin' Griffin, What w111 Griffin at'n'do? (Garbage pelight 11).

Lee's verbe is not pure music, ror, despite Cammaerts' claims, Noneense; but Cammerte' observatione lead in the right direction for an exploration of the musical elements in Nonsense and poetry.

Rhythm is sound considered in its temporal dimension, and is inextricable from Krigteva's chora. Toril Mol highlights the relationghip between the two: "The chora is a rhythmic pulaion rather than a new language" (162). Because the chora is the "gource" of the semiotic and therefore central to this bandar-logical theory. its rhythms are integral to nonsense. Robert hase perhape intuited as much when he argued:

Rhythm is always revolutionary ground. It is always the place where the organic arises to abolish the mechanical and where energy announces the abolition of tradition (98). He contende that "[n]ew rhythms are new perijeptions" (98), but even old rhythms offer alternative perspectives. As chapter two showed, strongly articulated semiotic rhythms can shift emphasis from sense to sound, from meaning to material, and in the process can foreground how sense is made. That in itself is revolutionary.

The oymbolic is aptly summarized as "God/Law/Definition"; each of these elemente is rich in structure, but none of them exhauste the poesibilities of structure. Criticiem of Nonsense"s tendency to use rigid etructures misese the point because structure is not antithetical to the aemiotic or a writing of the body. Lear's limericks, as was argued in chapter one, are no lese nonseneical for their tight form. 
Some of the most nonsensical works of modern and contemporary literature, for instance Linnegane wake, embrace intricate, albelt unueual, etructural rigors. In fact it seems appropriate to conflate Kristeva's terming of music as pure semiosis with the seemingly opposite, and frequently given, definition of mueic as pure structure to argue that the semiotic is pure structure. Pure etructure as lopposed to) pure meaning; form as opposed to content, and form which points to itself is content.

Content, information, communication are irrelevant or non-exietent in the eemiotic. All disorders are orders of another ilk. An infusion of the chora into grammatical language can pervert its structure without doing away with grammar; the semiotic can superimpose another structure onto an anterior one, or can bring two or more opposing ways of meaning together. Boulez writes that structure is the point of contact between poetry and music and "that poets [among them Joyce] who worked on language itself are the ones who left the most visible imprint upon the musiclen" (53). Such a cross-over implies that musicians and experimental writers are, as this chapter ie, most concerned with the structure of sound.

Robert Bringhurst and James Winn each characterize Joyce's work as chordel $(116 ; 297)$. That is an especially helpful term when read in light of Winn' description of chords as "intersections of contrapuntal lines" (334)." This definition points towards a facet of intertextuality, or what Krieteva call. "transposition, "s that "passage from one signifying oystem to another," which emphasizes the manynese, the polyvalence of each enunciated object. As was suggested in chapter three, this paseing from one signifying system to another best characterizes the relationship between nonsense and music. Monsense is

\footnotetext{
-Winn bases his definition on ideas found in Ezra Pound's Antheil and the Treatise on Harmony.

"Kristeva has re-named "intertextuality." Although she intends Bakhtin's sense of the term, she calls it "transposition" to avoid confusion with its popular and imprecise use (see Revolution 60).
} 
a converging, inter-mingling, transliterating that moves in and out of varioue sign aysteme and, In doing so, takes with it the residuee of those syetems.

When the rhythmic structures of music move into language, two eign syetems are walking in step. Sometimes, when she was small, my daughter (a confluence of ancestors) would plop herself onto my foot, wrap har arme around my $\mathrm{leg}$ and ask me to walk her into the next room. something similar happene when a confluence of several sign syotems (mueical. visual and verbal have been mentioned, though eeveral othere, including mathematical and philosophical as Carroll' work proves, are also poseible) situates itself in language, transposes itself into a medium which, laden with all these elements, must radically alter its movemert. Nonsense is a ailly walk. Of course because the nonsense considered here is linguistic in nature, it always toes in towards language. But a nonsense that toes towards music, or mathematics, or any other component Is conceivable too.

Cage, for instance, creates a form of nonsense in his poem sequence "Empty Words" which is arguably more mueical than linguietic. Following Norman 0 . Brown, he calle gyntax the "arrangement of the army" (BN 11), and insists upon the "demilitarization of language: a serious mueical concern" (184). He attempts to demilitarize it by moving through its five component materials (sentences, phrases, words, syliables, letters [11]) until his poem's final section offers only an arrangement of lettera on the page (see Fig. 9), language gone AwoL. It ' a matter of perspective whether "Empty Words" is nonsense or gibberish, but the equence does juggle a meaning, and quite a polemical one, encoded by some seemingly random and supposedly meaninglese lettera whlch actualiy cefer back to earlier sentences and phraees.

Cage has not escaped springer' a contention that even noneenee words have "rudimentary morphemic aseociatione" (508) -- though there are fow morphemes here. However he has in part reduced language to a 

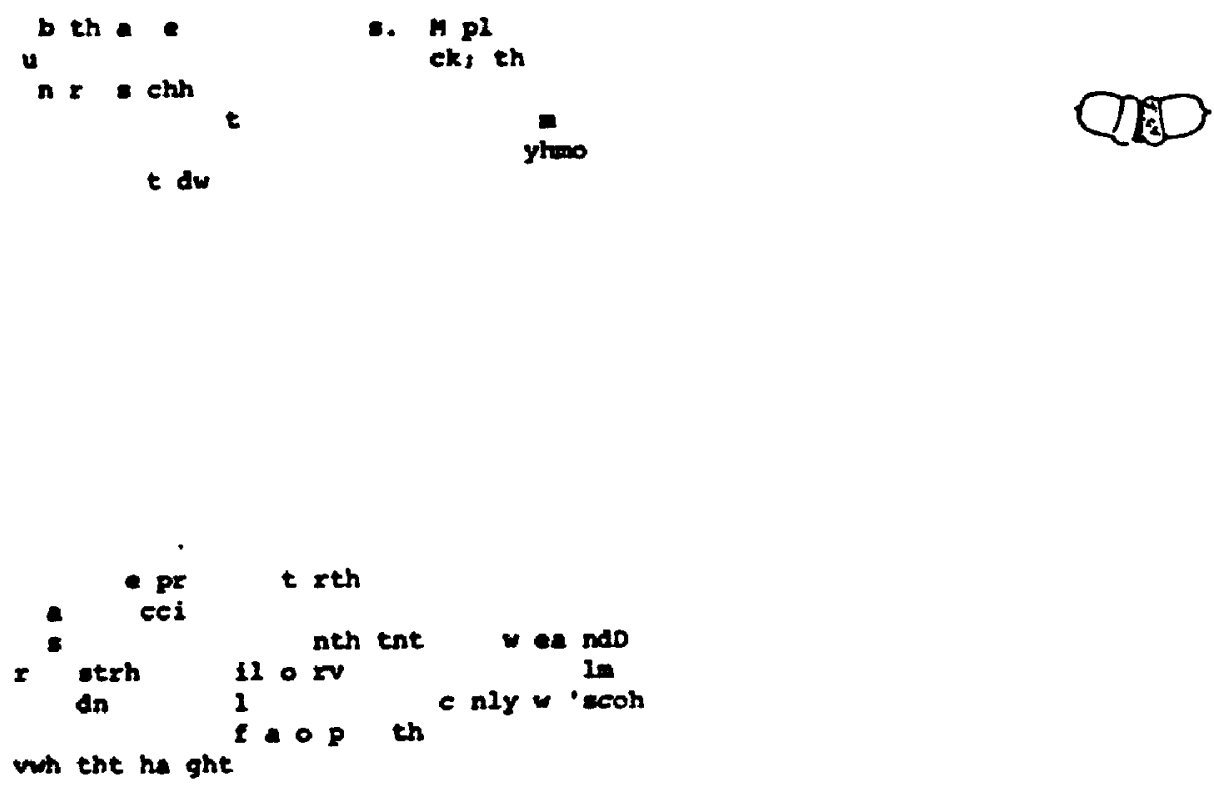

rh. Ho is

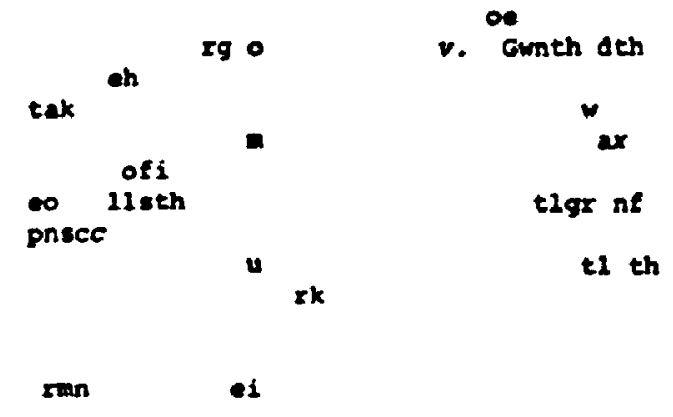

dryt $a=n I:$ rpr rstwe rd $00 \mathrm{~g}$ we A. Athbn ing losooarp w Th ldott a

b 11 a no yspe ndv ft nab 
tonal construct, has made it "multidimensional," multifoliate; it has been given a manyness of meaning (Orlov 2د4). But is he left with language or with a visual representation of lts anteriorities? Is this a musical "ecore" or a concrete poem? It is possible that he has puehed language over the edge that eeparates it from music, as he suggest. (65). However, if he has done this, he has pushed language into a nonseneical music. His use of letters in "Empty Words" allows a aymbolization which threatens its ability to mean musically, or so Blacking would contend. Rather than transposing music onto language, he may have transposed language onto music. Moreover, this noneense only exists musically if one accepts the premise that disorder is a form of order, and so accepts the existence of an unidentifiable structure within the work. As literature, Cage's work is closest at this point to sound poetry, a category of literature which bends notions of poetry almost to breaking.

A different example of language being articulated as music is found in bp Nichol's Book 5 of The Martyfology. This is no surprise coming from Nichol, a renowned sound poet and experimenter with the tonal and visual aspects of larguage. In Book 5, Nichol tries to establish "a system for using text to generate melody" (Dutton 9) by writing part of the text on a musical staff. Paul Dutton explains that "when a letter in the text was the name of a note, the text moved to the line or space correspondil,g to that note, remaining on that line or epace until the next note-name letter occurred" (9). (See Fig. 10 for a ample.) The text is chanted; the duration of each pitch depends on the amount of text on the given line. The resulting music sounds, according to Dutton, "somewhat reminiscent of Gregorian chant -- or should I say, given its aleatoric basis, Gregorian chance?" (10). Though Nichol': experiment, in this instance, doesn't quite match Cage's for oheer flaunting of the musical residue in language, his playful exploitation of the alphabetical intersection of musical and linguistic notation 


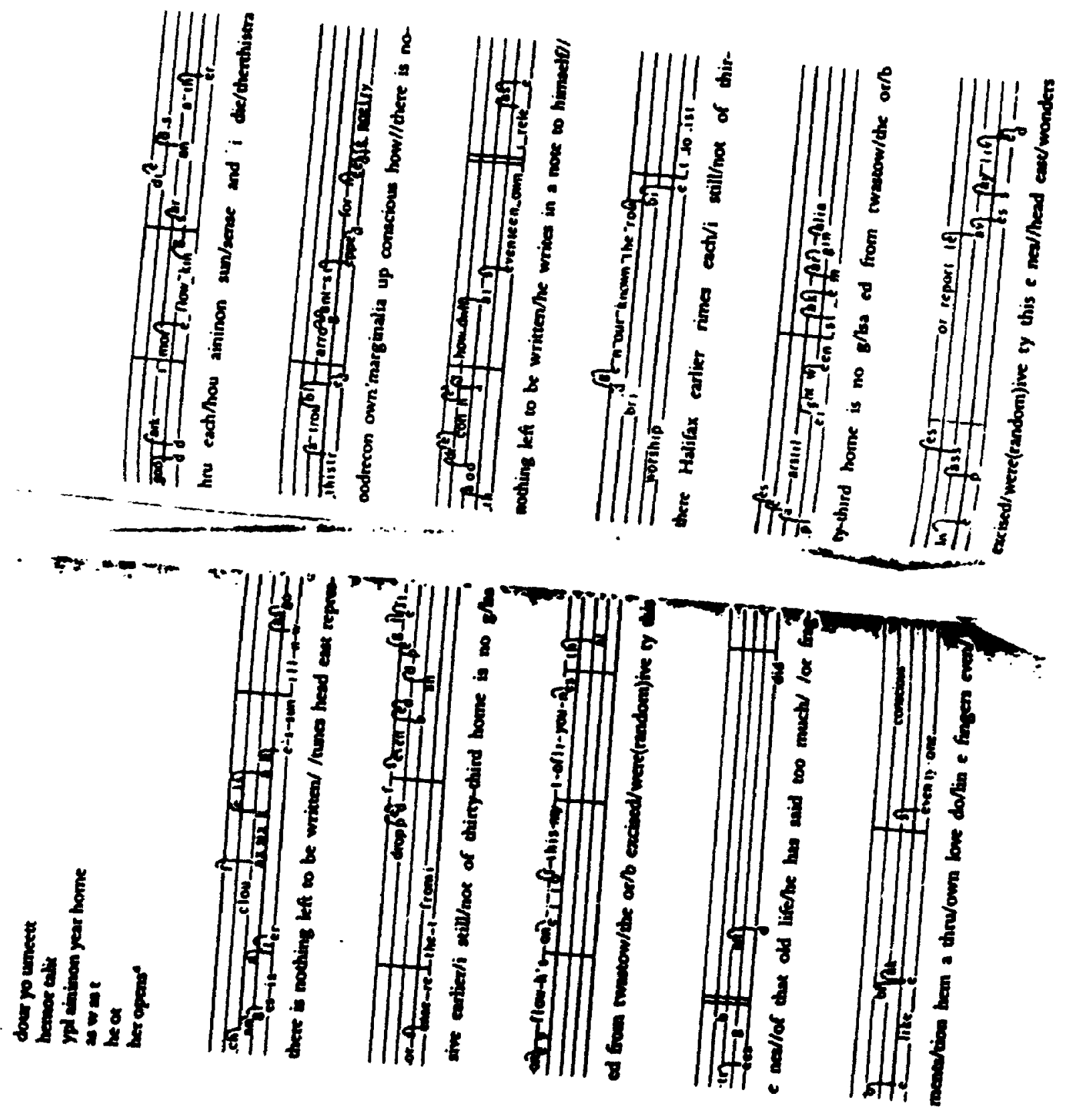

F18. 10 
points to the possibilities inherent in viewing written language as a notational system for its more concrete aspecte. Jonathan Albert, in his eseay "A Language of Spoken Movement," suggests the alphabet can be viewed as a "series of directions" rather than as "naming syatem" (1415). As such it is a symbolic representation which shares similarities with musical notation. By forcing certain letters of the alphabet to incorporate their musical functions within a lingual context, Nichol implies the musical possibilities for alt lettera. On more accessible and, one might argue, more insidious level, rhythm, 10 the temporalization of sound, is working in grammatical language when it remains on this side of the border between language and music. In "How to Read," Ezra Pound gives his now famous definition of melopoeia, a poetry in which

the words are charged, over and above their plain meaning, with some musical property, which directe the bearing or trend of that meaning... (and have) a contrary current, a force tending often to lull, or to distract the reader from the exact sense of the language. It is poetry on the borders of music (170-72). Melopoeia is "a function of language in which the rhythmical organization is developed internally" (Welsh 234). It matches valery's story about the primacy of rhythm in writing, and how that rhythm is related to the body. Valery relates in "Poetry and Abstract Thought" being "gripped by a rhythm" one day while walking in Paris, and then by

10 Henri Meschonnic, in his important study Critioue du ruthme: Anthropolooue historique du lanaage argues for a different understanding of the term "rhyinm." For him, it is "the continuous movement of sionifiance constructed by the historical activity of a subject" (Bedetti 93) and "exposes the subject (suiet d'enonciation) through a body language" (93). He argues that rtythm, as he construes it, is more important than meaning, and that "as the organization of the subject in and by its language, has no further tie, except historically, with structuralism, or with its home, polemics" (96). Consequently he challenges the binary nature of the sign, its split between "lanoage/anoue" and contends that the liriking of rhythm and materiality maintains such a split, as does, in his view, Kristeva's definition of itythm "in terms of the irrational versus the rational" (101). While his approach differs from mine, his intent is, in part, similar -- to reconsider the nature of the sign (in $\mathrm{my}$ case, the nonsensical sign) through an understanding of how the body can "dwell" in language. 
another rhythm, wo "certain etrange trangyeres relations were eet up between these two principles" (61). These rhythme were, he concludes, the result of the confluence of the external world, the body and the mind (62). And they were the physlcal experience of the rhythmic body opawing ideas. While he eaye these particular rhythme were too complicated to be worked into poetry, he uees the etory to acknowledge that poetry often finds ite impetue flect in a rhythm, not an idea. Much of Andrew Welsh's Roote of lytic deale preciecly with this melopoelc poetry, which he linke with "primitive" charms and chante whose sole motivatione are sound and rhythm respectively $(145,162)$. H1. quotation of a tranelated song of the Inult from the coppermine River region finds an unlikely counterpart in zukofeky' "A-23": The big bow, he constantly sende it stralght. He constantly bende it, i yai ya i ai yai yai ya

(Weleh 163).

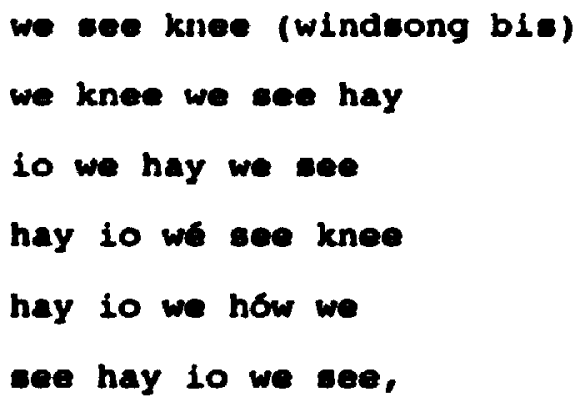


poetic presence (Corman 315), rhythm, not metaphor, is a poem' most important element (Dembo 287). Nowhere does this come through as clearly as when sound and rhythm fracture an initially sensical entence, leaving the senee scattered throughout the phonic permutatione of the 1ines. What is left may be "akin [to] jabber" ("A-23" 539), but it is also a poetry which, to use cage's phrase, "[allowe] musical elemente (time, sound) to be introduced into the world of worde" (silence $x$ ).

Not for Wallelowers: sitweil' Bhythmle plaposition

Edith Sitwell calla the preface to her collected poeme "some Notes on My Own Poetry," though she might well have entitled it "Notes for wallflowera" because in it she defends her experimental writing style from the criticieme of those unwilling to enter into her poetic dances. In order to etretch itself beyond the over-worked etylistic cliches found in poeme influenced by the high victorians, her writing [inquires] into the effect on rhythm and on speed of the use of rhymes, assonances, and dissonances, placed at the beginnning and in the middle of lines, as well as at the end, and in most elaborate patterns (xvi).

"Rhythm," she holds, "might be described as, to the world of sound, what light is to the world of sight. It shapes and gives new meaning" (xv). Following this metaphor, sitwell choreographe her poems, gives them the aural shape of nureery rhyme and of dances like the waltz, the polka, the mazurka and the hornpipe; she chooses over and over again to let wound and movement dictate her use of language. The reault: wonderfully flowing poems which augment their diatinctive rhythme with strangely catachrestic images. A nonsensically-timid, wallflower-ioh reader ie left quite out of any Intelligible dance, tapping her foot. sltwell' "dances" are intelligible, though in somewhat 
irreguler way. "When sounds become signs," writes Charles F. Altman In "Intratextual Rewriting," "thelr sound value le all but discarded, for to play it up would 'becloud the intelligibility' of language" (49). But this is precieely what sitwell does: pley up the concrete anpect of her language, not to becloud senee but to re-vitalize it. And though the resulting language is hardly atald, it etill maintaine a diacernible, albeit subordinated, meaning. Or rather, it maintains a meaning in part constituted by rhythm. Often the poems in her best known volume, Fasde, are named after particular dances, a clear gesture that the movement of the poem is a particular node around which meaninge collect. Such ie the caee with "Fox Trot" (137-8). (See Appendix VII for the text of the poem.)

"Fox Trot" is given essentially from a child's parapective. In 1t, sitwell conflates innocent perceptions of the nursery with the nursery rhyme and with the besic one-two-three-pause rhythm of the fox trot. The poem moete 2 ukofaky' poetic requiremente -- "a 'ontext associated with 'mueicel' shape" (Preponitions 16) -- explicitly, letting ite shape and order grow out of its musical patterns. It does so mont appropriately, because the poem deals in part with order growing out of the rhythwe of life, and with the way human activity (symbolized by hunting, farming, reigning and the eating of the egg la mythic allucion to the creation of the world) at afternoon tea -- itself a civilizing ritual) erhances, controls, directs and protects the fertility of nature.

But that merger of form and content, that decidedly musical intent, results in an obscuring or estranging of sense, a shifting quasl-surreal movement resulting from sitwell's belief that "rhythm is one of the principal tranelatore between dream and reality" (xv). Her work is not nonsenes and the eemiotic does not erupt into the eymbolic with such vigour as to collapse words in upon themselves or make portions of the poem indecipherable. But the reader is caught in the 
atruggle between meaning and movement, the otruggle of meaning as movement. She must decide whether to sift through the thickly rhyming sentences and order their mythic and commonplace allusions into some sort of message, or to forsake all that and let her tongue do some "pantomimic dancing" (Paget, Human spaech 202).

"Will you, wo'n't you, will you, wo'n't you, will you join the dence?" (AN 108) run the lyrice of "The Lobeter Quadrille", the MockTurtle and Gryphon's "invitation" to join the dance is an opportunity to accept a set of rules which defy the narrow perapective of Alice, who neither understande the quadrille nor wishes to join it, indeed is happy to see it end. Sitwell's poem, though its language is 1 ess permeable than that of "The Lobster Quadrille," offers the same opportunity: to join thie dancing poem, but at the cost of the reader's pre-existing notione about how words mingle and poems mean.

The first three slow and firmly pronounced lines, or steps ("old) sir/ Faulk"), are followed by longer, brisker lines made up of several stressed and unstressed syllables -- the unstressed syllables, quick stepe before a pause. The atrongly articulated rhythm, though decidedly more intricate than those of nursery rhymes, etill maintains part of that flavour. But its changes in speed distinguish it from the more regular movement of the nursery rhyme. Those first three downbeats are repeated throughout the poem in various configurations -- "Tall as a stork"; sit/And/sleep"; "Headows/Where"; "Water/Hissed." More akin to nursery rhymes are "Fox Trot"'s quite regular endrhymes: gun/sun; sheep/sleep/weep; Cry/sigh; Meg/peg/egg; he/tree/the; crane/atrain/again. Sometimes these true rhymes are placed right next to each other ("why cry?"; "I eigh"), giving, as sitwell supposes, the effect of "(leaping) Into the air . . . [as] light and bodiless endings" (xxi11). It if ironic, considering the sense of the worde themselves, that sitwell would give them these added lilts, lilte which are unignorable in their placement at the snds of succeeding lines. They're 
twice as opringy because that first little leap ("why cry?") is so soon repeated ("I eigh").

sitwell adds complexity through her tightly woven internal rhymes. Such sound play folds lines back in upon themselves, or over other lines: "Oh, the nursery-maid Meg/ with a leg like a peg", "Picked it up as spoil to boil for nursery tea, said the mourners in the." These true rhymes underscore the rhythm of light and lightness which she aims for, and are reprecentative perhaps of patches of light in amonget the moving shadowe of country landecape, as sitwell suggests (xxvii), or rare glimpses of the fox (itself associated with light in the image "reynardcoloured sun") darting (trotting) through the early morning cornfields. Reading the true rhymes in this latter fashion ouggests that the poem's title is a punning with the reader and a playful inquiry into the metaphorical nature of the dance's name.

The fact that the fox is never liter ally named gives it the tenuous, slinking presence it must have for sir Faulk, the huntsman who is, one assumes, chasing it away from the hen house. The fox here is both a presence and atsence, seemingly dramatizing the behavlour and character of the semiotic. That his reeudonym ("sun") finds a true rhyme in "gun" is a loaded gesture which ultimately reveats an innocence of vision; in this poem lion and lamb, or rather hunter and fox, share lullabies.

But the poem is, according to sitwell, not merely an attempt at incorporating the kinetic rhythms of dance in language; it is also an experiment with assonance and dissonance, those sound patterns which make up the various shades of darkness in her rhythmic landscape. As such the palrs off words like Faulk/tall/otork/stalk/walk/smock -"dissonances, so subtle they might almost be assonances" (xxv11). These function in much the same way as the internal true rhymes, overlapping lines and sentences, but they never quite let the edges meet, a faint lisp to counterpolnt the more innocent true rhymes. Ac times they give a 
hesitant unity to contraries, not unlike that found in nursery lore; the elant-rhyme of "hunteman" and "reynard-coloured gun,"

especially in line 15, "The hunteman and the reynard-coloured eun and I eigh," strengthens the nonsensical tie between hunter and hunted. Sitwell lets assonance "smooth" out her lines. A line like "Among the pheasant-feathered corn the unicorn has torn, forlorn the" she claims, "might consist of one word only were it not for the change from sunninese to darkness" (xxvii). Such a view may be hard to swallow, but it indicates an important underlying assumption -- these words exist for their sound far more than for their sense. That sound runs them into one another with a washing flow similar to dance music and to the dark rhythms of Hopkins' "Spelt from sibyl's Leaves," though with decidedly different results. Sitwell's poem may leave the reader with the upgide of civilization -- staving off the Flood -- but she is nevertheless inundated by an ocean of sounds, a rising and falling tide of rhyme which leaves her wondering if the best reader of sitwell doesn't. have gills, perhaps, or sport a shell.

Dancing is in many ways a nonsensical pursuit -- a series of motions that have meaning only within their own context, that define themselves. It falls into many of Huizinga's categories of play -especially his contention that play involves a set of arbitrarily established rules which set the governed action apart from the outside world. Valery, comparing dance to poetry, calls it "a system of acts, but acts whose end is in themselves. It goes nowhere" (207). While valery' concern is poetry's refusal to communicate on a merely business-like or prosaic level, his analogy holds for sitwell's work twice over. Set against the "progreseion" of the dance (a movement through a series of prescribed steps only to return to the first step and begin again) is the regreseion of the rhyme, a continual turning back in upon itself, joining hands with the words that have gone before and resisting each line's attempt to go "somewhere" -- that is, on to 
the next line. Not only, then, does the actual incorporation of so dominant a rhythm introduce a semiotic nonseneicality to the poem, but also the tightly woven, almost incestuous play of these rhymes echoes and foreatalle the action of the dance precisely because they turn in upon themselves.

"on edae primagd private privet" :
The sense of zukofaky' sound

"But I would remind you, first," writes Eliot in The vigic of Poetry.

that the music of poetry is not something which exists apart from the meaning. Otherwise, we could have poetry of great musical beauty which made no sense, and I have never come across such poetry (13).

Eliot's position is open to a criticism of rigidity and unfairness, even though it does allow for a musical poetry which parodies, as opposed to makes, sense. His example of such parody is Edward Lear; "his non-sense is not vacuity of sense: it is a parody of sense, and that is the sense of It" (14). Since Lear's poetry has a sense, Ellot feels justified in praileing its musicality, which at times, he contends, is related to the "blues" (14). Eliot can stretch his notion of the sense and sensibility of music in poetry enough to accommodate Lear, but his brief commente on Lear' nonsense miss its complex and radical respones to traditional sense, and one wonders if he could stretch much farther. Could he stretch it far enough, for instance, to embrace the works of his contemporary zukofsky? If the worke of anyone challenge eliot's notion that there cannot be a musical poetry without senee, zukofaky'a do. some of his poetry relies so heavily on the orchertration of linguintic tones that ite lexical meanings can elude the reader almost entirely. such posms rest almost on the edge of sense -- private, muslcal, linguietic zuzzles. 


$$
\begin{aligned}
& \text { Take, for Instance, "Privet" from Bo flowere: } \\
& \text { League guet etrum ovally folium } \\
& \text { looped leaf nodes winter icejewel } \\
& \text { platinum stoneseed true ebony berries } \\
& \text { gray-jointed persistent thru green hedge } \\
& \text { ash-or-olive order white panicles heavy } \\
& \text { with daffodil doxy red blood pale } \\
& \text { reign paired leaves without tooth } \\
& \text { on edge primmed private privet }
\end{aligned}
$$

The title gives a etarting clue, and, having wended her way all the way through the poem, the reader is rewarded with the title reiterated as an italicized, emphatic summary. This circling motion implies a totally enclosed world of sound and words, a universe akin to that of Nonsense. Despite the disconcerting and unrelenting juxtapositione between its title and itg final word, this poem has an alternative order relating back to the visual/aural synaesthesia that zukof sky is so fond of. The "syntax" of this poem, gesturally maintained despite its lack of punctuation, is the line of the poet's sight as he explores a privet hedge, taking in leaves, branches, berries, seeds. An important part of this exploration concerns the words themselves, the components of this lingual hedge. The visual order is equally rooted in a thick seriea of sounde not unlike the density of the privet zukofeky contemplates.

Each word, juxtaposed with other, seemingly incongruous words, resonates, sends out sonal shoots. Sometimes those shoots anticipate words that aren't there. Cid corman, by picking up on the equation of ashes and death, finds in "ash-or-olive" the phrase "dead or alive." Other times, the sounde hide words which are actually there, neating within a weave of gyllables. The firat line, for instance, is a homophonlc translation of the Latin name for privet -- Ilqustrum ovalifollum (Corman 308); it hides the Latin original undernaath ita Ingliah phonic equivalents. The line begins the intertwining oo typical 
of the poems the "gu" of "League" branches out into "gust," whose final two letters edge into "gtrum"; the "um" in "strum" alips around to the and of "folium" while the first and last ayllable of "ovally" meet in the middle of "follum." Other sound patterne work throughout the plece too: alliteration ("looped leaf"; "ash-or-olive order"; "daffodil doxy"; "primmed private privet"), a sort of hind-end alliteration or the charing of final phonemes ("red blood"), internal rhyme ("otrum"/"folium"/ "platinum") and slant rhyme ("pale"/"paired") all make appearances.

As Corman argues "the ear finds its way to sense -- if attentive" (308): zukofoky': "thruat (is) towards getting us to sound the words and diacover the sense -- to bring us into play -- to participate" (306). His language is not reduced to empty sound, as Tigges writes is the case with Nonsense (Anatomy 155)," but rather aptly fits orlov's characterization of tone as "multidimensional" (134). The reader is "left off-balance" (Quartermain 204), and language is over-burdened with meaning which resides in the intimate associations of words. zukofsky' poem publicizes the private struggle of the semiotic to move meaning toward sound. In response to this struggle, in the face of its overwhelming affront to stable and stolid sense, the reader reade "Privet" from a position of ignorance, as one coming to a now language and hearing it particlea musically. Ench word in the poem, by meaning phonically as well as sensically, opens the horizons of the poem; once a reader pierces the privacy of zukofeky' meaning the's inveigled into leaping the hedge, residing in a fleld which is circumscribed (as is the poem) by privet. The sounds of the poem generate associations ad infinitum; they crescendo and fade away. And in doing so they tie together separate words, break other words down into syllables,

"Language, as has been argued throughout this chapter, can never be just sound since even the smallest units of linguistic sound carry the residue of language's sense. Tigges overstates his case in order to emphasis the primacy of sound at times in Carroll's work, like the Cheshire cat's pig/tig question discussed earlier. 
morphemes, phonemes as the language shifts, growe, a living plant. zukofsky and his wife Celia use a similar sound-senes in their "translations" of catullus. The translations were widely maligned withir the community of Latin scholars, who failed to underatand the Zukofakye' intention and the rigorous method which governed their work. one critic, in fact, was so confused and outraged by their catullue he questioned their sanity (Hatlen 351).

The translating principle which so offended the critice wae a homophonic one. Each word of the original becomse for the zukofakys a nugget of sound to be partially transliterated into English; each tranglation containe the same number of lines and syllables as the original and "as far as possible the length and the sound of the English syllables echo Catullug'a Latin syllables" (Hatlen 349). In their introduction to the translations, the zukofskys explain that they have "[followed] the sound, chythm, and gyntax of his Latin--[tried], as is said, to breathe the "literal" meaning into him" (n.p.). "The zukofakye remind us," writes Burton Hatlen, "that the 'litters," the letter, is an aural and visual shape, not a "meaning" (348). They privilege the sound of the poetry, treat each word as a series of sound units and try to translate the aural shape, the kinesis they find in Catullus' poems over and above his meaning. This return to the littera of literal is the essence of musicalized poetry. By breaking language down to its most basic element, the zukofekys, and the sound poete considered later, "reduce" it to its most scalar level, it clearest point of intersection with music.

Louis and Celia zukofaky come closest to writing pure Nonsense here, where their words mean first musically. They refuge, Hatlen ineists, to "[assume] that words are mere husks, to be stripped away so that we can get at the 'meaning'" (347). The same can be said of many sound poets. Iines like these from the translation of Catullue' poem 32 show just how closely the zukofskys followed the sound of the poems 


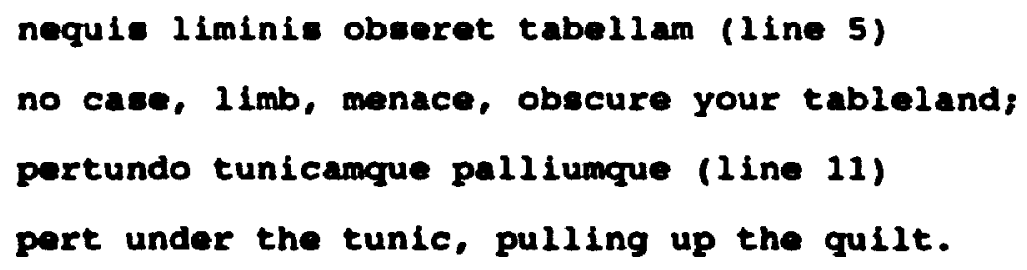

A brief glance at just one element in Hatien' reading of poem 32 demonetrates this roving and expanding meaning admirably. For inetance, he argues that the conal/metaphorlcal translation of the flrot word "amabo" into "I'm a bow" wae "latent" in the Iatin version, Juet "walting to be freed" (351). The bow, to Hatlen's mind, is not a literal bow -- though the association of the bow with Cupld and so with love couldn't have been lost on the zukofeky -- but an erect penis. Which is "a 'bow" in at least three senees it curves $11 k e$ a bow, it is almod at an object of desire, and it 1a ready to ehoot" (351). Hatlen'a metaphor underifnes the exual, often bawdy nature of catullus' poetry. 
The transliteration goes farther, though, offering a homonymic reading of bow as "beau" -- murmuring underneath the metaphorical enenousnese of the English, which Hatlen so astutely identifies, is a quaint, countrified, innocent sexuality as well, a witty and incongrous conflation made poseible only by the sonal quality of the writing.

There are lines in these translations where, as Guy Davenport put: it, "Catullus has come alive, as alive as if he were breathing garlic in your face" (369). Davenport's light-hearted description implies that the zukofeky" have done what they set out to: "breathe the ilteral" meaning with him" (Catullug. "Preface" n.p.). Their breathing together with Catullus, their "conspiracy," holds the grain of his verse. By letting the letters, the sounds, of catullus mean equally with the sense, these translations exploit and explore that Barthesian, Kristevan, nonsensical interface between language and sound.

The zukofakys are not alone in their use of homophonic translation, of course. Numerous examples of this technique exist, some less serious in intent than theirs. For instance, Mots diHeures: Gougreg, Rameg The d'Ant in Manuecript uses the homophonic tranelation of forty Mother Goose rhymes into French as the basis for a wonderfully witty parody of scholarly pretention. The "discoverer, editor and annotator" of these poems, Luis d'Antin van Rooten, claims the curious verses were part of the meagre possessions of one Francois Charles Pernand d'Antin, retired school teacher, who died at the age of ninety-three in January of the Year of our Lord, 1950, while marking papers ("Foreword" n.p.).

And, while he himself could do little more than annotate parte of the poems, he "(hopes] some more perceptive scholar, with the help of [his] notew, will bring greater clarification to these esoteric fragments" ("Foreword" n.p.).

Van Rooten then goes on to present the poems. The flrst, a homophonic translation of "Humpty Dumpty," and a few of lte annotatione, 
will suffice to illuetrate the flavour of the work and how the book chellenges meaning not only through ite emphasizing of sound but also through ite literal misdirections:

Un patit d'un potit

s'Gtonne aux Hallea

Un potit d'un petit

Ah! dagrese te fallent

Indolent qui ne sort cesse

Indolent qui ne se màne

Qu'importe un petit d'un petit

Tout cai de Reguennee.

The footnote explaining the firet line claims "Un petit d'un petit" is "the inevitable result of a child marriage." A much longer one, gloseing "aht degrés te fallent," reads:

since this personage bears no titles, we are led to belleve that the poet writes of one of those unfortunate idiotchildren that in olden days existed as a living skeleton in their family' closet. I am inclined to belleve, however, that this is a fine piece of misdirection and that the poet is actually writing of some famous political prisoner, or the 11 legitimate offspring of some noble house. The Man in the Iron Mask, perhaps? (n.p.)

The footnotes supplied by van Rooten do more than send up echolerly pretentione which overlook the obvious for the obecure; they exemplify the nonseneical pull that marks this book. Susan stewart comment. that footnotes are one way of eplitting the direction of a text, because they fracture the unity of direction and view which may be offered (74). Such is certainly the case in yote d'Heuce: fougene Bames the movement of the homophonic translation to let sound man as sound, or as sonal likeness, is continually interrupted by van Rooten's sham explanatione. Even that initial movement, however, is hardly 
unified ince the words which van Rooten uses to tranelate Mother Gooe do not, as is the case with the zukofeky" Catullue, relay any of the aenee of the original nursery rhymes. The poeme, then, mean on at leaet four levele all the time: they mean ae sound, and they mean according to the original meaninge of their Bnglieh equivalente, according to their literal French tranelatione, and according to their annotatione. It is this confluence, conflict, of meaninge which urges these playful phonic puzzles towarde nonsense.

\section{"A New vay to Blow out candleg":} The Nonsenes of Sound Poetry

Steve Mccaffery once quipped that sound poetry is just "a new way to blow out candles" ("Sound Poetry: A survey" 18). He was making light of something which he recognizes as an intensely important exploration of language. Sound poetry, of all the poetries and poetice touched on in this study, is perhaps most akin to nonsense; its overt mueicalization of language makes finding any directly communicable meaning in it almost unheard of. In a more eerious mood, McCaffery names it an attempt at "the deformation of linguistic form at the level of the eignifier" ("Text-sound, Energy and Performance" 72), and the exploration of language at the purely phonic level of the phoneme. These explorations were pioneered by, among others, German Nonsense writer Chrietian Morgenstern and the Lewis Carroll of "Jabberwocky" (Mccaffery, "Sound Poetry," 6); this heritage ties it with claselcal Nonsense too. The phonemic exploration of sound poetry has been furthered considerably by the Dadalets and Futuriste of the early twentleth century, and by the numerous avant-garde artiete Influenced by them. Among them were Gile Molman and Francois Dufrene who in the 1950s, according to steve McCaffery's survey of the history of sound poetry, gave it "megapneumes," highly reminiecent of Derrida's ancient neumes, by "[pureuing] language back beyond the threshold of the word 
and letter to breath, energy and motion," thereby "[demonetrating] the Eull Inplication of a pneumatic centred communication" ("Sound Poetryt $\mathrm{A}$ Survoy" 15$)$

kcceffery, who performed in Canada' moet lmportant eound poetry eneamb10. The Four Horacmen, with Paul Dutton, Rafael Barreto-Rivera and bp Michol, relates sound poetry to krlateva' theory of the oubject-inprocete ("Lyric" Larynx" 183n). This attribution, even more then hie earlier clalmo about ancestry, or about the influence of the Noneenee tradition upon it. places sound poetry equaraly in the renge of the noneenee theory put together in chapter two.

sauseurean I inguietice pooited

- syetem of language from which

the agency of

the subject we

excluded. The sound poem for

a text-eound writing) re-ineerte

the primary agency of the oubject

as an instinctual

body-ase-gelf (181).

In his very wuch "not-sound" poem, "Lyric's Larynx," Mccaffery theorizes and poeticizes about the nature of sound poetry. He aseerts that sound poetry is not merely a return to the materialistic baeis of language (181), not merely cemiot1c: "1t is an agency for desire production, for releasing energy flow, for ecuring the paseage of libldo in a mitiplicity of flowe out of the Logos" ("Text-gound" 72 ). It is not, he argues, "any kind of noetalgic return to a preaclosymbolle matrix" ("Mothing 1a Forgotten" 124). Mccafeery Len't denying the link botween the body and sound, or that the sound of lenguage is related to the pre-1inguletic (a distilation of Krietera' ideas). Rather he contende that, $11 k$ a 11 works of the krietevan subject-In-procese, sound poetry blends the semiotic and the aymbolic. 
It requires the eymbolic, if only to have eowething to break down as lt releases libldinal forces. Though it is closer to the absolute disintegration of lingual madnees than, eay, Lear' limerlcke, even sound poetry is not without ite thet le reetrainte.

Minn euggeste that the centrallty of meaning to poetry and the inevitable aseociation of maningful concepte with phonemea and morphemes make a semblance of conse inescapable in sound poetry (321). That" the premise behind my earlier reading of colleen Thivaudeau" "Erom Ihrognogle Engestchln," which might be coneidered a very mild and syntactically reetrained variant of the contemporary sound poem. After all, even muelcalized language, according to Krieteva, "is not without signification" and so must contend with and crose the thetic (Berolution 63).

When Mccaffery talke about how the "acoustic" poem worke, his word are reminiecent of Hughes' a discuesion of the physicality of muelc quoted at length in chapter three, and recalled earlier in this chapter:

\author{
The acourtic poem bypases the cortex and addresees itedif \\ to the Central Nervous system. Energy tranamita as \\ fragmented linguistic particles, sound, vibrations and \\ electrochemical forces to the epinal column ("Text-cound"
} 73).

What is eseential here is the skirting around the cortex, "that interface of language and matter. . . the deciphering department of the mind" (72). Both Hughes and Mccaffery seek a language which, though it Inevitably Incorporates the symbollc, acts on a directly physlcal 1 evel. The fact that a theory of nonsenee is ueeful for underetanding this nowly evolving language of direct contact can be extrapolated from Mccaffery' call for "a whole new critlcal vocabulary baed on a andotice of drive and flow and patterned over a scheme of the neural" 
$(73) \cdot 12$

Other sound poete, like Britain' Bob Cobbing, play up the "presocionymbolic" origine of sound poetry more --"PARTLY it is a recapturing of a more primitive form of language, before communication by expreselve sounde became stereotyped into words, when the volce was richer in vibrations, more mightily physical" (39). But even cobbing emphatically pute qualificatione on this relationehip with the primeval by writing "pARTLY" In the upper case. Larry Wendt comes close to the mark when he writes that sound postry is an amalgam of nature and technology (70), of the "primal" and the "clvilized." Here is another way in which sound poetry is nonsensical, nonsense, as was argued earlier, urges the meeting and mingling of wuch nature/culture dietinctions.

This hesitation to embrace "primitive" sound as the sole source of sound poetry doeen't completely eradicate the primeval sounding which Cage calls for in Empty Morde, and which Hughes and Lilburn articulate in wholly different manners. Nor does it prevent one from attributing to sound poetry a portion of the orality which Deleure anve for echizophrenic language. Once again a reader lo faced with a language, 1ike Cage' nolses, so involved with its own material production and with the way the body can modulate sound (and how the machine can then distort and mix that sound), that Deleuze's distinctions are rendered vulnerable. Once again noises -- expecially when tape recorders are used -- become incorporeal, in Deleuse's terms, but retain so much of their corporeality that they do not and cannot mean abstractly. Sound poetry is a nonsense of the body, a "einging" of the desires over against the demands of communicative expreseion.

12 McCaffery might also hay salled for a new critical form, as well as vocabulary, to appropriately treat sound poetry, though it is perhaps just that a written paper cannot possibly do justice to any actual sound poent since it can't "reproduce it." These poems participate entirely in Ong's presence of evanescence; even their textual notation (which often borders on concrete poetry or abstract art) can give no precision. In sound poetry, the moment of performance is everything. 
Cobbing and his sometime collaborative partner paula claire make their cound poetry not only a nonsense of their own bodies, but alwo of other bodies. And in so doing, they have dramatically changed the notion of what can be considered textual notation. They often "[receive] 'song signals' from natural objects: a crose-section of a cabbage, a etone, a plece of rope, the textures aurface of bricke, cloth etc" (McCaffery, "Sound Poetry: A Survey" 14); these eignals are perhape analogous to the "agnala" Lilburn received when he lmagined how a pumpkin would eing. As claire writes in "The Notation of my Sound Poetry":

I began to realise that all patterns and markings could be considered as primitive codes, dictating to human perception much earlier than alphabets, provoking a responee in sound (56).

And the describes a group sounding at which she and her audience dropped to the floor and "read" the woodknots in the auditorium's floor (62). However, Claire and cobbing don't just read the objects around them; they also make use of the "optophonetic" notation (the use of "typographic variations in size to indicate proportionate variations in pitch and volume" (McCaffery, "Sound Poetry" 8)) developed by Dadaiet Raoul Hausmann and still quite prevalent in sound poetry circles. Like other sound poets, they use drawings and collages (often valued as nuch as works of art as they are as scores) which even more loosely chart vocal renderings. (see for instance fige. 11, 12). It is, perhape, when 1t: notation reaches these extremes that sound poetry most challenges traditional notions of what poetry is. One would be hard pressed to justify calling a cabbage a poen las opposed to the inepiration for a poem), but if the notational rendering of sound poetry if its text, it: cues for performance, then that is just what claire's and Cobbing'. experiments require.

A loose interpretation of claire's stement, quoted above, might 

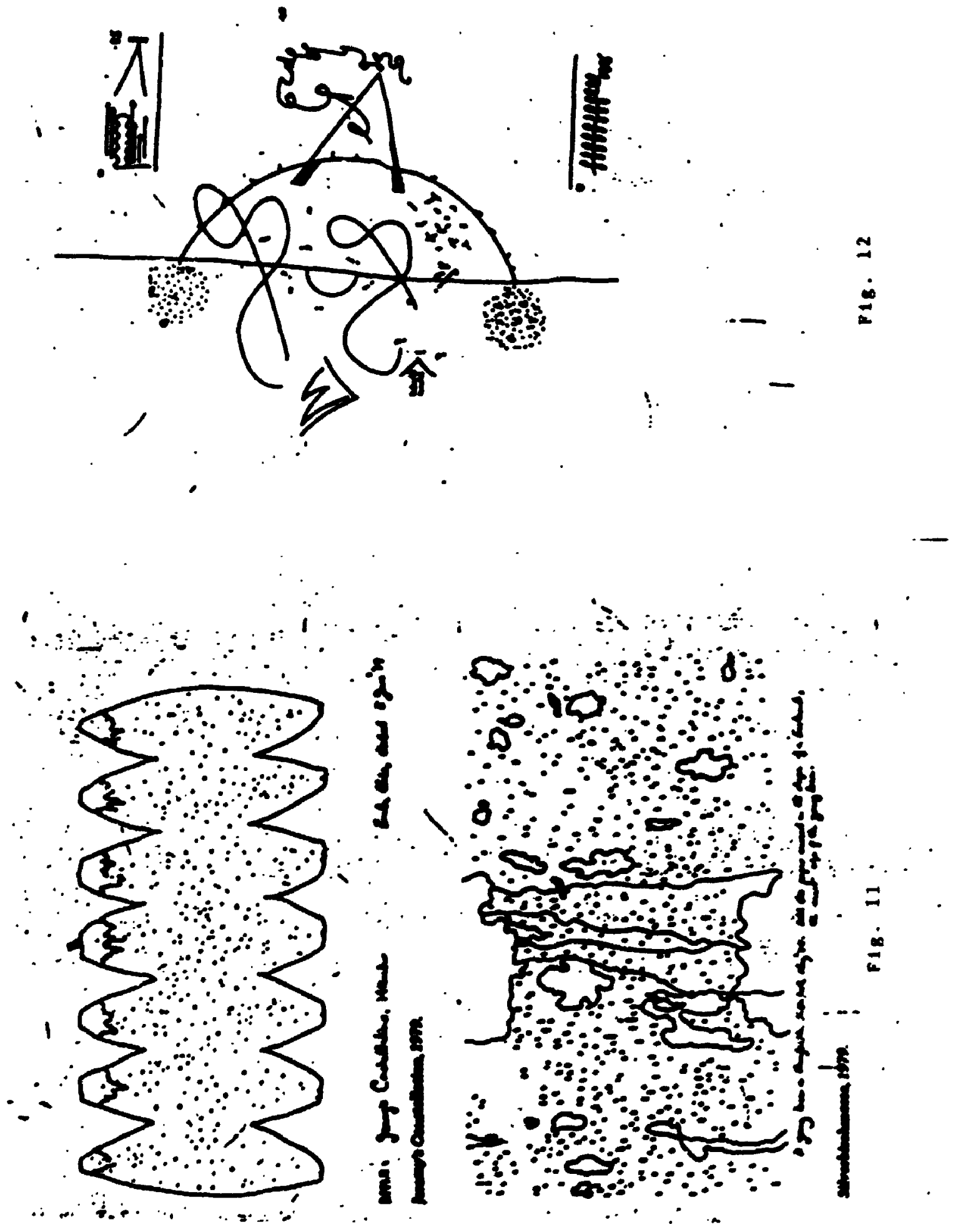
lend itself to Derridean interpretation -- patterne and markinge being a phyeical manifeetation of the arche-trace which precedes and Informe speech and sound. But McCaffery's qualification of the ldea of a text upsets such an interpretation, revealing the priority of sound over writing and demonstrating just how far from traditional poetry this "writing" stands, how much the graid is emphasized:

Text leelf (sic) as a dialectic term, not a score (the anchor of repeatability) but the thetical surface from which a performer reacts, projecting out into the unique flowings of the fissure created by that rebellion against the fixed ("Text-sound" 73 ).

The acoustic text becomes a radical example of "borierblur" -- a term Nichol borrowed from Argentinian poet Dom sylvester Houedard to describe the generic indeterminacy of much postmodernist "writing" ("Primary Days" 19). And it is only in its privileging of sound over writing, despite the inventiveness of its texts, that sound poesry risks exclusion from a nonsense canon.

Writing out of the highly politicized poetic of the $L=A=N=G=U=A=G=E$ movement, McCaffery views sound poetry as an assault on the capitalistic denigration of language, on its reduction of language to a merely meaningful commodity. "Against the order," he writes,

of

word, meaning, nomination

and syntax (i.e. against the

socio-cultural system of communication)

place the gestural body, attaching

itself to sound and rhythm

as autonomous dischargen (expenditures)

outside the utilitarian

production of meaning ("Lyric's Larynx" 182). 
The radical infusion of sound in experimental postry is an attempt to place this gesturing, polyphonic body into or next to language. The writing which results is often nonsensical. Some of the most adept practitionere of a musicalized poetic, Gertrude stein and the poeta aseociated with the journal $L=A=N=G=U=A=G=E$, remain to be considered. This other variant of nonsense, the writing "outeide the utilitarian/ production of meaning" so central to their work, will be the concern of the last chapter of this study. 
"O jongleurs, 0 belly laughs"

The first thing the eye meets on the page of Tim Lilburn's "Pumpking" (Names of God 42-3; see Appendix VIII for the text of the poem) is a huge patch of "0"'s; big and little, they proliferate, reckoning the shape of the pumpkins whose praises the poem sings. The page is the garden, thick with vegetable letters, a "rioting plot" whose long lines tumble about, sinuous vines stringing together those pumpkinesque vowels. The other thing that immediately strikes the looker -Lilburn is a poet whose embrace is as wide as the page, sometimes wider. But this poem is not just a rush and tangle of verbiage or herbiage. Lilburn takes full advantage of the play of the voice he hears in the pumpkins, the voice with which he imaginas a pumpkin would sing if it could. His answer to the implicit question of how does a pumpkin sing: clearly from the diaphragm, the seat of phonic fullness. The "Oompah Oompah Oompah" of these pumpkins rol.ls out of the moith with the roundness and substance of a pumpkin of mammoth proportions. A brassy, bass "tuba girthed" pumpkin. A pumpkin with lunge to match. The "oo" of "Oompah" is voiced again in the rest of the pumpkin's songs: "Booompah," "Doo dee doo dee doooo," "Carro-carroo." These are onomatopeic, words which mean what they sound, as well as Deleuzian nonsense words, which mean themselves. They are a point of intersection between music and word, and also between hoer and hoed. For the sound, the song's musical sense, is woven into the speech of, and picked up by, the speaker " I, weeding farmer, I, Caruso" that

-. . dung-booted serf, whose unhoed brain,

the garden's brightest fruit, ones

communton with the cowfaced cauliflowers, cucumbers twinkling like toes, and you, clown prince, 
oun dauphin of the rioting plot.

The "Identity" of the "weeding farmer" growe directly out of the song of the pumpkin ("carroo"/"Caruso"); he joins, "dung-booted," in the "oo" sound play, when he names the pumpkine "My Poohs."

Creating within the poem's genotext an echo of the noneeneical body (with its distorted and blending borders mentioned in chapter three), sound functions as a way of "marging" pumpkin and farmer, and as an indicator of Heccital The interdependence of identity that the pumpkins and the farmer share argues for a mimetic co-presence, an earthy imitation of the bodily presence which is so fundamental to the Chrietian (especially the Roman Catholic) principles of the euchariet and the incarnation.' For the genotext establishes a type of communion between the charactere of pumpkin and farmer, and articulates a contem)ilative (as opposed to actual) in-dwelling on the part of the poet.

There is another unity of sound, an alliterative and assonantal unity, which mirrore the oneness, the comuns "oneing" of poet and plant as well. Iilburn's stretching of this word's use, making it work a. a verb, reinforces the all-inclusiveness of that communion. Verb and noun stand joined: "one" now contains active and static, being and object, open and closed systems of life. And it is this "joy esperanto, [this] intenee Archimedean aha / of yellow," the music of praise, which underscores such closeness. "Communion with cowfaced cauliflowers," "cucumbers," "clown prince"; "bruited busled, bleseed these being-ward, barn-big,/ bibulous on light"; "puffing like perorating parliamentarians"; "self-hefted on the hill and shot" -- the genotext of

'I don't intend to suggest that all versions of the nonsensical body are theological or pose proofs for the doctrines of transubstantiation, consubstantiation or incarnation. However, given Lilburn's theological background (he was a Jesuit priest for years) and the influence which that backgrouno appears to have upon his poetic statements, it seems appropriate to note the affinities which the nonsensical body has with the doctrines mentioned above. All of these require one to reconsider the orientation of specific bodies within the worlil as a result of the (metaphorical, in some cases) merger or union of seeming oppositions, be it spirtt and flesh or symbolic mode and semiotic mode. 
thie poem doeen't engage just a fow letters. The wild writing and writhing of sound employs the entire exuberant, "exaultant" alphabet. Partial rhymes and internal rhymes that fold lines back in upon themselves or span whole stanzas add to the proliferation of sound: "Oompah" / "Boompah", "suburban" / "burp" / "brumpht"; "popeyes" /"apoplexies"/"flexed"; "dolphin"/"dauphin", "Carro-carroo. Are you well." Such rhymes lace the poem with an attempt (not entirely unlike Hughes's) at primal energy, the energy of growing, blossoming 1ife that ep111. out in ite long lines, and leape acrose stanza breaka: ". . How do? How do? How do? // Doo dee doo dee dooo."

The repetition of individual words supplements this primal energy too. Such repetitions in a row, like the one quoted above, do more than multiply the poem's sound games. They help move seneical words into the realm of nonsensical words; "How do? How do? How do?" begins to define itself as its echoing reiteration pushes it over the edge into the pure sound of "Doo dee."

But this phonic merging doesn't create an onslaught of sound of the sort in "spelt from Sibyl' Leaves." The pace of 'Pumpkine" keeps the sounds from massing, lends to the poem a serious frivolity. And this pacing is, perhaps surprisingly given the "lungs" those Oompah booompan' imitate, really quite puffy.

Caesura helps create that puffing effect throughout the poem; it is present more often than not as commas, full stops, or just large gaspe between "Oompah"s. But as caesura accrues and alternates with more fully-breathed lines, the puffing becomes a chug, the chugging a rocking momentum verging on dance:

-. dancing (thud), dancing (thud, brumpht, thud, brumpht) with the Buddha-bellied an. This movement is found in the very first lines: Dompah Oompah Oompah, fattening on the stem, tuba girthed, puffing like perorating 
parliamentariane,

The large spaces between the first three words close down to the mere wiop of a pase, the gulping of breath before the line's energy pushes over in enjambement to the second line. Again there is caesura, though brief. But after each caesura the cluster of worde grows, gaine length and so breath-force till the next caewura-laden line is reached: "Boompa Boompah Bocompah". Thle line repeate the same procese of lengthening and expanding breath and, after a briet end stop. plunges into the firet full line without a caesura. Such play with full and partial stope midine energizes the whole poem.

A central source of the energy, too, is the epithets that run throughout it; they are an outpouring of the reverence, the spirit of thie preim. And, because they never appear in isolation, they continue to generate the puffing-chugging-rocking dance.

-. God's jokes. O jongleurs, O belly laughs cuaking the matted patch, $O$ my blimpieh Prussian generals, o garden saueages, golden zeppeline.

Popeyes, my dears, muscular fruit

my sweets, pleasure thinge, my baubles, my Poohs

clown prince,

sun dauphin of the rioting plot.

Each string of epithets does more than augment the rollicking rhythm of "Pungkins," though. some measure of alliteration adde fuel to the momentum which accretion is building up. But of equal importance is the zany juxtaposition of "items" within these strings; Lilburn bringe together in these moments, and throughout the poem as a whole, a slew of secmingly disparate bite and pleces of life. This bricolage both adda humour and seriousness to his attempt to crose barriers. If a poem can 
work as well as this one does and still cross the borders that seemed to exist between zen Buddhism, German opera, Easter Island, st. Francis, the suburbs and cauliflower, then the stretch between pumpkin and poet is minimal at best.

Such juxtapositions and the images which grow out of them, out of the poem's spiritually and religiouely flexible world view ("vegetablea on a ball and chain"; "garden elephants. . . yahooing a yellow/which whallope air"), share the whimey of the finest of the Nonsense tradition; think of the odd mixing together of "The Owl and the Puseycat [who] went to sea/ In a beautiful pea-green boat," or the many creatures (the stork, the Duck, the Frog, the Fimble Fowl with a Corkscrew leg, the small Olympian bear, the Blue flute-playing Baboon and the Attery Squash, among others) who went to live in the Quangle Wangle' hat on the crumpety Tree, or the Jumblies who went to see in a seive (they didl). Here is Nonsense's non-contradictory opposition, a type of "co-presence."

Lilburn's is a psalm, a particularly, peculiarly serious psalm, whose nonsense reaches past dour-faced religiosity to an harmony achieved through a vegetative gesture towards transubstantiation, the "bodily" mixing of poet and plant, word and music. This harmony is ne:ther pantheistic nor monistic

because the union between poet and stone, poet and tree, poet and history is not a oneness of substance, but a oneness in relation, in election, in solidarity. The bonds are affective not physical, though the recognition of these erotic bonds completes the physical form of things. streams, persons, hills, the dead -- all are fully what they are when they are known as linked, in community with one another ("Thoughts" 36).

such community, such harmony, grows out of his unique use of nonsense. 
Chepter V -- "A 8111y corpes" $7:$

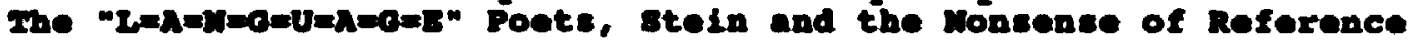

If the aim of philosophy is, as Wittgenstein claims, to whow the fly the way out of the fly-bottle, then the aim of poetry is to convince the bottle that there is no fly. (steve McCaffery, Evobs n.p.)

The move from purely descriptive, outward directive, writing toward writing centered on ite wordnese, ite physicality, ito haecceity (thienees) is, in ito impulse, an investigation of human self-samenese, of the place of our connection: in the world, in the word, in ourselves.

(Charles Bernstein, "Three or Four Thinge I Know About Him" 32)

Writing about a paragraph of experimental prose by Barret watton, Ron silliman wittily comment,, "referentiality is not merely dead, it makes for a eilly corpoe" ("The New Sentence" 78). Silliman' comment ien't only a quip, however; it's indicative of a serious query, about the status of reference and referentiality in language, which is central to much of the work by those writere 100 eely called " $L=A=N=G=U=A=G=E$ " poets. Not surprieingly, that query finds many and various answers in the experimental works of this "group," but all of these answers involve the relationehip between the world and the word, and the ways language helpe conetruct one's perception of reality.

The movement, whose members usually deny it in a movement, is named for convenience after $L=\lambda=N=G=U=\lambda=G=E$, an American fournal which offered a forum for their poetic investigations during the late seventies and early eighties; silliman claims $L=h=h=C=U=A=C=$ was "the firet American journal of poetice by and for poete" ("Language, Realiem and Poetry" xvil). The purpose of the fournal, eccording to charles Bernstein and Bruce Andrews, editors of $L=A=N=G=U=A=C=F$ and of The

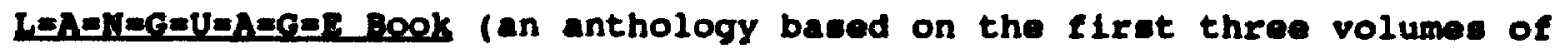


the magazine), was to "[foreground] compositional lesues and etyles of reading" ("Repossessing the Word" $1 x$ ). As a reault of such foregrounding, almost all of its participante engage in dramatic questionings of the nature of meaning and ite relationship with the political status quo, and with language' materiality. To do so they cite such writers and thinkers as Thoreau, Dickineon, the Ruseian Futurists, Stein, zukofsky and olson, wittgenstein, Barthes, Derride and Kristeva, among others, and offer an alternative poetic tradition radically opposed to Now Criticism and its formaliet and "moderniet" off-shoots.

The list of names from which this various poetic springs may already suggest an affinity with nonsense as it has been construed throughout this study. This final chapter will endeavour to show that a Nonsensical style of reading actively addresses some of the concerne about language which many of the " $L=A=N=G=U=A=G=E$ " poeta raise. After a consideration of the role of the reader, reference, referentiality, materiality and grammax -- some of the several lssues which participants in the movement confront -- the chapter concludes with brief readinge of two writers: Gertrude Stein, arguably the movement's most important literary ancestor; and Ron Siliman, a major " $L=A=N=G=U=A=G=E "$ poet, theorist and anthologist.

"The Writes of the Reader": Another view of Audience, Author and the self

First, to re-think the name. Many " $L=A=N=G=U=A=G=E$ " poet object to being collectivized by this term because their inquiries are not epecialized or made unique by virtue of their engagement with language. Almost all poetry maintains an intimate, probing relationship with language, and by it: nature highlight, language's delicate workings. But "conservative" poetry is lese partial, goes further towarde making 
1te exploration and exploitation of linguietic principles subtle, quiet. It doeen't demand of ite casual reader a conspiracy of "wording." A

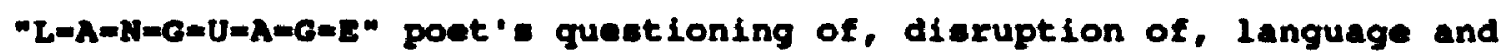
Iinguletic norme cannot be overlooked, it occure at such a basic level, in such a dramatic manner, that a reader is required to participate, to question, to probe, to leap from word to syllable to sound, to disorganize and re-organize the worde presented.

$A$ writer of " $L=A=N=G=U=A=G=E$ " poetry writes most succesefully when readere willingly join in the process. Jackson Mac Low, a literary precurdor of the movement, argues

it may be mont correct to call uuch verbal works [as characterize the movement] iperceiver-centered rather than ' language-contered' (and certainly rather than 'nonreferential'). Whatever the degree of guidance given by the authore, all or the larger part of the work of giving or finding meaning devolves upon the perceivers. The worke are indeed "perceiver-centered" ("'Language-centred" " 494).

Mac Low contende that the reading procese is one "In which perceivera are perceiving their own minds at work" (495), not, as in moretraditionally conceived writing, the minds of the authors.

" $L=A=N=G=U=A=G=E$ " poetry is not inscribed with a readily discernible (some would say "consumable") meaning. Rather, its meanings are "inseparable from the language in process" (Meseerli 3). Lyn Hejinian argues in "The Rejection of Closure" that euch "open" writing i. generative rather than directive. The writer relinguishes total control and challenges authority as a principle and control as a motive. The "open text" often cophasizes or foregrounde process, either the procese of the original composition or of subsequent compositions by readere $(134-5)$.

There is for these writers no one hypothetical mind supplied with the 
background detail neceseary to infer an author' intention. Their worke are geared to a complex of readers, unique individuale who ehare one common trait, an acceptance of the re-definition of reading which Bruce Androwe gives in "Text and Context" -- "RenDING: not the glazed gaze of the consumer, but the caraful attention of a producer, or co-producer" (36). Such a reader might serve many moderniet texta no lese well than she would these "postmodernist" ones. Likely it is a matter of the degree of involvement required which separates Andrews' reader from that of Pound or Eliot.

Such a reader would be quite unlike Allce, that spolleport in a verbal Wonderland. As Michael Palmer polnts out in an interviow with Lee Bartlett, a reader "[hae] to decide what (her) rela':ionohip to the poem is. It is a kind of poetry that ineista that the ceader is an active part of the meaning, that the reader completes the circuit" (128). Alice may escepe Wonderland by skeptically corfronting it: inhabitants -- "Who cares for you? . - You're nothing but a pack of carde?" (129) -- but the reeponstble reader of "perceiver-centered" poetry has no such out. She "cohabit [\$]" (Grenier, "Notes on Coolidge, Objectives, Zukofsky, Romanticism, and a" 533) with the poem, its writer, its language. She chooses to remain in Wonderland for the whole of the text, and longer since the lines drawn between text and worid are tenuous at best.

Hejinian's Hife, as the final inter-chapter will demonstrate, is in many waye typical of the movement. It of fers a fabric of verbal reacmblances which neem rooted obliquely in the world as one knows it; "A pause, a rose, something on paper" (7) -- these are words and grammatical forms which one recognizes, which one might even be able to pin to exterior referente, yet which function within the volume as a whole in ways beyond one's normal expectations of a word, and of poatic convention. These "refrains" not only accrue meanings through frequent repetition and re-contextualization. They also achieve a heightened 
status as words. Because they continually appear within new framoworke, they begin to matter as matter, as arrangemente of lettera, ayllables, a sounde which moan in relation to the other arrangemente of cound surrounding them. They become reconfigurations of the other lettera, ayllables, sounds, around them, fluid nodes which cryatallze, for the epace of a moment, aspecte of the verbal weave of Hefinian'a work. Hejinien' worde are poseibly wore accurate representatione of reality than the etald worde which typify a more intentionally comanicative diecouree, like that I'm engaged in here. And she needs a reader like the 1. 1 Hatter, or the Cheahlre-cat, or the Mock Turtle -- one who will play her (quite serious) game.

It is this insiatence on the participation of the reader in the making of the text' moaning, in the pleying of ite "lar yage gamos" (Wittgenstein's term is frequently adopted by these writera), which euppliee an opening for a etrategically Nonseneical reading. In The Beven and the Writing-Dek, Erancis Huxley defines Nonsense, the genre not the philosophical error, in thil ways

Nonsense, then, it a logical game played with feeling by at least two people, in a spirit of self-contradiction, in such a way that one thing leade on to the other to the constant ourprise and mutual enthusiam of both parties (10).

Huxley's definition is more restrictive, more rooted in logic, than the physical and subversive veraion of Nonsense construed in this study. By suggeoting that Nonsense reaides solely within a logical continuum, he ignores the paychically disruptive effects and implicatione of Nonsense; he fails to clarify that, as a logical game, Nonsense involves alternative forms of logic, and that often a poet's (or Nonsense writer'") logie is "1llogie" (Palmer 136).

However, Huxley'. Nonsense reader plays, contradicts herself and what she has boen taught to be the fundamental indicatione of self and world. Chapter one established the importance of play'g relationehip 
with Nonsence. That important relationehip is borne out in "perceivercentered" writinge as well, In what Vicki Mistacco calle "ludism," although her definition seeme to argue for a proliferation of meaninas. rather than the stretching of meaning or the multiplicity of waye to mean cruclal in nonmense:

'Ludiem' may be eimply defined as the open play of signification, as the free and productive interaction of forms, of signifiers and eignifieds, without regard for an original or ultimate meaning. In literature, ludiem aignifies textual play; the text is viewed as a game affording both author and reader the poselbility of producing endlese meanings and relationshipe (quoted in McCaffery, "Language Writing: from Productive to Libidinal Economy" 149).

" $L=A=N=G=U=A=G=E$ " poetry urges play and participation by using many of the materialist stretegies which are central to nonsenee and Nonsense -puns, juxtaposition, phonemic variation, the privileging of sound and rhythm -- and also by using metonomy and parataxis. Exactly how these atrategies function in "perceiver-centred" work will be discuseed later in the chapter.

such poetry is also based fundamentally on self-contradiction. This is not the self-contradiction which Huxley intends, for "languagecentred" writing' a contradiction undermines the notion of self, a sable and fixed identity. Here is another affinity with a bandar-logicul style of nonsense and with Kristeva's notion of the subject-in-process. Kristeva argues for a self continually fluctuating and re-constituting lteelf, continually being shaped by its intercourse with all forms of language, events and inetinctual drives. This self in flux, continually unmaking and remaking itself, is central to the slipperiness of nonsense and its location within the world of the text. The protean forme of Nonsense, which itself seeks to construe and construct a verbal 
universe, imply a reality in perpetual metamorphosis. For

" $L=A=N=G=U=A=G=E "$ poets especially, this implication extends to the very being of writer and reader, and can be related to a Heraclitean recognition that all thinge are in continual flux. Randa Dubnick argues that stein's use of repetition indicates such a Heraclitean reality (21). This fluctuating self can easily be related to the sipperiness of $" L=A=N=G=U=A=G=E "$ writing with it diminuation of the role of poetic voice and its reconceiving of author and audience, as well.

Marjorie Perloff, in "The word as Such: $L=A=N=G=U=A=G \times E$ peetry in the eightiee," contends that "the poet's voice functions as no more than a marginal presence, splicing together the given 'data'" (221). Rather than language being the medium through which the poet ' 8 voice or personality (or that which she assumes for each poem) is transmitted, the poet' voice eparsely supplements the tranemiseion of a linguistic "reality," serves as the almost invisible thread which sews the poem's verbal patchwork together. The "voice" presented in " $L=A=N=G=U=A=G=E$ " poetry resonates in the fractures and leaps, the fissures and echoes of the wrods themeelves. It appears often as nothing more than the principle governing "selection," as the eye (rather than "I") which collects and directs data. Since such writing works against a tranuparency of meaning, it evokes the shifting of a subject engaged in the very process of "being" which constitutes the act of writing and reading the text. The process by which the reader ferrets out the potentlal meanings of the text is also the process by which she relates the "vocal" idiosyncracies of the "author" to the idiosyncracies of her own perceptual world.

Charles Bernstein, in a telling critique of some extra-textual applications of Derridean theory, argues:

The lesson of metaphysical finitude is not that the world is fust codes and as a result presence is to be ruled out as anything more than nostalgia, but that we can have presence, 
insofar as we are able, only through a shared grammar. That our losses are not based on the conceptual impossibility of presence in the face of the "objects" of presence not being "transcendentally" locked into place, but rather on grounde that each person must take responsibility for -- the failure to make ourselves present to each other, to respond or act when the occasion demands ("The Objects of Meaning" 182).

This kind of relationshif with language or a "shared grammar" of meaning in use or context (Bernstein admits a stong wittgensteinian influence), results in a social, albeit fluctuating, self. It is a self, or presence, constructed out of the physical (as opposed to metaphysical) structures of language whose meanings are communally agreed upon. Such presence, tentative in comparison to the cryetalline logocentricity of formalism, is constructed throurh verbal agreements, interactions, explorations, through the graphic, phonic and sensical elements of a language which continues to "be," in flux.

Bernstein's stand on presence and language provides a useful response to radical deconstructionists; but it may also be borrowed to serve, if slightly stretched, as a cogent defence for Nonsense against charges of phonocentrism and metaphysicality. Nonsensical presence, as Iilburn' "Pumpkins" demonatrates, is communal, genotextual; it determines its own axis for the production of meaning and invites a reader to participate in a community-creating reading. By co-creating a shared grammar which articulates a limited presence, Nonsense and " $L=A=N=G=U=A=G=E$ " poetry blend, in admittedly differing ways, the roles of reader and writer. What Bruce Andrews says of "perceiver-centred" poetry can equally be said of Nonsense:

Language work resembles a creation of a community and of a world-vlew by a once-jivided-but-now-fused Reader and Writer. This creation is not inetrumental. It is immanent, in plain sight (and plain-song), moving along surface with 
all the complication of a charter or a town-meeting ("Text and context" 35 ).

Thie communal procese is self-determining in several ways; not only does it enable reader/writers to determine, temporarily, their "iselves," it is also established for individuale or a community by themselves and so not imposed upon them as are most forms of meaning. Andrewe' poetry beare this out too, as the following passage from a poem in Nobbling (quoted in Hartley 40) shows:

$$
\begin{aligned}
& \text { gaps } \\
& \text { shocks through }
\end{aligned}
$$

absorbing

hover

the aubjunctive

$$
\text { we' re }
$$

1 ess

thought:

Strange as it may first seem, the poers is a strong argument against culturally imposed constraints on reading, and for seeking out new ways of reading and constructing meaning. Reading as one would normally attempt to -- line by line, top to bottom, left to right -- little "enneo" can be made.

It's quite likely that much of the poem's impact would be lost if it were performed, since performance would probably limit the range of interpretative strategies available to the reader/listener, the performer would take on much of the burden of re-organization which, in the written version, falls to the reader. What Andrews' poen demonetrates is that alternatives, in the etyle of reading and expectations of the outcome of that process, do exiet and can result in varlous forme of sense. One can try to follow the traditional manner of reading and end up concentrating on each word individually; one can read 
from bottom to top, from right to left, or randomly. The most sustained and normative sense seems to result from reading inwarde from the left margin -- reading the words in an order based on their proximity to that margin; this method at least results in grammatically-acceptable phrases: "thoughts absorbing less hover we're gaps shocks through the subjunctive."

This sense culled from the poem also supports, in terms of content, Andrews' claims about form and thought. Thoughts do hover, stand in still-motion, when they aren't absorbing, working with, responding to their surroundings; though one wonders what they absorb "less" of. And it doesn't seem a theoretical stretch for Andrews to aay "we're gaps" -- especially if "we're" hovering through language in neutral, not actively engaging it or experiencing its process. If one doesn't work with and through language, one is a hole, a flssure in the communal constitution of the world; she is a "shock" (disruption) "through the subjunctive" (the conditional/self of existence). I wouldn't want to contend auch a reading of/into Andrews' poem is its ultimate or intended meaning; that would be contrary to the spirit of the poem and the poem itself. However one decides to re-configure it and to deal with its scattering of words,' the poem questions the process of reading, and calls for a new, exploratory relationship between writer, text and reader. These oddly spaced words are a means for comumunity.

The issues of the self, the reader and the writer, are tied to a much larger concern for many " $\mathrm{L}=\mathrm{A}=\mathrm{N}=\mathrm{G}=\mathrm{U}=\mathrm{A}=\mathrm{G}=\mathrm{E}$ " poets. In "An Interview with Tom Beckett," Bernstein points out:

It's a mistake, I think, to posit the self as the

The poem, with its scattered appearance, presents the illusion of randomness but is not an actual random or chance text. There is some element of conscious chaice which determines at least one axis of the puem -. for instance, Andrews chose the words of the poem, and chose ones which could be configured into a more or less meaningful text. Such a contention implicitly challenges the possiblity of the random text; even the chance works Cage produced using the I Ching have behind them the conscious choice to use the I Ching as a method for producing a text. 
primary organizing feature of writing. As many others have pointed out, poem exiets in a matrix of social and historical relation that are more oignificant to the formation of an individual text than any personal qualities of the life or volce of an author $(408)$.

Bernatein is not discounting the value of the author's "patterns of language - . and corresponding behavior or relevant quirks" (Hejinian, "If Written is Writing" 30) scattered throughout a poem in order to be forged into a tenuoue communal meaning heres rather he is recognizing that the socio-political context, more so than the author or reader, forms and informs the meanings of a text. Jerome McGann, in "Contemporary Poetry, Alternative Routes," writes that, for the writers of "perceiver-centred" poetry, "language is taken as the representative social form per we -- the social form through which society sees and presente itself to itself" (643). Language as a social form and force, or, more epecifically, the political expedience of reference, is the concern of the nest eection.

To Shew or Eschew the Fly?: Nonsenge and the " $L=A=N=G=U=A=G=E$ " Poet 's concern over Referentiality

"What is your aim in philosophy? -- To shew the fly the way out of the fly-bottle," muses wittgenstein in Philosophical Invertigationg I.309. This is his response to the restrictive claseifications, grammatical and referential, of Russell and yoore as they argued for a phllosophical use of language devoid of flux or socially generated moaning, a use whose hard and fast classifications created rather than resolved paradoxes. For Instance, since the word "mind" is a noun, Moore and Ruserell contended that in philosophical discourse it should behave as a noun does -- have location and attributes, some sort of concrete existence. But this, of course, contradicts the "sense" of 
mind. Wittgenetein's metaphor implies that the "fly" is alwaya, would alwaye be, free of the linguistic bottle if philosophers paid attention to the ordinary usage of language. Language's general, social and material functions prove the non-existence of the fly bottle. What wittgenstein argues for, here and in other places, is a renewed consideration of the social character of language and, in part, a rematerialization of language.

When McCaffery uses the metaphor as a springboard in the opening of Evoba, ${ }^{2}$ his meditations on the Invegtigations, he leaps in quite a different direction, and urges poetry to leap with him. The purpose of poetry, Mccaffery suggests, is to prove to the fly-bottle there was never any fly -- no reference, no contained or containable meaning. McCaffery's metaphorical twist departs from wittgenstein's original in several ways, not the least of which is his use of fly for my understanding of that use) to connote some sort of stable meaning. A socially-based meaning such as Wittgenstein promstes is uuc stable ur containable in the long run. Mccaffery's fly cannot exist in Wittgenstein's philosophy. Whether McCaffery's bottle can be convinced by poetry of the fly's nonexistence, a fly (or many flies) do(es) exist. In an attempt to liberate language McCaffery goes far beyond decontextualizing and twisting Wittgenstein's metaphor, however; he posits the impoesible -- a non-referential language.

The notion that reference is culturally determined is widely accepted by almost all of the " $L=A=N=G=U=A=G=E$ " poets; their position grows out of readings of theorists like Sapir, who promotes the highly controversial theory that people live "at the mercy of the particular language which has become the medium of expression for their society" (quoted in "Disappearance of the Word" 7). But Mccaffery has extended that notion in some quite radical ways. He argues, like many other

\footnotetext{
${ }^{2}$ See the first epigraph to this chapter.
} 
" $L=A=N=G=U=A=G=E$ " poete, that capitalist oociety and its distinctly claseist version of reality are transmitted through language by dematerializing 1t. However, he goes on to characterize and condemn reference purely in terme of a capitalist market economy.

The Capitaliat rationale ie: you can produce and consume everything and everywhere providing it flowe and providing it' $=$ exchangeable. Reference marke a point of extreme liquidity in the sign. It is, In fact, the line along which the signifier liquidates iteelf, exchanges itself for the other by means of the flow occurring along the surface of a grammatical meaning ("From the Notebooks" 161).

Reference, he suggests, being an exchange-oriented commodity, is merely a "surplus-value" (McCaffery, "Diminished Reference and the Model Reader" 13)." In fact, McCaffery goes so far as to suggest that reference is an example of commodity fetiehism in language: This linguietic promise that the ignified gives of something beyond language $1^{\prime}$ ve come to feel as being central to capitaliem (the fetish of the commodity) and derived from an earlier theologicolinguistic confidence trick of "the other life" ("Intraview" 189).

What he wante is a language of use-value, not of eurplus-value, a language which emphasizes the signifier and so the production, not the conaumption, of language ("Diminished Reference" 14). Such a view le purposefully polemical; like the other writers of this movement, McCaffery takes an extreme stance, pushing the isgue of materiality as opposed to reference to an illogical, almost Idealist, limit.

In his often insightful study, Textual Politice and the Lanouage Roete, George Hartley suggests that:

${ }^{3}$ This essay appeared in an earlier version titled "The Death of the Subject: The Implications of Counter-Communication in Recent Language-Centered Writing." 


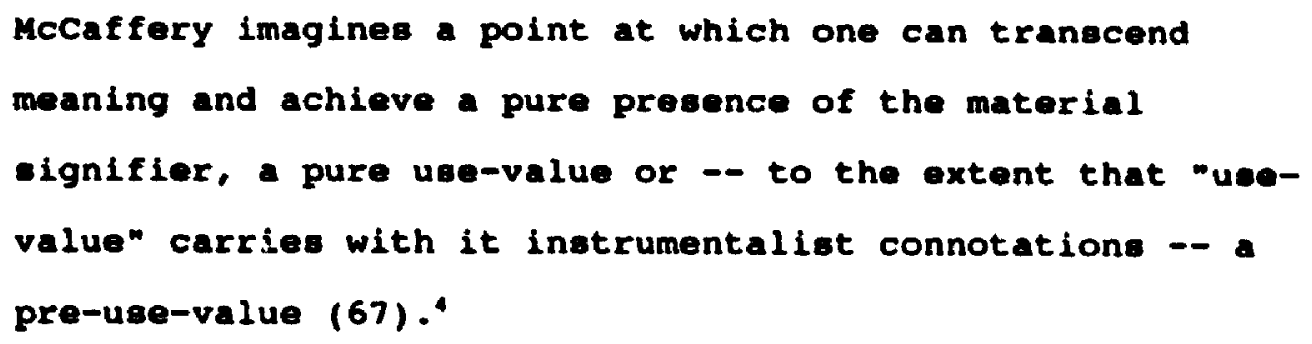

What this call for a "pure presence of the material signifier" suggeste ie that McCaffery really wants a non-referential language. Or wanted -he admite in "Nothing if Eorgotten but the Talk of How to Talk: an Interviow by Andrew Payne" that aspects of this approach have "certain naiveties" (124): indeed this approach's extremity pushed it into the realm of the unrealizable. A purely material language doea not exiat. unlese perhaps as music or gesture; it has no linguistic incarnation. Such a language is also not nonsensical, since, to borrow Mccaffery's early terminology, nonsense needs both use-value and surplus-value, both materiality and reference to be effective.

However, while Mccaffery admits there are limitations to his initia) emphasis on the purely material, he still contends that even if reference is not entirely fetishistic, s and if the invitation to the reader to join in the process of creating/completing the text smacks of "ideological contamination," literature should be read "not as forms and atructures, but as operative economies. Here," he continues, the notion of expenditure, 108s, the sum total of

\footnotetext{
4I is important to note that while Hartley offers a sound analysis of some of McCaffery's work, he ultimately presents a lop-sided view, wholly ignoring all of McCaffery's more "conventional" writing - conventional in the sense that he uses whole words, phrases, sumetimes even syntactically correct sentences. Every piece by McCaffery, which Hartley refers to, is a graphemic "collage" or sound poem. Thus, while Hartley gives a good reading of McCaffery's theoretical stances lbetter of his earlier ones than his later ones), he fails to consider many of McCaffery's writings that are more muted, less radical. McCaffery is willing and able to use referential language in exciting and innovative ways; he doesn't limit himself to a pure materiality.

5ackson Mac Low offers a telling response to McCaffery's orıginal claim of fetıshısm in "Language-centered" when he asks: "What could be more of a fetish or more alienated than shces of language stripped of reference?" -- if it could be, that is. Mac Low contends that it's impossible to subtract all reference from language (492).
} 
effects of a general economized nature, would emerge to ralativize the more "positive" utilitarian ordered reading $(124)$

Mccaffery represents the extreme version of what can be culled, roughly apeaking, one aide of the eplit over referentiality among

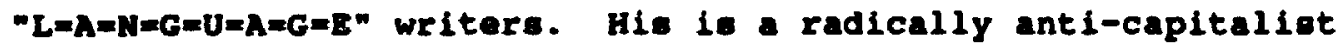
interpretation of the workinge of language, an approach which, finally, Is nelther easily combined with noneense nor a eucceseful defence of non-capitalietic lingulstic interaction." Nonsense's inability to reepond to or alleviate the concerns expreseed by this esentially nonreferential position is ironic aince some of McCaffery's theoretical work (as chapter four has shown) containe many ldeas which can be contrued as sympathetic toward nonsense. However, nonsenes is not ever, as chapter one's taxomony indicated, entirely non-referential, nor for that matter is language. Balancing meaning and non-meaning, sense and not ense, requires, not that reference be completely undermined, but that on come level reference be employed (often against itself) within Noneensical writing.

That is what Ron Silliman's approach to reference argues. silliman, an influential and important " $L=A=N=G=U=A=G=E$ " writer, begins from what appears to be the same point as McCaffery. But through some fine diecriminatione, he develops a much more workable (and, incidentally, nonsensical) understanding of the relationship between language and reference, an understanding which is not as radical or as elf-defeating as McCaffery' is.

- One of the most problematical aspects of relating reference with capitalism is the fact that reference existed as a central function of language long before capitalism existed. While some " $L=A=N=G=U=A=G=E "$ poets might defend their position by suggesting that the advent of written language initiated a division in society between the literate and the non-literate, and by extention the upper and the lower classes, such a defence seems naive, and uses an extremely loose definition of capitalism. The capitalist system may not urge an engagement with language's materiality, but neither do many non-capitalist societies. At best, then, the terminology used to criticize and explain capitalism can be used metaphorically to provide one way of interpreting how language may function. 
In a pivotal essay first published in 1977, "Disappearance of the Word, Appearance of the World," Silliman linke lingual transparency with the emergence of capitalist soclety. When words and meaning are "surplus," when they are blindly and blandly consumed, they become tranoparent. The title of the eseay, in fact, eaye it all, silliman' contention is that only by dulling the experience of language to a point where one looks through, not at, language, can a capitaliet society appear ae the "given" it would like to be. The implication is that an appreciation of the materiality of language could insidiously lead to a diseatisfaction with a society which emphasizes a continual abetracting, moving away from the physicality of making, using, doing.

"Surplus-value," and its resulting consumerism, is passive and inert. The vast majority of people are isolated from the processes of production by it, and, silliman contends, they are equally isolated from involvement in the production of language. "What happens when a language moves toward and passes into a capitalist stage of development," he suggests,

is an anaesthetic transformation of the perceived tangibility of the word, with corresponding Increases in its expository, descriptive and narrative capacities, preconditions for the invention of "realism," the illusion of reality in capitalist thought. These developments are tied directly to the function of reference in language, which under capitalism is transformed, narrowed into referentiality $(10)$.

As Jerome MeGann points out $(640)$, Silliman makes an important distinction between reference and referentiality. To be fair, given his corpus of essays on this problem, it is referentiality not reference which is the ailly corpse silliman writes of. That words refer is not the problem; the problem is, for silliman, that capitalism requires worde to do nothing but refer, to reside inertly on the page with a 
readily discernible meaning waiting to be culled from them by a reader who demands of her thinking faculties the least possible effort. And capitaliem, silliman suggests, in order to remain pre-eminent, requires that these worde refer to ite notion of the world. Lee Bartlett. characterization of the movement' general respones to reference is in accord with sililiman's:

The lesue is not, then, reference per se, but a reaction to a prevailing poetice which seems to be unawere of the cocial implicatione which hover just above ite acceptance as a first given of an unquestioning referentiality ("What is 'Language Poetry'z" 748).

A frequent metaphor for this blandly referential aspect of worde if the window. In "Writing Social Work \&olitical Practice," Bruce Andrewe puts it this way:

One mode of writing tips its hat to assumptions of reference, representation, transparency, clarity, description, reproduction, positivitum. Words are mere windows, substitutes, proper names, haloed or subjugated by the thinge to which they seem to point (133).

of course, these windows, one assumes, are well-washed -- without dirt, grit, or scratches; and no screens, nothing to impede the clarity of view, the tranemiesion of vision. Not all windows, one should be quick to say, can be so easily looked through and dismiseed; some, like the stained glass in Hejinian's Ky Life are beautiful in and of themeelves, foreground their own materiality -- their colour, texture, subtle imperfections -- while simultaneously offering a transformed view of "reality" beyond. As the final inter-chapter will ohow, Hefinian's is a language of colour and artietry, a language which refere to itwelf and to referente. Like stained glase, it is a language which makes iteste obvious.

For far too many peopie, however, language functions in a 
tranoparent manner -- it informe, it is not continually reformed. To argue in favour of such a use would Indicate, at the very least, a naive viow of language. But the inalatence that this function of language is capitalietic in nature and intent overlooks obvious counter-arguments and extende itself into overatatement. For inetance, the socialist Realiam of the stallniet ora bred what 1s arguably the moet polemical and uninteresting use of language in this century. Silliman would, I think, lay the blame on the use of "realiem," capitalism' "illueion of reality" (10); however, even this defence can't deny that the problem if realism more so than capitalism, and that, no matter who developed it, realiem is available for the diseemination of any socio-political viowpoint. ${ }^{7}$

$$
\text { silliman also argues that literature' movement from communal }
$$

event to individual pastime can be traced from the birth of the printing prese right back to the invention of the alphabet, "the Initial, precapitalist, division of labor in language" ("Disappearance of the Word" 12). The implications of this attribution of lingual labour division, that written language is the precursor to humanity'socio-political fall, are blatantly phonocentric and suggest a surprising naivete. Another position which silliman takes in the essay which seems, at firet, to be equally problematical is his idealization of geatural language, something he locates contemporarily in the nonsense syllables

'In a fascinating essay, "Strangeness," Lyn Hejinian meditates on the possibilities of another form of realism. She says,

I don't mean after-the-fact realism, with its emphasis on the world described (the objects of description). nor do I want to focus on an organizing subjectivity (that of the perceiver-describer); nor, finally, am I securing the term to a theory of language. I propose description as a method of invention and of composition (32).

Hejinian uses the analogy of scientists or early explorers who, not knowing what about their new discoveries would be valuable, made note of all things equally. Such realism revels not in ordering the world, but in pointing to it. She suggests,

it is exactly the strangeness that results from a description of the world given in the terms "there it is." "there it is." "there it is" that restores reainess to things in the world and separates things from ideology (44).

What she calls for is a realism which escapes the constraints of genre and which, recognizing the fullness of language, presents a reality "ordered" sensually and linguistically. This, as will be seen, is the order of My life. 
of varloue tribal cultures. In the unrevieed version of "Disappearance of the Word, "Silliman praises gesture as the earliest and moet Independent form of reference:

In its primary form, reference takes the character of a gesture and an object, such as the picking up of a stone to be used as a tool. Both gesture and object carry their own integrities and are not confused: a sequence of gestures is dietinct from the objects which may be involved, a dietinct as the labor procese is from ite reaultant commoditiea $(L=A=N=G=U=A=G=E$ Book 125$)$.

A gentural language, one assumes, requires activity, production, particlpation and completely precludes "consumptive" referentiality. silliman' model is not a verbal language and does little to euggest what the nature of the reference betwes.; object and gesture is, or how that nature can be translated in worde; does the picking up of a stone for a tool refer to the etone? to ite availability as a tool? Is It perhape an example of metaphor? Is it a radical example of meaning as use -- the picking up of a stone means tool because I use it this way? How does such a model entertain the referential capabilities of noune? since all genture is active, is a gestural language ontirely constructed out of active verbe?

His model of how the expressive purity of such gesture is to be carried over into language (through lts material nature -- rhythm, rhyme, nonsense eyllable) creates a tempting solution, however. This is eapecially true eince, as I have already argued, the materiality of language is what, in the usual act of referring, interferes with its

- Silliman's text, originally printed in A Hundred Posters 14 (1977), appears in its unrevised version in The $L=A=N=G=U=A=G=E$ Book (121-32). A slightly modified version is in silliman's volume of collected essays The New Sentence. All references to the essay, except the one to which this note is appended, are from the modified version. Part of the quotation which follows has been removed in the newest version of the essay; this removal does not alter Silliman's stance about gestural language. Because the unrevised version fits more smoothly and clearly into the process of my argument, I have chosen to use it here. 
abstract referential powers, rhyme, rhythm, alliteration and other materialist techniques are the scratches and impurities on the referential window of language. They incorporate procese into language, and in doing so they divert attention from pure referentiality. It. a charming paradox -- the remnante of a primary form of reference disarm paseive referentiality. An ${ }^{*}$ it brings quite dramatically to the fore the notion that the importance of the act of referring is not to be diemiased out of hand. Rather an untempered, passive gleaning of reference, the debasing of the word to referentiality (to reference only). 15.

Ten years after the publication of "Disappearance of the Word," silliman locates in realiem, the genre for which a transparent referentiality is central, the sort of conundrum which his earlier views of gestural language implied. "The utopia of realism," he writea:

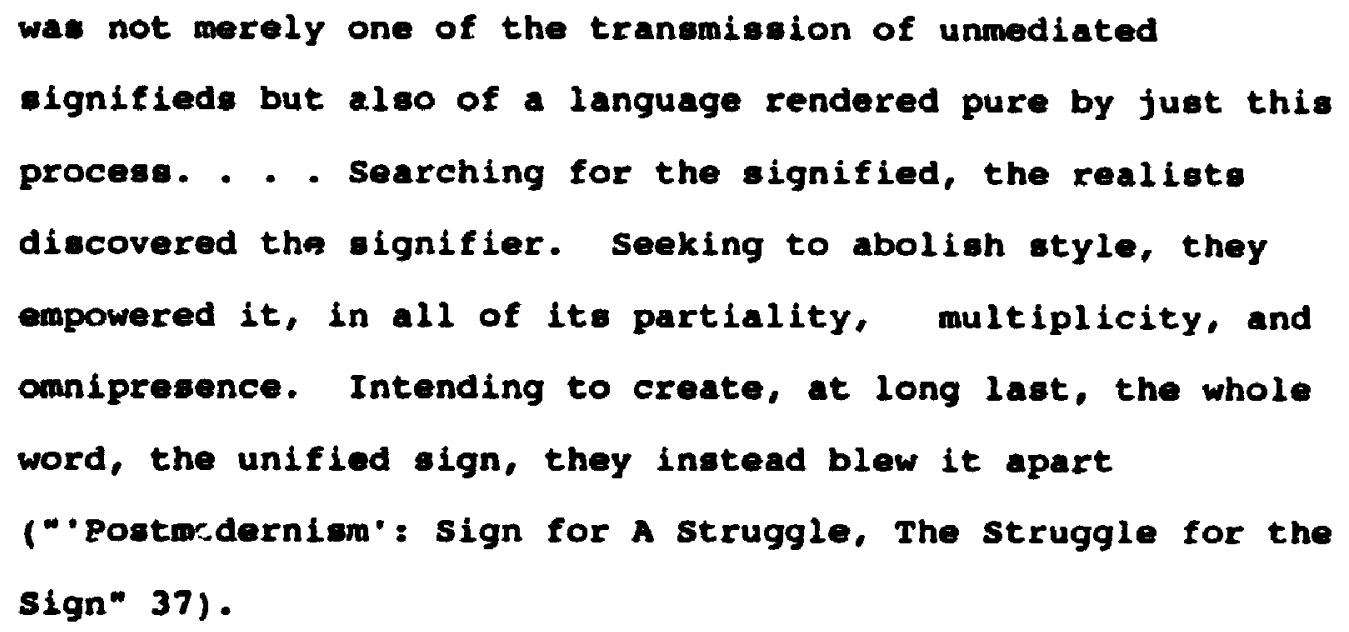

The Ignified, realism and referentiality rely on the signifer, the very thing they intend the reader to ignore, to look through. Such a reliance has built into it the need for a stylized attention to the -ignifier, a preservation and polishing of it to ensure ite functioning which reeulte in its appearance, not its disappearance.

Bernatein agrees that it 18 not the end of reference which "perceiver-centred" writing seeks, "Not 'death' of the refurent," he writes, 
-- rather a recharged use of the multivalent

referential vectors that any word has, how words in combination tone and molify the assoclations made for each of them, how 'reference' then is not a one-on-one relation to an 'object' but a perceptual dimension that closes in to a pinpoint, nail down (thig word) ("Semblance" 34). One way to recharge the use of "referential vectors" is by "[making] the etructured of meaning in language more tangible and ill that way allowing for the maximum resonance for the medlum" (35). It is this which $" L=A=N=G=J=A=G=E^{n}$ poetry and Nonsense eeek -- a reverberating eort of reference, a language which, like Wittgenstein's fly, has been shown the way out of the fly-bottle, not eschewed; how this is achieved will be discussed next.

\section{"The condition of ite vordnege" : The Shared Kateriality of "IEA=N=G=UEA=Gex" Writing and Nongenge}

One of the major premises of this study is that nonsense is the expression of semiotic materiality erupting into the conmunicative and rational aspects of language, an eruption which is absolutely simultaneous with the production of language. That is, without the eymbolic' traneparent repository for language the semiotic chora would have no place to erupt; and conversely the symbolic cannot exist without the hypothetical pre-existence of the same chora. This symbiogis 18 essentially the paradoxical relationship often acknowledged between reference and materiality within "Language-centered" writing." That the principles of Honsenes and " $L=A=N=G=U=A=G=E "$ poetry are so closely aligned is clearest in the extremity of their methods for making

"I should reiterate that this "movement," like any other group of people, is not in complete agreement over any of the issur $s$ raised. This generalization indicates a point of relative consensus which is attended by a great many subtleties and points of contention. 


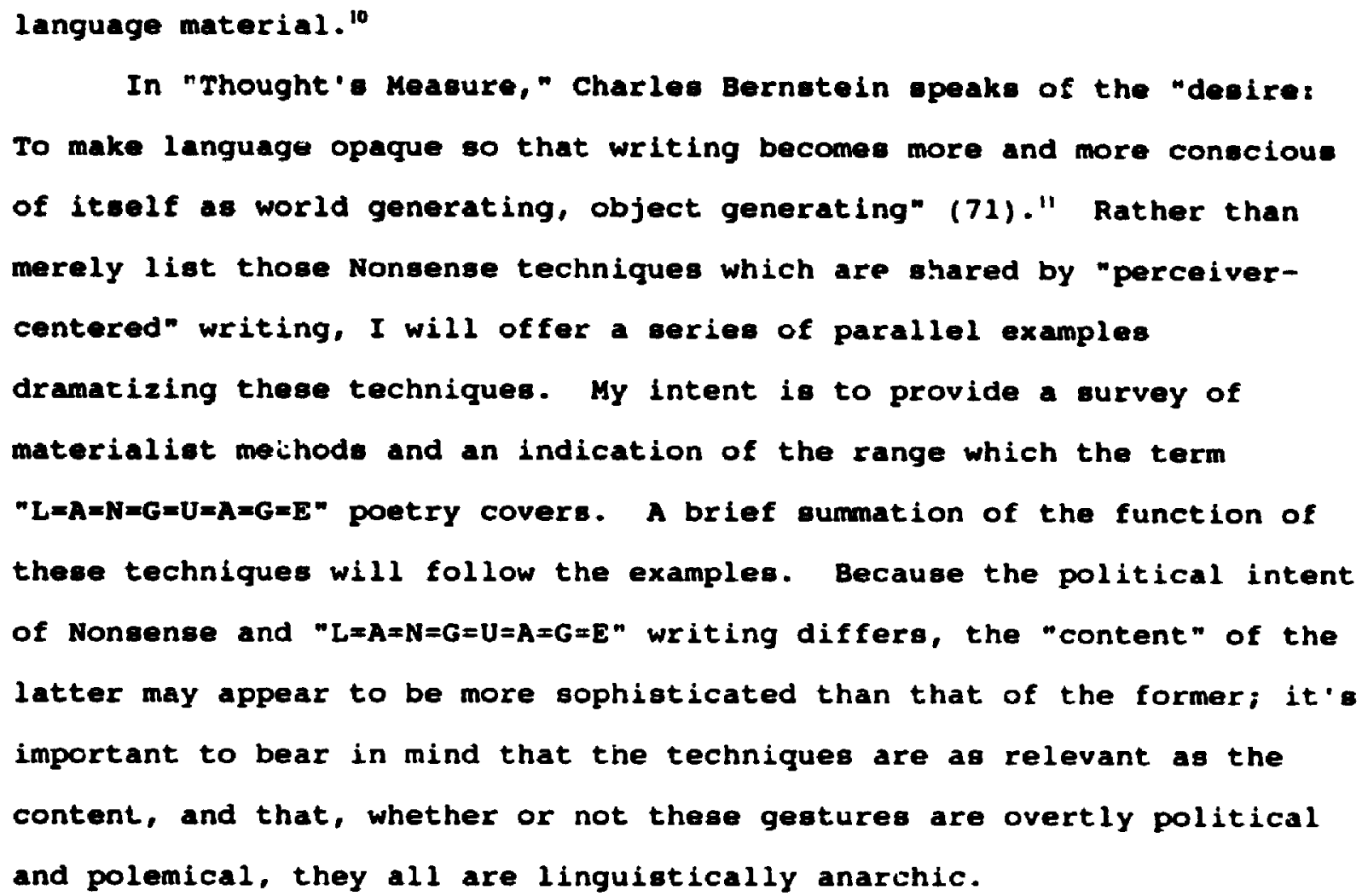

10 It' . urtant to note that there is one very large rifferent between Nonsense and $-L=A=h=G=U=A=G=E^{\prime \prime}$ poetry -- the same "whit $h$ exists between Nonsense and ecriture feminine. Nonsense is avowedly apolitical, drawi,y attention to the politics of our structures of meaning but offering no one polemical response to that politıcal nature. " $L=A=N=G=U=A=G=E$ " poetics are for the most part Marxist or Soridist in perspective and point their linguictic revolutions in those directions.

11 Clearly Bernstein makes a distınction betweer, critıcal and creative writıng here. While many " $\mathbf{L}=\mathbf{A}=\mathbf{N}=\mathbf{G}=\mathbf{U}=\mathbf{A}=\mathbf{G}=\mathbf{E}$ " poets, including Bernstein, proouce theoretical and critical writings which defy the traditional and commuiucative norms of such genres, the attempt to write about abstractions in a re-materialized language emphasizes the limitations of a fully material means of communication. The quotation from Bernstein to which this note is appended, for instance, would be vastly different land possibily less effectivel if he used language which approached the level of materıality which McCaffery originally sought. 
forms. The traditional form of this technique often appears in Lear's prose, especially as a means of naming: "Diaphanous Doorscraper," "the Co-operative Cauliflower" and "the Tropical Turnspitg" are just a fow examplee ("The Story of the Four Lit':le Children" 106, 102, 94), however, the best example is the long passage describing the Even-song of the Blue-Bottle Fliee quoted in chapter one. Carroll." "The Hunting of the Snark" is equally rich with its entirely alliterative cast of Baiter, Bellman, Boojum, Barrieter, Bandersnatch, Broker, Beaver and others. Even the Snark turns out to be a Boojum.12

This device is also found such in "Language" poetry as Susan Howe' Defenestration of Praque:

\author{
Right or ruth \\ rent \\ to the winds shall be thrown
}

words being wind or web

What (pine-cone wheat-ear

sea-shel1) what

("from 'speeches at the Barriers'," quoted in Messerli, "Lanquage" Poetrieg: An Anthology 34 ).

Certainly in Lear's case, sense is dirested by the sound; the meaning or applicability of a word is made secondary in importance to an often arbitrarily determined phonic pattern; the doorscraper may be labeled "diaphanous" because the sound of the word fits the patterning of the prose. So the music of a word matters as much as, if not more than, its relatively abstract designatory functions; such an exaggerated material

12 Reading Carroll's poem from this perspective helps one respond to those critics who claim "The Hunting of the Snark" is a working through of existential angst. The animating tension of the poem is "to 'B' or not to 'B'" as opposed "to be or not to be." 
function ie typical of nonsense. While the alliteration in Howe's poem does not reach the excesses one often finds in Nonsense verse, one sill euspects that word inoice has been limited, if not entirely governed, by the phonic patterns working within her text.

A more interesting and less common form of alliteration also found in Nonsense and " $L=A \sim N=G=U=A=G=E$ " poetry might be called "alphabetization"; this involves a sequence of "poems" governed by the alphabet, in which the whole of each "poem" is built around one letter. Again Lear provides the most obvious Nonseneical example with his many "alphabets." Take for instance the letter " $V$ " from "Twenty-six Nonsense Rhymes and Pictures":

The visibly Vicious vulture, who wrote some Verses to a Veal-cutlet in a Volume bound in Vellum (219).

bp Nichol's Aleph Beth Book bases each of its 26 concrete poems on a letter of the alphabet (see Fig. 13). And Tina Darragh, commenting in "Procedure" on her interest in the dictionary' and alphabetical organization, says:

what interests me is the coincidence and juxtaposition of the words on the page in their natural formation (alphabetical order). In reference to each other, they have a story of their own (108).

In such foems as this one from on the corner to off the corner, she meditates on the relationships between dictionary entries:

"'oilfigh' to 'old chap' for 'C'"

Performing military service for the king and bearing a child have a common medieval root. The progression to this point 1. first academic, then technical. Textbooks give way to

\footnotetext{
${ }^{13}$ The organizational premise of the dictionary, as chapter one pointed out, is itself nonsensical.
} 


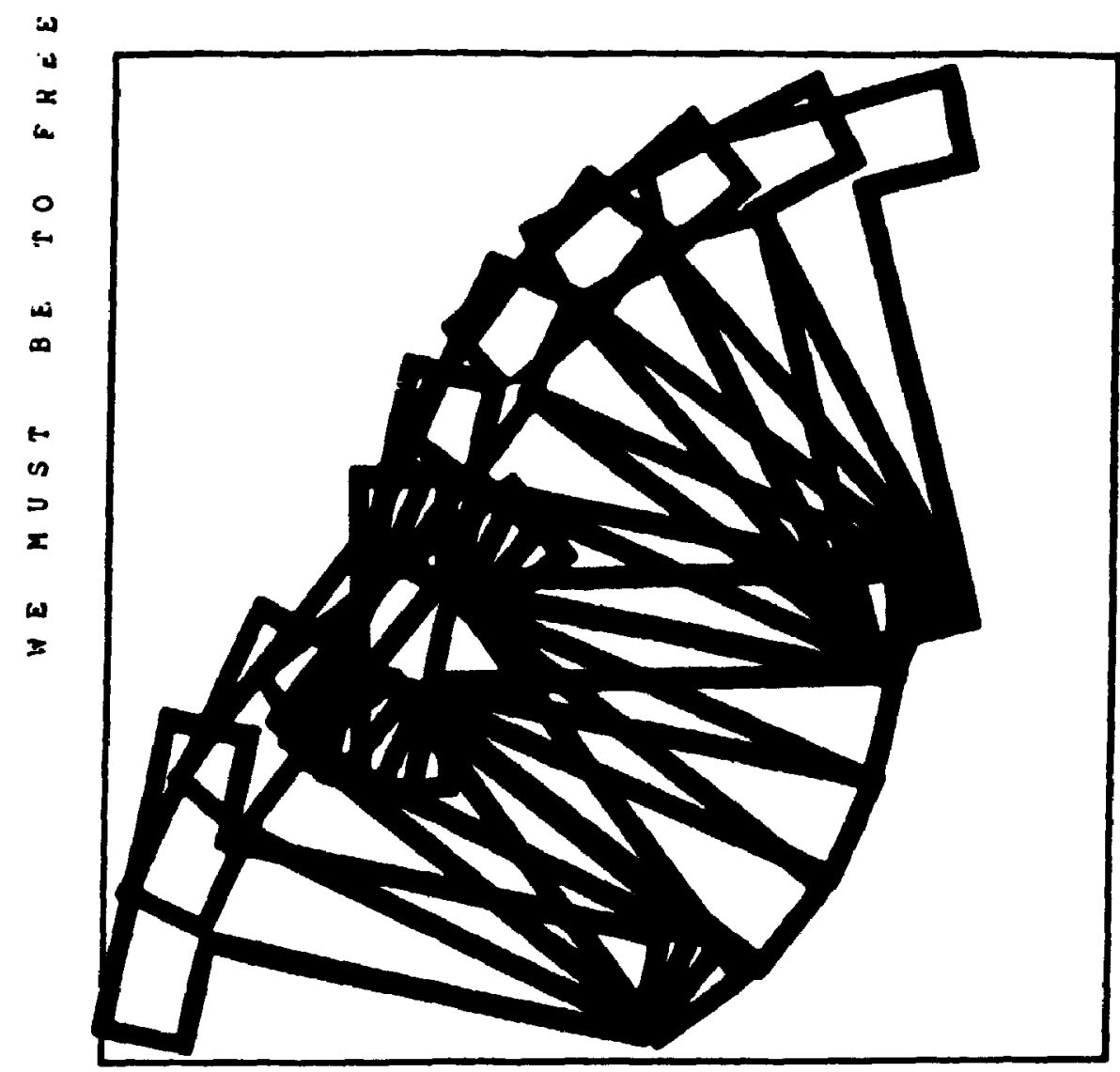

256

$\underset{1}{a}$

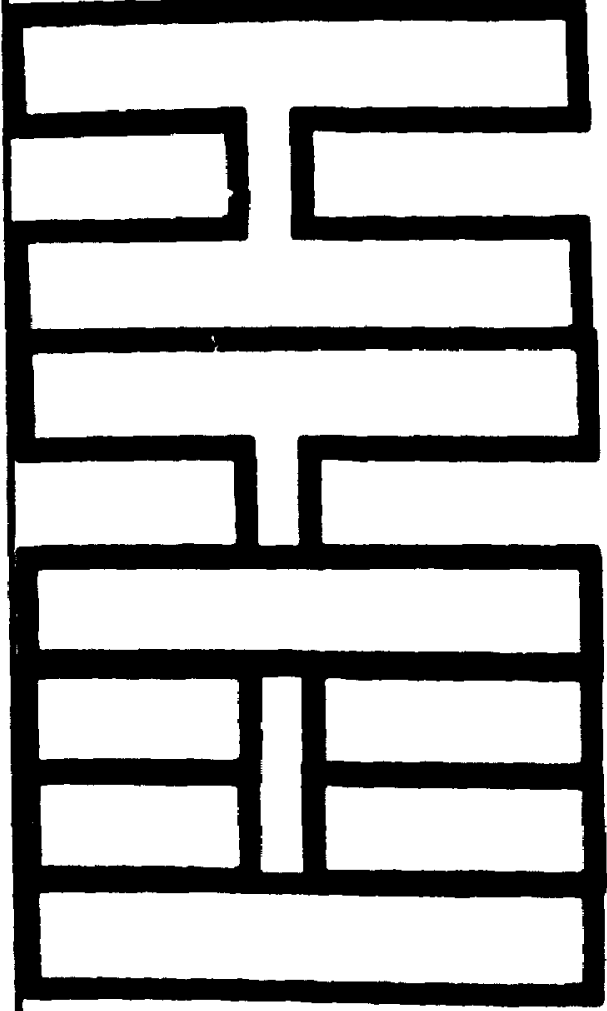

$\dot{0}$
$\overrightarrow{0}$
+
0
0
$=$ 


\section{$25 \%$}

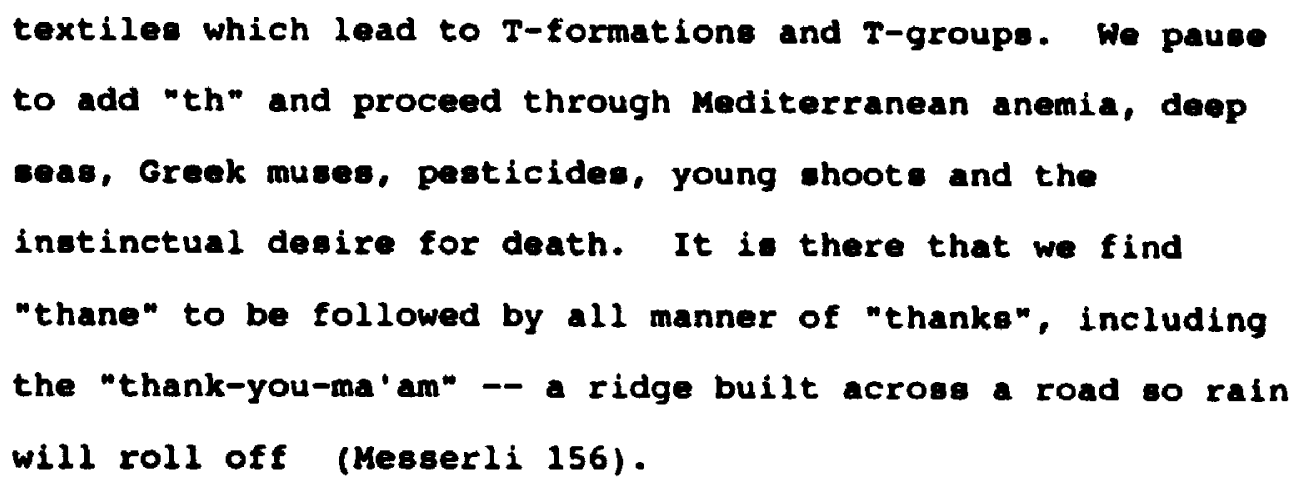

Homonyms: Both groups of writers explore homonymic conetructions, and the disparity between the written form and the sound of words. Lear's most famous example is probably this song found in his story "The History of the Seven Families of the Lake Pipple-Popple":

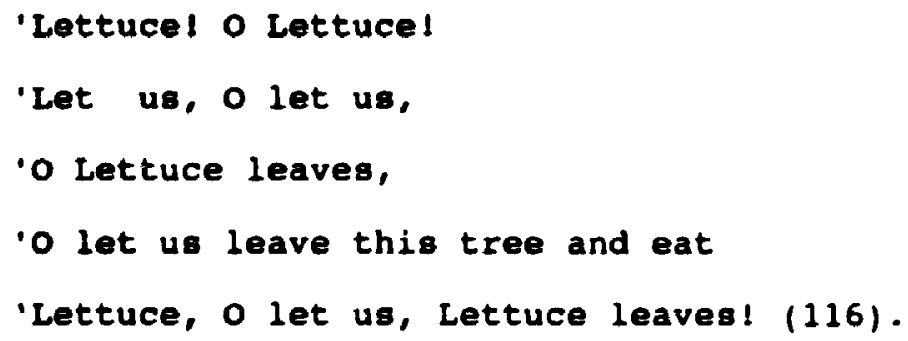


the fact that language exists in several different ways simultaneously.

Juxtapogition: Another shared technique, juxtaposition appears most often in Noncenee as an anarchic dielocation, or the joining together of phrases or referente which have no clearly articulated, or seneical, connections. It has already been briefly considered in the context of Lilburn': "Pumpkins." Contemporary Nonsense author/illustrator, Edward corey, however, uses a juxtaposition more akin to that found in the "L=A=N=G=U=A=G=E" writers. The Helplege Doorknob, a "shuffled story," ie a series of twenty cards which can be read in $2,432,902,736,640,000$ different waye" (n.p.) and which is meant to be shuffled into an almost infinite number of non-sequiturs and juxtapostions. Its only organizing principle is alliterative; each sentence and every proper name begin with the letter "A":

Albert left for Peru. Agatha taught Adolphus to dance the one-step. Ambrose took an overdose of sarsaparilla. A myeterious urn appeared in the grounde. Agatha pedalled to the neighbouring village for help. Andrew received a post-card from Amaryllis.

Gorey' story carries Nonsense's use of juxtaposition into the realm of the seemingly random, an area already entered by writers like John Cage, who relies heavily on what he calls "chance operations," or bp Nichol, whose anthology of concrete poetry, The cogmic chef, and poem, still water, are boxed books which can be read in a multiplicity of orders. other, sightly less radical, examples of juxtaposition abound in this poetic movement. Hejinian' Hy life, the subject of the next inter-chapter, shows her use of non-sequitur, and stands as a fine example of her own theory of a realism of "strangeness" being enacted. A remarkably witty and successful example of juxtaposition and collage i. David Bromige's "My Poetry," a ten-page prose piece which blends together snatches of reviews (laudatory and critical) of his work with a 
refreehingly cavalier reponee to criticism. Here's a sort (and metaphorically relevant) excerpt:

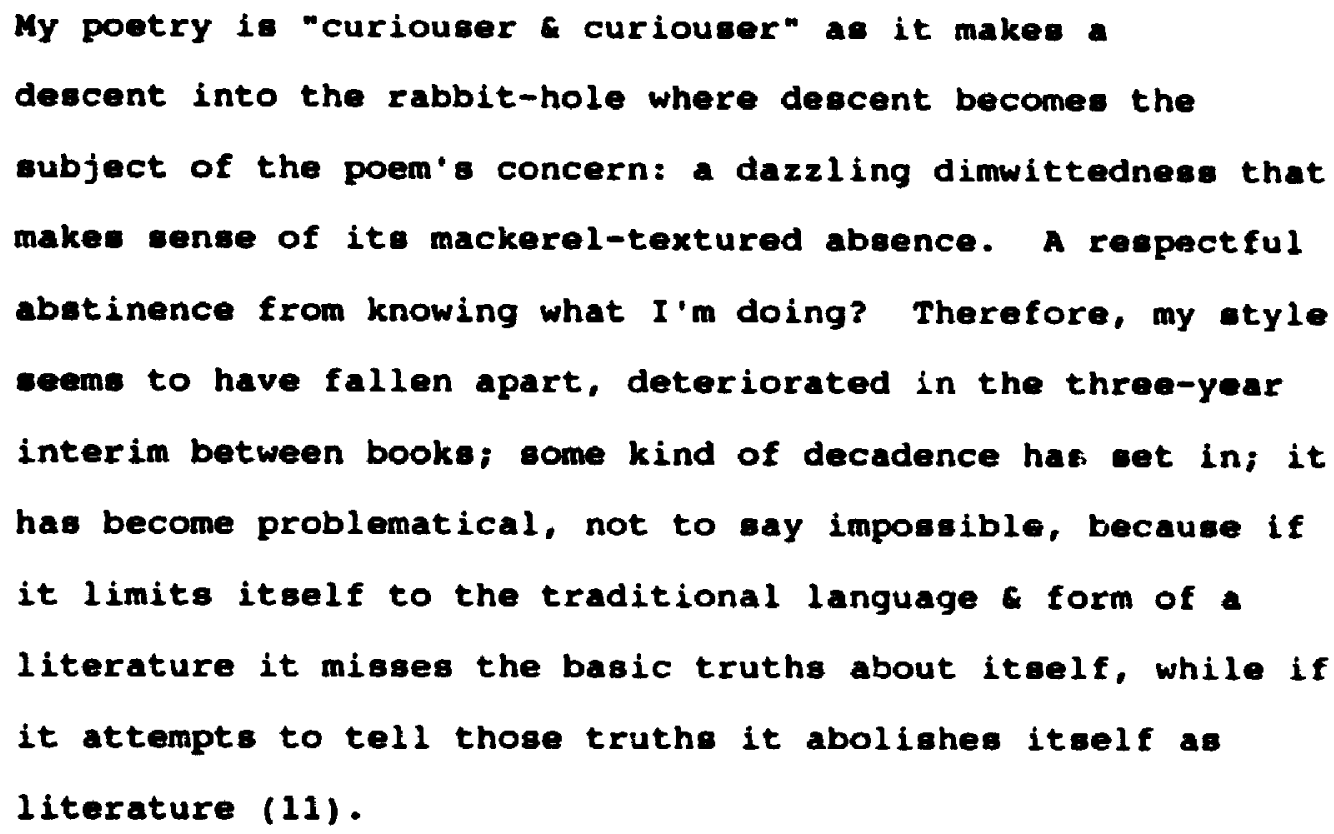

Palindromes, Paragrams and Play: Reading words backwards or fragmenting them to find other words is another shared technique. Sylvie and Bruno in Carroll' sylvie and Bruno concluded consider the palindrome EVII/LIVE (Complete Workg 529). Nichol's The Martyrology is rife with the dis-assembling and re-sssembling of words; one of its basic techniques is the breaking open (and secular personification/canonization) of words which begin with "st"; "gtriking" becomee "st. Riking," "strange," "St. Range"; "stand," "st. And" and so on." such language play defies traditional orders of reading and regarding words. The word becomes a sequence of elementa to be reconfigured, re-arranged, re-read.

Phonemic Shifte: Carroll's use of such shifts and their implications has

14 Nichol's playful re-configuration of language here uses another technique, abbreviatıon, whuch is also potentially nonsensical since it alters and draws attention to a word's material nature (visual, phonic) while maintaining its referential nature. 
been diecuesed quite exteneively in chapter four's look at the "pig"/"fig" queation in Alice's Adventures in vonderland. A similar instance of this whit occure earlier in the novel when Alice, falling down the rabbit hole, wonders "Do cats eat bats? Do cats eat bats?" and sometimes 'Do bate eat cats?' for, you see, as she couldn't answer either question, it didn't much matter which way she put it" (20). Hejinien'. Hy Life engages in such phonemic rambunctiousness too: "Between plow and prow" (65); "The grass in my glass" (68). And Darragh's "olzfich' to 'old chap' for 'C'," quoted above, demonetrates ac Marjorie Perloff points out, "the vagaries of worde that can, with the shift of a angle phoneme or two, mean such different things as 'thane' and 'thanks'" ("The Word as Such" 216).

Bepetition: Like many of the techniques considered in this section, repetition is commonly found in many other forms of writing. An exaggerated or distorting use of it, however, is typical of Nonsense and " $L=A=N=G=U=\lambda=G=E$ " poetry. In Nonsense, repetition can take many forms: the repetition of eingle words, phrases, lines or refrains. Lear covers the whole range of repetitive styles -- from the repeated last words of hie self-enclosing limericks, to the more traditionally poetic refraine of "The Pelican Chorus":

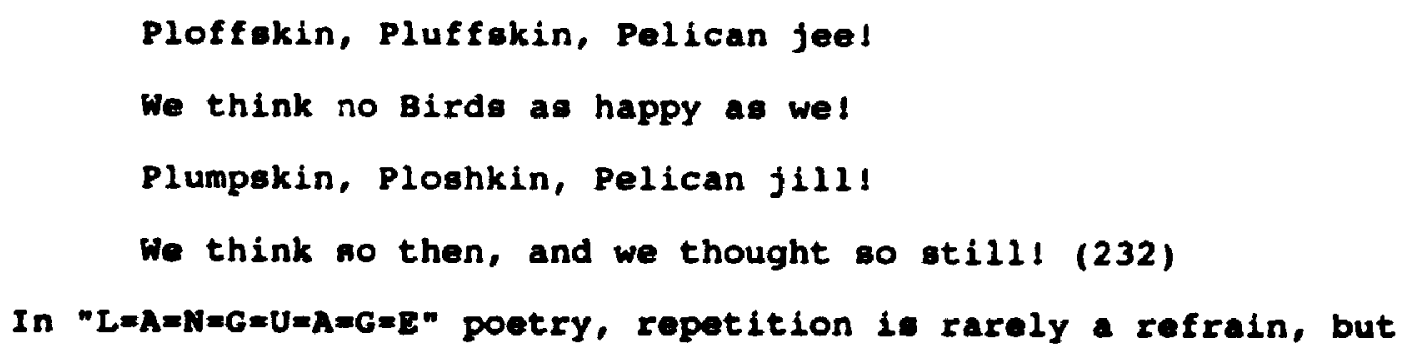
words, phrases and lines are frequently repeated or re-used in varying contexts. Such repetition, as will be demonstrated later, is central to viche and is also a major structural factor in silliman's ketiak. It frees words from a eingleness of meaning, allowing them simultaneously to accrue other meanings based on their new contextual uses and to 
acquire a structural and phonic meaning. They begin to mean as textural components, as nodes around which the text composes itself; and perhaps even more importantly, they begin to mean as sound.

Rhyme and Rhythm: Chapter four has already argued for the importance of these two elements in a Noneensical writing/reading of poetry. In claseical Monsense thyme and rhythm are companions as conetant as Lear's Owl and Pusey-cat.

The Owl and the Pusey-cat went to sea

In a beautiful pea-green boat,

They took some honey, and plenty of money.

Wrapped up in a five-pound note.

The owl looked up to the stars above,

And sang to amall guitar,

- 0 lovely Pussy! o Pussy, my love,

What a beautiful Pussy you are,

You are,

You are!

What a beautiful Pusay you are!" (61)

" $L=A=N=G=U=A=G=E$ " poetry rarely uses such overt and rhyme since it resiets conventional forms; rather rhyme and rhythm tend to be subtly internalized as in these "sentences" from ky hife and Ketiak respectively: "Raisins, cheese, the Japanese" (64); "This day's reaches features peaches" (20). The latter example features assonantal as wall as true rhyme. Because this use of rhyme is internalized, its subversiveness is more textural, less structural, than the strongly defined and definable rhythmic units found in much Classical Nonsense. Yet in both types of rhythmic and rhyming incursion -- subtle or overt -- cound manipulates, challenges, sense's normal place of privilege. The musical movement of the words vies with their meaning for supremacy. 
All of these techniques, and many othere (euch as puns, neologiame, and anagrame) are attempte to centre language and poetry on "the condition of [their] wordnese" (Bernatein, "Three or Four Thinge" 29-30). When one eubscribes to the myth that the referential capacity of language pointe solely to the exterior object for which each word is a eign, or when one Ignores language' Innate abilities to point -imultaneously to an exterior object and to iteelf, then language -- as the writere of percelver-centred work ergue - - is de-materialized. If on '- percoptione and underotanding of the world are filtered through and expreseed by language, then fabricating and privileging a world which is linguietically transparent and tranecendental results in the 10en of a variety of poseible worlde, in the linguietic textures which would make those worlde viable. Through a careful attention to linguietle detail in the procese of reading or writing, however, one can dwell in the algnifier. A new awarenese of language, with a heightened attention to ite part in the creation of sense, can allow one to experience the making of meaning. Then one can re-integrate her view of the world lnto a balanced materiality.

Such a material language needs, however, neither to undermine skeptically the material existence of the exterior world nor to nullify the poesiblity of presence within that world. Bernetein pleade for "the doeper reality of the interpenetrability and interdependence of all oppositions as appositions" ("I Think I Understand" 287), a elmultaneoue merger and co-existence which a emanalytic approach to Noneenee maintaine is typical of this genre and this type of linguigtic deformation. In "The Objects of Meaning," Bernetein argues as well for auch a bridging, conflating or blending of the function of the olgnifier and eignified (a very Uonsenalcal prospect) when he writes One might eay, againet Derrida, that desiring production is the "primary elgnified," if that is underetood as production of a form of life, where worde have 
truth where they have meaning, In yee (182).

Calling attention to the material procesees of language as a type of maning, and eplitting or momentarily diverting a reader' attention from (as opposed to destroying) traditlonal senes in this manner allowe for the combination of the functions of aignifier and aignified and the reconetitution of the eign within a Noneensical paradigm. The eign becomer a palimpeest which lete both elgnified and signifler show through it; abetract and concrete qualities reside in it aimultaneously. When different eign syotems are situated upon each other in order to put preseure on the sign -- and it should be pointed out that many of the techniques used to heighten a word's rational nature are as much muelcal or painterly (for instance, cubiet juxtaposition) as they are 1 ingual -the nature of the sign itself is challenged and changed. To rematerialize language, then, is to re-define the eignifying process, to re-locate it within the realm of the signified and so fundamentaliy alter the etructure of the eign.

Author a Grammar:

Towards Hew Grammatical porma

Such alteration of course causes serious ripples in grammar, but does not call for ite overthrow or elimination. While gramnatical principles can be ueed to promote linear and one dimeneional language, grammar is not, as Mccaffery claims,

a huge conciliatory machine (which assimilates] elements into a ready structure. This grammatical structure can bo likened to profit in capitaliam, which is reinvested to abeorb more human labour for further profit ("from The Notebooks" 160 ).

Grammar is an abeolutely eseential factor in the manufacture of the type of 1 inguistlc experiment which lntereste both Nonsense and $" L=A=N=G=U=A=G=E$ " writer. Not only does it, as one manifestation of the 
Krieteven eymbollc, make possible the expression of the chora, those material energies which re-establish language within the body and the phyeical world, but it also throwe into rellef the immeneity of the avant-garde' aubveraion of language. If all semblance of atructure and reference has been nullified, then the subvereivenese of the gesture ie overwhelmed by the pure physicality of the moments the complete eredication of the thetic (as such a nullification would indicate) could only suggest a poychle upheaval of such magnitude that one would be thruat back into the a pre-symbolic wildnese of the nowborn. Chomaky' three levele of grammar -- grammaticality, Iemigrammaticality and ungrammaticality -- help illuminate the ripples within elgnification caused by the creation of the Nonsensical, palimpaestic sign in a more practical way. Marianne Dekoven, in $A$ Different Lanqunge, her insightful etudy of Gertrude stein, suggest. that it is semi-gramaticality, not ungramaticality, which makes posaible avant-garde writing. 's Phrases like Chomsky' example of this second degree of grammaticalnese, "colorlese green ideas eleep furiouely," are, De Koven argues, "meaningful, readable, suggestive, resonant" (10). Semi-grammaticality, she continues, not only undermines or fragments coherent meaning, it also subordinates meaning altogether to the linguietic surface, the signified to the signifier: we notice the etrangenese or Ereshness of the verbal combinations themselves -- the words "atand out" as words -- before we reginter consciously their dedetermined, unresolved articulations of lexical meanings (11).

is It should be noted that the text of sound poetry constitutes a special case which is, if anything, agrammatical -. especially if McCaffery's characterization of the texts for sound poetry as a thetic interface is accepted. Since the thetic is nof a part of the symbolic, merely the point of transition into, or the point of creation of, the symbolic, the thetic can claim no real degree of grammaticality. Rather it has a peripheral relationship which does not actively participate in grammatical production or destruction. Such is the text of the sound poem; the actual performance however is, according to McCaffery, the oral release of libidinal drives and so is usually an ungrammatical assaut on meaning and order. 
While De Koven' deecriptica of the procese of semi-grammatical signification differe from my view of the dynamic of Nonsense in her insistence on the primacy of the signifier over the aignifed (a palimpsestic si, 2 requires that uneasy balance which is integral to Nonsenae), it should make clear the fact that in eemi-grammaticality the re-aligned "power" structure of signification finds its most cogent expreseion. Pure grammaticality is a grammar of the old eign, where the referent and referentiality atand ae privileged componente; ungrammaticality is a grammar of a completely defused aign -- defused in terms of potential to function within a signifying aystcan, and defused in terme of ite organization, that is, broken apart. If semigramaticality is to male "sense," it requires participatory reading and shared grammar, the authoring of a communal grammar -- a theme that has reverberated throughout this chapter. Before looking at samples of work by stein and silliman which engage this semi-grammaticality, I'11 consider the rules of one communal grammar which has become quite widely accepted within the " $L=A=N=G=U=A=G=E$ " movement - silliman's notion of "the new sentence."

Silliman's theory takes the sentence as the limit of grammatical or lingual organization. "The sentence is the horizon," he contends, "the border between. . . two fundamentally distinct types of integration" ("The New Sentence" 87). These types of integration are, on one hand, the arranging of lingual units into sentences, and on the other hand "higher orders of meaning -- such as emr: " (87) which integrate collect, ins of related or independent sentences. The paragraph is no longer "a unit. . . of logic or argument" (90) but rather a "guantity, a stanza" (90). That being the case, silliman suggest:

the torquing which is normally triggered by linebreaks, the function of which is to enhance ambiguity and polysemy, has moved directly into the gramar of the sentence. At one 
level, the completed sentiance (1.e., not the completed thought, but the maximum lavel of grammatic/linguistic integration) has becone equivalent to a line. a condition not previously imjssed on sentences $(90)$.

Silliman's is a unique kind of semi-grammaticality. Each sentence, viewed in isolation, appears to be grammatical. But when a group of sentences is read in a sequen. $\epsilon$, it reveals the non-sequitous nat:ure which generptes its energy, and a srupts normal grammar at the level of what linguist:c pragmatiom calls co-reference. These sentences, read as a unit, require a dramatic re-reading, re-conceiving and re-integrating. Collectively, new sentences encourage a perpetual parallax, a continually furtiner shift from the traditional emantics in which, individually, they can we read. Silliman wants a syllogistic movement which is "limited," and "controlled"; consequently he tries to create ayllogism which lies between sentences and orchestrates the overall movement of the paragraph in order to "[keep] the reader's attention at or very close to the level of language, that is. most often at the sentence level or below" (91).

It is precisely this syllogistic movement which makes silliman's new grammar a forum for the Nonsensical sign; the words of this type of sentence atand as referential and as material. For iristance, "But trees are not orderly" (Ketjak 53) is a workable, grammatical form, albeit fragmentary; one can cull a referential meaning from this sentence on its own. When, however, such a sentence fragment is juxtaposed with other sentences, its grammatical relations are undermined and the mataricil aspect 7 of the sentences and the words must be consulted to form new patterns of meaning.

But trees are not orderly. How propose to release the fly from the bottle. Blgger, to serve you better. The moth that destroyed cleveland. Close cover before striking (53). These words don't cease to refer to trees, flies, bottles, moths, 
Cleveland, covers. However, they do not refer to just these thinge; they also "refer" to, or enact, slogans or quotations which accumulate without imposed order, to themselves as language with a pre-exiating and constantly shifting identity. With a reach that stretches in two directions, outward and inward, as a sort of double-headed indicating arrow, each word eclipses the referential and material function within a fluctuating grammar which exists to emphasize that eclipse.

"A continual athleticism" : Tender Buttons and Nonsense

Despite Wim Tigges' claim that Gertrude stein is an absurdist and not a writer of Nonsense (Anatomy 41), a Nonsensical strategy rewards the reader of stein, and especially the reader of Tender Buttons. Considered by many to be stein's most successful experimental work, this small volume of prose poems or meditations is divided into three sections -- one on objects, one on food and one on rooms -- each of which is further sub-divided into individual pieces on, for the most part, examples of objects, food and rooms, respectively.

This glimpsing of stein's prose is meant to illustrate a means of reading and not to confront the whole of stein scholarship with its dramatic eplit over whether stein's works has, literally, no cohercnt meaning (as De Koven argues throughout her study'b) and so exigts solely to glorify the signifine, or whether it is a cryptic encoding of social and sexual meanings which can be teased out through subtle manipulations or intricate twists of logic and etymology (a position taken in varying degrees by, among others, Rieke, Perloff and steiner).

However, I will admit I don't accept the contention that stein'o

16 Although I don't agree with all of De Koven's conclusions, her study is a fine applicatirin of Kristeva's theory of poetic language to Stein's work and well worth the careful consideration of anyone interested irı reading Stein's wark froin either a Kristevan or Nonsensical point of view. 
work in Tender Buttong is wholly non-referential or unrepresent:-tional. In an interview with Robert Hass, stein discussed her method of writing Tender Buttong:

I used to take objects on a table, like a tumbler or any kind of object and try to get the picture of it clear and separate in my mind and create a word relationship between the word and the things seen (quoted in Copeland, Language Time Gertrude stein 88 ).

As opaque an her writing may be in these "otill-1ifes" (Perloff, "Poetry as Word-System" 99) of objects, food and rooms, stein is attempting to (re)present some external object. But she is trying to do so through the interioritles of language. Her sub-titles are not empty gestures; as De Koven notes, they "make as well as mock meaning," for they focus each piece (or poem), and in doing so give the reader a concrete referent as a grounding location (79). De Koven argues that these titles are "arbitrary" (79), but I would urge that they are so only in terms of stein's choice of an object to respond to or with; they are not names merely pulled out of the air and appended to writings which are completely separate from them. The pieces in Tender Buttons are samples of what Randa Dubnick calls a "mimesis of the intersection of the present moment of consciousness with an object" (28); they are samples of the blending of Hejinian's descriptive realism, a realism of "strangeness" (see footnote 5), with an associative linguistic presence. The end result of such blending is what Bob Perelman, in an untitled reading of stein, calls "a continual athleticism, leaping free of the gravity of the familiar" (199). It is a leaping free of gravitational forces (and linguistic ties) which bind one, tightly and permanently, to the earth, the object, and simultaneously a leaping free of the grave seriousness of language. For the most overwhelming qualities of stein's Tender Buttons are its passion for and intimacy with language, and its wit. 
Strongly marked by her interest in and understanding of Cubiem, Tender Buttoms "paints" its subjects in a fractured language that attempts to relate the presentness of the moment in which the subject of the piece is experienced. There is no conventional description in the volume; one doesn't find a piece on potatoes, say, that runs along these 1 ines:

A potato's shape is usually oval or a rounded oblong. Unripe potatoes are green, new ones have a thin skin, flecked with tan, older ones a thicker brown skin. Inside, potatoes are a whitigh-cream colour but they turn quickly to brown when exposed to air. Small protuberances, known as eyes, are really the beginning of roots. The potato grows underground.

Rather, Stein's three potato pieces, printed one after the other, are brief and wholly uninformative, if one is looking for the size, weight, colour and texture of this tuber. It is the verbal "reality" of the potato, and how that reality occupies, with sly humour, her ever live:y consciousness, which stein depicts:

POTATOES.

Real potatoes cut in between.

POTATOES.

In the preparation of cheese, in the preparation of crackers, in the preparation of butter, in it.

ROAST POTATOES.

Roast potatoes for (51).

Stein's decision to include three takes on potatoes, and to put them side by side, may indicate her belief that all things change continually, that nothing, not even a potato, remains the same from one moment to the next. It also indicates that she is not trying for vigual 


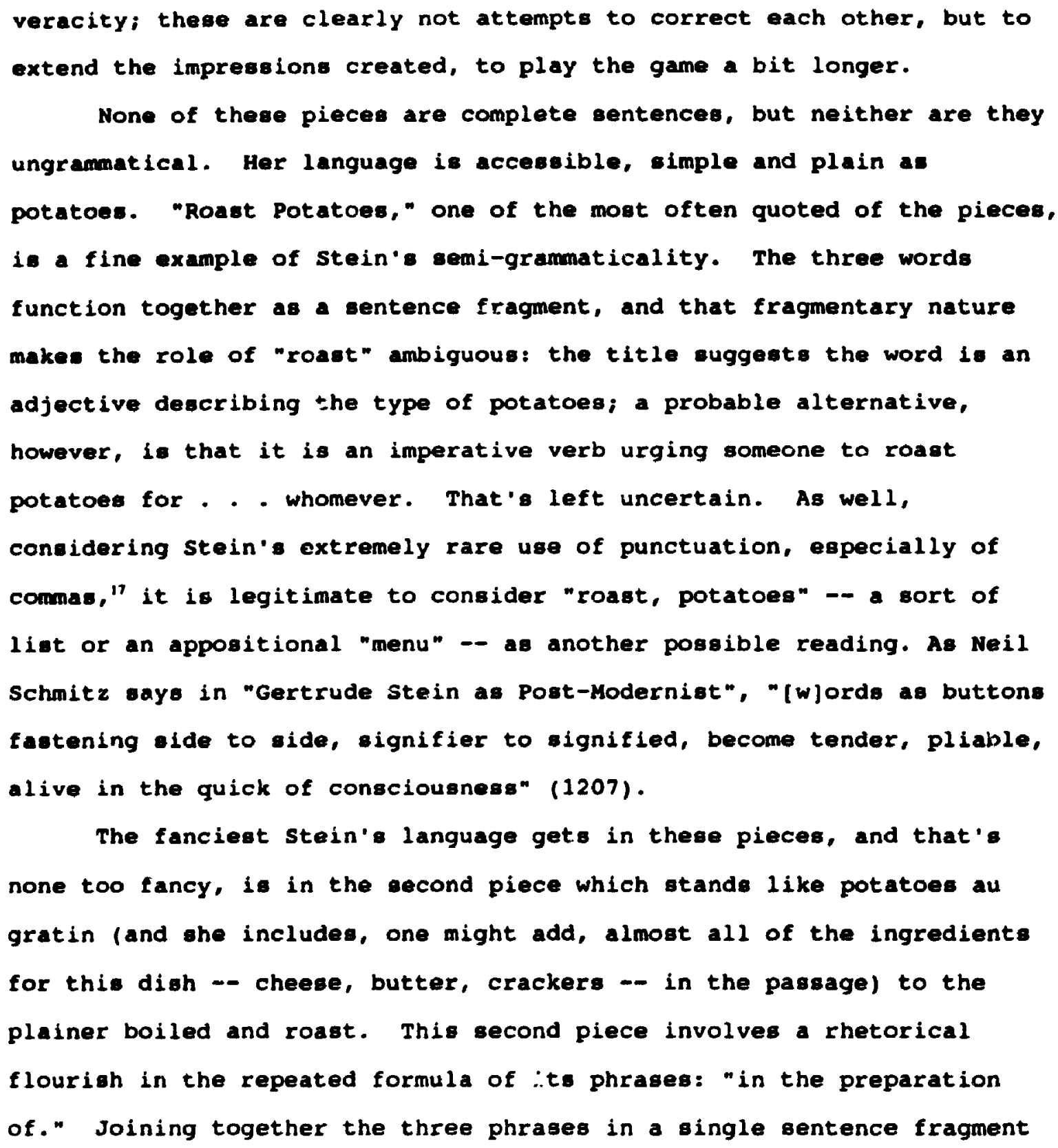

"In "Poetry and Grammar," Stein outlines her contempt for the comma: As I say commas are servile and they have no life of their own, and their use is not a use, it is a way of replacing one's own interest and I do decidedly like to like my own interest my own interest in what I am doing. A comma by helping you along holding your coat for you and putting on your shoes keeps you from living your life as actively as you should lead it and to me for many years and I still do feel that way about it only now I do not pay as much attention to them. the use of them was positively degrading (219-20).

Stein's ironic use of commas in the midst of such scathing condemnation is a delightful poke at herself. 
underscores a musical materiality where words, by virtue of their repetition, have their sense underplayed and their sound accentuated. And it encourages a momentum flatly undercut by the very abrupt ending of the pattern "in it"; the flatness of the ending puts extra weight on "it" -- an ambiguous pronoun with no clearly established antecedent. This may be a tactic for undermining any attempt at a literal decoding of the piece -- the reader is left, ultimately, wondering what "it" is. stein also writes a series of four "Chicken" pieces; the final one uses sound very playfully in its two sentences:

stick stick call then, stick stick sticking, sticking with a chicken. Sticking in a extra succession, sticking in (54).

Here the semiotic pushes Stein's words quite far into the realm of sounds. What "sticking" has to do with "chicken" is mostly sonal; in fact what each of these phrases has to do with "chicken" is sonal. To suggest that stein is flippantly rhyming here, and that the rhyme gets out of control, would be wrong. There are rules operating, but rules which don't necessarily conform to the usual ways of making meaning; Stein doesn't balk at playing havoc with the structures of meaning, or at stretching them to a breaking point, but she creates such disturbarises through a very structured and rigorous sort of play. "Number" sequel. $\& g$ and repetition are vital to the organization of the passage; for instance, twelve is a central tu the prose poem's configuration. The first sentence is made of three phrases spliced together. The first two phrases each have four syllables, the third has Ix; the increase in syllables, however, is to accomodate "chicken" the "subject" of the piece, which is mentioned just once at what turns out to be its exact centre. The second sentence has two phrases, one of nine syllables one of three, making a total of twelve gyllables. The phrases are structured so that twelve syllabies precede "chicken" and twelve follow it. The number four is also important since both "stick" 
and "aticking" are repeated four times. This repetition increases the cheer muslcality of the passage; if "Chicken" is about anything it may be about the music of the word naming this wholly unmusical bird.

That musicality is carried further by the primary structural feature of the "poem" -- rhyme. Each phrase begins with a word or ayllable rhyming with the first syllable of "chicken" and ends with one rhyming with its final oyllable -- "then," "-ing," "-en," "-ion, " in." Consequently each of the phrases has a "frame" that is little more than a sonal shift from "chicken," but which is never used twice: "atickthen," "otick-ing," "stick-en," "stick-ion," "stick-in." This phrasal framing is quite appropriately rhyme, however, since the "frame" which contains this piece is entirely made up of rhyme. The passage as a whole it a atretching out of rhymes on "chicken," and the phrases are similarly a stretching of that rhyme to the point where other words and rhymes can be inserted into the midst of the elongated rhyme.

The elongation of the rhyme is most noticeable, and most vulnerable, in the first phrase of the second sentence. Previously a pattern had been established -- the four gyllable phrases followed by the third phrase of six syllables seem regular enough, especially since the extra syllables of "sticking with a chicken" forcefully re-iterate the subject (chicken), rhyme pattern, and movement (the poem as a whole "sticks" with chicken) of the passage, and as I mentioned above, form ito syllabic centre. However, the phrase "sticking in a extra succession," while maintaining the rhyme pattern, completely disrupts any seeming system of four syllable phrases. What stein does is, quit. literally, stick in "a extra succession" of syllables whose rhythmic and verbal flat-footedness is further emphasized by the use of the improper aru-cle ("a" not "an") -- this is a phrase which loses the tune. The "extra succession" is really an over-extension; for the twelve syllable rule to be met, "sticking in," which is tacked on to the end of the centence, can only have three syllables. Once again the key is flat. 
In a piece like "Chicken," stein is not a Nonsense writer; while reference exists at some level, most of the meaning of the poom iwelle in the actions of the signifier. There is no delicate tension between the signifier and the oignified; the balance is upset. Yet a reader. refusal to abandon reference in the face of "Chicken"'s nbvious semiotic overload can still serve her reading of it. By retaining vestige of the title's referent, a reader can counter-point the semiotic music of the joem with the actual music of the bird; in this case the stubborn refusal to admit there is not a literal chicken in the poem rewards the reader with what may well be Stein's witty implication -- that this poom is about as musical as a chicken gets, and carries a tune for about as long as one can, too.

\section{inese Bandar-logic:}

Silliman's Ketjak

In a parenthetical note to his brief consideration of Ron Silliman'B work, Stephen Fredman reveals thut ' 'Ketjak' is the Balinese monkey chant from the Ramavana" (144). That's an appropriate preface for a Nonsensical/bandar-logical reading of Silliman's volume. Ketjak is both bandar-logical and musical, perhaps musical because bandarlogical. Fredman observes that "the experience of reading" Ketiak, and Silliman' formally gimilar work Tjanting,

is akin to the experience of modern music.. - or art, in which the exfoliation of formal patterns - - of repetition and variation defined by complex operations -- gives the aesthetic pleasure (144).

That there is a formal pattern governing Ketjak is easily discernible from a quick glance at the book's first page; to discern how complex it is takes more careful looking. Silliman established rules for the writing of Ketjak, made it a language game that borders on Nonsense. The page has three and a half paragraphs on it -- separated from each 
other by a large white space. Each paragraph is markedly larger than the previous one. A quick counting of sentences proves that the paragraphs' number of sentences is continually doubled: the first paragraph has one sentence, the second two, the third four, the fourth eight and so on. The twelfth and final raxajraph is forty-five pages long and almost one half of the length of the whole book, a far cry from the two word paragraph thut begine the volume.

While silliman doesn't regulate the length of indlvidual sentences, he does place more demands on his work than just the number of sentences per paragraph. Each sentence, sometimes in its exact form and sometimes slightly modified, is repeated in every paragraph. The firat paragraph becomes the first sentence in each succeeding paragraph. As well as being a crucial structural principle, silliman's use of that placement for this first "paragraph" ("Revolving door.") provides insight into a reader's experience of the text, since the book often feels like trips through just such a door -- each run through longer and faster. Barret watten compares the work itself, with its fascinating variations on repetition, to "a fractal curve of an experience that might be reduced to "revolving door"" ("Ron Silliman, Mohawk and Ketjak" 271).

This clearly marked structure of Ketjak offers more than "aesthetic pleasure"; it dramatizes many of the aesthetic principles, and works through many of the problems of referonce, which have been issues in this chapter. Charles Bernstein, commenting on silliman's "poetry of visible borders," writes:,

Such poetry emphasizes its medium as being constructed, rule governed, everywhere circumscrihed by grammar syntax, chosen vocabulary: designed, manipulated, picked, programmed, organized, so an artifice, artifact (40-1). Sillimen's repetitions certainly function this way, revealing a programmatic "code" behind the self-generating paragraphs; but so too do 
the other materialist techniques which he uees.

Not surprisingly, there is a good deal of sound play here. Pune like "the eye is the limit" (26) -- which could also be an aesthetic comment -- are fairly frequent. And so are clusters of words which seem meditations on sound: "Wept, swept, slept" (37); "An harbor, Ann Arbor" (37): "Ontic antics in the attic" (26); "Ives jives" (29): "Cupcake corral" (58); "Sea-sick sea serpent" (71); "Never fear, chandelier" (70). Many of these words seem to be grouped together solely because of their sonal affinities, but their humour lies equally in the possiblity of their being referentially active as well, in otriking a temporary balance between sound and sense. It is not just the sound of "Cupcake corral" which is funny, but, like Carroll's Looking-Glass entymology, the momentary imagining of such a thing, and, as a friend notes, of the showdown which might occur there.

The same is true of other sentences which are not examples of sound play so much as combinations of words which, because of their improbability or strangeness, emphasize themselves without completely obscuring the often humourous potential of literalness: "This tapestry concerns the mass capture of rabbits" (15); "Brushing dry leaves of dead poets" (26); "Garbage mind pear1 diver" (47).

Many of Silliman's sentences are phrases and expressions culled from the world around him; advertising slogans, cartoons, nursery rhyme, popular songs -- nothing is free from his borrowing pen. Sylvester the cat, from Warner Brothers' Tweetie Bird cartoon, is represented by his favourite saying "Suffering succotash" (48); Cecil the sea-sick sea serpent, from the "Cecil and Beanie" cartoon also appears (71); a line from a fifties song is altered to "Who put the bob in the Baba Ram Dass" (50); and every matchbook ever made finds a voice in "close cover before striking" (53). He not only represents the world as words, he also incorporates the world of public words.

Juxtaposition is probably the most obvious technique silliman 
uses, and, when combined with the required repetition of sentences, one of the moet humourous, as the following excerpt shows. These are the leet fow entences from paragraphe four through eight; while it would be poseible to quote the endinge in wch a way a to incorporate both of the final eontences from paragraph four in each aucceed, ag quotation, for reseons of length, I will reetrict myelf.

A eequence of object, eilhouettes, which to him appeare to be a caravan of fellaheen, a circus, dromedaries pulling wagone bearing tiger cagee, fringed eurreys, tamed oetriches In toy hats, begins a sow migration to the right vanishing point on the horizon line. We ate them (4).

A sequence of objects, silhouettes, which to him appears to be a caravan of fellaheen, a circus, dromedaries pulling wagons bearing tiger cages, fringed eurreye, tamed oetriches in toy hats, begine a sow migration to the right vanishing point on the horizon 1 ine. The implicatione of power within the ability to draw a single, vertical straight line. Look at that room filled with fleshy babies. We ate them (5).

The implicit power within the ability to draw a single, vertical straight line. That was when my nose began to peel. Look at that room filled with flechy babies, incubating. A tall glass of tawny port. We ate them (7).

That was when my nose began to peel. Get aboard. Look at that room filled with fleshy babies, incubating. Points of transfer. A tall glase of tawny port. The shadowe between houees leave the earth cool and damp. A slick gaggle of ambasiadore. Wo ate them (9). 
Shadows between houses leave earth cool and damp. Retina burn. A slick gaggle of ambassadore. Aatronaute hold hands, adrift in the sky. We ate them. The flag (14). Many of silliman'e techniques are evident in a comparimon of these passages. The incongruity of juxtaposition and the black humour created by the repeated and abrupt ending -- "We ate them" -- is extremely effective. The juxtaposition is especially so, illustrating as it does the working principles of silliman' theory of the "now entence." A continual barrage of non-eequiture demande that a reader continually shift her stance on the sentences, on how they fit together. Sometimes sentences seem to fit together at first, as in this other example -"Where is JFK's brain. Yonder" (73)." Or in the gzdegnme "cannibalism" implicit in one of the examples above: "Look at that room filled with fleshy babies. We ate them" (5). But the continually expanding context ultimately puts an end to any narrative unity.

Silliman's repetition, or as the examples above illuatrate his near repetition (sometimes the change is as subtle as the lack of pluralization on one word), requires that each sentence be re-integrated not only within its own paragraph but also within the movement of the paragraphs as a whole. What is demanded, then, is a continually precise attention to the sentences or propositions presented and the structures of meaning which Ketiak generates, or requires the reader to generate. It is not enough to have read once about fat, fleshy babies and then to glide over that sentence's other incarnations -- to do so would be to lose out on all sorts of meaningful combinations for that sentence.

silliman intersperses these paragraphs with sentences which may be deemed directly or metaphorically relevant to his aesthetic stance. For instance:

Attention is all (5).

18 Silliman's choice not to use question marks in Ketiak undermines the referentıality of some of its sentences; interrogative words don't function in their traditional sense. 


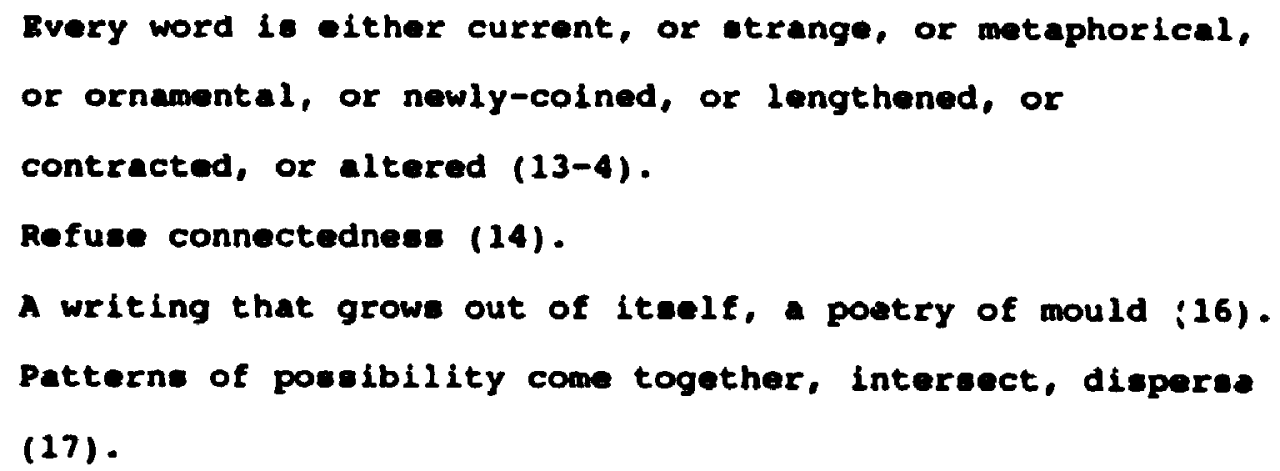

19 Since Ketiak is published by This, a small press in San Francisco, Silliman's many references to "this" may be plavfully self-referential too. They may also "refer" to the magazine by the same name. It is actually This magazine which Silliman is discussing in "Language, Realism, Puetry" when he comments on the nature of the word "this." 
of other pieces of language, : $t$ is to mean the way one is used to it meaning. Silliman' use of "this" is an extreme example of the language of the new Nonsensical ugn.

"This" appears in many other instances where silliman seeks in immediacy of reference:

This before, this after $(29)$.

This sentence has five words $(27)$.

You read this sentence before (34). [This sentence createa

a nice paradox the first time around.]

This sentence is not what $t$ intended (43).

Here is an empirical fact, this word is used like this (50). This list $(50)$.

In each case, the referential gesture towards an exterior object is turned back upon itself, partially frustrated so that the words of the sentence become the exterior object referred to.

Within the precision of the structure he sets out for Ketjak, silliman creates work which is vibrant and strangely lyrical, one whose wit and linguistic particularity is uniquely intertwined with ito governing rules. Indeerl, the work is almost a paradigm of the fusion of materiality and "Rule," of semiotic and symbolic. Neither structure nor particular takes precedence over the other; rather they complement each other. By calling this relationship complementary I don't intend to suggest that meaning resides in an easy and static way in Ketjak. Sense constantly makes and unmakes itself; meaning is both conservatively coherent (occasionally, temporarily) and constantly constructed. There is a symbiosis which "resolves" iteelf naturally here; a reader never forgets the presence of the structure, she even reads jor it, but that structure is never read to the exclusion of its individual elements. The paragraphs in Ketjak are monkey chants, a sort of bandarlogical lingual enactment of the type of discourse the Bandar-log brag about in Kipling'" "Road-Song of the Bandar-log"; but so, then, 10 most 
" $L=A=N=G=U=A=G=E^{n}$ poetry:

$$
\begin{aligned}
& \text { All the talk we ever have heard } \\
& \text { Uttered by bat or beast or bird -- } \\
& \text { Hide or fin or scale or feather -- } \\
& \text { Jabber it quickly and all together! } \\
& \text { Excellent ! Wonderful I Once again! } \\
& \text { Now we are talking just like men (66). }
\end{aligned}
$$

This talk of sound and word is never precisely referential but neither can it escape reference; and the people whose verbal universe is jabbered are poets who clearly, whether or not one agrees with their ideas or appreciates their work, are as passionate about language as they are anxious about its socio-political manipulation. While Nonsense does not necessarily share their political mandate, ic most certainly shares their conviction about the importance of the signifier. Nonsense can serve the writing and the anxiety of the " $L=A=N=G=U=A=G=E$ " writera: it exposes and embraces the structures and elements of language with a passion similar to theirs; it alters the sign in such a way that many of the problems about conventional language which they write can be addressed; it sympathizes with their concerns, plays their games enthusiastically, and enters their community. But it never loses its apolitical nature, its individuality. 
"What then is a window"

Lyn Hejinian's yy life meanders lovingly over its own minutiae. Or perhape leaps is a better word for the vigorous ohifts and the continual non-sequiture that mark this "autobiography," with its probing and paseionate language ebbing and flowing over a lifetime. In both the first and second editions Hejinian withholds the stable reassurances of genre and form. Rather than titled or numbered chapters, there are long paragraphe -- 37 in the first edition, 45 in the second. Each paragraph begins with an italicized phrase, seemingly unrelated to what follows, and each, Hejinian suggesta, is "a time and place, not a syntactical unit" (96). Gone are clear divisions between poetry and prose, lyric and narrative. Gone is any clear association of history with memory. Hejinian belongs to the " $L=A=N=G=U=A=G=E$ " poetry movement, so it's no aurpriee that her autoblography challenged the function of verbal expreseiton and the nature of meaning, as well as genre, by overlaying itself with a musical arrangement of language, ar emphasizing of the material aspects of words. Meaning is everywhere in this text -- and yet nowhere for one unwilling to liaten closely. For Hejinian's meaning is neither traditionally conceived nor stable. Her "life" is a clustering of phrases and fragments, where sequences of more than three clearly and semantically linked sentences are quite rare; it is a dramatic working through of Ron silliman's theory of the "New sentence." The reader must aft through and re-shape the text. No easy way through or out of the book is offered; nor should it be, because vy life is the articulation not just of Hejinian's own life, but of a reader's as well.

"What follows a strict chronology has no memory" (13).

Charles Olson talks of "selection" in his eseay, "Human Universe", writing and even living, he saye, are a whittling down of "that lovely 
-iding thing, chaos" (59). Each involves the organization of a universe, of poem or person, through selection from an incomprehensibly rich mass of stimulae and sensations, bits and pieces. "For any of us, at any instant," he claims, "are fuxtaposed to any experience, even an overwhelming single one, on several more planes than the arbitrary and discureive which we inherit can declare" (55). Selecting inevitably betrays the flow between these planes, creates a flaw in one's perception of aniverse that does not revolve around humanity a limited means of expressing itself.

since writing and living are a betrayal of one's "lived" experience, what is memory? Born in. Lived at. Schooled at. Married him. Bore her. Stories of such turning points or times of shift, even when thick with description, thin one out. Where are: the postcard of Emily Brontë' dog; the red and white package of Hungarian Mammoth Squash seeds (world record -- 451 lbs! Atsolutely the largest squash you can grow!); the blue plastic E with feet; cobalt therapy, a flying squirrel: postage stamps on a.a.s.e."; a gtamped thin tin bird with fuschia wings; ants crawling out of peonies my mother cut for my sixth grade teacher; dandelions, from this window, from this angle: blossoms on the $\mathrm{m}$, tree. Where is the language for the plenitude of which such details are only crude indicators?

Iyn Hejinian offers a selection. But what she selects, how she re-organizes her life, produces not a chronology of significant events, but a sonal and visual dramatization of how language constructs one' "reality" and one' memories. She presents an intuition of the "pure duration," the on-goingness, the presentness of time, and simultaneously the wonderful plasticity, the expansive, procreative embrace of both memory and language. 
"Thinking about the time in the book, it ia really the time of your Iife" (55).

Not only is the book the lived time it recounts; it is the time apent writing the book, and reading it. Beyond this, Hejinian"s language -- her fragments, her repetitions, her memories and echoes -Aseault the notion of a language whose logic flowa with time, which can be read or experienced only in a forward-moving or progresaive time frame. By constantly and varlouely reworking worde and phraees so they reappear eeemingly epontaneous, non-sequential and almost unmotivated, Hejinian tries to break out of narrative and inguistic chronology. Which is not to suggest that yy tife has no narrative progression. The eubtle movement of language from a distilled child'g voice (more recalled than re-enacted) to the more "mature" sensibility of a crafter of words, together with the increase of "theoretical" asides,' produces an underetated portrait of the artiet. But Hejinian is more immediately concerned with linguietic and temporal "transgreseion," with resieting traditional and etaid notions of the time of language, by revealing ito spatial nature, rendering it an object to be not remembered so much as renewed ("I heard it anew not again" she writes (82)). Memory is a ueeful meane for renewing language and experience both; it musees up chronology, adjuste or shifte "reality" dragging history into (making hletory into) the present.

"Is that a basis for desciptive sincerity. I am a ohard, eignifying isolation - here I am thinking aloud of my affinity for the eparato fragment taken under scrutiny" (52).

1 These theoretical statements, like those in Silliman's Ketiak discussed in chapter five, are of no more or less importance than any other sentence in this text. To privilege any one of them would be to undermine one of the book's (and the movement's) premises -- that language is valuable as much for what it is as for what it points to or means. 
Hejinian's minutiae: "A pause a roges something on paper" (7); "Foxtails, the juice of a peach, have fallen on the flesh of this book" (39): "What I felt was that fige resemble kidneys" (55); "Those hard white grains of sand are flea egge" (62); "The calves of the cowboy'legs are rubbed shiny, left with no hairs. Pelicans hatch naked from the egg" (86).

Here is an exquisiteness of detail so lyrically precise, so supple, that Hejinian's is not the only life reclaimed. Just saying the title includes the reader. Each time I read this book, I feel the weight and wonder of my own childhood slinking up the skin on my arme, smell the summers of too-many-barbecues and ketchup-cooking-at-thefactory; I find another moment of my life waiting to be rediscovered. Things once extraneous are loved into an intensity that selection had denied them. And more importantly, as will be argued later, words are given an intensity, a thisness, of their own; they begin to exist as words, rather than as linguistic referrals to greater and other "Outside."

What helps excavate these "extraneous" elements and moments in Iife is the seeming leck of selection, the apparent randomness with which fragments seemingly peripheral to the major events of a life are thrown together. For instance, Hejinian doesn't describe giving birth, but remarks instead, "When the baby was born I lost considerable importance, eurrendered it to him, since now he was the last of his kind" (64). The observation is, as usual, a non-sequitur:

Yet I admit I'm atill afraid of something when I refuse to rise for the playing of the national anthem. The wailor on the flood, ten times the morning sun, made of wooden goldfish. When the baby was born I lost considerable importance, surrendered it to $\mathrm{him}$, since now he was the last of his kind. "Fundamental dispersion," he sald, and then, "no nozzle." The coffee drinkers answered ecstatically, 


$$
\text { pounding their cups on the table (64). }
$$

Thie type of dielocation requires that one read not for a definitive meaning, but rather to engage the procese of the making of meaning and to discover the web of potential relations that resonates between eentences. Their connection is one of interwoven tiseue, the texture of muscle rather than the firm definition of bone.

ronly fragments are accurate. Break it up into single words, charge them to combination" (55).

If this text charts a life-line, it traces it from one otriking detall to another, from incarnation to new incarnation of Individual worde, from point to point. "A point, in motion, is a line" (33) writes Hejinian, and the points that constitute her life are in constant motion. "Strange," Rilke writes, in the first Duino Elegy, to see meanings that clung together once, floating away in every direction. And being dead lo hard work and full of retrieval before one can gradually feel a trace of eternity. -- Though the living are wrong to belleve

in the too-sharp distinctions which they themselves have created (155).

With each recurrence in vy life of a phrase, of an image, eventually of a word, meaning does not merely gather; "language [becomes] restless" (17) and "meaninge. . . [float] away/ in every direction" (Rilke 155) -- lodging temporarily with an old friend, a new companion, until the Individuality, the creases and crevices of each word-image-phrase are momentarily enlivened. "But a word ls a bottomless pit" (8). There is alwaye more to retrieve and imagine. Hejinian's act of retrieval, while It et11l involves a degree of selection, undercuts those "too-sharp" distinctions of the resolutely or obsessively "selective," those living 
who are so busy hewing out their own world they neither revel in chaotic source, nor acknowledge that they have indeed selected, shaped, their world.

"Language which is like a fruitakin around fruit" (43).

Life as language: "The dictionary presents a world view. . . (T) he bilingual dictionary doubles that, presente two" (79). Hejinian adds her eloquent "voice" to the many others insisting that the world and the self are composed of language. Her version is partly comprised of theoretical statements. Single sentences (for instance, "To some extent, each sentence has to be the whole story" [67].) give outright and as completely as possible her belief that life is built with and upon language. But these sentences are rarely presented as something beyond the thoughts of a particular moment. They are organic with the process of observation from which such asides grow. And while theoretical statements are signposts, they are not maps. No one can claim authority on how to interpret the signs Hejinian leaves. Each reader finds her own paths through this labyrinthine text.

In The dance of the intellect, Marjorie Perloff talks of Hejinian' creation of "a language field that could be anybody"s autobiography, a kind of collective unconscious whose language we all recognize" (225). Hejinian mentions "a portrait bowl" (25); I think of a linguietic "play box," a firet-cousin-oncy-removed to the one James Reaney creates in Colourg in the Dark, and comments upon in his preface to 1t:

The theatrical experience ir front of you now is designed to give you that mosaic-all-things-happening-atthe-same-time-galaxy-higgledy-piggledy feeling that rummaging through a play box can give you (v). But My the doesn't have the "ancestral coffin plates" and "school 
relica" (or the eventually cohering world vision) that are in Reaney' play box (v). Hejinian'a toy and eccentric ephemera are wordes her game is language.

"Miechief logic; Mise Chief" (29).

Hejinian handles worde. She picks them up, turns them over, looks at their underbellies. Some she turns over and over -- each use a different game, a new possibility; some she discards as broken; some she breake. This handing allows an almost continual breaching of the thetic; the semiotic values of sound and matter assert themeelves throughout this text, requiring that its reader at the very least regieter linguistic disturbance, but more usually revel in such disruption.

Juxtaposition is part of the game. Hejinian's juxtapositions sit a serious moditation next to a commonplace assertion to see what friction comes of such elbow rubbing:

If I was left unmarried after college, I would be oingle all my life and lonely in old age. In such a eituation it is necessary to make a choice between contempt and an attempt at understanding, and yet it is difficult to know which is the form of retreat. We will only understand what we have already understood. The turkey is a stupid bird. And it is scanty praise to be so-called well-meaning (53).

The wit here is more subtle than that in Hejinian's revision of williams -- "No ldeas but in potatoes" (70). But the subtlety is invigorating; the reader is called to play along. Rejolce in displacument, illogic; recognize the supplenese, the plasticity, of language and of meaning not firmly bound by conventional expreselon. "Collaborate with the occasion" (29). 
Aphorisms abound: "pretty is as pretty does. . . See lightning, wait for thunder" (7). As Perloff pointe out, these aphorieme are "juet slightly out of sync," a result of "the language of adulte [impinging] on the child's world with all its prescriptions, admonitions, and "wiedome," (224) and of the often witty juxtaposition of entences throughout the book. Cliches are guestioned too, or at leaet called to a reader': attention, though not with the unremitting thoroughnees of Chrietopher Dewdney' "The Dialectical Criminal: Hand in Glove with an Old Hat" (Predatore of the Adoration 168-69): "You cannot linger 'on the 1amb" (11): "We 'took' a trip as if that were part of the baggage we carried. In other words, we 'took our time'" (47). Grammatical rules are rephrased: "Pronouns skirt the subject" (77). Some are "contradicted": "After C, I before, E except" (68). Hejinian toys with wandering letters, as in "I've heard that it once was a naoron" (77) or in the frequently repeated phrase "a name trimmed with colored ribbone" (14 et passim) which finds its "source" in "a pony perhaps, his mane trimmed with colored ribbons" (15). In all these instances, she calle attention to how language changes, how literalism tampers with meaning and with the world constructed out of language.

she exults in the phonic play of words, the rhyming elip of letters, the compelling nature of rhythm: "Between plow and prow" (65); "Raisine, cheese, the Japanese" (64). Such phonic play illuminates the limitatlons of "sense." A reader soon Einds herself lingering not over meanings, but over the tumble of the words themselves -- "The grass in my glase" (68); "I was not afraid in the dark, hearing the low owl, in the 11ght, the bird knocking in the eun. I hear it anew not again" (82).

"If words matched their thinge we'd be imprisoned within walls of eymmetry" (70). 
Becaube the naxxow language of the eymbolic, in ite traneparency. cannot contaln and exprese the many planes on which any thing exiete. auch language "atope" that thing. mover away from ite fluctuating reality. Hejinian remarke on this in her eseay "The Rejection of closure":

Children objectify language when they render it their pleything, in jokes, puns, and riddles, or in gloesolallac chants and rhymes. They diecover that worde are not equal to the world, that a sift, analogous to parallax in photography, occure between thing levents, ideae, objects) and the words for them -- a dieplacement that leaves a gap (138).

This gap showe in ty life: "I lnsert a deccription: of agonizing opring morning freshnese, when through the open window a anell of cold duet and bude of broken early grase, of achoolbooke and rotting apples, traile the eound of an aixplane and a flock of crowe" (48). Self-consciously she namee thle "a description" -- she is not offering a landscape, a etting. she is giving words instead.

Yet her continual repetition of worde in a changing context lete them shimer with varying resonances and dramatizes how the longlng for a union betwer. word and thing can be euperseded by the pure power of a word which weane itself, fully, intensely. For Hejinian the union between word and object can be had only by making the word itcelf an object, not by joining it to the object to which it refers. By say ing thinge intenely, she marke the movement away from referential fuelon of word and world, and farther etill, marke the deflection of a potentially etable meaning. The randomese of repetition and re-orientation auggest that, despite Hefinian'a careful joininge and juxtapoeitions, maning travele of its own accord. Worde become glorlous in their new oldnese. They etand inteneely as themselves. 
"We had been in Erance where every word really was a bird, a thing einging" (85).

"One of my favourite words was birde and will be. If they are but flight: to a conclusion, I will wait patiently to look at them (89).

stein claime that language can exist "as birds ae well as worda" ("What is English Literature" 30), and that worde are a part of the etrangenese of the world. Certainly, the ineietent rise and fall of words is a source of atrangenese in Hy lifes the continual repetition (or "insietence" as stein suggest: -- in "Portraits and Repetitions" (166-67) -- it might more properly be termed) of the comonplace epeech which marks life. Michel Foucault has commented that " $(w)$ e live in a world completely marked by, all laced with, discourse, that is to say, utterances which have been spoken, of thinge said, of affirmatione, Interrogations, of discourses which have already occurred" (Ruan, "An Interviow with Michel poucault" 177). This is very much Hejinian': world. Her writing of it is an intense listening.

"The obvious analogy is with music, which extends beyond the space the Eigure occupies" (57).

"When you speak you play a language. The obvious analogy is with mulac" (82).

It would be a poor listener who did not pick up on Hejinian': "obvious analogy" with music since it is an important theme (and a theme more musical than literary) throughout ky hife. Not only because it elf-reflexively accounts for the repetitione ("The new cannot be melodic, for melody requires repetition" $(62)$, but also because it suggests sowething important about meaning in this book. Because most statcment: are decontextualized, and because the reader must "make" her own sense, maning is clearly an iesue here. Hejinian raises the 
queation of meaning in many of her theoretical musings: "What is the maning hung from that depand" (16). How much does one need to mean, to be intelligible, and why? what sort of ascumptione about language hang on a desire to mean? what is one doing to, or with, the otatement (the language) or the stated (the object or the ldad) when one mene it" (42).

Or, how does one mean? Ultimately the how overrides the what. How Hefinien mane is mueicelly -- not merely with correnpondence between word and thlings not purely referentially. She is not etriving for a referential, or Krietevan eymbolic, meaning. Sentences, like A paure. a rose, romething on paper (7), are themes (in the musical definition of the word); they are repeated in ever changing conflgurations, and even as they accrue associative and contextual meaning, they develop a potent sound value. Their continual echoes otand as musicel ldeas, aural images that vary and combine to create an "intuitive" lyric which speake intimately, truatingly.

"Soneual," roverberating senee challengee logical, cerebral sence; dielocatione challenge knowable order. Despite the rigour, the concentration, the extreme exertion which goes into creating them, music and the mueical language of by hife wove beyond the cerebral. "[But] though I could say the muslc brought these places "home' to we," Hejinian writes,

the composition itsele grew increasingly strange as I listened again, lese recognizable, in the dark, as when one repeats a word or phrase over and over in order to disintegrate its associations, to defamillarize it (113). A work of this intenalty which tries so hard to construct one gramar out of another, to defamiliarize the very aubetance of one "s world and "eelf," is an act of lncredible control and precieion. That makea Hejinian so succeseful is her "lack of clarity," her leap beyond pure Idac to amotion, spirit, rhapeody. 
"Through the window of Chartres, with no view, the light tranemite the color as a scene. What then is a window" (65).

" $L=A=N=G=U=A=G=E$ " writers frequently use the image of the window to symbolize the traneparent language which the semiotic attempte to undermine, a language which exist, solely to refer to a stable, outside world. Hejinian offere another take on this metaphor; there in a type of "window-language" which is not traneparent, which lets both window and language exiet as, and for, themselves, to demonetrate their own beauty. If language must be a window, why not a window like the etained glase of Chartres, why not one of colour and texture, a composition which is ite own landscape, which adda tincture to the world outside and noticeably alters the "reality" one perceives through it? What then ig a window. 
Conclusion - Killing the Rhino:

The (a) Political Nature of Honsense

\begin{abstract}
As for the Rhinoceros, in token of their grateful adherence, they had him killed and stuffed directly, and then set him up outside the door of their father's house as a Diaphanous Doorscraper (Edward Lear, "The story of the Four Little Children who Went Round the World" 106).
\end{abstract}

In the early 1960s, Jacques Ferron and others founded Quebec': Rhinoceros party, a parody political party meant to be at once a send-up and indictment of the canadian political situation of the day, an anarchic exposure of the absurdities inherent in a government dominated by a Liberal party which didn't, in Ferron's opinion, represent the needs or the best intereste of the province or the country. To be put forward as a candidate for the Rhinos, one had to be smart enough to play the fool and deeply comitted to losing (Ellenwood 4-5). The affinities with Nonsenss are clear.

When Ferron died in 1985, the party threw him out -- a suitable and to a pesudo-polibical career. The gesture is not unlike that made by Violet, slingeby, Guy and Lionel, In Lear's "The story of rour little Children who Went Round the World." As an expression of their gratitude to the chinoceros who carried them on its back for so much of their return journey they had it killed and stuffed.

If Nongense is not political, contrary to Gott's belief (noted in chapter one) that it is essentialiy a literary playground for the Britioh reactionary, what is it? I've used the term "apol1tical" geveral times when comparing Nonsense to what I consider to be its clo-eat apparent relations, feminism and " $\mathrm{m}=\mathrm{A}=\mathrm{N}=\mathrm{G}=\mathrm{U}=\mathrm{A}=\mathrm{G}=\mathrm{E}$ " poetry, both 
of which are avowedly and intensely political. This apolitical nature should not be misconstrued, however; Nonsense is politically enabling, but it is not politically programmatic. It is political in the way that the Rhinoceros party is political: its "platform" is at once ridiculous and (often gently) ridiculing. As such it allows one to recontextualize sande taken by more traditional parties/language. This conclusion will attempt to suggest, briefly, ways in which this theory of Nonsense could be construed as (a)political.

The Nonsensical sign discussed in chapter five is one of the most useful tools for this re-contextualization, for it exposes, as does nonsense generally, the process of meaning production. Like " $L=A=N=G=U=A=G=E$ " poetry, which is perhaps the closest equivalent to Nonsense currently being produced in the English-speaking world, nonsense language shows that purely referential language is impossible, and that to read as if language were purely referential is not to engage language at all. By emphasizing jointly the materiality and saferentiality of the signifying process, the Nonsensical gign reveals how language itself can be exploited for political purposes; it proves the lie in the "realistic" and "transparent" sign. But at the same time, by demonstrating that reference is absolutely necessary for a sign to function within verbal language, nonsense questions the political kidnapping of the sign by those who espouse radical materiality, like that proposed in the early theoretical writings of " $L=A=N=G=U=A=G=E$ " poet steve McCaffery.

This palimpsestic Nonsensical sign, through which both signified and signifier show, undercuts Idealism and McCaffery's somewhat Idealistic rendering of the material sign, and undercuts as well the theory that meaning is constantly deferred. Within this sign reside both meaning and meaninglessness, since fas Deleuze argues and $I$ discuss in chapter one) the true Nonsense word means only itself and so disrupt. the flow of sense production; such words are at once sign, signified and 
elgnifier. The Nonsensical sign (the bandar-logos) finds its prototype and one of ite etrongest articulations in the Nonsense words of Carroll and Lear. Disrupting the production of eense, these Nonsense words reveal how that production is carried outs they demonstrate as well the ability of words to mean as eites of confluence, as the coming together of two or more linguletic eeries, and (even more important) of various eign eyetems. It is this coming together of aign systems, the "transliteration" of one way of meaning (be it visual, musical, or gestural)' onto verbal language in order to facilitate the muelcalization of language, which I have auggested characterizes nonsenee; by "mueicalization" I mean letting language call attention to ite material and etructural aspecte. Music, as chapter four suggested, 1. purely material, purely formal. It refere only to iteelf, and to its principles of arrangement. Not even nonsense language can do that, but it can move toward adopting some part of the workings of mueic in order to qualify ita referential capacity.

of the two writers of classical Nonsense considered here, Iear is undoubtedly the most musical writer; he frequently employe sound against eenee, letting sound patterne dominate and dictate the worde he chooses. This attentiveness to the sound of language is one point of connection between nonsense and poetry. In fact, the closest ordinary language comes to the Nonsensical sign is in the homonym. It encapeulates the balance between materiality and reference essential to the Nonsensical sign; each is needed for the homonym to function succesefully. Wot of the poets treated in this otudy challenge language' more communicative features by imbuing lt with phonic and rhythmic ordere to the dieturbance of 111 ueory univocal sense. Sound becomes a means of

The alternative ways of meaning I have mentioned are non-lingual, one could argue pre-lingual, and distort the verbal sign/sign system in the process of inhabiting it. Of course, ways of meaning which are not as easily related to the pre-lingual can also inhabit verbal language and create nonsense; however, since this study is concerned with the incursion of the pre-lingual, or semiotic drives as they are construed by Kristeva, as a shaping force within nonsense, 1 chose to consider those ways of meaning which are more closely affiliated with the semiotic. 
"apoliticization," a way to qualify meaning or to posit alternative oysteme of meanings within a poem and thereby challenge exieting sense etructures, but without the sort of overt political content often found in literature. of couree, politically motivated poete, like Rlch, aleo orchestrate sound to underscore, and occasionally to undermine, their etated positions. However, the latter use, be it conscious or not, le "apolitical." For writers like Lilburn and Hopkins, sound is also a means of embodyling the "thisness" of language iteelf, of emphasizing the nature (the "being") of the medium for reference. Thus sound implicitly sreates a link between nonsense language and poetic language; both nonsense and poetic language require of a reader an alertness of ear to which the "transparency" of language le beside the point. Such alertnese, or attentiveness, usually initiates inquiry (just how le the sound working in each poem?); and such inquiry may challenge or extend traditional or conventional models of existing linguistic gtructures. The musicalization of language has much to do with what Julia Krieteva calls the "oralization" of the mother"s vocalic body. In fact, many French theorists (some of them proponents of ecriture feminine, some not) suggest that writing (ecriture, $t$ lat writiry which produces Baxthes" "writable" as opposed to "readable" text) is both a writing out of, and towards, the mother's body. If this is the case, musicalized language is by its very nature politicized, absorbed by the feminist venture.

I suggested in chapter three that musicalization is part of the way any body "manifests" itself in language - not an actual indwelling, a physical presence, it is rather a paychical one. While theories of a literally "physical" language have much to offer to a reader of nonsenee, the body in language, as I understand it, is the incursion into language of pulsions and drives a evidenced in, for instance, morphemle dieplacement, phonic play and rhythmic upheaval.

This out-pouring of what Kristeva calls the semiotic into the 
etructures of rational discourse (her eymbolic) challenges the univocal Lliueion of communicative language, and injecte into it a bandar-logical element -- alternative (and often parodic) rhythms and orders of meaning. The eamiotic is not chaos (nor "chaotic" in the traditional eense of having no order). It, too, is structured, but it has the etructure of desire, and so ie vasty different from the eymbolic. Within this Krieteven paradigm, within ito balance between traditional and dieruptive way of opeaking. is rooted my own articulation of noneenee. I euggest that such language is a product of the opeaking of the amiotic, and can be read according to a sightly modified veraion of Krieteva's theory of poetic language. Where I differ from Kristeva 1. In my re-designation of her third term. The thetic -- her permeable berrier between semiotic and symbolic -- for me thus becomes noneenee itself, something not conceivable within her framework. This permits me to argue for a slding scale of nonsensicality.

Because tha semiotic (in both Kristeva's and my understanding) is in some way present in every articulation, all language is potentially nonsensical and al language, to a leseer or greater degree, writes the body -- but does so from a peychological/metaphorical position. This position is a radical departure from that of Gilles releuze, who separates language and nonsense(s) into those expressions which deal with the "surface" of the body, and so are allied to sense, and those which bombard the schizophrenic body, and so create noneense. Much of his criticiem of Nonsense rests upon the relationehip which it has for, more to the polnt, does not have) with the body.

A elightly different take on bodily or physical language can be found in perceptually-based language; this language ie involved in the Interplay between body and langrage, between the cemiotic and the symbolic, but is so involved while attempting, at the same time, to permit the minlmum of interference between perceptual/aenelcal experience and the relation of that experience. Writero like zukofeky 
attempt to push linguistic expression as near as poseible to the actual experience of the aenses. He writes of "gynaesthesia," In which he attempte to maintain sensual integrity by "translating" the experience of one sense into the realm of another sense. Olson and Marlatt also seek a more "direct transmission" of experience, a less "selected" version of reality. These approaches auggest that a perception/bodycentred writing ia viable; and they imply, as does nonsenes language, that the ordere of the senses and the body are equal in importance to those of the more traditional logical forms which establieh political and social norms.

By the rubbish in our wake, and the noble nolse we make. Be sure, be sure, we're going to do some splendid things! (Kipling, "Road-Song of the Bandar-log" 66)

How does a physical/musical bandar-logical version of nonsense relate to earlier theories? Certainly this new reading of nonsense departs from or challenges many of the ways of looking at nonsense (coneidered in the first chapter of this study) which were advanced throughout the nineteenth and twentieth centuries. While I have derived many of my ideas about nonsense from these theories, I have attempted to extend the understanding of the term, and to free it from the charge of being overly conservative in its relation to language. My understanding of nonsense does not remove its associations with dream or play or anarchy or even philosophy, but it does eotablieh a new, perhape more critically useful, range of associations.

I have followed susan stewart, the foremost American critic of nonsense, in arguing the importance of its relationship with all forms of language and literature, but I emphasize (as she does not) the role of the semlotic in producing nonsense, and I place more importance upon 
nonsenes' relationship with the body than she does. For her, Nonsense as genre or as linguistic discuption does not initiate strategies of reading capable of llluminating difficult writing. Rather, she regards nonsense as part of a literary and oral continuum and critique. Our perepectives (more than our actual stances upon the interaction of nonsense with the rest of literature) differ.

That an underetanding of nonsenes can promote a subtler reading of "sensical" writing than is often generated by traditional reading styles has, I think, been shown in the six inter-chapters and in the brief analyees of poetry provided in chapters two through five. Reading poetry at both the material and the referential levela, letting these two levels challenge as well as corroborate each other -- in other words, not assuming that all patterns work towards the articulation of a angle mensical sentiment, but rather allowing for the (sometimes balanced) co-existence of conflicting syotems within a literary work -makes for richer, deeper readings. It allows literature the same eplrited inconsietency which makes nonsense so often unpredictable, so vital and so protean.

"There' plenty of room" Alice saye indignantly to the March Hare, the Mad Hatter and the Dormouse (Alice's Adventures in Wonderlend 75 ) when they try to dismiss her from their party. Alice is right about that and, by extension, she is right about nonsense too. There is pienty of room at the tea-party table: room for Nonsense and nonsensical writers, room for traditional and experimental writers, room for politic rhinos and subversive monkey-folk. There 1 room at critical and theoretical tables for nonsense too. In fact, nonsenes as a critical and theoretical tool has much to offer literary atudies. 
going on at the March Hare's table. The more room one sees, the more room there is. Let Alice be seated; and suddenly violet, Guy, Lionel and Slingsby are there. Soon Kipling and Thibaudeau, Ferron, Lilburn, Joyce, Hejinlan and Hopkins are pulling up chairs. But nonsense is not just a tea-party. It has its own (a)political clout, and packs a punch while punch is poured. 
Appendix I

from Thrognogle Engextchin: A relationship

Inwhich you meet Throgmogle and Engestchin and you

may feel that the latter is not a fully developed character

and you are probably right.

Throgmogle Fordful

manty overgoo

bog manty gong goppling

rill cum nack throggins.

Choomin:

Chillchinchar Engestchin

chanty chopcharchill

chorey chopcharchill chooley

chingle choon chingley

choodle.

Thogmogle Fordful?

Chillchinchar Engestchin?

Fulford mog-gle throg

Throgaing

Bersaboom

Bessaboom

Thregains

Manty choon Manty

chorey manky 


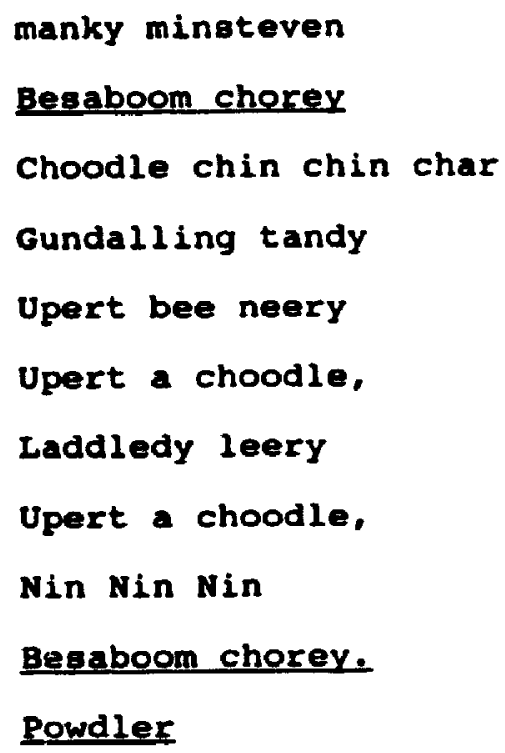

Fordful mogle

chorey chumbles

dipdu danker.

Engestchin chuh

chuh

ch

h

Para pom

tandle: 
303

Chillchinchar Engestchin

chanty chop charchill

chorey chop charchill

chingle chun chingley

choodle

ooldum.

Throomogle Fordful

manty overgoo

rhinger minsteven

bog manty gong goppling

rill cum nack throggins.

Para pom tandle. 


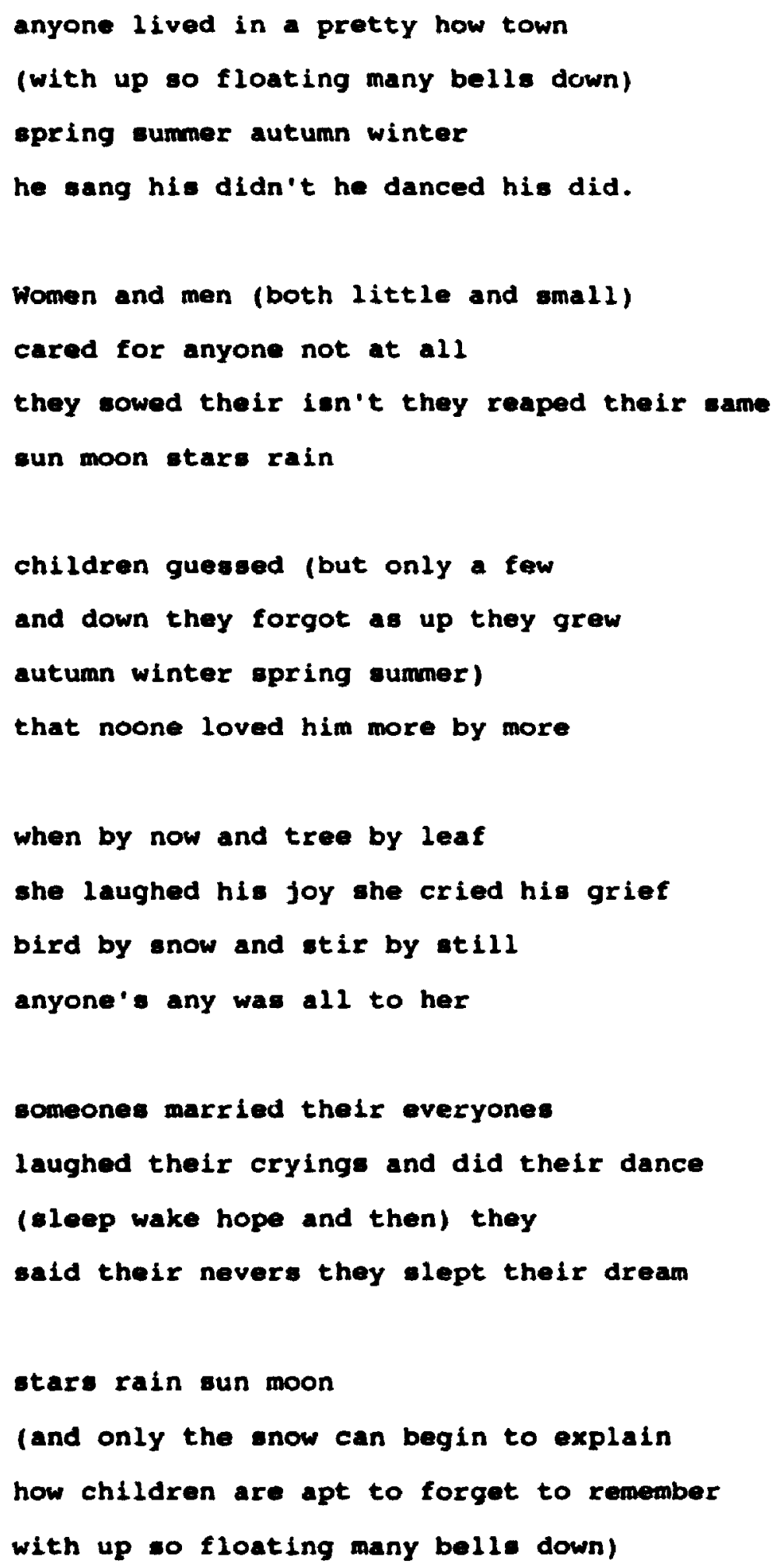


30 s

one day anyone died 1 guess

(and noons stooped to kiss his face)

busy folk buried them side by side

little by little and was by was

all by all and deep by deep

and more by more they dream their sleep noons and anyone earth by april

wish by spirit and if by yes.

Women and men (both dong and ding)

sumer autumn winter spring

reaped their sowing and went their came

sun moon stars rain 
"Verses from the Knave of Hearts" Trial"

They told me you had been to her,

And mentioned me to him;

She gave me a good character,

But said I could not awim.

He eent them word I had not gone

(We know it to be true):

If the should push the matter on,

What would become of you?

I gave her one, they gave him two,

You gave us three or more;

They all returned from him to you,

Though they were mine before.

If I or she should chance to be Involved in this affair,

He trusts to you to set them free, Exactly as we were.

My notion was that you had been

(Before she had this fit)

An obstacle that came between

Him, and ourselves, and it.

Don't let him know she liked them best,

For this must ever be

A secret, kept from all the rest,

Between youraelf and me. 
"Spelt from Sibyl's Leaves"

Earnest, earthless, equal, attuneable, vaulty, voluminous, . . stupendous

Evening gtrains to be time's vast, womb-of-all, home-of-all, hearee-of-a11 night.

Her fond yellow hornlight wound to the west, her wild hollow hoarlight hung to the helght

Waste; her earliest stars, earlstars, stars principal, overbend us, Fire-featuring heaven. For earth her being has unbound; her dapple is at end, as-

tray or aswarm, all throughther, in throngs; self in self steeped and pashed - quite

Disremembering, dismembering all now. Heart, you round me right

With: Our evening is over us; our night whelms, whelms, and will end us.

Only the beakleaved boughe dragonish damask the tool-smooth bleak light; black,

Ever so black on it. Our tale, o our oracle! Let life, waned ah let Iife wind

Off her once skeined stained veined variety upon, all on two spools; part, pen, pack

Now her all in two flocks, two folds -- black, whitef right, wrong; reckon but, reck but, mind

But these two; ware of a world where but these two tell, each off the other; of a rack

Where, selfwrung, selfstrung, sheathe- and shelterless, thoughts against thoughts in groans grind. 
$30 \mathrm{~s}$

"Altarwise by owl-light"

Sonnet VI

Cartoon of slashes on the tide-traced crater,

He in a book of water tallow-eyed

By lava's light split through the oyster vowels

And burned sea silence on a wick of words.

Pluck, cock, my sea eye, said medusa's scripture,

Lop, love, my fork tongue, said the pin-hilled nettle;

And love plucked out the stinging siren's eye,

old cock from nowhere lopped the minstrel tongue

Till tallow I blew from the wax's tower

The fats of midnight when the salt was singing;

Adam, time's joker, on a witch of cardboard

spelt out the seven seas, an evil index,

The bagpipe-breasted 1 ladies in the deadweed

Blew out the blood gauze through the wound of manwax. 
"Road-Song of the Bandar-log"

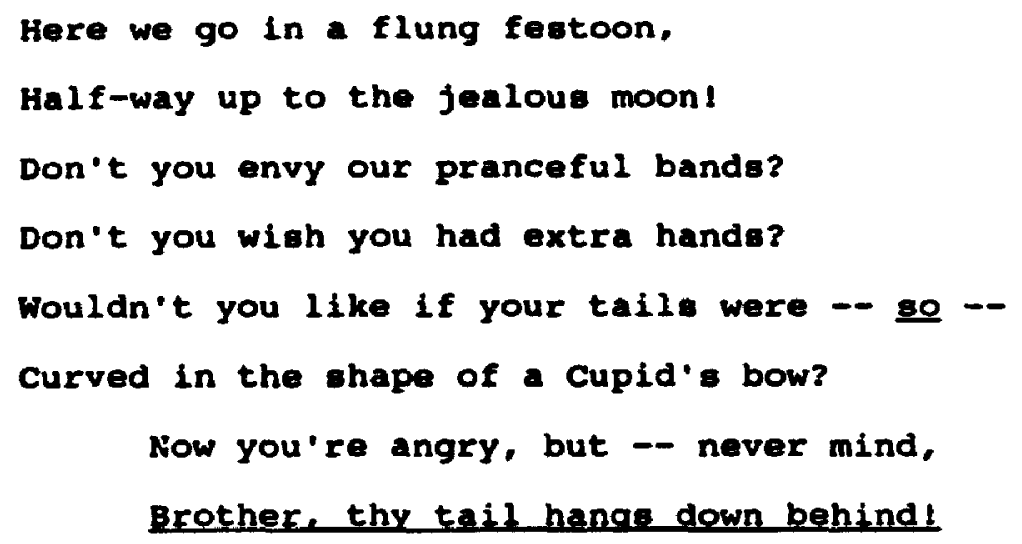


Then join our leaping lines that gcumfigh through the pines,

That rocket by where, light and high, the wild-arape swings.

By the rubbish in our wake, and the noble noige we make,

Be sure, be sure, we're going to do some splendid things! 


\section{Appendix $v$}

"I's (Pronounced Eyen)"

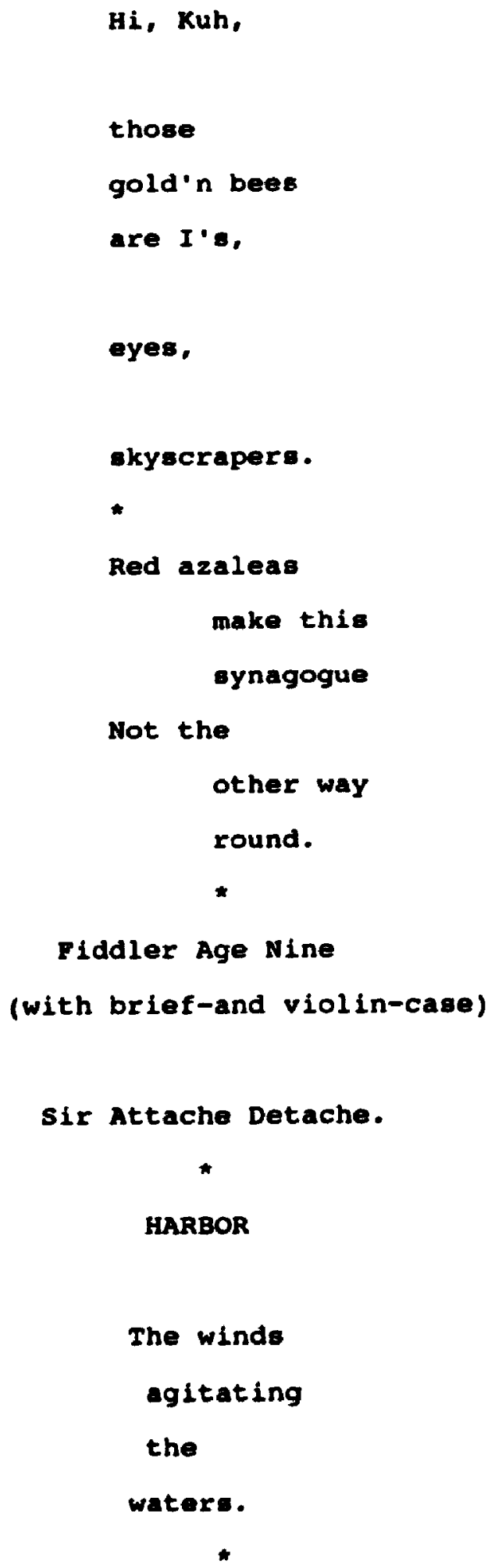


$31:$

FOR

Four tubas

or

two-by-four's.

$\bullet$

Angelo

the superintendent's

Porto Rican Helper --

see

I work

alread' start roof pla'form

n scratching floor

on

Eight

if

I

can do

you

good.

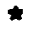

SEVEN DAYS A WEEK

A

good man

when everybody

is draping

the flag on a holiday

he's behind a box 


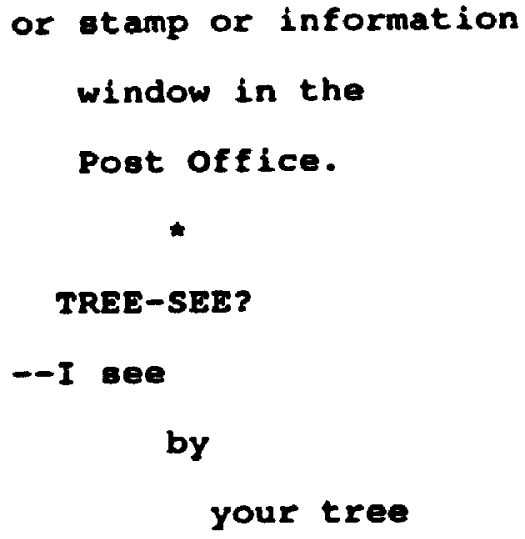

ABC

He has wit--

but who has more--

who looks

some way more

withal

than 
314

one eye

weeps, his voice

$\star$

AZURE

Azure

ag ever

adz aver 
"Our whole Life"

Our whole life a translation

the permissible fibs

and now a knot of 1 ies

eating at itself to get undone

Words bitten thru words

meanings burnt-off like paint

under the blowtorch

Al1 those dead letters

rendered into the oppressor's language

Trying to tell the doctor where it hurts

like the Algerian

who walked from his village, burning

hia whole body a cloud of pain

and there are no words for this

except himself 
"Fox Trot"

$$
\begin{aligned}
& \text { old } \\
& \text { six } \\
& \text { Faulk, }
\end{aligned}
$$

Tall as a stork,

Before the honeyed fruits of dawn were ripe, would walk,

And stalk with a gun

The reynard-coloured sun,

Among the pheasant-feathered corn the unicorn has torn, forlorn the

Smock-faced sheep

sit

And

Sleep;

Periwigged as William and Mary, weep . .

'Sally, Mary, Mattie, what's the matter, why cry?'

The huntsman and the reynard-coloured sun and I sigh;

'Oh, the nursery-maid Meg

With a leg like a peg

Chased the feathered dreams like hens, and when they laid an egg

In the sheepskin

Meadows

Where

The serene King James would steer

Horse and hounds, then he

From the shade of a tree

Plcked it up as spoll to boil for nursery tea, said the mourners. In the 
317

Corn, towers strain,

Feathered tall as a crane,

And whistling down the feathered rain, old Noah goes again --

An old dull nome

With a head like a pome,

seeing the world as a bare egg,

Laid by the feathered air; Meg

Would beg three of these

For the nursery teal

of Japhet, Sher, and Ham; she gave it

Underneath the trees,

Where the boiling

Water

Hissed,

Like the goose-king' feathered daughter -- kissed

Pot and pan and copper kettle

Put upon their proper mettle,

Lest the Flood -- the Flood -- the Flood begin again through these l 


\section{Appendix VIII}

"Pumpkins"

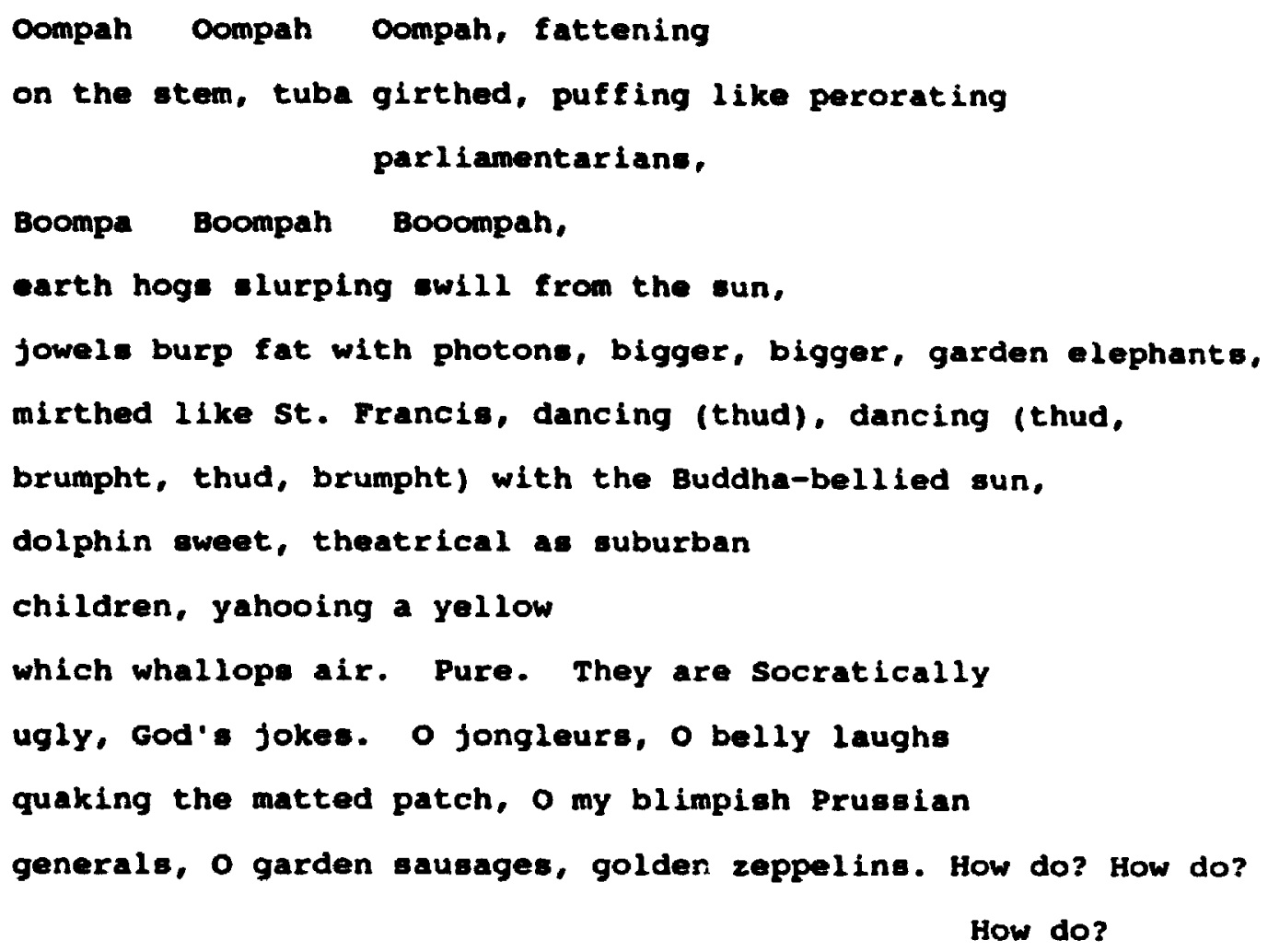


wel1?

I, weeding farmer, I, Caruso

them at dawn crow in the oun

cymballing mornings

and they Brunhilde back, foghorne, bloated alto notes

baroquely happy.

Not hoe teeth, not Rhotenone, but love,

brulted, busied, bleseed these being-ward, barn-big,

bibuloue on light, rampantly tolid

as Plato'- Ideas, Easter Island

fles lumps of meaning, rolling heads

in my 6-year-old nightmares,

vegetables on a ball and chain, sun anvile

booming with blows of temperature.

Come, phenomena, gourde of light, teach

your joy enperanto, your intense Archimedean aha

of yellow to me, dung-booted serf, whose unhoed brain,

the garden's brightest fruit, ones

communion with the cowfaced cauliflowers,

cucumbers twinkling like toes, and you,

clown prince,

eun dauphin of the rioting plot. 
WORKS CITED

Albert, Jonathan. "A Language of Spoken Movement." Open Letter 5.3 (Summer 1982): 11-16.

Altman, Charles F. "Intratextual Rewriting: Textuality as Language Formation." The sion in vuric and Literture. Ed. Wendy Steiner. Austin, Texas: Univ, of Texas Press, 1981: 39-51.

Ammons, A.R. "Smell Song." The Selected Poeme 1951-1977. Now York: W.พ. Norton Co., 1977: 69.

Andrews, Bruce and Charles Bernetein. "Reposeeseing the Word." The $L=A=H=G=U=A=G=E$ BoOk. Ed. Bruce Andrews and Charles Berngtein. Carbondale, Illinois: Southern Illinois Univ. Press, 1984: ix-xi. -..-.-... "Text and context." The $L=A=N=G=U=A=G=E$ Book, 31-38.

--_-----. "Writing social Work c Political Practice." The $L=A=N=G=U=A=G=E$ Book, $133-36$.

Auden, W.H. "In Memory of W.B. Yeats." Selected Poeme. Ed. Edward Mendelson. New York: Vintage-Random House, 1979: 80-83.

Baler, A.C. "Monsense." Encyclopedila of Philosophy. Ed. Paul Edwards. New York: Mackillan Company The Free Prese, 1967: vol. 5, 520-22.

Bakhtin, Mikhail. Babelaig and Hie Morld. Trans. Helène Iowolsky. 1968; Bloomington, Indiana: Midland Book - Univ. of Indiana Press, 1984.

Barthes, Roland. "From speech to Writing." The Grain of the Volce: Interviews 1962-1980. Trans. Linda Coverdale. New York: Hill and wang, 1985: 3-7.

stephen Heath. Glasgow: Fontana-Wm. Collins and Sons, Ltd., 1977: 179-89.

- The pleasure of the Text. Trans. Richard Miller. New York: Hill and Wang, 1975. 
-...... S/Z. Trans. Richard Miller. New York: Hill and Wang, 1974.

Writing Deqree zero ind Elemente of semiology. Trans. Annette Lavers and Colin Smith. 1967; Boston, Mass.: Beacor. Preas, 1970.

Bartlett, Lee. "What is 'Language Poetry'7" Critical Inquiry 12 (Summer 1986): 741-52.

Baum, Alwin L. "Carroll' Alices: The Semiotice of Paradox." Lewio Carrol 1: yodern Critical Vlews. Ed. Harold Bloom. pp. 65-81. Beaujour, Michel. "The game of poetics." Yale French studies $41(1968): 58-67$. Bedetti, Gabriella. "Interview: Henri Meschonnic." Diacritics 18.3 (Fall 1988): 93-111.

Bernatein, Charles. "An Interview with Tom Beckett." Content'g preams Egrays 1975-1984. Los Angeles: Sun Moon Press, 1986: 385- 410. -...-... "I Think I Understand Alan Davies." Content's Dream, 286-8.

-- "-- The Objects of Meaning: Reading Cavell Reading Wittgenstein." Content'g Dream, 165-83.

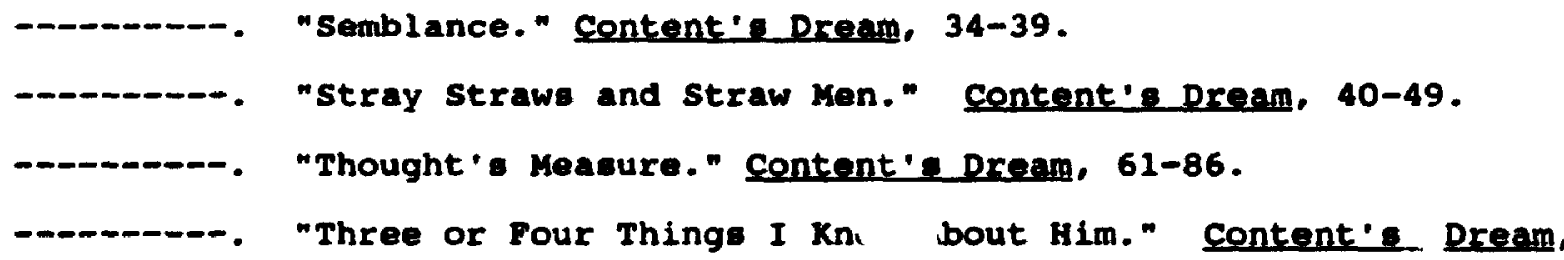
13-33.

Blacking, John. "The Problem of 'Ethnic' Perceptions in the Semiotics of Music." The sian in Mugic and Literature: 184-94.

Bloom, Harold. "Introduction." Lewis Carroll: Modern Critical Views, 1-11.

Bogue, Ronald. Deleuze and Guttari. London: Routledge, 1989. Bouth, wayne 4 . Freedom of Interpretation: Bakhtin and the Challenge of Feminist Criticiom." Critical Inquify s (September 
$1982): 45-76$.

Boulez, Pierre. Notes of an Apprenticeship. Ed. Paul Thevenin. Trans. Herbert Weinstock. New York: Alfred A. Knopf, 1968.

Bowering, George. "Given This Body: an interview with Daphne Marlatt." Open Letter 4.3 (Spring 1979): 32-88.

Breton, Andre. Manifestoeg of Surrealism. Trans. Richard Seaver and Helen R. Lane. Ann Arbor: Univ. of Michigan Prese, 1969.

Bringhurst, Robert. Pieces of Map, Pieces of Music. Toronto: Mcclelland and Stewart, 1986.

Bromige, David. "Intention E Poetry." TALKS:Hille6/7. (Spring 1980): 25-49.

- - My Poetry." My Poetry. Berkeley, California: The Figures, 1980: 11-20.

Brossard, Nicole. The Aerial Letter. Trans. Marlene Wildeman. Toronto: The Women's Press, 1988.

Bruns, Gerald L. Modern Poetry and the Idea of Lanquage: A Critical and Historical Study. New Haven, Conn.: Yale Univ. Press, 1974.

Bush, Jamie. "Ted Hughes's Concept of Language: Beyond Inscription." Unpublished essay, 1987.

Byrom, Thomas. Nongense and Wonder: The Poems and Cartoons of Edward Lear. New York: Brandywine Press -- E.P. Dutton, 1977.

Cage, John. Empty Words: Writings 13-178. Middletown, Connecticut: Wesleyan Univ. Press, 1979.

--------. Sifence. Middletown, Connecticut: Wesleyan Univ. Press, 1961.

Cammaerts, Emile. The Poetry of Nonsense. London: George Routledge \& Son Ltd., 1925.

Carroll, Lowis. Alice' Adventures in Wonderland. Alfee in Wonderland. Ed. Donald J. Gray. New York: W.W. Norton \& Co., 1971: 1-99. 
Carrol1, Lewis. The complete Worke of Lewis Cerroll. New York: Vintage-Random House, 1976.

Chawaf, Chantal. "IInguistic Flesh." Trans. Yvonne Rochette-0zzello. New French Feminieme. Ed. Elaine Mariks and Isabelle de Courtivron. New York: Schocken Books, 1981: 177-78.

Chesterton, G.K. "A Defence of Nonsense." A Century of Engligh Ereaye: An Anthology Ranging from caxton to R.L. Stevenson \& the Writere of Our Own Tims. Ed. Erneat Rhys and Lloyd Vaughan. London: J.M. Dent G Sons Ltd., 1913, 446-50. . "How Pleasant to Know Mr. Lear." A Handful of Ruthora: Eesays on Booke and Hriterg. G.K. Chesterton. Ed. Dorothy Collins. London: sheed and ward, 1953, 120-24.

-2.--_-. "Lewis Carroll." A Handful of Authore, 112-19.

Chukovaky, K. Erom Two to Five. Berkley, California: Univ. of California Press, 1968.

Cixoue, Helene. "Sorties: Out and Out: Attacks/Ways Out/Forays" The Newly Born Woman. Heline Cixous and Catherine clement. Trans. Betey Wing. Minneapolis, Minn.: Univ. of Minnesota Press, 1975: 63-132.

claire, Paula. "The Notation of my Sound Poetry." Open Letter 5.7 (Spring 1984): 56-74.

Clark, Katerina and Michael Holquist. Mikhail Bakhtin. Cambridge, Mass.: Belknap Press - Harvard Univ. Press, 1984.

clcmont, Catherine. "The Guilty One." The Newly Born Noman, 3-59. Cobbing, Bob. "Some statements on sound Poatry." sound Poetry: A Catalogue for the Eleventh International sound Poetry Fegtival. Ed. Steve Mccaffery, bpNichol. Toronto: Underwhich Editions, 1978: 39-40.

Cohen, Leonard. Benutiful Logere. Toronto: NCL--McClelland and stewart, 1966.

Copeland, Carolyn Faunce. Innouge o Time o Gertrude stein. Iowa 
City: Univ. of Iowa Press, 1975.

Corman, Cid. "In the Event of Words." Louig zukofkgy: Man and Poet.

Ed. Carroll F. Terrell. Orono, Maine: National Poetry

Foundation/Univ. of Maine at Orono, 1979: 305-36.

Coward, Rosalind and John Ellis. Lanquage and Materialism. London: Routledge and Kegan Paul, 1977.

Crewes, Judith. "Plain Superficlality." Lewis Carroll: Modern critical Views, 83-102.

Culler, Jonathan. On Deconotruction: Theory and Criticiam after

Structuralism. Ithaca, New York: Cornell Univ. Press, 1982.

cummings, e.e. "anyone lived in a pretty how town." 100 selected poems.

New York: Grove Press Inc., 1959: 73-74.

Darragh, Tina. "oilfish' to 'old chap' for 'C'." "Language" Poetries:

An Anthology. Ed. Douglas Messerli. New York: New Directions, $1987: 156$.

-1..-.. "Procedure." The $L=A=N=G=U=A=G=E$ Book, 107-8.

Davenport, Guy. "Zukof sky's English Catullus." Louig Zukofsky: Man

and Poet: 365-70.

Dekoven, Marianne. A Different Lanquage: Gertrude Stein' Experimental

Writing. Madison: Univ. of Wisconsin Press, 1983.

Deleuze, Gilles and Félix Guattari. Anti-oedipus: Capitalism and

Schizophrenia. Trans. Robert Hurley, Mark Seem and Helen R. Lane.

New York: Viking Press, 1977.

Deleuze, Gilles. The Logic of Sense. Trans. Mark Lester and Charles stivale. Ed. Constantin V. Boundas. New York: Columbia Univ. Press, 1990.

Dembo, L.s. "Louis Zukofsky: Objectivist Poetics and the Quest for Form." Louis zukofeky: Man and Poet: 283-303.

Derrida, Jacques. Of Grammatology. Trans. Gayatri Chakravorty spivak. Baltimore and London: The Johns Hopkins Univ. Press, 1974. 
Dewdney, Chriatopher. Predators of the Adoration: Selected Poema

1972-82. Toronto: Modern Canadian Poet: Serien--Mcclelland and stewart, 1983.

Dubnick, Randa. The structure of Qbecurity: Gertrude stein. Language and cublem. Urbana and Chicago: Univ. of Illinois Prese, 1984.

Dutton, Paul. "bpNichol and the Past-Present of a Future Music." Hueicworke 44 (Autumn 1989): 4-16.

Ede, Lise s. "The Nonsense Literature of Edward Lear and Lewis Carroll." DAI 76-3420 Ohio State University, 1975.

Eliot, T.S. "Dante." Selected Ereave. London: Faber and Faber, 1951: $237-77$.

--_. ----. The Mugic of Poetey. Folcroft, Pennsylvania: The Folcroft Press, Inc., 1942.

Ellenwood, Ray. "Introduction." Brick 16 (Fall 1982): 4-5.

Farwell, Marilyn R. "Adrienne Rich and an Organic Feminiat Criticiem." Colleae Enalish 39.2 (October 1977): 191-203.

Foucault, Michel. Madnese and Civilization: A Higtory of Insenity in the Age of Reason. Trans. Richard Howard. 1965; New York: Vintage - Random House, 1973.

- "-.----. "Theatrum Philosophicum." Lanquage, Counter-Memory, Practice: Selected Egraye and Interyiews. Trans. Donald F. Bouchard and Sherry simon. Ed. Donald F. Bouchard. Ithaca, N.Y.8 Cornell Univ. Prese, 165-96.

Fredman, Stephen. Poat's Proge: The crisle in American Veree. Cambridge: Cambridge Univ. Press, 1983.

Freud, sigmund. Jokeg and Their Relation to the Unconecioue. Trans. James strachey. Ed. Angela Richarde. 1960, London: Penguinviking Books, 1976.

-.-.----. The Interpretation of Dreams. Trans. A.A. Brill. Now York: The Modern Library, 1950. 
Frye, Northrop. Anatomy of Criticism: Four Egeaye. Princeton, Now Jersy: Princeton Univ. Prese, 1957.

Gardner, Martin. (Ed.) The Annotated Alice. Harmondsworth, England: Penguin Books, 1970.

Gee, James Paul. "Anyone's Any: A View of Language and Poetry Through an Analyeis of anyone lived in a pretty how town.". Lanquage and Style 16.2 (Spring 1983): 123-37.

Gorey, Edward. The Helpless Doorknob: A Shuffled Story. n.p.: 1989. Gott, Richard. "For Marxista nonsense verse is no laughing matter." Kanchestor Guardian Weekly. December 4, 1988.

Grenier, Robert. "Notes on Coolidge, Objectives, Zukofsky, Romanticism, And ". In The American Tree. Ed. Ron Silliman. Orono, Maine: National Poetry Foundation-Iniv. of Maine at Orono, 1986: 530-43.

Haas, Robert. Twentieth Century Pleasures. New Iork: Random House, 1978.

Haight, M.R. "Nonsense." British Journal of Af 3thetics. 11.3 (Summer 1971). 247-56.

Hancher, Michael. "Humpty Dumpty and Verbal Meaning." Journal of Mesthetics and Art Criticism. 40.1 (Fall 1981): 49-58.

Hanslick, Eduard. The Beautiful in Music. Ed. Morris Weitz. Trans. Gustav Cohen. 1885; New York: Bobbs-Merrill Co., Inc., 1957.

Hartley, George. Textual Politics and the Lanquage Poets.

Bloomington and Indianapolis: Indiana Univ. Press, 1989.

Hatlen, Burton. " Zukofsky as Translator." Louig Zukofeky: Man and Boet: 345-64.

Haughton, Hugh (Ed). The Chatto Book of Nonsense Poetry. London: Chattc Windus, 1988.

Hayman, Ronald. Artaud and After. Oxford: Oxford Univ. Press, 1977. Heath, Peter. "The Philosopher's Alice." Lewie Carroll: Modern critical Viowe: 45-52. 
HejInian, Lyn. "If Written is Writing." The $L=A=N=G=U=A=C=E$ Book: 29-30.

-...-.. Ny hife. Los Angeles: Sun and Moon Press, 1987.

-.-----. "The Rejection of Closure." Poetice Journal 4 (May 1984): 134-143.

- "Strangeness." Poetics Journal 8 (June 1989): 32-45.

Henkle, Roger B. "The Mad Hatter' World." The Virginia Quacterly Beview 49.1 (winter 1973): 99-117.

Hoffetadter, Douglas. "Stuff and Nonsense." Metamagical Themae: quetting for the Fesence of Kind and Pattern. New York: Basic Booke, Inc., 1985: 213-31.

Holquist, Michael. "What is a Boojum?: Nonsense and Modernism." Yale Erench studieg XIIII (1969-70): 145-64.

Hopkins, Gerard Manley. The Poems of Gerard Manley Hopkins. Fourth Edition. Ed. W.H. Garnder and N.H. Mackenzie. Oxford: Oxford Univ. Press, 1970.

Howe, Susan. "from Speeches at the Barriers." "Language" Poetrieg: An Anthology: $34-36$.

Huizinga, Johan. Homo Ludens: A Study of the Play-zlement in Culture. 1950, Boston: Beacon Prese, 1955. Huxley, Frances. The Raven and the Writing Deak. London: Thames and Hudson, 1976.

Irigaray, Luce. Speculum of the other Homan. Trans. Gillian C. Gill. Ithaca, New York: Cornell Univ. Press, 1985.

- Thie sex which If Not One. Trans. Catherine Porter and Carolyn Burke. Ithaca, New York: Cornell Univ. Press, 1985. Jones, Ann Rosalind. "Writing the Body: Toward an Underetanding of Licriture fominine." The New Peminiet Criticiom: Eesaye on Vomen. Literature E Theory. Ed. Elaine Showalter. Now York: Pantheon Books, 1985: 361-77.

Joyce, James. Einnegane Wake. 1939; Now York: Penguin-Viking Books, 
1976.

Kipling, Rudyard. The Jungle Book. 1894, London: Puffin-Penguin Books, 1987.

Korg, Jacob. Lanquage in Modern Literature: Innovation and Experiment. New York: Barnes and Noble, 1979.

Kristeva, Julia. About Chinese Women. Trans. Anita Barrows.

London: Marion Boyars, 1974.

Semiotic Approach to Literature and Art. Ed. Leon S. Roudiez.

Trans. Thomas Gora, Alice Jardin, Leon S. Roudiez. New York:

Columbia Univ. Press, 1980: 23-35.

- Lanquage: The Unknown. Trans. Anne M. Menke. New York:

Columbia Univ. Prese, 1989.

-------- Revolution in Poetle Lanquage. Trans. Margaret waller.

New York: Columbia Univ. Press, 1984.

--------. "The speaking Subject." On Signs. Ed. Marshall Blonsky.

Baltimore, Maryland: Johns Hopkins Univ. Press, 1985: 210-20.

-------. "Word, Dialogue and Novel." Degire in Language: 64-91.

Lacan, Jacquea. "The subject and the Other." The Four Fundamental

Concepts of Prycho-Analysis. Trans. Alan Sheridan. Ed.

Jacques-Alain Miller. New York: พ.พ. Norton Co., 1977: 203-15.

Lecercle, Jean-Jacques, Philosophy through the Looking-Glass:

Lanquage, nongenge, desire. La salle, Illinois: Open Court, 1985.

Lear, Edward. The Complete Nonsense of Bdward Lear. Ed. Holbrook

Jackson. London: Faber and Faber Ltd., 1947.

Lechte, John. Julia Kristeva. London: Routledge, 1990.

Lee, Dennis. Garbege Deliaht. Toronto: Macmillan of Canada, 1977.

-_-_---. "Roote and Play: Writing as a 35-Year-Old Children."

Canadian Children'e Literature 4 (1976): 28-58.

Leitch, vincent B. Deconstructive Criticlem: An Advanced 
Introduction. Now York: Columbla Univ. Prese, 1983.

Lilburn, Tim. Namer of God. Lantzville, B.C.: Oolichan Books, 1986.

-_-_---. "Thoughte toward a chrietian poetics." Brick: A Journal

of Reviews 29 (Winter 1987): 34-36.

Livingeton, Myra Cohn. "Nonsense Veree: The Complete Escape."

Celebrating Children' Booke. Ed. B. Hearne, M. Kaye. New York:

Lothrop, Lee and Shepherd Booke, 1981: 122-39.

Mac Low, Jackson. "'Language-centered"." In The American Tree: 49195.

Marlatt, Daphne. Touch to My Tonque, Edmonton: Longspoon Press, 1984 . Martin, Stephen-Paul. gren Form and the Fominine Imagination. (The

Politice of Reading in Twentieth-Century Innovative Writingl.

Washington, D.C.: Maisonneuve Press, 1988.

Mccaffery, Steve. Eroba: The Invertiations yeditations 1976-78.

Toronto: Coach House Press, 1987.

-1.--o. "From the Notebooks." The $L=A=N=G=U=A=G=E$ Book: 159-62.

-.-.--.. "Intraview." The $I=A=N=G=U=A=C=E$ Book: 189 .

-.-.-.-. "Language Writing: from Productive to Libidinal

Ecomony." North of Intention: Critical Writings 1973-1986. New

York and Toronto: Roof Books/Nightwood Editions, 1986: 143-58.

--.----. "Nothing is Foraotten but the Talk of How to Talk: an

Interviow by Andrew Payne." North of Intention: 110-30.

- "-..-.. "Sound Poetry: A survey." Sound Poetry: A Cataloque:

6-18.

-.-2.-... "Text-sound, Energy and Performance." Sound Poetry: A

Catalogue: $72-73$.

McGann, Jerome J. "Contemporary Poetry, Alternate Routes."

Eritical Incuify 13 (spring 1987): 624-47.

Mckay, Don. "Notes on Poetic Attention." The second Mackitlan

Anthology. Ed. John Motcalf and Leon Rooke. Toronto:

Macmillan, 1989: 207-208. 
Messerl1, Douglas. "Introduction." "Language" Poetries: An

Anthology: 1-11.

Miller, Edmund. "The Sylvie and Bruno Books as Victorian Novel." Iewis Carroll: Modern critical Vieun: 53-63.

Moi. Toril. Sexual/Textual Politicr: Feminiet Literary Theory.

London: New Accent: Series--Methuen, 1985.

Moore, Marianne. "The Monkeys." The Complete Poeme of Marianne Moore.

New York: Viking--Mackilian Co., 1967: 40.

Nichol, bp. The Martyroloay Book 5. Toronto: Coach House Prese, 1982 .

- Primary Days: Housed with the Coach at the Press, 1965

to 1987." Proyincial Egsayg 4 (1987): 19-25.

--n----. Still Water. Vancouver: Talonbooks, 1970.

Noakes, Vivien. Edward Lear: The Life of a Wanderer. 1968; London: Ariel Books-B.B.C., 1985.

Norris, Christopher. Decongtruction: Theory and Practice. London: Methuen 1982.

Olson, Charles. "Human Universe." Selected Writings. Ed. Robert Creeley. New York: New Directions Press, 1966: 53-66.

-.---.-. "Projective Verse." Selected Writinae: 15-26.

- Proprioception. San Francisco: Writing -- Four Seascne Foundation, 1965.

Org, Walter. The Presence of the Word. New Haven, connecticut: Yale Univ. Press, 1967.

Orlov, Henry. "Towards a Semiotics of Music." The Sign in Busic and Literature: 131-37.

Palmer, Michael. "The man by contrast is flxed oymmetrically'." Talking Poatry: Conversations in the Workshop with contemporary Boete. Ed. Lee Bartlett. Albuquerque, New Mexico: Univ. of New Mexico Press, 1987.

Partridge, Eric. "The Nonsense Words of Edward Lear and LewiE 
Carroll." Hore. There and Eyerywheres Eronye Upon Lanouage.

London: Hamich Hamilton, 1950: 162-88.

Perelman, Bob. "untitled." The $L=h=N=C=U=h=C=E$ Book: 199-200.

Perloff, Marjorie. "Poetry as Word-Syotem: The Art of Gertrude

stein." The Pontice of Indeterminacy: Rimbaud to cage.

Princeton: Princeton Univ. Prese, 1981: 67-108.

-D.--D. "The Word as Such: $L=A=N=G=U=A=G=E$ poetry in the

eighties." The dance of the intellect, studile in the pontry of

the Pound Tradition. Cambridge: Cambridge Univ. Preas, 1985:

215-38.

Pitcher, George. "Wittgenstein, Nonsense, and Lewis Carroll." The Manachusette Review VI (1965): 591-611.

Pound, Ezra. "How to Read." Polite regaye. London: Faber and Faber, 1937: 155-92.

Quartermain, Peter. "'Not at All surprieed by Science': Louis zukofaky' firat Half of 'A'-9." Louid zukofaky: yan and Poet: 203-25.

Rich, Adrienne. "Our whole Life." Doorframe: Poems selected and New 1950-1984. New York: W.W. Norton C Co.. 1984: 133.

Rieke, Alison Rae. "Sense, Nonsense, and the Invention of Languages: James Joyce, Loule Zukofeky, Gertrude Stein." DAI 8428431. Univ. of Kentucky, 1984.

Riffaterre, Michael. Semiotice of Poetry. 1978; Bloomington, Indiana: Mldland Books-Indiana Univ. Press, 1984.

Rilke, Rainer Maria. "Duino Elegies." The selected Poetry of Rainer Waris Rilke. Trans. Stephen Mitchell. New York: Vintage-Random House, 1984: 151-211.

Rose, Angus. selections from The Tatler and The spectator of stegle and Addinon. Now York: Penguin-Viking 1982.

Ruas, Charles. "Postscript: An Interview with Michel Foucault." Denth and the Labyeinth: The World of Raymond Roureel. Michel 
Fousault. Trans, Charles Ruas. Berkeley, California: Univ. of Callfornia Prese, 1986: 169-86.

Schafer, R. Murxay. The Thinking Far. Toronto: Arcana Editions, 1988 .

Schmitz, Neil. "Gertrude stein as Post-Modernist: The Rhetoric of Tender Buttone." Journal of Modern Literature 3.5 (July 1974): 1203-18.

Scott, Gail. Sphcer Like stalre. Toronto: The Women'e Prese, 1989. Sowell, Elizabeth. The Field of Nongenge. London: Chatto and Windus, 1952.

Sheringham, Michael. "From the Labyrinth of Language to the Language of the Senses: the Poetry of Andre Breton." Sensibility and creation: Studieg in Twentieth century French Poetry. Ed. Roger Cardinal. New York: Barnes and Noble -- Harper C Row, 1977: 72-102.

silliman, Ron. "Disappearance of the Word, Appearance of the World." The New Sentence. New York: Roof Booke, 1987: 7-18.

-..---. Ketiak. San Francisco: This, 1978.

-.-.--.-. "Language, Realism, Poetry." In the American Tree:

$x v-x x i i 1$.

--_-_--. "The New Sentence." The New Sentence: 63-93.

-------. "Postmodernism': sign for a struggle, struggle for the sign." Poeticg Journal 7 (September 1987): 18-39. silverman, kaja. The subfect of Semiotice. New York: Oxford Univ. Prese, 1983.

Sitwell, Edith. Collected Poems. 1957; London: Papermac-Macmillan and Co., 1982.

Smith, A.C.H. Orohart at Persepolle. London: Eyre Methuen, 1972.

Smith, Paul. Diegening the subiect. Minneapolis: Univ. of Minnesota Press, 1988.

Sonstroem, David. "Making Earnest of the Game" Modern Lanquage 
Quarterly 28 (1967): 192-206.

Springer, George P. "Language and Mueic: Parallele and Divergences." in For Roman Jakobson: Trave on the ocgarion of His sixtieth

Bitthday. Ed. Morria Halle et al. The Hague: Mouton \& Co., 1956? 504-13.

stein, Gertrude. "Poetry and Grammar." Inctures in America.

Boston: Beacon Prese, 1935: 209-46.

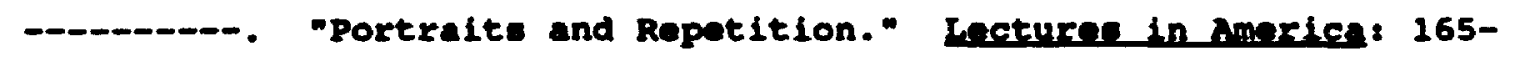
206.

---_---. Tender Buttone. 1914, Hew York: Haskell House

Publiehers, 1970.

--.---. "What is English Literature." Lectures in Americs: 11-

55.

steiner, Wendy. The colore of Rhetoric: Problem in - Relation betwenn yodern witerature and Painting. Chicago: Univ. of Chicago Prean, 1982.

Stevene, Wallace. "The Noble Rider and the Sound of Worde." The Hecerery Angel: Freaye on Relity and the Imagination. London: Faber and Faber, 1951:3-36.

--- "Noten Toward a Supreme Fiction." The Palm at the End of the wind: selected Poene and a Play. Ed. Holly stevens. Now York: Vintage Books-Rendom House, 1972: 207-34.

stowart, Sucan. Jorgenes: Aepete of Intertextuality in Folklore and fletion. Baltimore, Maryland: The Johne Hopkins Univ. Prese, 1978.

Sutherland, Robert D. Lanquage and tewile Carol. The Hagua: Mouton, 1970.

Thibaudeau, colleen. The yarthe Landecapen. Coldetream, Ont.: Brick Booke, 1984.

Thowas, Dylan. The Poeme. Ed. Daniel Jones.London: Everyman's Library-Dent, 1971. 
--.----. "Notes on the Art of Poetry." Kodern Poetice. Ed. Jamee scully. New York: HeGraw-Hill Book Co., 1965: 185-94.

Tiggea, Wim. An Anatomy of Literary Nonsense. Ameterdam: Rodopi Editions, 1988.

-..----. "An Anatomy of Nonsense." Exploratione in the Field of Nongense: 23-46.

Treece, Henry. Dylan Thomag: 'Dog Among the Pairieg'. Second Edition. London: Ernest Benn Ltd., 1956.

Valery, Paul. The Art of Poetry. Trane. Deniee Folliot. The collected works of Paul Valery Vol. VII. New York: Pantheon, 1958: 111-13.

van Rooten, Luis d'Antin. Yots d'Heures: Gousses, Rames The distith

Yanuscript. 1967; New York: Penguin Books, 1980

Vigeura, Susan T. "Nonsense and the Language of Poetry." Signal 42 (1983) \& 137-49.

Watkins, Vernon. (Ed.) Letterg to Vernon Watking. 1957; Wegtport, Conn.: Greenwood, 1982 rpt.

Watten, Barrett. "Ron Silliman, Wohawk and Ketiak." The $L=A=N=G=U=A=G=E$. Book: $270-71$.

Welsh, Andrew. Roote of Lyric: Primitive poetry and yodern

Poetice. Princeton, New Jersy: Princeton Univ. Press, 1978.

Wendt, Larry. Metropolitan Fractalizations: Six Text-Sound Compositions." Sound Pootry: A Sataloque: 69-70.

Winn, James Anderson. Unaupected Eloquence: A Higtory of the

Relatione between Poetry and yuric. New Haven, connecticut: Yale Univ. Preas, 1981.

Wittgenetein, Ludwig. Philosophical Investigationg. Trans. G.E.K. Anscombe. 1953; London: Basil Blackwell 1958.

Woolf, Viriginia. A Room of One's Own. 1929, London: A Triad Grafton Book--Colkin: Publishing Co., 1977.

zukofoky, Celia and Louls. Catullue. London: Cape Goliard Prose, 
1969.

zukofsky, Louis. " $A^{n}$. Berkeley, California: Univ, of California Press, 1978.

--- ----. NLL: The Collected Short Poems 1923-1964. New York: พ.พ. Norton \& Co.. 1971.

-..--.-. Bottom on Shakespeare. volume 1. Austin, Texas: The Ark Pres8, 1963.

-------- Bo Flowerg. Lunenberg, Vermont: The Stinehour Press, 1978.

-------- Prepositions: The collected Egsays of Louis zukofsky. Berkeley, California: Univ. of California Press, 1981.

--.---.-. [Sincesity objectification]. Louis Zukofsky: Man and Poet: $265-81$. 